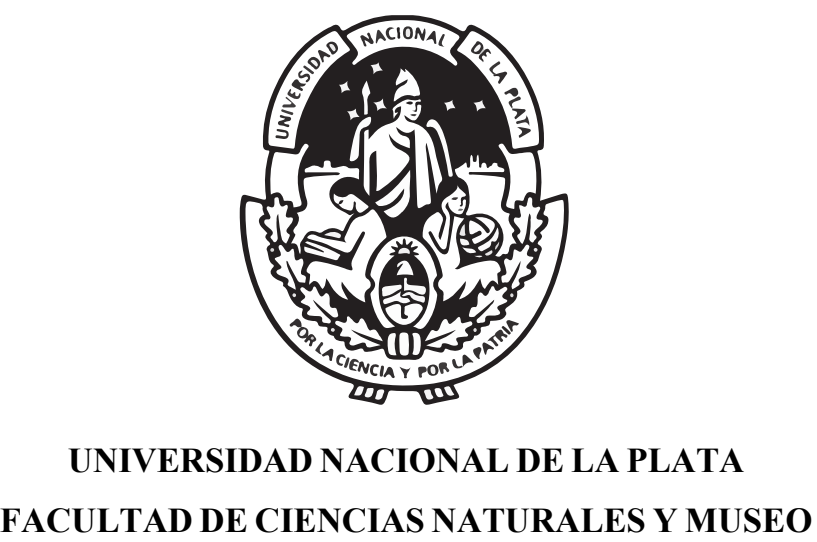

\title{
ANÁlisis PALEOFLORÍSTICO DE LA FM Río TURBIO (EOCENO DE LA PROVINCIA DE SANTA CRUZ) Y SU RELACIÓN CON LOS CAMBIOS PALEOCLIMÁTICOS GLOBALES: EVIDENCIAS ESPOROPOLÍNICAS
}

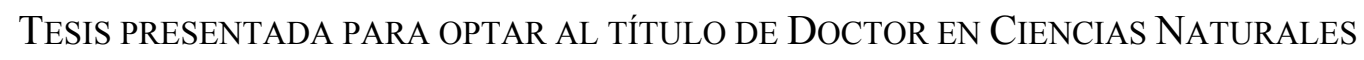

DAMIÁn ANDRÉS FERNÁNDEZ

DiRECTOR DE TESIS: VIVIANA D. BARREDA

CODIRECTOR: MARÍA CRISTINA TELLERÍA

Buenos Aires, 2018 
Análisis paleoflorístico de la Fm Río Turbio (Eoceno de la provincia de Santa Cruz) y su relación con los cambios paleoclimáticos globales: evidencias esporopolínicas

Resumen

En la presente tesis se da a conocer el contenido palinológico recuperado de las sedimentitas marinas aflorantes en la comarca de Río Turbio, provincia de Santa Cruz, asignadas a la formación homónima. Se muestrearon 10 perfiles de los que se tomaron 60 muestras, 40 de las cuales resultaron palinológicamente fértiles. Las asociaciones de esporomorfos recuperadas presentan una gran abundancia y diversidad. En general están dominadas por especies de Nothofagidites, Podocarpidites y Myrtaceidites. Las esporas de helechos son frecuentes y diversas. Todas las muestras (con una excepción) presentan dinoquistes, siendo en general más frecuentes los Gonyaulacoideos en detrimento de los Peridinoideos. Se contaron un total de 22.805 especímenes de esporomorfos y 9.486 especímenes de paleomicroplancton. Los primeros se agruparon en 116 morfoespecies, de las cuales 77 se reconocieron por primera vez para la formación, 3 son nuevas para la ciencia, 4 representan el primer registro para Sudamérica y una lo es para Argentina. La abundancia de paleomicroplancton, principalmente de dinoquistes apoya la reconstrucción de un ambiente de depositación marino somero. Los dos miembros de la Fm Río Turbio (FRT) fueron reconocidos por su contenido palinoflorístico mediante un análisis de agrupamiento. Se observó también un tercer grupo de muestras en el tope de la secuencia que presenta una asociación particular, con formas cálidas y alta diversidad, las cuales podrían ser de edad Oligocena. Se llevó a cabo el primer análisis de diversidad para la FRT, mediante la confección de curvas de rarefacción. Según los análisis realizados, a lo largo de toda unidad las formas cálidas están presentes y la diversidad florística es alta. Sin embargo, las formas cálidas son más abundantes y la diversidad es ligeramente mayor en el Miembro Inferior. Esto sugiere que el lapso abarcado por las muestras eocenas de la FRT se correspondería con una disminución de la temperatura media anual, coincidiendo con modelos previos en base a isótopos de oxígeno, pero no se alcanzarían niveles de marcado empobrecimiento ambiental y de la diversidad florística.

Palabras clave: Palinología, Eoceno, SW de Santa Cruz, diversidad, paleoclima. 
Paleofloristic analysis of the Río Turbio Formation (Eocene of Santa Cruz Province) and its relationship with global paleoclimatic changes: sporopolinic evidence

\section{Abstract}

The palynomorph content recovered from marine deposits exposed along Río Turbio, in Santa Cruz Province, assigned to the homonymous formation is described. Ten sections were sampled for a total of 60 samples, of which 40 were palynologically productive. The palynomorph assemblages are rich and diverse. In general they are dominated by species of Nothofagidites, Podocarpidites and Myrtaceidites. Fern spores are frequent and diverse. All the samples (with one exception) yielded dinocysts, among which Gonyaulacoids are more frecuent than the Peridinoids. A total of 22.805 sporomorphs and 9.486 microplankton specimens were counted. The sporomorphs were grouped into 116 morphospecies, of which 77 were recognized for the first time in the unit, three are new to science, four represent the first record for South America and one the first record for Argentina. The abundance of microplankton, primarily dinocysts, supports the interpretation of a shallow marine depositional environment. Samples from the two members of the Río Turbio Formation (RTF) were distinguished based on their palynomoph content by performing a cluster analysis. At the top of the sequence, a third group of samples was recognized that yielded a specific association, containing forms indicative of warm climate and high diversity, which could be Oligocene in age. A diversity analysis for the RTF was performed for the first time, by means of rarefaction curves. The entire unit is characterized by high levels of floristic diversity and the presence of warm climate forms. However, the latter are more abundant and the diversity is slightly higher in the Lower Member. This suggests that the period represented by the Eocene samples of the RTF would correspond to a decrease in the mean annual temperature, consistent with previous models based on oxygen isotopes, but without significant deterioration of environmental and floristic diversity.

Key words: Palynology, Eocene, SW Santa Cruz, diversity, paleoclimate. 
Agradecimientos:

A mis directores, Viviana Barreda, María Cristina Tellería y Luis Palazzesi; jurados de la tesis, Marta Morbelli, Mirta Quattrocchio y Edgardo Romero; miembros de la División Paleobotánica del MACN, especialmente a Roberto Pujana, Carolina Panti e Isabel Vilanova; técnicos del MACN, Orlando Cárdenas, Amalia González, Sebastián Mirabelli y Fabián Tricárico; mis compañeros del laboratorio 73, Patricio Santamarina, Diego Urteaga, Rocío González Vaquero, Florencia Filipini, Marcos Ércoli, María José Pío, Sabrina Soria y Carlos Greppi; a Munira Cáceres y Guillermo Aguirrezabala (arte de tapa e impresión); al grupo del CTPA, STRI, especialmente a Carlos Jaramillo; a Mihail Tomescu; a mis familiares y amigos; y muy especialmente a María Adolfina Savoretti, por directa o indirectamente colaborar para que esta tesis pudiera completarse. 
A mis viejos. 
ÍNDICE

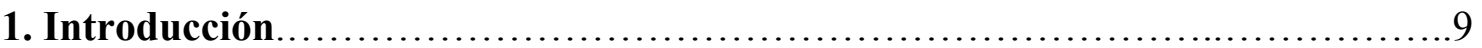

1.1. Marco teórico 9

$\begin{array}{lr}\text { 1.2. Ubicación geográfica } & 12\end{array}$

$\begin{array}{ll}\text { 1.3. Clima y flora actuales } & 13\end{array}$

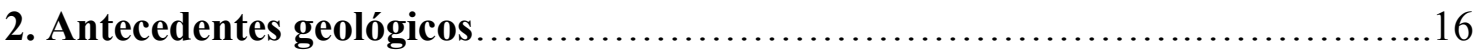

$\begin{array}{ll}\text { 2.1. Estratigrafía } & 16\end{array}$

$\begin{array}{ll}\text { 2.2. Edad } & 17\end{array}$

$\begin{array}{ll}\text { 2.3. Floras eocenas de Patagonia } 20 & 20\end{array}$

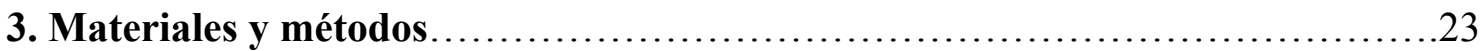

3.1 Muestreo y procesamiento paleopalinológico 23

3.2 Marco estratigráfico $\quad 25$

3.3 Palinología sistemática 32

3.4 Análisis polínico y rarefacción 32

4. Palinología de la Formación Río Turbio.................................... 34

4.1. Asociación palinológica: características generales 34 
Algae

Closteriaceae 35

Dictyosphaeriaceae 36

Scenedesmaceae 36

Zygnemataceae 37

Briofitas 37

Pteridofitas 38

Blechnaceae 38

Dicksoniaceae 39

Gleicheniaceae

Hymenophyllaceae 42

Lycopodiaceae 43

Ophioglossaceae

Osmundaceae

Polypodiaceae

Schizaeaceae

Pteridofitas de afinidad desconocida

Gimnospermas

Araucariaceae

Ephedraceae

Podocarpaceae

Gimnospermas de afinidad desconocida 
Dicotiledóneas

Aquifoliaceae

Bombacaceae

Casuarinaceae

Convolvulaceae

Cunoniaceae

Ericaceae

Euphorbiaceae

Fabaceae

Gunneraceae

Loranthaceae

Malpighiaceae

Malvaceae

Misodendraceae

Myrtaceae 72

Nothofagaceae 74

Olacaceae 79

Onagraceae 80

Polygalaceae

Proteaceae

Sapindaceae 87

Dicotiledóneas de afinidad desconocida

Monocotiledóneas 
Arecaceae

$\begin{array}{lr}\text { Poaceae } & 102\end{array}$

Monocotiledóneas de afinidad desconocida 103

5. Comparación con otras asociaciones paleógenas............................. 105

6. Estudios palinológicos complementarios vinculados a esta tesis................114

7. Análisis palinológico cuantitativo .......................................... 118

$\begin{array}{ll}\text { 7.1 Análisis de agrupamiento } & 118\end{array}$

$\begin{array}{lr}\text { 7.2 Tendencias principales } & 120\end{array}$

$\begin{array}{ll}7.3 \text { Resultados de rarefacción } & 125\end{array}$

8. Discusión y conclusiones............................................... 127

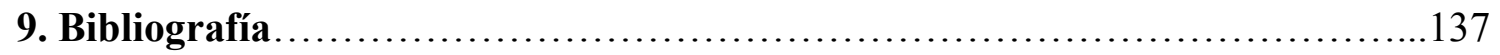

APÉNDICE 1 - MUESTREO Y ANÁLISIS CUANTITATIVO.....................171






\section{Introducción}

En la presente tesis se da a conocer el contenido palinológico recuperado de las sedimentitas marinas aflorantes en la comarca de Río Turbio, provincia de Santa Cruz, asignadas a la formación homónima. Hasta el momento, la mayor parte de los estudios palinológicos realizados se han centrado en el análisis de ciertos grupos, como las Gymnospermae y Nothofagaceae (Romero, 1977) o algunas Angiospermae (Romero \& Zamaloa, 1985). Este estudio constituye un nuevo aporte al conocimiento del Paleógeno de Sudamérica siendo el primer análisis integral de la unidad teniendo en cuenta el conjunto de la asociación y su variación en diversidad y abundancia.

En esta contribución se estudió el cambio en número de especies fósiles a lo largo de la Formación Río Turbio (FRT) cuya edad fue asignada entorno al Eoceno medio - Eoceno superior (pudiendo llegar al Oligoceno, Malumián \& Caramés, 1997, Guerestein et al., 2014, Fosdick et al., 2015) y su relación con los cambios en la paleotemperatura media anual.

El estudio sistemático detallado de los esporomorfos continentales permitió reconocer 116 formas fósiles, de las cuales 77 se reconocieron por primera vez para la FRT y 3 especies son nuevas para la ciencia. A partir de las afinidades botánicas de dichos palinomorfos fue posible reconstruir parte de la historia de la vegetación eocena del sudoeste de Patagonia, así como inferir condiciones paleoambientales y sugerir algunos aspectos paleobiogeográficos.

\subsection{Marco teórico}

El registro fósil de Patagonia contiene información relevante para formular hipótesis fundamentadas respecto a los cambios en la diversidad de la flora ocurridos durante los últimos millones de años. Estos cambios fueron determinados por 
importantes factores externos particularmente ligados a la fragmentación del Gondwana (la separación de Antártida de Australia y Sudamérica) con el consiguiente aislamiento térmico de Antártida (Zachos et al., 2001). Los registros de polen y esporas fósiles son muy útiles para reconstruir la vegetación y el clima del pasado. Si bien un espectro polínico aislado tiene un valor limitado para representar la vegetación original, una sucesión cronológica de tales espectros refleja muy bien la composición de la vegetación productora y provee valiosa información sobre los cambios en las comunidades vegetales, el clima y la paleogeografía (Moore et al. 1991; Erdtman, 2003).

De acuerdo a la curva propuesta por Zachos et al. (2001) (Figura 1) desde el Paleoceno medio hasta el Eoceno temprano existió una tendencia hacia un pronunciado aumento de las paleotemperaturas globales, alcanzando su pico hace aproximadamente 52-50 Ma, aumento conocido como "el óptimo climático del Eoceno temprano” (EEOC, sigla en inglés), lapso durante el cual se desarrollaron las paleofloras más diversas y reconocidas del Paleógeno de Argentina (por ejemplo Laguna del Hunco y Río Pichileufú) (Wilf et al., 2003, Wilf et al., 2005). Luego del EEOC se produjo una tendencia general hacia condiciones más frías, iniciada en el Eoceno medio temprano (50 a $48 \mathrm{Ma})$ y que alcanzaría su clímax en el límite Eoceno/Oligoceno. Los dos Miembros que constituyen la FRT se habrían depositado durante en esta parte del Paleogéno por lo que su análisis florístico resulta de fundamental importancia para cuantificar la influencia de los cambios paleoclimáticos en las floras australes.

De esta manera, el objetivo de esta tesis doctoral es analizar la composición de la Fm Río Turbio y los cambios en la diversidad de las floras del extremo austral de Patagonia durante el Eoceno, Eoceno/Oligoceno? momentos en los cuales se producen importantes cambios paleoclimáticos y paleogeográficos vinculados con la 
fragmentación del Gondwana occidental y el establecimiento de las primeras glaciaciones en Antártida hacia fines del período.

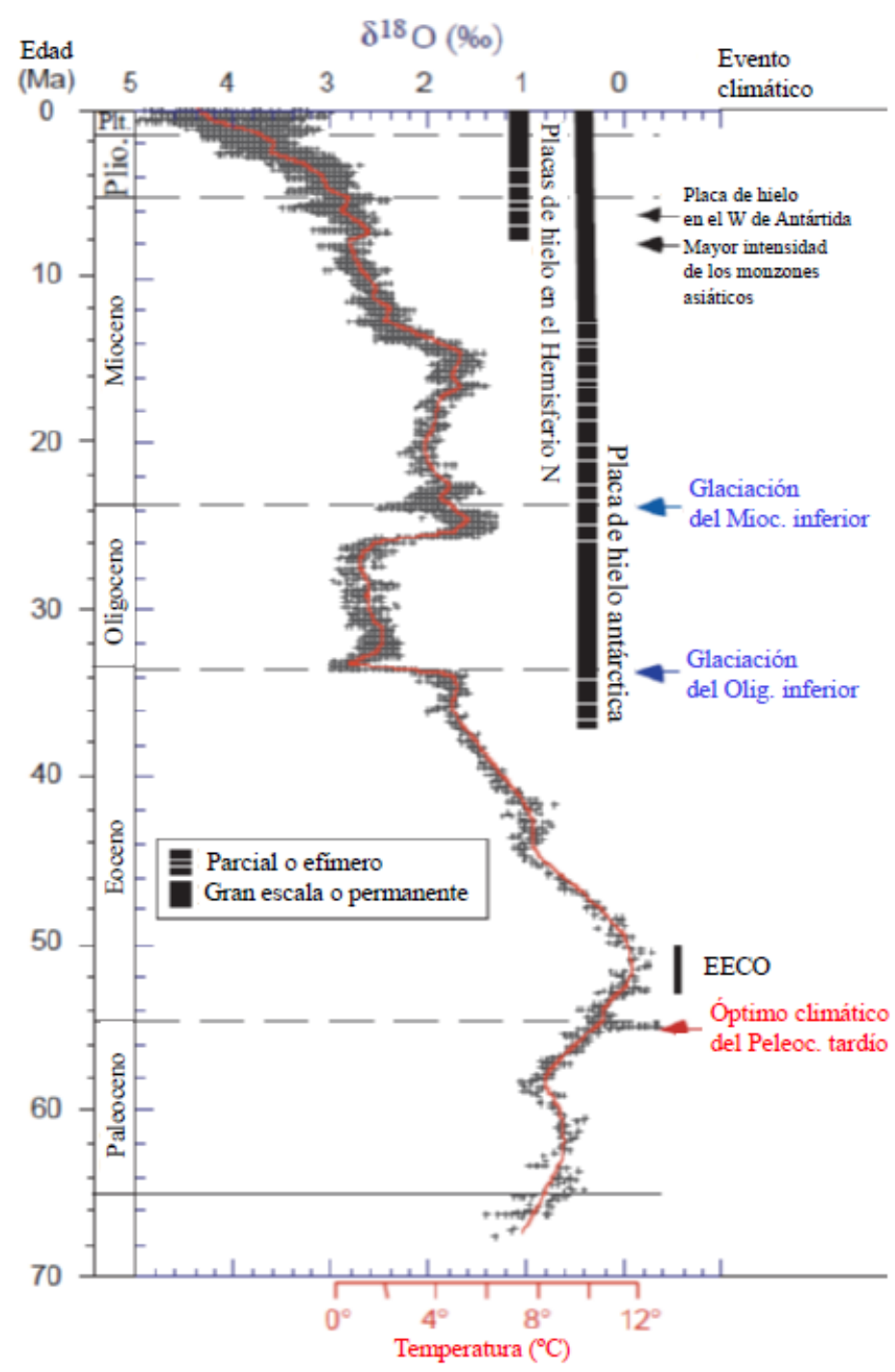

Figura 1. Curva de temperatura media anual estimada en base a fluctuaciones en la concentración de $\mathrm{O}^{18}$ atmosférico (modificado de Zachos et al., 2001).

Hipótesis de trabajo

La progresiva disminución en la temperatura media anual registrada durante el Eoceno y Oligoceno determina una progresiva disminución en la diversidad florística a lo largo de la Formación Río Turbio. Esta hipótesis se basa en una serie de supuestos: (1) el polen preservado en las rocas es un reflejo de la flora que lo produjo, (2) las curvas de isótopos de oxígeno permiten estimar las paleotemperaturas de los océanos, 
(3) las paleotemperaturas oceánicas están directamente relacionadas con las paleotemperaturas globales, y (4) la temperatura es uno de los factores climáticos que determina la flora de una región.

\subsection{Ubicación geográfica}

El área de estudio está situada en el sector centro-sur de la Cuenca Austral o Magallánica (Figura 2). Esta cuenca se originó durante la separación entre América del Sur y África en un proceso extensivo asociado a la efusión de rocas volcánicas que componen el basamento de la misma (Malumián \& Caramés, 1997). Se encuentra ubicada en el extremo sur de Sudamérica, abarcando una parte importante de la provincia argentina de Santa Cruz, la chilena de Magallanes, la zona oriental del estrecho del mismo nombre, la isla Grande de la Tierra del Fuego y una porción de la plataforma continental argentina lindante al este de las mismas.

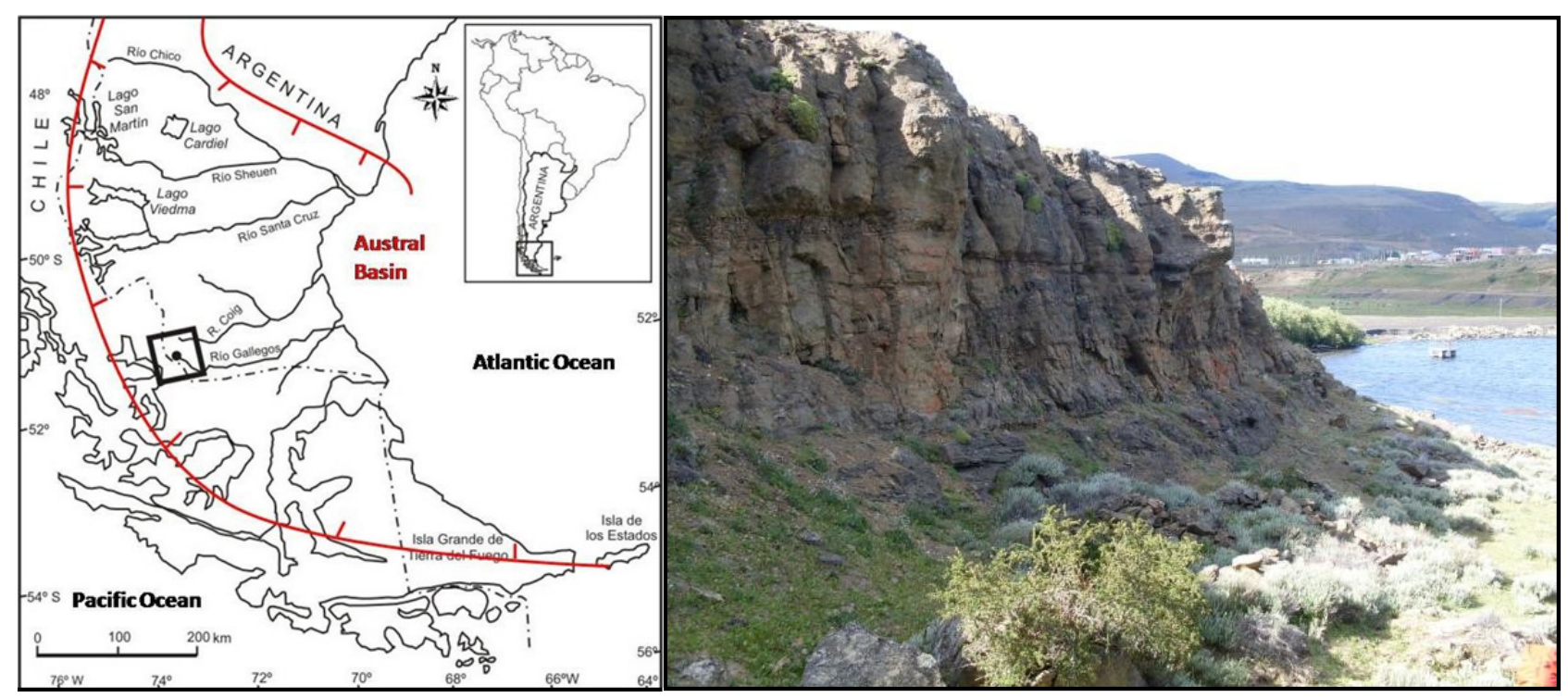

Figura 2. Localización del área de estudio. Afloramiento de la Fm. Río Turbio, estación 9. 


\subsection{Clima y flora actuales}

\subsubsection{Clima}

El clima de la Comarca de Río Turbio está clasificado como continental subpolar (Kottek et al., 2006), el cual en general es frío y húmedo pero más seco que en otros distritos, con nevadas y heladas todo el año, incluso con presencia de nieve cubriendo el bosque varios meses en el invierno. El clima húmedo es causado por el ingreso de masas de aire húmedo desde el océano Pacífico y una con una baja tasa de radiación solar. La precipitación media anual es de $1000 \mathrm{~mm}$. La temperatura media anual es de $5.4{ }^{\circ} \mathrm{C}$, una máxima absoluta de $28{ }^{\circ} \mathrm{C}$ y mínima absoluta de $-30{ }^{\circ} \mathrm{C}$.

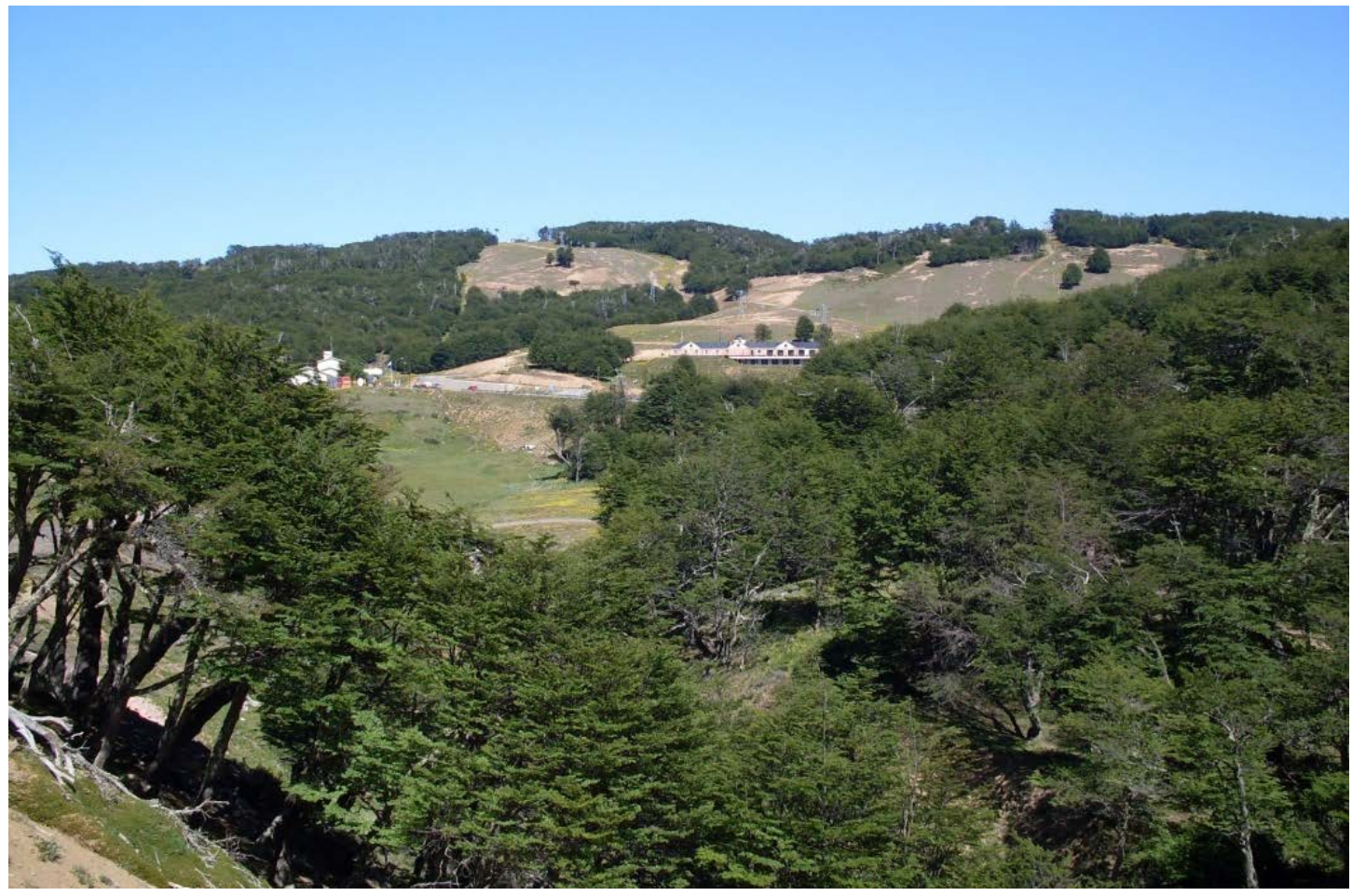

Figura 3. Área de estudio. Bosque de Nothofagus antarctica. 


\subsubsection{Flora}

La comarca de Río Turbio pertenece al distrito fitogeográfico del bosque caducifolio de la provincia fitogeográfica subantártica (Cabrera, 1976). Este distrito cubre una angosta franja del sudoeste del Cono Sur sudamericano e incluye distintas formaciones de bosques templados y fríos, caracterizado por dos especies caducifolias de Nothofagus: $N$. antarctica (ñire) que se ubica en las llanuras y desagües, en los valles o colinas suaves y $N$. pumilio (lenga) que ocupa las partes más altas y de mayor drenaje (Figura 2). Otro componente característico es Austrocedrus chilensis (ciprés de la cordillera). Estos bosques han sido explotados de forma intensiva y sólo se observan de ellos relictos o rodales aislados (Roig \& Faggi, 1985). En el área de estudio son frecuentes las praderas, generalmente inducidas por el hombre, muy ricas en especies adventicias de origen europeo.

Estrato arbóreo

La principal especie arbórea en el área de estudio es la antes mencionado Nothofagus antarctica (G. Forst.) Oerst. (ñire), la acompañan Lomatia hirsuta (Lam.) Diels (radal), Embothrium coccineum J.R. Forst. y G. Forst. (notro), Maytenus boaria Molina (maitén común) y Schinus montanus (Phil.) Engl. (laura), entre otras.

Estrato arbustivo o sotobosque

Entre los arbustos, las especies más conocidas son Berberis microphylla G. Forst. (calafate) y Berberis darwinii Hook. (michay), Azara microphylla Hook. f. (chínchín), Chusquea culeou E. Desv. (caña colihue), Gaultheria mucronata (L. f.) Hook. \& Arn. (chaura), Aristotelia chilensis (Molina) Stuntz (maqui) y Fabiana imbricata Ruiz \& Pav. (pichi), entre otras. 
Estrato herbáceo

Destacan: Blechnum penna-marina (Poir.) Kuhn, Polystichum mohrioides (d'Urv.) C. Presl, Loasa argentina Urb. \& Gilg, Codonorchis lessonii (Brongn.) Lindl., Gunnera magellanica Lam., Alstroemeria aurea Graham (amancay), entre otras especies.

Estrato epifítico y muscinal

Abundan los líquenes, musgos, parásitas del género Misodendrum Banks ex DC., hongos como Cyttaria darwinii Berk. (1lao-llao), entre otros.

Estrato escandente

Destacan: Eccremocarpus scaber Ruiz \& Pav., Mutisia decurrens Cav., y Mutisia spinosa Ruiz \& Pav. (mutisias o virreinas), Ribes magellanicum Poir., entre otras. 


\section{Antecedentes geológicos}

\subsection{Estratigrafía}

La FRT se localiza en la Cuenca Austral, en el sudoeste de la provincia de Santa Cruz (Figura 2), y está representada por secuencias depositadas en ambientes marinos poco profundos, alcanzando un total de 600 metros de espesor en el área tipo (Furque y Caballé, 1993). Esta formación está compuesta por areniscas finas a gruesas, conglomerados finos, niveles limo-arcillosos y de coquinas, con intercalación de cinco mantos de carbón (Malumián et al., 2000). La FRT se divide en dos Miembros, el inferior y el superior. El Miembro inferior (Figura 4 A), asociado al límite Eoceno inferior a medio (Malumián, 2002; Guerstein et al., 2010c), se dispone en discordancia sobre sedimentitas marinas someras de la Fm. Cerro Dorotea depositadas durante el Paleoceno (Malumián et al., 2000; Malumián, 2002). El Miembro superior de la FRT (Figura 4 B) se asigna al Eoceno medio superior - Eoceno superior inferior (Malumián, 1999, 2002; Furque \& Caballé, 1993; Casadío et al., 2009), y por encima de una discordancia erosiva se reconocen depósitos continentales de edad Eoceno tardíaOligoceno temprana de la Fm. Río Guillermo (Leanza, 1972; Arguijo \& Romero, 1981; Ramos, 2002). La sedimentación de la Cuenca Austral durante el Paleógeno se puede dividir en cuatro ciclos sedimentarios relacionados con importantes incursiones marinas del Océano Atlántico (Malumián, 1999, 2002; Malumián \& Náñez, 2011). El Miembro superior de la FRT está caracterizado por areniscas finas a gruesas y conglomerados con intercalaciones de niveles arcillosos y abundantes restos vegetales acumulados en ambientes costeros, dominados por olas o mareas (Furque \& Caballé, 1993; Pujana et al., 2011; Rodríguez Raising, 2010), o en ambientes de planicies costeras o estuarios exteriores dominados por mareas (Pearson et al., 2013). Según Malumián (2002), 
representa la sedimentación en ambientes submareales correspondientes a un período transgresivo-regresivo iniciado en el Eoceno medio superior, el cual está caracterizado por un nivel glauconítico muy extendido dentro de la Cuenca Austral (Calegari et al., 1993). Dicho nivel glauconítico permite correlacionar al Miembro superior de la FRT con la Fm Man Aike en la provincia de Santa Cruz (Concheyro, 1991; Malumián, 1990; Casadío et al., 2009; Guerstein et al., 2014), con la Fm. Leticia (Olivero \& Malumián, 1999, 2008; Guerstein et al., 2008), la sección inferior de la Fm. Cerro Colorado y el Glauconítico B en la provincia de Tierra del Fuego, y con la Fm. Leña Dura y Fm. Loreto en Chile (Fasola, 1969; Archangelsky \& Fasola, 1971).

\subsection{Edad}

Hünicken (1955) sobre la base de las tafofloras, le asignó una edad que abarcaría desde el Eoceno medio hasta el Oligoceno medio. Más tarde en 1966, en el estudio detallado de la tafoflora de la sección inferior, señaló una edad eocena, quizás temprana y media. Cabe señalar que corresponde a la primera asignación al Eoceno, y particularmente limitado inferiormente al Eoceno medio, de sedimentos marinos en la Argentina, basado en un estudio paleontológico.

Borrello (1956) consideró para la sección inferior (grupo medio) una edad eocena - $\mathrm{u}$ oligocena temprana - mientras que a la superior (grupo superior) una edad francamente oligocena.

Groeber (en Hoffstetter et al., 1957) llegó a la conclusión que los depósitos comenzaron a formarse a partir del Eoceno, basándose en que sus conglomerados de base contienen rodados del Chilelitense (del Paleoceno-Eoceno). 


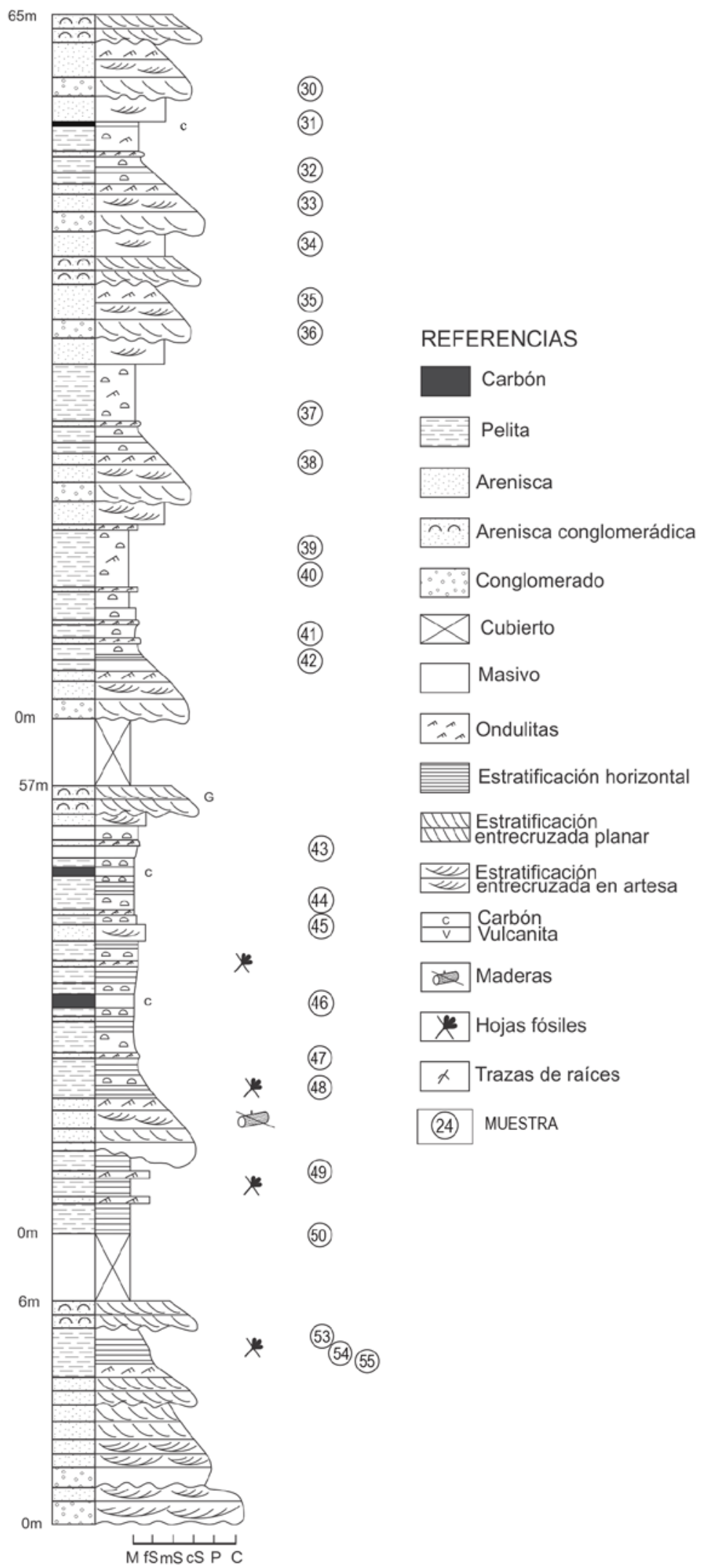

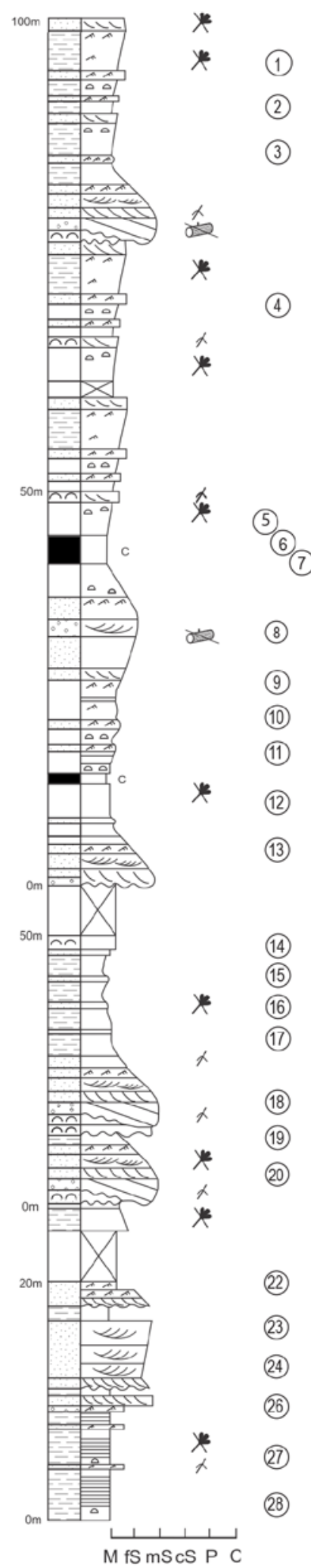

Figura $4 b$

Figura $4 \mathrm{a}$

Figura 4. Perfil esquemático de los Miembros Inferior (a) y Superior (b) de la Formación Río Turbio en los alrededores del Ao. Sta. Flavia (modificado de Panti, 2010). 
Archangelsky $(1968,1969)$ por el paleomicroplancton, concluyó que la datación tentativa más lógica es la de Eoceno inferior alto y Eoceno medio bajo para el Miembro Inferior y Eoceno medio alto y Eoceno superior bajo para el Miembro superior. Estimó que no están representados el Oligoceno y el Paleoceno. En otros estudios realizados por Archangelsky y Fasola (1971) sobre el paleomicroplancton paleógeno de la Patagonia, y posteriormente por Archangelsky (1972) y Archangelsky y Romero (1974a, b), sobre las esporas y el polen, se aceptó la misma edad.

Romero (1977) sobre un cuadro comparativo de los biocrones de polen de Nothofagaceae y Gymnospermae de la FRT, concluyó que la única época en la que coinciden los biocrones es el Eoceno.

Carrizo et al. (1990), mediante microfósiles calcáreos, otorgaron una edad eocena media, Lutetiano, dentro de las edades correspondientes a las zonas P11 y P14 de la escala internacional de Blow (1979). Torre (1993) realizó varios perfiles sobre el tramo inferior de la FRT, que había resultado estéril o con muy escasa microfauna para los mencionados autores, y le asignó edad eocena media al tramo inferior.

Según Riccardi y Rolleri (1980) la presencia de Venericardia en la sección inferior indicaría una edad eocena.

Malumián et al. (2000) consideran al Miembro superior como Eoceno medio superior a Eoceno superior bajo, equiparable al intervalo de las Zonas P12-P15. El miembro inferior, sería en principio post Paleoceno y pre-Eoceno medio superior por su posición estratigráfica; su tafoflora afín con la de Laguna del Hunco, sugiere una edad similar que según dataciones radimétricas ( $c f$. Mazzoni et al., 1991) se encontraría entre el Eoceno inferior superior a medio inferior. Las diferencias micro y megafaunísticas y del microplancton, sumado a la existencia de un banco glauconítico basal en el miembro 
superior, indican para dichos autores la existencia de por lo menos un hiato de magnitud no definida entre los miembros inferior y superior, que apoya esta interpretación.

Guerestein et al. (2014) estudiando dinoquistes sostienen que las asociaciones de la parte más superior de la Fm Man Aike están altamente correlacionadas con las de la parte inferior del miembro superior de la FRT. Las altas frecuencias de Enneadocysta dictyostila y las últimas ocurrencias de Hystrichosphaeridium truswelliae y Arachnodinium antarcticum indican que estos intervalos estratigráficos oscilan entre los 45,5 y los $39 \mathrm{Ma}$ (finales de Luteciano a Bartoniano inferior). Así, los dinoquistes junto con la distribución de microfósiles calcáreos, afinidades de moluscos y los datos de ${ }^{87} \mathrm{Sr} /{ }^{86} \mathrm{Sr}$ limitan la edad de la Fm Man Aike y formaciones equivalentes a $c a .42$ a 39 Ma. Por otra parte, los autores sugieren que la parte superior del miembro superior del FRT no es más antigua que el Priaboniano (37 Ma).

Fosdick et al. (2015) presentan en un estudio preliminar una nueva geocronología de zircones detríticos $\mathrm{U} / \mathrm{Pb}$ de la cuenca de antepaís cenozoica de Magallanes (cerca de $51^{\circ} \mathrm{S}$ ), tanto en Argentina como en Chile, que arrojaría luz sobre la procedencia sedimentaria y ajustaría el momento de sedimentación de las formaciones Cerro Dorotea, Río Turbio y Río Guillermo. Estos autores proponen que la depositación del miembro superior de la FRT habría ocurrido durante la transición Eoceno-Oligoceno $c a$. 33-34 Ma y continuó hasta $c a . \leq 26$ Ma.

\subsection{Floras eocenas de Patagonia}

En la Cuenca Austral, donde se acumularon los depósitos de la FRT, la sedimentación comenzó en el Jurásico extendiéndose hasta el Cenozoico, depositando una espesa pila sedimentaria continua pero ligeramente deformada, muy bien expuesta en el suroeste de la provincia de Santa Cruz y en las costas surorientales de Tierra del 
Fuego. Estas secuencias han merecido numerosos estudios geológicos y estratigráficos (Arguijo \& Romero, 1981; Carrizo et al., 1990; Malumián et al., 2000). Sin embargo, hay solamente unos pocos estudios de megafloras y palinofloras en el Cretácico superior y Cenozoico de Cuenca Austral. Datos puntuales provienen del Cenomaniano (Palamarczuk et al., 2000), Maastrichtiano-Daniano (Archangelsky \& Romero, 1974; Romero, 1973; Menéndez \& Caccavari, 1975) y estudios más detallados fueron realizados en el Eoceno (Hünicken, 1967; Menéndez \& Caccavari, 1975; Romero, 1977; Olivero et al., 1998; Carrillo-Berumen et al., 2013) tanto en afloramientos como en muestras de perforaciones.

La flora de Laguna del Hunco (Berry, 1925a, 1925b, 1928, 1932; Romero, 1986; Wilf et al., 2005) es una de las asociaciones más diversas conocidas hasta el momento. De edad eocena temprana (52,13 Ma) consta de 102 especies reconocidas entre las que es posible encontrar dicotiledóneas, monocotiledóneas, coníferas, ginkgofitas, cycadales y helechos (Wilf et al., 2005).

La flora de Río Pichileufú fue estudiada por Berry (1935a, 1935b, 1935c, 1938); y asignada a un rango de edad muy amplio entre el Paleoceno y el Mioceno (González Díaz, 1979; Rapela \& Kay, 1988). Estudios recientes con dataciones Ar/Ar absolutas indican una edad Eocena media (47,46 $\pm 0,05 \mathrm{Ma}$, Wilf, et al., 2005). Berry (1938) describe 125 especies de angiosperma además de helechos, cycadales, ginkgofitas y coniferales.

La Formación Quinamavida de edad eocena temprana (Troncoso \& Muñoz, 1988) consta de 29 especies descriptas de angiospermas (Troncoso, 1992) las que, junto con la asociación encontrada en Río Pichileufú, formarían parte del tipo florístico mixto sin Nothofagus (Troncoso \& Romero, 1998). 
Para la FRT, Romero (1977) analizó el registro polínico particularmente referido a las Nothofagaceae y Gymnospermae. Otros contribuciones sobre la formación incluyen las de Romero y Zamaloa (1985) y Fernández et al. (2012) sobre polen de angiospermas, Romero y Castro (1986) sobre restos fúngicos, González Estebenet et al. (2012) sobre diatomeas, Guerstein et al. (2014) sobre quistes de dinoflagelados, los realizados por Berry (1937a), Hünicken $(1955,1967,1995)$ y Panti (2010) sobre hojas fósiles y Ancibor (1990), Brea (1993) y Pujana (2008) en maderas fósiles. 


\section{Materiales y métodos}

\subsection{Muestreo y procesado paleopalinológico}

Para llevar a cabo el objetivo principal planteado se muestrearon para estudios paleopalinológicos varias secciones aflorantes en la comarca de Río Turbio. El muestreo se realizó durante una campaña en diciembre de 2011. Los estratos muestreados en este estudio pertenecen a la FRT. La potencia máxima de la FRT se estima en unos 650 metros, y el muestreo realizado en este trabajo representaría su totalidad. 40 de las 54 muestras tomadas resultaron fértiles para palinología (Apéndice, Tabla 1). En este trabajo se adoptó la estratigrafía propuesta por Malumián et al. (2000).

La ubicación de todas las localidades de donde provienen las secciones analizadas se encuentran en la figura 5. Las muestras extraídas fueron en todos los casos referidas a perfiles de detalle (Figuras 6-8). Para realizar los perfiles se tuvieron en cuenta las características granulométricas y composicionales de los distintos estratos, su geometría, estructuras sedimentarias y contenido fosilífero. La distancia entre las muestras, en un mismo perfil, fue variable, y condicionada principalmente por las características litológicas dominantes en cada sección. Las sedimentitas de grano fino son, en general, más productivas en términos palinológicos que las de tamaño de grano mayor. Por ello, en los sectores dominados por pelitas, el número de muestras colectadas es mayor.

En el laboratorio de ácidos fuertes del Museo Argentino de Ciencias Naturales "Bernardino Rivadavia" se procedió al procesamiento de la totalidad de las muestras extraídas. Las técnicas para el procesado palinológico fueron tomadas de Wood et al. (1996), las cuales involucran: 1) molido de 30 gramos de roca, 2) ataque con ácido fluorhídrico al $100 \%$ (eliminación de silicatos), 3) ataque con ácido clorhídrico al 33\% 
(eliminación de carbonatos y fluorosilicatos), 4) refinamiento del residuo orgánico, 5) filtrado sucesivo con mallas de 200, 25 y $10 \mu \mathrm{m}$. y 6) montaje en gelatina glicerina. Los preparados palinológicos serán depositados en el Museo Regional Provincial Padre Manuel Jesús Molina (Río Gallegos, Santa Cruz). Las coordenadas de los especímenes fósiles ilustrados corresponden al microscopio Leica DM 500.

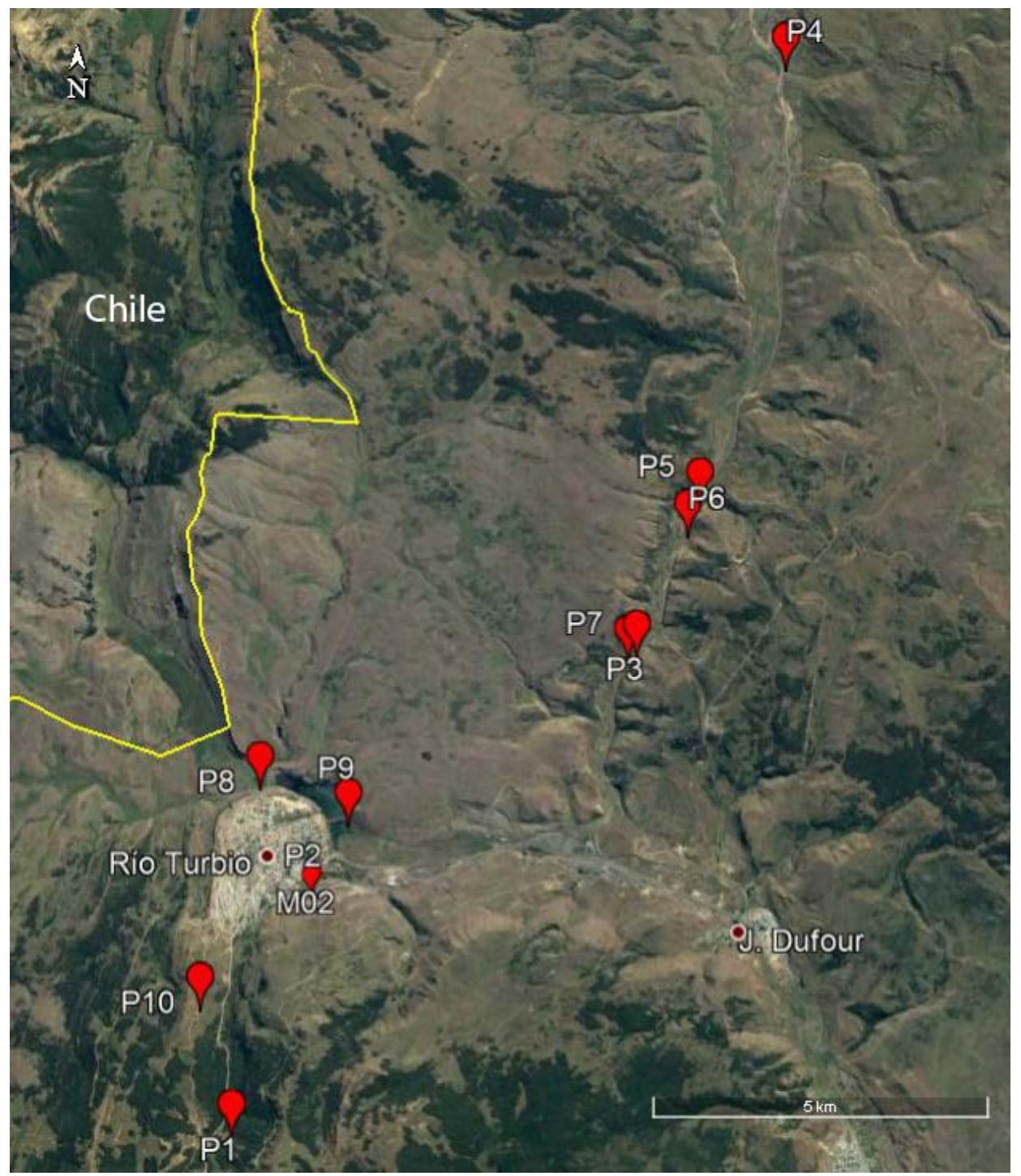

Figura 5. Imagen satelital de la región sudoccidental de la provincia de Santa Cruz, alrededores de la ciudad de Río Turbio, señalando las localidades muestreadas. P1-10: perfiles 1 a 10; M02: estación "Mina 2". 
Para el estudio del material utilizando MEB, el residuo de las muestras fue suspendido en etanol al $90 \%$, se montaron en tacos y se examinaron utilizando el microscopio XL30 TMP SEM Philips en el Museo Argentino de Ciencias Naturales "Bernardino Rivadavia".

\subsection{Marco Estratigráfico}

La FRT corresponde a la parte marina del "Magallanense" sensu Brandmayr (1945). Feruglio (en Fossa Mancini et al., 1938) denomina a la unidad Estratos de Río Turbio, terminología adoptada por Hünicken (1955) para los sedimentos de la sección marina de Brandmayr. Más tarde, Leanza (1972) adoptó formalmente el nombre como FRT. Esta formación es normalmente dividida en dos miembros, con un espesor total de aproximadamente 600 m (Furque \& Caballé, 1993). La FRT se apoya en discordancia erosiva sobre la Formación Cerro Dorotea con un hiato que podría abarcar gran parte del Eoceno Inferior.

Según lo que se puede observar en los afloramientos de esta unidad en la sierra Dorotea (Yacimientos Carboníferos Río Turbio), y en el valle del río Guillermo más los resultados de los sondeos llevados a cabo por ENADIMSA (1986) el espesor de esta unidad varía entre los 380 y $480 \mathrm{~m}$. En los afloramientos visitados es claro que la variación en los espesores se debe tanto al relieve de la base de la unidad (paleovalle o valle inciso) como también al cercenamiento de la parte superior de la unidad previo a la depositación de la suprayacente Formación Río Guillermo a partir de un basculamiento hacia el Este de las capas. Esto se demuestra por el espesor de la sección superior de la FRT entre el manto de carbón Dorotea y la base de la Formación Río Guillermo que disminuye de 220 a $90 \mathrm{~m}$ en una distancia de $5,5 \mathrm{Km}$. de Este a Oeste (Hünicken, 1955). 
Malumián y Caramés (1997) dividen a esta unidad en dos miembros (Tabla 1) tomando como límite un nivel altamente glauconítico que coincide con cambios macro y microfaunísticos mayores, y que se interpreta como la base de un conspicuo episodio transgresivo.

\begin{tabular}{|c|c|c|}
\hline $\begin{array}{l}\frac{\mathrm{O}}{m} \\
\stackrel{\underline{x}}{2} \\
\frac{\mathrm{O}}{\underline{\underline{x}}}\end{array}$ & $\begin{array}{l}\text { MIEMBRO } \\
\text { SUPERIOR }\end{array}$ & $\begin{array}{l}\text { - SECCIÓN SUPERIOR } \\
\text { - COMPLEJO CARBONOSO SUPERIOR } \\
\text { (CCS): } \\
\text { - MANTO DOROTEA } \\
\text { - MANTO A } \\
\text { • MANTO B } \\
\text { - SECCIÓN MEDIA }\end{array}$ \\
\hline 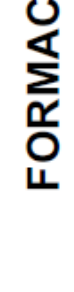 & $\begin{array}{l}\text { MIEMBRO } \\
\text { INFERIOR }\end{array}$ & $\begin{array}{l}\text { - COMPLEJO CARBONOSO INFERIOR } \\
\text { (CCI): } \\
\text { • YACIMIENTO SUPERIOR } \\
\text { • YACIMIENTO INFERIOR } \\
\text { - SECCIÓN INFERIOR }\end{array}$ \\
\hline
\end{tabular}

Tabla 1. División esquemática de la FRT, tomado de Panti (2010).

Miembro inferior (Figuras 6 y 8, Perfiles 1-2, 7-9)

Alrededor de $67 \mathrm{~m}$ de espesor, incluye a la denominadas sección inferior y al Complejo Carbonoso Inferior de la FRT (Tabla 1, Figura 4 A). Está compuesto por un conglomerado basal, areniscas gruesas a finas con estratificación entrecruzada de escala grande a mediana, coquinas y areniscas limosas con invertebrados marinos y restos de plantas, localmente hojas y particularmente troncos silicificados. Lo cubre el "Complejo Carbonoso Inferior" (CCI), que comprende dos ciclos antragénicos, el más antiguo muestra un conglomerado fino inicial, que decrece en granulometría hasta arcillitas, arcillitas carbonosas y finalmente yacimientos de carbón. Estos últimos, se conocen 
como "yacimiento inferior". El ciclo más joven repite la misma secuencia y es cubierto por el "yacimiento superior". La sucesión representa la evolución de un sistema mareal, en donde los conglomerados corresponden a los canales de mareas y las facies pelíticas superiores a las planicies mareales fangosas (inter a supramareales). En estas últimas los rasgos de mareas son muy conspicuos tales como laminación flaser, ondulosa y lenticular y delgadas ritmitas mareales. Al CCI se le asigna una edad eocena media temprana (Malumián \& Caramés, 1997). Se tomaron 17 muestras (muestras nro. 31, 3342, 45-47, 49, 50 y 53) en afloramientos correspondientes a este miembro (Figuras 6 y 8; Apéndice 1, Tabla 1).

Miembro superior (Figuras 6 y 7, Perfiles 3-6)

Aproximadamente $340 \mathrm{~m}$ de espesor, incluye a la sección media, al Complejo Carbonoso Superior y a la sección superior de la FRT que puede separarse en cuatro secciones. Los espesores registrados en las diferentes perforaciones exploratorias indican una importante variabilidad en el espesor de este miembro, posiblemente reflejando los diferentes niveles de erosión alcanzados previos a la depositación de la suprayacente Formación Río Guillermo.

La primera sección (65 a 75 m) yace sobre un sustrato duro ("hardground"), comienza con un nivel basal altamente glauconítico seguido por conglomerados finos, areniscas y areniscas limosas con invertebrados fósiles marinos y vegetales carbonizados. El nivel glauconítico basal representa un extendido nivel de inundación sobre el cual se desarrolla una sucesión somerizante con depósitos de plataforma marina. La segunda sección comprende un notable conglomerado que se apoya sobre una superficie erosiva que fue usada como límite entre los miembros Superior e Inferior de esta Formación por varios autores (Malumián \& Caramés, 1997). Consiste en 
areniscas finas a gruesas intercaladas con niveles glauconíticos, arcillíticos y coquinoides dispersos (100 a $134 \mathrm{~m}$ ) que representan nuevamente depósitos litorales. La tercera sección incluye el "Complejo Carbonoso Superior" (CCS) (18 a 54 m), que está formado por ocho ciclos antragénicos (entre ellos el "Manto Dorotea") los cuales fueron depositados en ambientes marginales. Al CCS se le asigna una edad eocena media tardía (Malumián \& Caramés, 1997). La cuarta sección consiste de areniscas, limolitas y arcillitas con intercalaciones de conglomerados y coquinas de ostras (100 a $140 \mathrm{~m}$ ) que representan nuevamente ambientes costeros con fuerte acción mareal. Se reconocen canales de mareas que presentan conspicuas superficies de migración lateral, pequeños ciclos granocrecientes correspondientes a deltas de mareas e intervalos políticos interpretados como depósitos de lagoon o albúferas. Para las secciones Media y Superior se tomaron 23 muestras (muestras nro. 1-3, 5, 9-23 y 25-28) (Figuras 6 y 7 , Apéndice 1, Tabla 1).

En cuento al ambiente de depositación, la FRT representa sedimentación durante un período de ascenso del nivel del mar con fluctuaciones menores, que se inicia con la inundación del relieve labrado previamente durante un período de bajo nivel relativo del mar. La división propuesta por Malumián y Caramés (1997) permite separar el relleno de un valle inciso inicial (Miembro inferior) de la sedimentación en ambientes marinos y marginales posteriores a la colmatación del valle (Miembro superior). Las distintas secciones reconocidas en trabajos previos deberían ser cuidadosamente revisadas pero muy posiblemente ellas representen ciclos transgresivos-regresivos de mayor frecuencia dentro de la evolución general del sistema depositacional (Panti, 2010). 
PERFIL 1

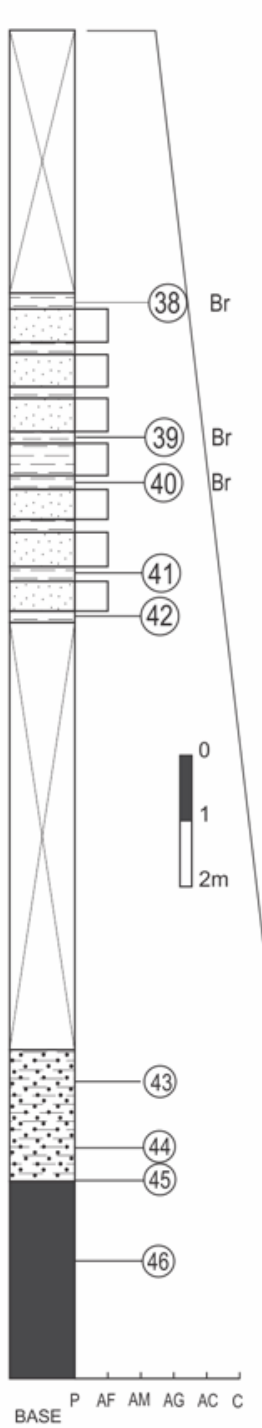

PERFIL 2

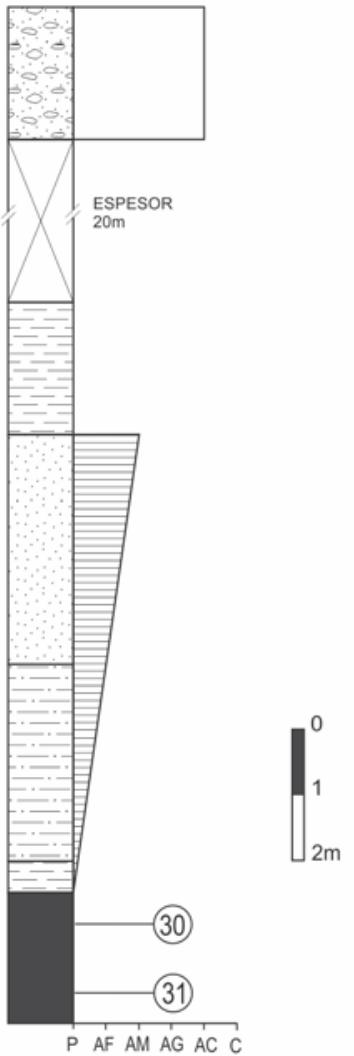

PERFIL 3

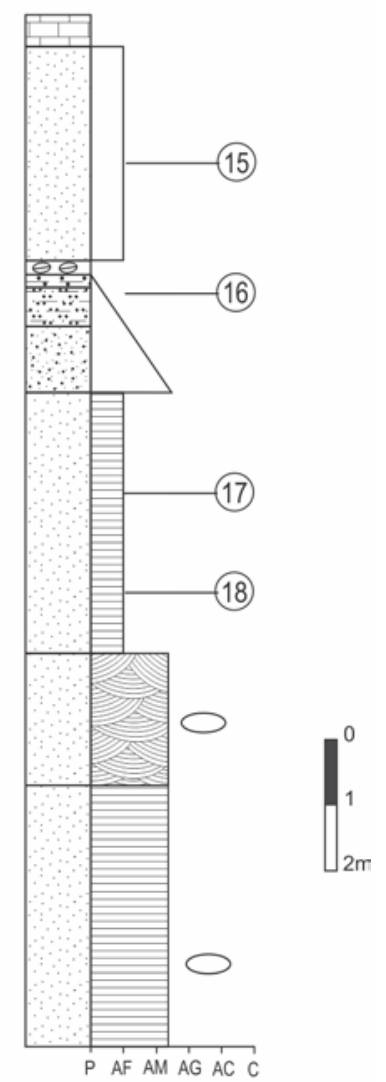

\section{REFERENCIAS}

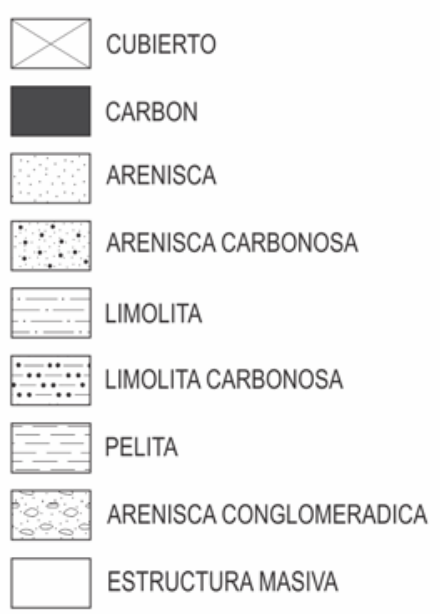

$\because \because$ PELITA CARBONOSA

$\theta \ominus$ COQUINAS

CALIZA

$\Rightarrow$ ESTRATIFICACION ENTRECRUZADA

ESTRATIFICACION PARALELA

$\bigcirc$ CONCRECIONES

(46) MUESTRA

Br Briznas

Figura 6. Perfiles muestreados en la región sudoccidental de la Pcia. de Santa Cruz, alrededores de la ciudad de Río Turbio correspondientes a las localidades señaladas en la figura 5 (perfiles 1-3). 
PERFIL 4

PERFIL 5


ESPESOR

CONGLOMERADOS

RIO GUILLERMO



PERFIL 6

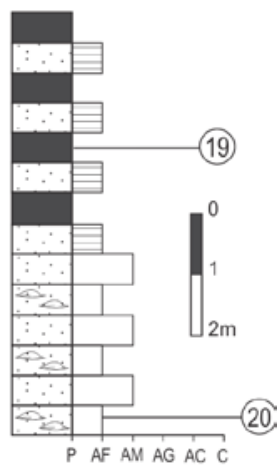

REFERENCIAS

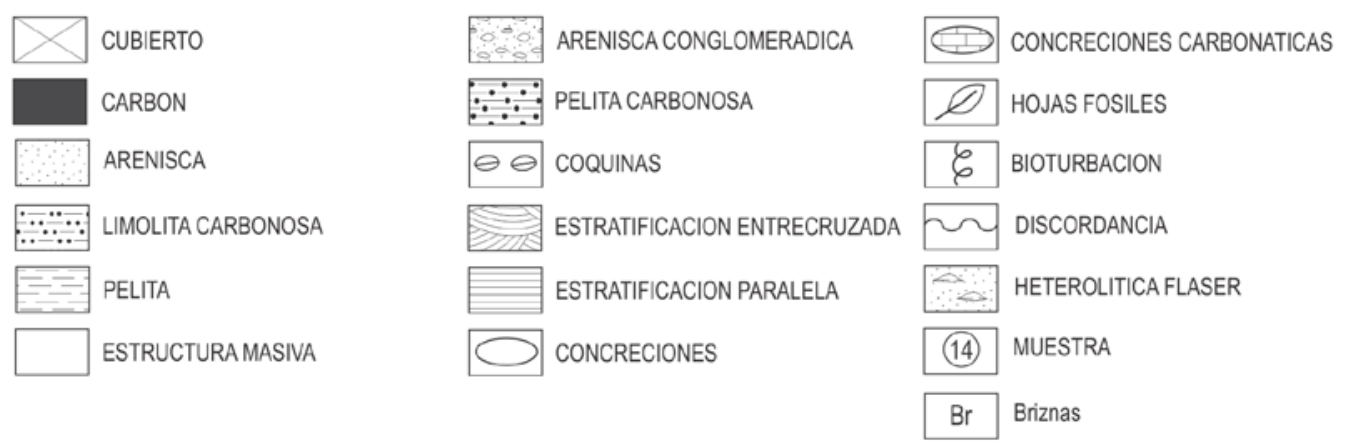

Figura 7. Perfiles muestreados en la región sudoccidental de la Pcia. de Santa Cruz, alrededores de la ciudad de Río Turbio correspondientes a las localidades señaladas en la figura 5 (perfiles 4-6). 
PERFIL 7

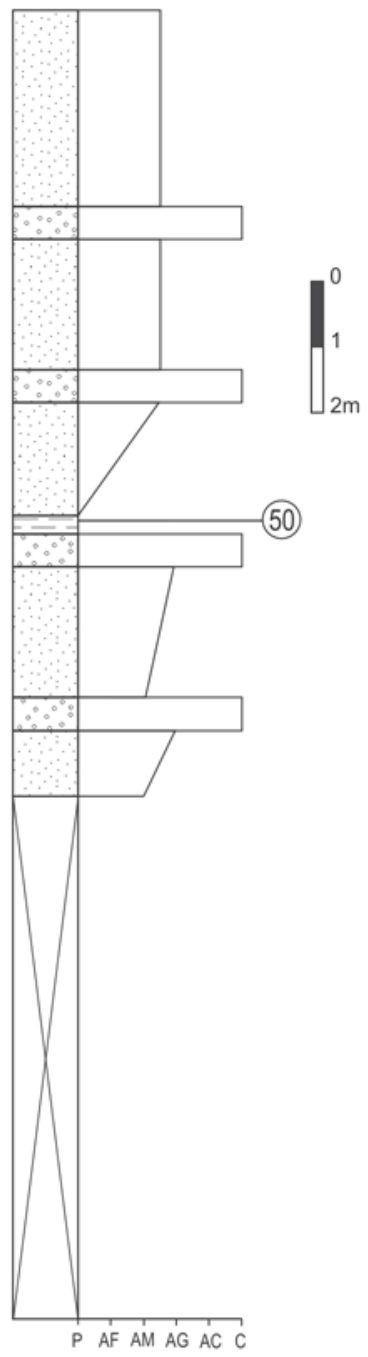

PERFIL 8

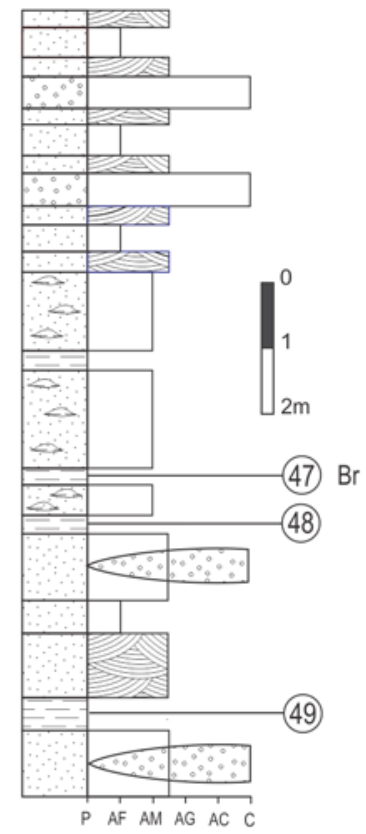

PERFIL 9

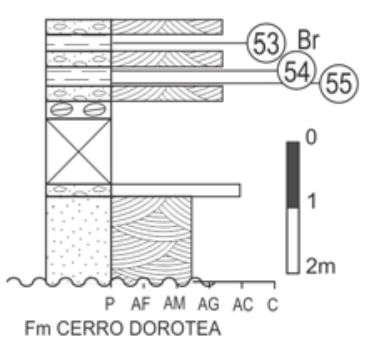

MINA 02

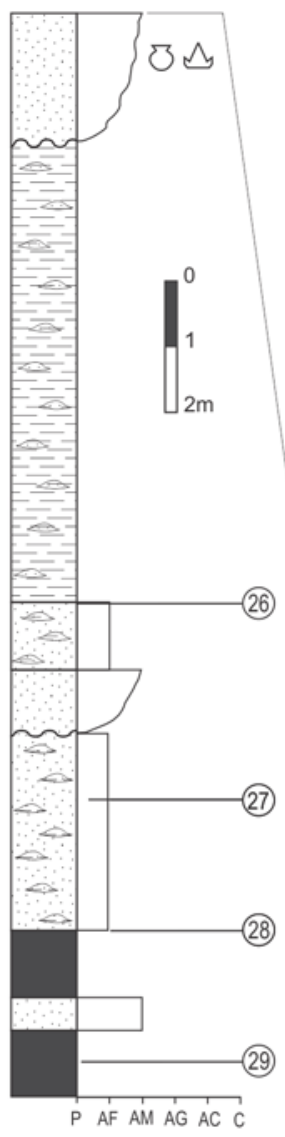

(21)



REFERENCIAS

\begin{tabular}{|c|c|c|c|c|c|}
\hline 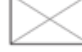 & CUBIERTO & $=$ & PELITA & $\sim$ & DISCORDANCIA \\
\hline & CARBON & $=0$ & HETEROLITICALENTICULAR & 3 & BIVALVOS \\
\hline & ARENISCA & & HETEROLITICA FLASER & Bi & BRIZNAS \\
\hline & ARENISCA COGLOMERADICA & & ESTRATIFICACION ENTRECRUZADA & $\Delta$ & DIENTE DE TIBURON \\
\hline & CONGLOMERADO & & ESTRUCTURA MASIVA & (24) & MUESTRA \\
\hline$\because$ & PELITA CARBONOSA & $\theta \theta$ & COQUINAS & & \\
\hline
\end{tabular}

Figura 8. Perfiles muestreados en la región sudoccidental de la Pcia. de Santa Cruz, alrededores de la ciudad de Río Turbio correspondientes a las localidades señaladas en la figura 5 (perfiles 1-3) 


\subsection{Palinología sistemática}

El principal sistema de clasificación utilizado en palinología es artificial, basándose estrictamente en aspectos morfológicos, sin tener en cuenta relaciones filogenéticas (Iversen \& Troels, 1950; Erdtman \& Straka, 1961). Otros sistemas clasifican naturalmente los tipos morfológicos fósiles, asignándoles nombres de taxones actuales. En este trabajo, se utilizarán ambas clasificaciones: se asignarán nombres artificiales a los nuevos tipos morfológicos propuestos, pero se utilizará la terminología natural (por encima del nivel de familia) para agrupar morfogéneros, los cuales se ordenarán alfabéticamente. En este trabajo, si bien se hace mención a algunas especies que son inéditas, las mismas carecen de nombre debido a que aún no han sido publicadas de acuerdo a las normas establecidas por el Código de Nomenclatura. La terminología para describir a los tipos polínicos corresponde a Punt et al. (2007).

\subsection{Análisis polínico y rarefacción}

Para cada muestra, se contó un mínimo de 300 especímenes continentales en la fracción mayor a $10 \mu \mathrm{m}(+10)$, como así también los palinomorfos encontrados en la misma superficie de la fracción mayor a $25 \mu \mathrm{m}(+25)$. Se contaron un total de 22805 esporomorfos y 9486 paleomicroplancton. Los grupos de muestras fueron delimitados mediante CONISS (Grimm, 2015), un análisis de agrupamientos sobre los datos de porcentaje, con transformación de raíz cuadrada (para mejorar la normalidad, Sokal \& Rohlf, 1995) y restricción estratigráfica. El programa Tilia Versión 2.0.41 se utilizó para graficar los palinogramas (Grimm, 2015). En el apéndice 1, tabla 4, se detallan las categorías a las que se asignaron las especies para realizar los palinogramas. 
La diversidad (S) se utilizó para denotar el número de especies (Rosenzweig, 1995). La diversidad dentro de una muestra se estimó utilizando rarefacción, una técnica de interpolación que estima cuántas especies se hubieran encontrado si la muestra hubiera sido menor (Raup, 1975). Los análisis de rarefacción se realizaron usando R for statistical computing, versión 2.2.0 (R-Development-Core-Team, 2005) y el paquete Vegan (Oksanen et al., 2005). Se seleccionaron 15 muestras con frecuencia absoluta de dinoquistes de entre 90 a 427, para minimizar la diferencia en el ambiente de depositación. 


\section{Palinología de la Formación Río Turbio.}

En este capítulo se presentan las principales características vinculadas con la preservación, composición, y diversidad de la asociación palinológica recuperada de las sedimentitas analizadas, junto con las descripciones sistemáticas de todos los tipos morfológicos de origen continental hallados hasta el momento. Las descripciones siguen un orden alfabético por morfogénero de algas de agua dulce, briofitas, pteridofitas, gimnospermas y angiospermas (dicotiledóneas y monocotiledóneas). Se presenta primero una descripción morfológica que comprende a las dimensiones de los palinomorformos, seguida del nivel donde fue encontrado y sus registros previos, finalmente se incluyeron observaciones, comparaciones y su afinidad con grupos actuales. En el caso de los palinomorfos de registro amplio, ya descriptos en la bibliografía, se incluyen observaciones sobre razgos del material de la FRT (preservación, una síntesis de los atributos que los caracterizan, o que los diferencian de formas similares presenten en la asociación, entre otros aspectos). Los tipos desconocidos fueron señalados como tales, y agrupados en el taxón morfológicamente más afín.

\subsection{Asociación palinológica: características generales}

La distribución de los niveles fértiles (palinológicamente productivos) ha sido relativamente homogénea a lo largo de los perfiles analizados. Como se mencionó anteriormente, 40 de las 54 muestras estudiadas resultaron fértiles (Apéndice 1, Tabla 1). El grado de preservación de las asociaciones palinológicas va de regular a muy bueno, siendo en general bueno. Se preservan formas pequeñas, con estructuras delicadas e incluso tétrades y políades. 
Las asociaciones de esporomorfos presentan una gran abundancia y diversidad. En general están dominadas por especies de Nothofagidites, Podocarpidites y Myrtaceidites. Las esporas de helechos suelen ser frecuentes, al igual que las cutículas de plantas que están presentes a lo largo de toda la formación, con una buena preservación de marcas de poros, estomas y células. Todas las muestras (con una excepción) presentan dinoquistes, siendo en general más frecuentes los Gonyaulacoideos (Lámina 20, figura J) en detrimento de los Peridinoideos (Lámina 20, figura K). Otros componentes del paleomicroplancton destacables son las uñas de ácaros (Lámina 20, figura I), también presentes, aunque en baja frecuencia, en casi todas las muestras. La materia orgánica amorfa es abundante.

4.2. Palinología sistemática

Algas

Familia Closteriaceae

Closterium Nitzsch ex Ralfs

Closterium lunula Ehrenberg \& Hemprich ex Ralfs.

Closterium sp.

Lámina 1, figura $\mathrm{A}$

Dimensiones: eje mayor: $20 \mu \mathrm{m}$ (1 ejemplar).

Procedencia: Miembro Superior de la FRT.

Observaciones: Algas carofitas, unicelulares, de forma elíptica y ambientes de agua dulce. Las formas estudiadas en la FRT son muy semejantes a las reportadas por 
Songtham et al. 2004 para el Mioceno medio de Tailandia (Closterium thailandicum Songtham et al. 2004).

Familia Dictyosphaeriaceae

Botryococcus Kützing 1849

Especie tipo: Botryococcus braunii Kützing 1849

Botryococcus sp.

Lámina 1, figura B

Dimensiones: diámetro de la colonia: 35 a $50 \mu \mathrm{m}$; diámetro de cada célula: 5 a $10 \mu \mathrm{m}$ (5 ejs.).

Procedencia: Miembro Superior de la FRT.

Observaciones: las colonias son reconocidas por la presencia de estructuras en forma de copas. Estas copas se agrupan en "clusters", los que le confieren una forma característica. Es un género cosmopolita, presente desde el Carbonífero. Actualmente son particularmente frecuentes en lagunas, o pantanos de agua dulce, aunque puede tolerar aguas salobres.

Familia Scenedesmaceae

Scenedesmaceae indet.

$$
\text { Lámina 1, figura C-D }
$$

Dimensiones: eje mayor: $21(24,6) 28 \mu \mathrm{m}$ (10 ejemplar).

Procedencia: Miembro Superior de la FRT.

Observaciones: Algas carofitas, de ambientes de agua dulce. 
Familia Zygnemataceae

Catinipollis Krutzsch 1966

Especie tipo: Catinipollis geiseltalensis Krutzsch 1966

Catinipollis geiseltalensis Krutzsch 1966

Lámina 1, figura E-F

Dimesiones: diámetro ecuatorial: $25(28,8) 31 \mu \mathrm{m}$ (10 ejs.).

Procedencia: Miembro Inferior y Miembro Superior de la FRT.

Registros previos: especie cosmopolita ampliamente distribuída desde el Maastrichtiano hasta el Mioceno (ver citas en White, 2006).

Observaciones: esta especie es poco frecuente en la FRT. Los especímenes están bien preservados, permitiendo la observación de caracteres diagnósticos como la exina uniestratificada y la ornamentación que consiste en verrugas redondeadas próximas entre sí.

Afinidad botánica: Van Geel (1978) interpretó morfoespecies parecidas a las zygosporas o aplanosporas de las Zygnemataceae.

Briofitas

Orden Sphagnales

Cingutriletes Pierce 1961

Especie tipo: Cingutriletes congruens Pierce 1961 
Cingutriletes australis Archangelsky 1972

Lámina 2, figuras A-B

Dimensiones: diámetro ecuatorial: $26,4 \mu \mathrm{m}$ (1 ejemplar).

Procedencia: Miembro Superior de la FRT.

Registros previos: especie ampliamente distribuida desde el Cretácico superior del Hemisferio Sur (ver citas en White, 2006). Eoceno de Alemania (Krutzsch, 1959) y Paleoceno de EEUU (Stanley, 1965).

Pteridofitas

Familia Blechnaceae

Peromonolites Erdtman 1947 ex Couper 1953

Especie tipo: Peromonolites bowenii Couper 1953.

Peromonolites vellosus Partridge en Stover \& Partridge 1973

Lámina 2, figuras C-D

Dimensiones: diámetro ecuatorial mayor: 33 (37) $41 \mu \mathrm{m}$.; diámetro ecuatorial menor:

21 (27) $33 \mu \mathrm{m}$.; diámetro polar: 23 (25) $28 \mu \mathrm{m}$.

Procedencia: Miembro Inferior y Miembro Superior de la FRT.

Observaciones: las formas observadas en la FRT son muy semejantes a los de la descripción original. Peromonolites archangelskii Baldoni incluye esporas monoletes similares a $P$. vellosus distinguibles por tener lesuras más cortas. Siguiendo el criterio de Barreda (1997), aquí se la considera como junior sinónimo de $P$. vellosus. 
Registros previos: Paleoceno a Mioceno de Argentina (Archangelsky, 1972; Baldoni, 1987; Barreda 1997). Paleoceno Medio a Mioceno Tardío de Australia (Stover \& Partridge, 1973). Oligoceno Tardío de la Dorsal del Meridiano Noventa Este, Océano Índico (Kemp \& Harris, 1977). Mioceno de Nueva Zelanda (Mildenhall \& Suggate, 1981; Mildenhall \& Pocknall, 1989).

Familia Dicksoniaceae

Cyatheacidites Potonié 1956

Especie tipo: Cyatheacidites annulatus Cookson 1947

Cyatheacidites annulatus Cookson 1947

Lámina 2, figuras E-F

Dimensiones: diámetro ecuatorial: 57 (64) $87 \mu \mathrm{m}$; cíngulo 7 (9) $12 \mu \mathrm{m}$; endosporio: 1 $\mu \mathrm{m}$; exosporio: $1 \mu \mathrm{m}$ (10 ejs.).

Procedencia: Miembro Inferior y Miembro Superior de la FRT.

Observaciones: las formas observadas son muy semejantes a las reportadas por Archangelsky (1972) aunque corresponden a los valores menores de los rangos de medidas. Se observaron tres formas que varían en la ornamentación de la cara proximal: con protuberancias bajas en tres áreas bien delimitadas; con verrugas altas; o con 3 carenas formando un triángulo.

Registros previos: especie ampliamente distribuida en Gondwana desde el Cretácico Inferior hasta el Mioceno Superior (ver citas en Raine et al. 2011).

Afinidad botánica: Lophosoria quadripinnata. 
Matonisporites Couper1958

Especie tipo: Matonisporites phlebopteroides Couper 1958.

Matonisporites sp.1

Lámina 2, figuras G-H

Descripción: espora trilete de contorno triangular a subtriangular en vista polar, lados cóncavos y ángulos redondeados. Lesura recta casi llegando a los vértices de la espora, se encuentra rodeada por un engrosamiento de la exina de hasta $2,5 \mu \mathrm{m}$. Cara proximal psilada. Cara distal rugulada. La exina se presenta engrosada en los vértices variando entre 5 y $6 \mu \mathrm{m}$.

Dimensiones: diámetro ecuatorial máximo: $45 \mu \mathrm{m}$; espesor de la exina: $3 \mu \mathrm{m}$ (2 ejs.).

Procedencia: Miembro Superior de la FRT.

Observaciones: el presente material muestra similitud con $M$. ornamentalis ilustrado por Barreda (1997) aunque los individuos aquí estudiados presentan lesura y vértices engrosados.

Trilites Erdtman \& Couper 1947

Especie tipo: Trilites tubereuliformis Cookson 1947

Trilites fasolae Archangelsky 1972

\section{Lámina 2, figuras I-J}

Dimensiones: diámetro ecuatorial: 36 (45) $52 \mu \mathrm{m}$; espesor de la exina: 2-3 $\mu \mathrm{m}$ (10 ejs.).

Procedencia: Miembro Inferior y Miembro Superior de la FRT. 
Observaciones: las formas observadas son muy semejantes a las reportadas por Archangelsky (1972) aunque no alcanzan las longitudes mayores observadas en dicha contribución. Su afinidad con la familia Dicksoniaceae es dudosa.

Registros previos: Eoceno de Argentina (Archangelsky 1972), Cretácico Superior de Antártida: (Baldoni \& Barreda 1986) y Eoceno de Chile (Troncoso \& Barrera, 1980).

\section{Trilites parvallatus Krutzsch 1959}

\section{Lámina 2, figuras K-L}

Dimensiones: diámetro ecuatorial: 38 (52) $67 \mu \mathrm{m}$; espesor exina en los ángulos: 4-6 $\mu \mathrm{m}$; espesor exina en los lados: $2-3 \mu \mathrm{m}$ (20 ejs.)

Procedencia: Miembro Inferior y Miembro Superior de la FRT.

Observaciones: las formas observadas son muy semejantes a las reportadas por Archangelsky (1972) aunque de menor dimensión. Su afinidad con la familia Dicksoniaceae es dudosa. Es la espora más frecuente en los sedimentos examinados en el presente estudio.

Registros previos: especie cosmopolita de amplia distribución desde el Albiano Inferior al Neógeno (ver citas en White, 2006).

Familia Gleicheniaceae

Gleicheniidites Dettmann 1963

Especie tipo: Gleicheniidites senonicus Ross 1949

Gleicheniidites circinidites Dettmann 1963

Lámina 3, figuras A-B 
Dimensiones: diámetro ecuatorial: 33 (37) $41 \mu \mathrm{m}$ (10 ejs.).

Procedencia: Miembro Inferior y Miembro Superior de la FRT.

Observaciones: los ejemplares coinciden plenamente con Gleicheniidites $c f$. $G$. circinidites descripta para el Mesozoico superior del SE de Australia (Dettmann, 1963); principalmente en la presencia de pliegues interradiales y la forma subtriangular de la espora.

Registros previos: Argentina: Maastrichtiano al Paleoceno (Archangelsky, 1973; Romero, 1973; Papú, 1988a,b, 1989; Baldoni, 1992a; Baldoni \& Askin, 1993). Antártida: Santoniano-Campaniano al Paleoceno Temprano (Baldoni \& Barreda, 1986; Dettmann \& Thompson, 1987; Baldoni \& Medina, 1989; Askin, 1990a). Australia: Jurásico Tardío y Terciario Temprano (Cookson, 1953; Balme, 1957; Dettmann, 1963).

Gleicheniidites senonicus Ross 1949

\section{Lámina 3, figuras C-D}

Dimensiones: diámetro ecuatorial: 31 (40) $48 \mu \mathrm{m}$; espesor de la pared: 1 a 1,5 $\mu \mathrm{m}$; engrosamientos interradiales ecuatoriales: 3,5 (4) $5 \mu \mathrm{m}$; margo: 1,6 (2) 2,6 (10 ejs.).

Procedencia: Miembro Inferior y Miembro Superior de la FRT.

Observaciones: estos ejemplares coinciden con los descriptos por Archangelsky (1972). Se caracteriza por la presencia de engrosamientos interradiales ecuatoriales y lesura con labios.

Registros previos: esta especie se encuentra ampliamente distribuida en todo el mundo, desde el Jurásico hasta el Neógeno (citas en White, 2006 y Raine et al., 2011).

Familia Hymenophyllaceae 
Leptolepidites Couper 1953

Especie tipo: Leptolepidites verrucatus Couper 1953

Leptolepidites densus Archangelsky 1972

\section{Lámina 3, figuras E-F}

Dimensiones: diámetro ecuatorial: 75 (82) $86 \mu \mathrm{m}$; espesor de la exina: 1,5 $\mu \mathrm{m}$; alto de las verrugas: 3 (4) $5 \mu \mathrm{m}$; diámetro de verrugas: 4 (5) $6 \mu \mathrm{m}$ (10 ejs.).

Procedencia: Miembro Inferior y Miembro Superior de la FRT.

Observaciones: las formas observadas son semejantes a las de la descripción original, difieren ligeramente en el contorno en vista polar, que no es tan triangular; en las dimensiones, es algo menor; y en las verrugas que son más homogéneas en el material aquí estudiado. El material estudiado corresponde a los valores menores de los rangos de medidas.

Registros previos: Argentina: Cretácico Superior a Eoceno (Archangelsky, 1972; Baldoni, 1993). Chile: Eoceno (Troncoso \& Barrera, 1980).

Familia Lycopodiaceae

Concavisporites Pflug en Thomson y Pflug 1953

Especie tipo: Concavisporites rugulatus Pflug 1953

Concavosporites sp. I en Archangelsky 1972

Lámina 3, figuras G-H

Dimesiones: diámetro ecuatorial: 27 (30) $32 \mu \mathrm{m}$ (9 ejs.).

Procedencia: Miembro Inferior y Miembro Superior de la FRT. 
Observaciones: las formas observadas en la FRT son muy semejantes a los de la descripción original de Archangelsky (1972), aunque el material aquí estudiado presenta dimensiones ligeramente menores.

Afinidad botánica: género Huperzia.

Concavosporites sp. II en Archangelsky 1972

\author{
Lámina 3, figuras I-J
}

Dimensiones: diámetro ecuatorial: 26-39 $\mu \mathrm{m}$ (4 ejs.).

Procedencia: Miembro Superior de la FRT.

Observaciones: las formas observadas en la FRT son muy semejantes a los de la descripción original de Archangelsky (1972). Aunque se estudiaron pocos ejemplares, los mismos muestran las menores dimensiones del rango conocido.

Afinidad botánica: género Huperzia.

Retitriletes Pierce 1961

Especie tipo: Retitriletes globosus Pierce 1961.

Retitriletes austroclavatidites (Cookson 1953) Doring et al. en Krutzsch 1963

Lámina 3, figuras K-L

Dimensiones: diámetro ecuatorial: 32 (35) $42 \mu \mathrm{m}$ (15 ejs.).

Procedencia: Miembro Inferior y Miembro Superior de la FRT.

Observaciones: las formas observadas en la FRT son muy semejantes a las reportadas por Archangelsky (1972). 
Registros previos: especie cosmopolita ampliamente distribuida en depósitos desde el Triásico (ver citas en White, 2006).

Afinidad botánica: género Lycopodium.

Familia Ophioglossaceae

Foveotriletes Van der Hammen, 1954 ex Potonié, 1956

Especie tipo: Foveotriletes scrobiculatus (Ross, 1949) Potonié, 1956

Foveotriletes sp. 1

Lámina 4, figuras A-B

Descripción: espora trilete, subtriangular, de lados ligeramente cóncavos y ángulos redondeados. Lesura recta casi llegando a los vértices de la espora. Pared de 3,3 $\mu \mathrm{m}$ de espesor. Superficie proximal y distal con perforaciones del exosporio menores a $1 \mu \mathrm{m}$ de diámetro, densamente distribuidas, sin un patrón definido.

Comparaciones: sólo se cuenta con un ejemplar, lo que no permite comparaciones más exhaustivas. Foveotriletes sp. 1 Jaramillo \& Dilcher 2001 posee foveolas de $2 \mu \mathrm{m}$ de diámetro. F. margaritae (Van der Hammen 1954) Germeraad et al. 1968, presenta lesura con labios. F. ornatus Regali et al. 1974 presentan foveolas de $1 \mu \mathrm{m}$ de diámetro. Foveotriletes "microfoveolatus", presenta idéntica ornamentación pero posee lesura con labios descripta (Jaramillo et al., 2007).

Dimensiones: diámetro ecuatorial: $37,6 \mu \mathrm{m}$ ( 1 ejemplar).

Procedencia: Miembro Superior de la FRT.

Observaciones: la proximidad de las perforaciones no permite describirlas como foveolas, pero por su similitud general se asigna a esta forma al género Foveotriletes. 
Familia Osmundaceae

Baculatisporites Thomson \& Pflug 1953

Especie tipo: Baculatisporites primarius (Wolf) Thomson \& Plug 1953

Baculatisporites comaumensis Potonie 1953

Lámina 4, figuras C-D. Lámina 21, figura A

Dimesiones: diámetro ecuatorial: 36 (44) $65 \mu \mathrm{m}$; espesor de la exina: $1 \mu \mathrm{m}$; báculas: 1 $3 \mu \mathrm{m}$; verrugas: $1-2 \mu \mathrm{m}$ (11 ejs.).

Procedencia: Miembro Inferior y Miembro Superior de la FRT.

Observaciones: en la fracción +10 , formas frecuentemente rotas o alteradas, posiblemente por su gran volumen en comparación con el resto de la asociación y su exina delicada.

Registros previos: especie cosmopolita de amplia distribución desde el Pérmico inferior al Neógeno (ver citas en White, 2006).

Afinidad botánica: otra afinidad propuesta es Hymenophyllaceae - Hymenophyllum flexuosum, H. cruentum (Macphail \& Cantrill 2006).

Baculatisporites turbioensis Archangelsky 1972 (modificada)

Lámina 4, figuras E-F

Dimensiones: diámetro ecuatorial: 37 (44) $61 \mu \mathrm{m}$; margo: 1-2 $\mu \mathrm{m}$; pared: $1 \mu \mathrm{m}$; báculas: 1-2 $\mu \mathrm{m}$ (10 ejs.).

Procedencia: Miembro Inferior y Miembro Superior de la FRT. 
Observaciones: las formas observadas son muy semejantes a las de la descripción original de Archangelsky (1972). En la fracción +10 , formas frecuentemente rotas o alteradas, posiblemente por su gran volumen en comparación con el resto de la asociación y su exina delicada. Se diferencia de B. comaumensis por presentar margo y una esculturación de mayor tamaño.

Registros previos: Maastrichtiano superior a Mioceno de Argentina (Archangelsky, 1973; Zamaloa \& Romero, 1990; Baldoni, 1993; Barreda, 1997a; Zamaloa, 2000). Cretácico superior a Paleoceno de Antártida (Baldoni \& Barreda, 1986). Eoceno de Chile (Troncoso \& Barrera, 1980; Baldoni, 1987).

Familia Polypodiaceae

Polypodiisporites Potonié 1931 ex Potonié 1956

Especie tipo: Polypodiisporites favus Potonié 1931 ex Potonié 1956

Polypodiisporites perverrucatus (Couper 1953) Khan \& Martin 1971

$$
\text { Lamina 4, figuras G-H }
$$

Dimensiones: diámetro ecuatorial mayor: 46 (50) $57 \mu \mathrm{m}$; diámetro polar: 33 (36) 40 $\mu \mathrm{m}$; verrugas: 2-5 $\mu \mathrm{m}$ (10 ejs.).

Procedencia: Miembro Inferior y Miembro Superior de la FRT.

Observaciones: las formas observadas son muy semejantes a las de la descripción original de Couper (1953) aunque presentan valores menores en todas sus dimensiones.

Registros previos: especie ampliamente distribuida en el Paleógeno y Neógeno de Gondwana (ver citas en White, 2006). 
Polypodiisporites speciosus Khan \& Martin 1971

\section{Lamina 4, figuras I-J}

Dimensiones: diámetro ecuatorial mayor: 33 (38) $44 \mu \mathrm{m}$; diámetro polar: 19 (21) 23 $\mu \mathrm{m}$; diámetro ecuatorial menor: 24 (26) $28 \mu \mathrm{m}$ (10 ejs.).

Procedencia: Miembro Inferior y Miembro Superior de la FRT.

Observaciones: las formas observadas son muy semejantes a las reportadas por Archangelsky (1972).

Registros previos: especie ampliamente distribuida en el Paleógeno y Neógeno de Gondwana (ver citas en White, 2006).

Familia Schizaeaceae

Biretisporites Delcourt et al. 1963

Especie tipo: Biretisporites potoniaei Delcourt \& Sprumont, 1955

Biretisporites sp. I en Archangelsky 1972

Lámina 4, figuras K-L

Dimensiones: diámetro ecuatorial: 28 (3) $35 \mu \mathrm{m}$; ancho del margo $2 \mu \mathrm{m}$.; espesor de la exina: $2 \mu \mathrm{m}$. (10 ejs.).

Procedencia: Miembro Inferior y Miembro Superior de la FRT.

Observaciones: las formas observadas son muy semejantes a las reportadas por Archangelsky (1972), corresponden a los valores menores de los rangos de medidas.

Klukisporites Couper, 1958

Especie tipo: Klukisporites variegatus Couper, 1958 
Klukisporites scaberis (Cookson \& Dettmann 1958) Dettmann 1963

$$
\text { Lámina 5, figuras A-B }
$$

Dimensiones: diámetro ecuatorial: 30 (32) $34 \mu \mathrm{m}$; muros: $3 \mu \mathrm{m}$; lúmenes: 2-2,5 $\mu \mathrm{m}$ (10 ejs.).

Procedencia: Miembro Inferior y Miembro Superior de la FRT.

Observaciones: las formas aquí estudiadas se asemejan a las ilustradas por Cranwell \& Srivastava (2009) para el Hauteriviano del sur de Chile. Aunque se han estudiado pocos ejemplares, los mismos muestran muros más anchos y lúmenes menores. El material se encuentra generalmente roto, pero es fácilmente identificable por su característico retículo.

Registros previos: especie cosmopolita ampliamente distribuida desde el Jurásico superior al Paleogeno (citas en White, 2006).

Pteridofitas de afinidad desconocida

Cyathidites Couper 1953

Especie tipo: Cyathidites australis Couper 1953

$$
\text { Cyathidites minor Couper } 1953
$$

Lámina 5, figuras C-D. Lámina 21, figuras D-C

Dimensiones: diámetro ecuatorial: 25 (30) $45 \mu \mathrm{m}$; pared: 1-2 $\mu \mathrm{m}$ (20 ejs).

Procedencia: Miembro Inferior y Miembro Superior de la FRT. 
Observaciones: las formas observadas son muy semejantes a las reportadas por Archangelsky (1972). Junto a Deltoidospora minor y Trilites parvalatus, C. minor es la esporas más frecuentes en la FRT.

Registros previos: especie cosmopolita ampliamente distribuida desde el Pérmico hasta el Neógeno (citas en White, 2006).

Deltoidospora Miner 1935

Deltoidospora hallii Miner 1935

Deltoidospora cf australis (Couper) Pocock 1970

Lámina 5, figuras E-F

Dimensiones: diámetro ecuatorial: 50 (60) $70 \mu \mathrm{m}$ (10 ejs).

Procedencia: Miembro Inferior y Miembro Superior de la FRT.

Observaciones: especie similar a $D$. minor pero de un tamaño significativamente mayor.

Deltoidospora minor (Couper) Pocock 1970

Lámina 5, figuras G-H. Lámina 21, figura D

Dimensiones: diámetro ecuatorial: 18 (26) $32 \mu \mathrm{m}$.

Procedencia: Miembro Inferior y Miembro Superior de la FRT.

Observaciones: esporas triletes reconocibles por su contorno triangular a subtriangular, de lados rectos y exina lisa. El material estudiado presenta exina delgada (1 $\mu \mathrm{m})$ y diámetro ecuatorial variable. 
Registros previos: especie cosmopolita ampliamente distribuida desde el Triásico hasta el Oligoceno (citas en White, 2006).

Laevigatosporites Ibrahim 1933

Especie tipo: Laevigatosporites vulgaris Ibrahim 1933

Laevigatosporites ovatus Wilson \& Webster 1946

Lámina 5, figuras I-J

Dimensiones: diámetro ecuatorial mayor: 32 (38) $43 \mu \mathrm{m}$; diámetro ecuatorial menor: 28 (31) $34 \mu \mathrm{m}$; diámetro polar: 25 (29) $33 \mu \mathrm{m}$ (10 ejs).

Procedencia: Miembro Inferior y Miembro Superior de la FRT.

Observaciones: las formas observadas son muy semejantes a las reportadas por Archangelsky (1972).

Registros previos: especie cosmopolita ampliamente distribuida desde el Carbonífero hasta el Neógeno (ver citas en Whites, 2006).

Leiotriletes Potonie y Kremp 1954

Especie tipo: Leiotriletes sphaerotriangulus Potonie \& Kremp 1954

\section{Leiotriletes minor Moreau-Benoit 1966}

Lámina 5, figuras K-L

Dimensiones: diámetro ecuatorial: 27 (29) $37 \mu \mathrm{m}$.

Procedencia: Miembro Inferior y Miembro Superior de la FRT. 
Observaciones: siguiendo a Archangelsky (1972), incluye las formas similares a Cyathidites minor y a Deltoidospora minor pero que presentan lados convexos en vista polar.

Registros previos: Europa: Devónico al Paleógeno (ver citas en White, 2006).

Verrucosisporites Potonié y Kremp, 1954

Especie tipo: Verrucosisporites verrucosus Ibrahim, 1933

Verrucosisporites sp. 1

Lámina 6, figuras A-B

Descripción: espora trilete, subtriangular, de lados convexos y ángulos redondeados. Lesura recta, ocupando $3 / 4$ partes del radio de la espora, con labios. Exina de 1,2 $\mu \mathrm{m}$ de espesor, superficie proximal y distal ornamentada con verrugas. Las verrugas varían desde circulares a subpoligonales, separadas entre sí por un espacio similar al grosor de las mismas. La superficie entre las verrugas es psilada.

Dimensiones: diámetro ecuatorial: $47 \mu \mathrm{m}$; verrugas: 1 - 4,5 $\mu \mathrm{m}$ (1 ejemplar).

Procedencia: Miembro Inferior de la FRT.

Comparaciones: sólo se cuenta con un ejemplar, lo que no permite comparaciones más exaustivas. Verrucosisporites rotundus Singh 1964 presenta verrugas más densamente distribuidas y labios de mayor espesor.

Verrucosisporites sp. 2

Lámina 6, figuras C-D

Descripción: espora trilete, subtriangular, de lados convexos y ángulos redondeados. Lesura recta, ocupando $3 / 4$ partes del radio de la espora. Exina de $1 \mu \mathrm{m}$ de espesor, 
superficies proximal y distal ornamentadas con verrugas pequeñas $(1-1,5 \mu \mathrm{m}) \mathrm{y}$ gránulos. Verrugas, circulares, poco densamente distribuídas sobre la superficie de la espora, sin un patrón definido.

Dimensiones: diámetro ecuatorial: 39,5 $\mu \mathrm{m}$. (1 ejemplar).

Procedencia: Miembro Inferior de la FRT.

Comparaciones: sólo se cuenta con un ejemplar, lo que no permite comparaciones más exhaustivas. Tuberositriletes? descripta por Jaramillo \& Dilcher (2001) para el Paleoceno-Eoceno de Colombia lesura de radios mayores, con labio, contorno ecuatorial subcircular y un menor diámetro ecuatorial $(26 \mu \mathrm{m})$.

Verrucosisporites sp. 3

Lámina 6, figuras E-F

Descripción: espora trilete, subtriangular, de lados convexos y ángulos redondeados. Lesura recta, ocupando $3 / 4$ partes del radio de la espora, con labios. Exina de 2,2 $\mu \mathrm{m}$ de espesor, superficie proximal y distal ornamentada con verrugas. Las verrugas son muy bajas ( $2 \mu \mathrm{m}$ en corte óptico) y de base amplia, cubriendo densamente toda la superficie.

Dimensiones: diámetro ecuatorial: 44 - $49 \mu \mathrm{m}$ (3 ejs.).

Procedencia: Miembro Superior de la FRT.

Comparaciones: Converrucosisporites proxigranulatus Brenner 1963 presenta verrugas más altas (3-4 $\mu \mathrm{m})$, unidas lateralmente y gránulos en la cara proximal. 
Pteridophyta indet. 1

Lámina 6, figuras G-H

Descripción: espora de tamaño grande $(78 \mu \mathrm{m})$. Exina delgada, de 1,5 $\mu \mathrm{m}$ de espesor. Esculturación verrucada. Forma de las verrugas variables. Las verrugas varían desde circulares a subpoligonales y se encuentran distribuídas sin patrón aparente sobre la superficie de la espora, separadas entre sí por un espacio similar al grosor de las mismas. La superficie entre verrugas es escabrada.

Observaciones: por su gran tamaño y exina relativamente delgada presenta una mala preservación. $\mathrm{Su}$ ornamentación característica permite reconocer fácilmente sus fragmentos. Se desconoce el tipo de abertura.

Dimensiones: diámetro aproximado: $78 \mu \mathrm{m}$. (1 ej.).

Procedencia: Miembro Inferior y Miembro Superior de la FRT.

Gimnospermas

Familia Araucariaceae

Araucariacites Cookson 1947

Especie tipo: Araucariacites australis Cookson, 1947

Araucariacites australis Cookson, 1947

Lámina 6, figuras I-J

Dimesiones: diámetro: 61 (71) $81 \mu \mathrm{m}$; espesor de pared: 1-2 $\mu \mathrm{m}$ (10 ejs.).

Procedencia: Miembro Inferior y Miembro Superior de la FRT. 
Observaciones: las formas observadas en la FRT son muy semejantes a las publicadas por Romero (1977), aunque el material aquí estudiado no alcanza los tamaños menores reportados en dicha contribución.

\section{Afinidad botánica: Género Araucaria}

Registros previos: especie cosmopolita ampliamente distribuida desde el Jurásico al Neógeno (ver citas en Raine et al., 2006).

Familia Ephedraceae

Equisetosporites (Daugherty) emend. Pocock 1964

Especie tipo: Equisetosporites chinleana (Daugherty) Pocock 1964

$$
\text { Equisetosporites notensis (Cookson) Romero } 1977
$$

$$
\text { Lámina 6, figuras K-L }
$$

Dimensiones: diámetro ecuatorial: 28-44 $\mu \mathrm{m}$; diámetro polar: 11-17 $\mu \mathrm{m}$; ancho de barras 1,1 $\mu \mathrm{m}$; número de barras 12; eje longitudinal/eje polar 2,5-2,6 (5 ejs.).

Procedencia: Miembro Inferior y superior de la FRT.

Registros previos: Argentina: Eoceno a Mioceno (Romero, 1977; Barreda, 1997b). Nueva Zelanda: Oligocene Superior (Pocknall, 1985).

Afinidad botánica: género Ephedra.

Familia Podocarpaceae

Dacrycarpites Cookson \& Pike 1953

Especie tipo: Dacrycarpites australiensis Cookson \& Pike 1953 


\section{Lámina 7, figuras A-B}

Dimesiones: diámetro: 22 (27) $32 \mu \mathrm{m}$; ancho del saco: 19 (23) $25 \mu \mathrm{m}$; largo del saco: 9 (11) $14 \mu \mathrm{m}$; espesor de la pared proximal: $1,5-3 \mu \mathrm{m}$ (10 ejs.).

Procedencia: Miembro Inferior y Miembro Superior de la FRT.

Observaciones: las formas observadas en la FRT son muy semejantes a las publicadas por Romero (1977). Se diferencia de las otras especies trisacadas registradas para la FRT por el cuerpo con bordes crenados en vista polar y sacos de mayor tamaño.

Registros previos: especie ampliamente distribuida en depósitosGondwana desde el Paleógeno al Neógeno (ver citas en Raine et al., 2011).

Afinidad botánica: Dacrycarpus dacrydioides.

Microcachrydites Cookson 1947

Especie tipo: Microcachrydites antarcticus Cookson 1947

Microcachrydites antarcticus Cookson 1947

Lámina 7, figuras C-D. Lámina 22, figura A

Dimensiones: diámetro ecuatorial: 24 (26) $29 \mu \mathrm{m}$; ancho del saco: 11 (12) $13 \mu \mathrm{m}$; largo del saco: 9 (10) $11 \mu \mathrm{m}$; alto del saco: 7 (8) $9 \mu \mathrm{m}$; espesor pared proximal: $1 \mu \mathrm{m}$ (4 ejs.).

Procedencia: Miembro Superior de la FRT.

Observaciones: las formas observadas en la FRT son muy semejantes a las publicadas por Romero (1977). Se diferencia de las otras especies trisacadas registradas para la 
FRT por el cuerpo de contorno circular en vista polar y sacos de aspecto firme, proyectados distalmente.

Registros previos: especie ampliamente distribuida en Gondwana desde el Jurasico al Neogeno (ver citas en Raine et al., 2011).

Afinidad botánica: Microcachrys tetragona (Lange, 1982).

Phyllocladidites Cookson 1947

Especie tipo: Phyllocladidites mawsonii Cookson 1947 ex Couper 1953

Phyllocladidites mawsonii Cookson 1947 ex Couper 1953

\section{Lámina 7, figuras E-F}

Dimensiones: ancho del cuerpo: 27,5 (36) $44 \mu \mathrm{m}$; largo del cuerpo: 20 (32) $40 \mu \mathrm{m}$; ancho del saco: 15 (22) $30 \mu \mathrm{m}$; largo del saco: 7,5 (12) $15 \mu \mathrm{m}$; espesor pared proximal: 2 (2) $3 \mu \mathrm{m}$ (10 ejs.). Alto del cuerpo: 20-30 $\mu \mathrm{m}$; alto del saco: 9-10 $\mu \mathrm{m}$ (2 ejs.).

Procedencia: Miembro Inferior y Miembro Superior de la FRT.

Observaciones: las formas observadas en la FRT son muy semejantes a las publicadas por Romero (1977).

Registros previos: especie ampliamente distribuida en Gondwana desde el Cretácico al Pleistoceno (ver citas en Raine et al., 2011).

Afinidad botánica: Dacrydium franklinii y género Lagarostrobos.

Podocarpidites Cookson 1947

Especie tipo: Podocarpidites ellipticus Cookson 1947 


\section{Lámina 7, figuras G-H}

Dimensiones: ancho del cuerpo: 21 (32) $44 \mu \mathrm{m}$; largo del cuerpo: 12,5 (26,5) $39 \mu \mathrm{m}$; ancho del saco: 19,5 (27,5) $35 \mu \mathrm{m}$; largo del saco: 13 (16) $19 \mu \mathrm{m}$; espesor pared proximal: 1 (1,5) $2 \mu \mathrm{m}$ (11 ejs). Alto del cuerpo: 17 (23) $30 \mu \mathrm{m}$; alto del saco: 11 (16) $22 \mu \mathrm{m}(5$ ejs.).

Procedencia: Miembro Inferior y Miembro Superior de la FRT.

Observaciones: las formas observadas en la FRT son muy semejantes a las publicadas por Romero (1977). P. elegans es la morfoespecie de gimnosperma más frecuente en este estudio.

Registros previos: especie ampliamente distribuida en Argentina desde el Maastrichtiano superior hasta el Mioceno (Barreda, 1997b; Palamarczuk \& Barreda, 2000; Herbst et al., 2000; Mautino \& Anzótegui, 2002a).

\section{Podocarpidites marwikii Cooper 1953}

\section{Lámina 7, figuras I-J}

Dimensiones: ancho del cuerpo: $32(40,5) 61 \mu \mathrm{m}$; largo del cuerpo: 17 (25) 30,5 $\mu \mathrm{m}$; ancho del saco: 30,5 (39) $53 \mu \mathrm{m}$; largo del saco: $14(18,5) 25 \mu \mathrm{m}$; espesor pared proximal: 1 (1,5) 2,2 $\mu \mathrm{m}$ (13 ejs). Alto del cuerpo: 15 (22) $29 \mu \mathrm{m}$; alto del saco: 14 (20) $30 \mu \mathrm{m}(5$ ejs.).

Procedencia: Miembro Inferior y Miembro Superior de la FRT.

Observaciones: las formas observadas en la FRT son muy semejantes a las publicadas por Romero (1977). Aunque el material aquí estudiado presenta dimensiones 
ligeramente menores. Se diferencia de $P$. microreticuloidatus por presentar sacos relativamente mayores, de retículo abierto y fino.

Registros previos: especie ampliamente distribuida en Gondwana desde el Cretácico superior al Mioceno (ver citas en Raine et al., 2011).

Afinidad botánica: género Podocarpus.

Podocarpidites microreticuloidatus Cookson 1947

Lámina 7, figuras K-L

Dimensiones: ancho del cuerpo: 30 (40) $50 \mu \mathrm{m}$; largo del cuerpo: 15 (20) $30 \mu \mathrm{m}$; ancho del saco: 30 (35) $45 \mu \mathrm{m}$; largo del saco: 14 (18) $24 \mu \mathrm{m}$; espesor pared proximal: $1(1,5)$ $2 \mu \mathrm{m}$. (3 ejs.).

Procedencia: Miembro Inferior y Miembro Superior de la FRT.

Observaciones: las formas observadas en la FRT son muy semejantes a las publicadas por Romero (1977). Poco frecuente en este estudio, se diferencia de P. marwikii por presentar sacos relativamente pequeños, de retículo denso, y ancho menor que el del cuerpo.

Afinidad botánica: género Podocarpus.

Registros previos: especie ampliamente distribuida en Gondwana desde el Cretácico inferior al Pleistoceno (ver citas en White, 2006).

Podocarpidites rugulosus Romero 1977

Lámina 8, figuras A-B

Dimensiones: ancho del cuerpo: 20 (32) 42,5 $\mu \mathrm{m}$; largo del cuerpo: 25 (27) 32,5 $\mu \mathrm{m}$; ancho del saco: 22 (26) $29 \mu \mathrm{m}$; largo del saco: 12,5 (16) $20 \mu \mathrm{m}$; espesor pared 
proximal: 1,5 (2) 2,5 $\mu \mathrm{m}$ (10 ejs). Alto del cuerpo: 15 (21,5) $25 \mu \mathrm{m}$; alto del saco: 12 (13) $14 \mu \mathrm{m}(5$ ejs.).

Procedencia: Miembro Inferior y Miembro Superior de la FRT.

Observaciones: las formas observadas en la FRT son muy semejantes a las publicadas por Romero (1977). Se diferencia de las otras especies del género presentes en la FRT por presentar cuerpo subesférico, con borde crenado en vista polar y pared proximal delgada, de tectum verrucado a rugulado.

Registros previos: especie ampliamente distribuida en Argentina desde el Albiano hasta el Mioceno (Quattrocchio \& Guerstein, 1988; Guerstein, 1990; Guerstein \& Quattrocchio, 1991; Zamaloa \& Andreis, 1995; Archangelsky, 1996; Ruiz \& Quattrocchio, 1996; Barreda, 1997b; Herbst et al., 2000; Mautino et al. 2000; Palamarczuk \& Barreda, 2000; Zamaloa, 2000; Mautino \& Anzótegui, 2002a).

Afinidad botánica: Podocarpus nubigenus.

Gimnospermas de afinidad desconocida

Trisaccites Cookson \& Pike 1954

Especie tipo: Trisaccites micropterus Cookson \& Pike 1954

Trisaccites microsaccatum (Couper) Couper 1960

Lámina 8, figuras C-D. Lámina 22, figura B

Dimensiones: diámetro ecuatorial: 24 (27) $30 \mu \mathrm{m}$; ancho del saco: 15 (17) $19 \mu \mathrm{m}$; profundidad del saco: 3 (4) $5 \mu \mathrm{m}$; ancho de la depresión marginal: $1(1,5) 2 \mu \mathrm{m}$; espesor de la pared: $0,5-1 \mu \mathrm{m}(10$ ejs.).

Procedencia: Miembro Inferior y Miembro Superior de la FRT. 
Observaciones: las formas observadas en la FRT son muy semejantes a las publicadas por Romero (1977). Aunque el material aquí estudiado presenta dimensiones ligeramente menores. Se diferencia de las otras especies trisacadas registradas para la FRT por el cuerpo de contorno triangular en vista polar y sacos muy pequeños.

Registros previos: especie ampliamente distribuida en Gondwana desde el Jurácico superior al Mioceno (ver citas en Raine et al., 2011).

Angiospermas

Dicotiledóneas

Familia Aquifoliaceae

Ilexpollenites Thiergart 1937

Especie tipo: Ilexpollenites iliacus (R. Potonié 1931) Thiergart 1937

Ilexpollenites anguloclavatus McIntyre 1968

Lámina 8, figuras E-F. Lámina 22, figura C

Dimensiones: diámetro ecuatorial: $23-26 \mu \mathrm{m}$; diámetro polar: 24 (32) $37 \mu \mathrm{m}$; espesor de la exina: $3-4 \mu \mathrm{m}$; clavas: $1(1,6) 2,7 \mu \mathrm{m}$ (10 ejs.).

Procedencia: Miembro Inferior y Miembro Superior de la FRT.

Observaciones: las formas observadas en la FRT son muy semejantes a las la diagnosis original de McIntyre (1968), se caracterizan por ser formas prolatas, con clavas evidentes separadas entre sí y colpos poco evidentes.

Registros previos: Plioceno superior de Argentina (Anzótegui \& Acevedo, 1995). Cretácico a Neógeno de Australia (Stover \& Partridge, 1973, 1982; Martin, 1977, 1991; Tulip et al., 1982; Truswell \& Owen, 1988; Alley \& Benbow, 1989; Dettmann \& 
Jarzen, 1990; Pocknall, 1991; Macphail, 1999). Neógeno de Nueva Zelanda (Pocknall \& Mildenhall, 1984; Raine, 1984; Mildenhall \& Pocknall, 1989; Pocknall 1990, 1991).

Afinidad botánica: género Ilex.

Ilexpollenites clifdenensis McIntyre 1968

Lámina 8, figuras G-H. Lámina 22, figura D

Dimensiones: diámetro ecuatorial: 20-29 $\mu \mathrm{m}$; diámetro polar: 17 (26) $32 \mu \mathrm{m}$; espesor de la exina: $1,5(1,6) 2 \mu \mathrm{m}$; clavas: 0,5 (1) $1,75 \mu \mathrm{m}$ (10 ejs.).

Procedencia: Miembro Superior de la FRT.

Observaciones: las formas observadas en la FRT son muy semejantes a la descripción original de McIntyre (1968), aunque presentan tamaños menores. Se diferencian de las otras especies del género presentes en la FRT por presentar clavas de menor tamaño que en ocasiones se únen entre sí sin ningún patrón definido.

Registros previos: Eoceno y Plioceno superior de Argentina (Romero \& Castro, 1986; Anzótegui \& Acevedo, 1995). Eoceno a Mioceno de Australia (Martin, 1977; Owen, 1988; Alley \& Benbow, 1989). Eoceno a Mioceno de Nueva Zelanda (Pocknall \& Mildenhall, 1984; Raine, 1984).

Afinidad botánica: género Ilex.

Ilexpollenites megagemmatus McIntyre 1968

\section{Lámina 8, figuras I-J}

Dimensiones: diámetro ecuatorial: 28 (30) $32 \mu \mathrm{m}$; diámetro polar: 30 (33) $36 \mu \mathrm{m}$; espesor de la exina: $3-3,5 \mu \mathrm{m}$; clavas: $1,5-2 \mu \mathrm{m}$ (10 ejs.).

Procedencia: Miembro Inferior y Miembro Superior de la FRT. 
Observaciones: primer registro de esta especie para Sudamérica. Las formas observadas en la FRT son muy semejantes a las la diagnosis original de McIntyre (1968), aunque presentan tamaños menores. Se diferencian de las otras especies del género presentes en la FRT por presentar clavas de cabezuelas globosas y de mayor tamaño.

Registros previos: Eoceno superior a Oligoceno inferior de Australia (Alley \& Benbow, 1989). Oligoceno superior a Mioceno Temprano de Nueva Zelanda (Pocknall, 1982; Pocknall \& Mildenhall, 1984; Raine, 1984: Mildenhall \& Pocknall, 1989).

Afinidad botánica: género Ilex.

Familia Bombacaceae

Bombacacidites Couper 1960

Especie tipo: Bombacacidites bombaxoides Couper 1960

Bombacacidites isoreticulatus McIntyre 1965

Lámina 8, figuras K-L

Dimensiones: diámetro ecuatorial: $24(29,7) 36 \mu \mathrm{m}$; diámetro de poros: 1,5-3 $\mu \mathrm{m}$; engrosamiento de las aberturas: 1,5-3 $\mu \mathrm{m}$; espesor de la exina: 1-2 $\mu \mathrm{m}$ (10 ejes.).

Procedencia: Miembro Inferior y Miembro Superior de la FRT.

Observaciones: primer registro para Argentina. Las formas observadas en la FRT son muy semejantes a la descripción original de McIntyre (1965). Se caracterizan por presentar contorno ecuatorial circular, microretículo homobrocado y aberturas engrosadas. 
Registros previos: Paleogeno de Nueva Zelanda (Mildenhall, 1978; Raine, 1984; Raine \& Wilson, 1988; Pocknall, 1990).

Familia Casuarinaceae

Haloragacidites Couper 1953

Especie tipo: Haloragacidites trioratus Couper 1953

Haloragacidites trioratus Couper 1953

Lámina 9, figuras A-B

Dimesiones: diámetro: $26-30 \mu \mathrm{m}$ (3 ejs.).

Procedencia: Miembro Inferior y Miembro Superior de la FRT.

Registros previos: Oligoceno superior a Mioceno de Argentina (Barreda, 1997d). Oligoceno a Mioceno inferior de Nueva Zelanda (Couper, 1953; 1960; Mildenhall \& Harris, 1971).

Afinidad botánica: género Casuarina.

Familia Convolvulaceae

Perfotricolpites González Guzmán 1967

Especie tipo: Perfotricolpites digitatus González Cuzmán 1967.

cf. Perfotricolpites sp.

Lámina 9, figuras C-D

Descripción: grano de polen isopolar, radiosimétrico, subprolato, tricolpado, con colpos rectos a ligeramente ondulados, endoapertura inconspicua. Exina de 2,2 um de espesor, 
tectada perforada, psilada con columelas simples y conspicuas; sexina de 1,6 um y nexina de 0,6 um.

Comparaciones: las formas observadas en la FRT son muy semejantes al material reportado por Mautino y Anzótegui (2002b) como Perfotricolpites sp. para el Mioceno Superior de Catamarca (Fm Chiquimil), aunque dicho material es de mayor tamaño (diámetro ecuatorial: 30 um; diámetro polar: $40 \mu \mathrm{m}$ ).

Dimensiones: diámetro ecuatorial: $25,6 \mu \mathrm{m}$; diámetro polar: $29 \mu \mathrm{m}$ (1 ejemplar).

Procedencia: Miembro Inferior y Miembro Superior de la FRT.

Familia Cunoniaceae

Dicolpopollis (Pflanzl) Potonie 1966.

Especie tipo: Dicolpopollis kockeli Pflanzl 1956

Dicolpopollis sp. 1 (nueva especie)

Lámina 9, figuras E-F

Descripción: grano de polen isopolar, radiosimétrico, contorno en vista polar elipsoidal, dicolpado. Colpos estrechos, 1-2 $\mu \mathrm{m}$ de profundidad, convergiendo en los polos. . Exina de $1 \mu \mathrm{m}$ de espesor, psilada.

Dimensiones: diámetro ecuatorial: 8-12 $\mu \mathrm{m}$; diámetro polar: 10-16 $\mu \mathrm{m}$ (10 ejes.); profundidad de colpos: $1 \mu \mathrm{m}$ (1 ejemplar).

Procedencia: Miembro Inferior y Miembro Superior de la FRT.

Comparaciones: Dicolpopollis sp. descripta por Mildenhall (1994) para el Neógeno de Nueva Zelanda posee una escultura microreticulada y colpos menos profundos. Dicolpopollis metroxylonoides Khan 1976, es zonosulcada y de superficie escabrada. 
Afinidad botánica: el material estudiado es muy similar a Eucryphia glutinosa, aunque el polen de dicha especie es microreticulado.

Familia Ericaceae

Ericipites Wodehouse 1933

Especie tipo: Ericipites annulatus González-Guzmán 1967

\section{Ericipites $\mathrm{sp} .1$}

Lámina 9, figuras G-H

Dimesiones: diámetro de la tétrade: 25 (29) $30 \mu \mathrm{m}$; diámetro ecuatorial del grano individual: 18-20 $\mu \mathrm{m}$; espesor de la exina: $1 \mu \mathrm{m}$ (10 ejs.).

Procedencia: Miembro Inferior y Miembro Superior de la FRT.

Observaciones: estos ejemplares coinciden plenamente con el material descripto por Romero \& Zamaloa (1985) como Ericipites sp. para esta misma formación.

Familia Euphorbiaceae

Malvacipollis Harris 1965

Especie tipo: Malvacipollis diversus Harris 1965

Malvacipollis sp.1 (especie nueva)

\section{Lámina 9, figura I-J. Lámina 23, figura A}

Descripción: grano de polen apolar, subesférico, poliporado. Poros 4 a 9, distribuidos al azar por toda la superficie, difícilmente observables al MO. Exina de $<1$ a $1 \mu \mathrm{m}$ de espesor. Estratificación indistinguible al MO. Escultura equinada. Espinas notorias, de 1,6 a 2,9 $\mu \mathrm{m}$ de longitud, cónicas, de base amplia y extremo agudo, en ocasiones con 
constricción media, distribuidas de forma homogénea sobre la superficie. Superficie entre espinas psilada, en ocaciones con gránulos.

Dimesiones: diámetro ecuatorial: $20-21,2 \mu \mathrm{m}$. (5 ejs.).

Procedencia: Miembro Inferior y Miembro Superior de la FRT.

Comparaciones: Malvacipollis spinulosa Frederiksen, 1983 y M. diversus Harris 1965 estefanoporados con poros engrosados. M. spinyspora (Martin 1973) Mildenhall \& Pocknall 1989, exina más gruesa y superficie entre espinas escabrada. M. subtilis Stover in Stover \& Partridge 1973 estefanoporado, poros engrosados, exina más gruesa y espinas de mayor longitud.

Familia Fabaceae

Margocolporites Ramanujam 1966 ex Srivastava 1969 emend. Pocknall \& Mildenhall 1984

Especie tipo: Margocolporites tsukadai Ramanujam 1966 ex Srivastava 1969.

Margocolporites sp. 1 Palazzesi (2008)

\section{Lámina 9, figura K-L}

Descripción: grano de polen isopolar, oblato, contorno en vista polar subtriangular, tricolporado. Colpos largos y amplios (llegando a $2 \mu \mathrm{m}$ de amplitud en el ecuador), casi alcanzando los polos. Endoapertura circular, de $2 \mu \mathrm{m}$ de diámetro. Exina de 1,2 $\mu \mathrm{m}$ de espesor, tectada. Escultura psilada.

Dimensiones: diámetro ecuatorial: 16 (21) 29,6 $\mu \mathrm{m}$; diámetro de endoapertura: 1,7 (2,1) $4 \mu \mathrm{m}$; espesor de la exina: 0,6 - 1,6 $\mu \mathrm{m}$ (10 ejs.).

Procedencia: Miembro Inferior y Miembro Superior de la FRT. 
Observaciones: las formas observadas en la FRT son muy semejantes con las descriptas por Palazzesi (2008) para el Mioceno tardío del noreste de Chubut, aunque el material allí estudiado presenta endoapertura algo engrosada y exina ligeramente más gruesa $(1,5 \mu \mathrm{m})$.

Comparaciones: otras especies asignadas a Margocolporites poseen, a diferencia del tipo morfológico aquí descripto un margo evidente. M. tenuireticulatus Barreda 1997, presenta exina microreticulada.

Afinidad botánica: género Prosopis.

Familia Gunneraceae

Tricolpites reticulatus Couper 1953

Lámina 10, figura A-B

Dimensiones: diámetro ecuatorial: $25(27,8) 31 \mu \mathrm{m}(10$ ej.).

Procedencia: Miembro Inferior y Miembro Superior de la FRT.

Registros previos: distribuida ampliamente en depósitos del Cretácico superior al Terciario del Hemisferio Sur (Cookson, 1947; Fasola, 1969; Archangelsky, 1973; Kemp y Harris, 1977; Pocknall \& Mildenhall, 1984; Romero \& Castro, 1986).

Afinidad botánica: género Gunnera.

Familia Loranthaceae

Gothanipollis Krutzsch 1959

Especie tipo: Gothanipollis gothani Krutzsch 1959 
Gothanipollis bassensis Stover in partridge \& Stover 1973

$$
\text { Lámina 10, figuras C-D }
$$

Dimensiones: diámetro ecuatorial: $17(21,2) 26 \mu \mathrm{m}$. (10 ejs.).

Procedencia: Miembro Inferior y Miembro Superior de la FRT.

Observaciones: el material estudiado muestra tamaños variables y contornos en vista polar subtriangular de lados convexos llegando a trirradiados.

Registros previos: especie ampliamente distribuida en Gondwana desde el Cenomaniano al Mioceno (Raine et al., 2011).

Afinidad botánica: Ligaria cuneifolia.

Gothanipollis sp. 1 Palazzesi (2008)

Lámina 10, figuras E-F

Dimensiones: diámetro ecuatorial: $13,5(15,6) 22,5 \mu \mathrm{m}$; exina interapertural: 1-1,5 $\mu \mathrm{m}$. (7 ejs.).

Procedencia: Miembro Inferior y Miembro Superior de la FRT.

Observaciones: las formas observadas en la FRT son muy semejantes a las descriptas por Palazzesi (2008) para el Mioceno superior del Noreste de Chubut.

Afinidad botánica: Struthanthus acuminatus.

Familia Malpighiaceae

Perisyncolporites Germeraad, Hopping \& Muller, 1968

Especie tipo: Perisyncolporites pokornyi Germeraad, Hopping \& Muller, 1968 
Perisyncolporites pokornyi Germeraad, Hopping \& Muller, 1968

$$
\text { Lámina 10, figuras G-H }
$$

Dimensiones: diámetro ecuatorial: $21-23 \mu \mathrm{m}$ (2 ejs.).

Procedencia: Miembro Inferior y superior de la FRT.

Registros previos: Eoceno medio a Pleistoceno de Sudamérica y Caribe (Regali et al., 1974; Porta, 1974; Doubinger, 1976; Dueñas-Jimenez, 1979, 1986, 1999; de Lima \& Salard-Cheboldaeff, 1981; de Lima \& Dino, 1984; Escobar, 1984; de Lima et al., 1985; Fasola \& Paredes de Ramos, 1991; Colmenares \& Teran, 1993; Hoorn et al., 1994; Rull, 1997; Jaramillo \& Dilcher, 2000). Neógeno superior de África (Partridge, 1978; Salard-Cheboldaeff et al., 1992). Oligoceno inferior a Mioceno superior de Australia (Macphail \& Truswell, 1989, 1993; Macphail \& Stone, 2004).

Familia Malvaceae

Malvacearumpollis Nagy 1962

Especie tipo: Malvacearumpollis bakonyensis Nagy 1962

Malvacearumpollis sp. 1 (nueva especie)

$$
\text { Lámina 10, figuras I-J }
$$

Descripción: grano de polen esferoidal, pantocolporado, equinado. Endoapertura (6-10) circular de 1 a $2 \mu \mathrm{m}$ de diámetro. Colpos cortos, de 2-4 $\mu \mathrm{m}$ de longitud. Aberturas difíciles de observar debido a escultura. Exina de $1 \mu \mathrm{m}$ de espesor. Espinas de 1-3 $\mu \mathrm{m}$ de largo, cónicas, ápice atenuado, a veces curvado.

Dimesiones: diámetro ecuatorial: 16 (21) $28 \mu \mathrm{m}$. (10 ejs.).

Procedencia: Miembro Inferior y Miembro Superior de la FRT. 
Comparaciones: Malvacearumpollis mannanensis Wood 1986 presenta espinas de base amplia $\mathrm{y}$ columelada $\mathrm{y}$ un diámetro ecuatorial mayor $(40-70 \mu \mathrm{m})$. Malvacearumpollis bakonyensis Nagy 1962 presenta contorno elíptico endoapertura más evidentes por presentar espinas más dispersas.

Familia Misodendraceae

Compositoipollenites Potonié 1960

Especie tipo: Compositoipollenites tarragoensis Truswell \& Owen 1988

\section{Compositoipollenites sp. 1}

Lámina 10, figuras K-L

Descripción: grano de polen apolar, subesférico, poliporado. Poros simples con anillo, en número de 3-10 o 3-6, generalmente 3 a 6 , distribuidos al azar por toda la superficie. Exina de $1 \mu \mathrm{m}$ de espesor. Escultura equinada. Microespinas de tamaño variable, de $<1$ a $1 \mu \mathrm{m}$, de base amplia y extremo agudo, distribuidas de forma homogénea y poco densa sobre la superficie. En ocasiones, espinas en torno a los poros. Base de las espinas globosa. Superficie entre espinas psilada a ligeramente escabrada. Estratificación indistinguible al MO.

Dimesiones: diámetro ecuatorial: $10(15,9) 25 \mu \mathrm{m}$.; diámetro de poro: 1-3,5 (14 ejs.).

Observaciones: los especímes estudiados presentan variabilidad en sus medidas. Se requiere un mayor número de ejemplares y estudios posteriores para determinar si se trata de una sola entidad.

Procedencia: Miembro Inferior y Miembro Superior de la FRT. 
Registro previo: el registro de formas afines a Misodendraceae consiste en granos dispersos asignados a varios morfogéeneros (por ej. Sparsipollis, Compositoipollenites). Oligoceno a Plioceno de Argentina (Barreda, 1997; Palamarczuk \& Barreda 2000; Barreda et al., 2009; Zamaloa, 2000; Macphail \& Cantrill 2006; Zamaloa \& Fernández, 2016).

Afinidad botánica: género Misodendrum

Familia Myrtaceae

Myrtaceidites Cookson \& Pike 1960

Especie tipo: Myrtaceidites mesonesus Cookson \& Pike 1954

Myrtaceidites mesonesus Cookson \& Pike 1954

Lámina 11, figuras A-B

Dimensiones: diámetro ecuatorial: 15 (17) $19 \mu \mathrm{m}$; espesor de la exina: $1 \mu \mathrm{m}$ (10 ejs.).

Procedencia: Miembro Inferior y superior de la FRT.

Registros previos: especie ampliamente distribuida desde el Paleoceno al Plioceno/Pleistoceno de Gondwana (Thornhill \& Macphail, 2012).

Afinidad botánica: similar a mirtáceas actuales, incluyendo Eucalyptus (Cookson \& Pike, 1954; Martin, 1973). Otras afinidades sugeridas son Whiteodendron (McWhae, 1957) y Metrosideros (Martin, 1973).

Myrtaceidites parvus Cookson \& Pike 1954

Lámina 11, figuras C-D

Dimensiones: diámetro ecuatorial: 12 (14) $16 \mu \mathrm{m}$; espesor de la exina: 0,5-1 $\mu \mathrm{m}$ (20 ejs.).

Procedencia: Miembro Inferior y Miembro Superior de la FRT. 
Registros previos: especie ampliamente distribuida desde el Cretácico superior al Plioceno/Pleistoceno de Gondwana (Thornhill \& Macphail, 2012).

Afinidad botánica: Baeckea, Backhousia, Tristania, Kunzea, Leptospermum, Micromyrtus y Syzygium (Thornhill \& Macphail, 2012).

Myrtaceidites verrucosus Stover \& Partridge 1973

\section{Lámina 11, figuras E-F}

Dimensiones: diámetro ecuatorial: 15 (17) $19 \mu \mathrm{m}$ (10 ejes.).

Procedencia: Miembro Inferior y Miembro Superior de la FRT.

Observaciones: se observaron tanto la forma rhodamnoides (colpos cortos, toda la exina granuloso/escabrada) como la forma verrucosus (colpos largos, sólo apocolpio granuloso/escabrado) definidas por Thornhill \& Macphail (2012).

Registros previos: especie ampliamente distribuida desde el Eoceno inferior al Plioceno/Pleistoceno de Gondwana y en el Eoceno de Panamá (Thornhill \& Macphail, 2012).

Afinidad botánica: Myrtaceae tribu Myrteae (Thornhill \& Macphail, 2012).

Myrtaceidites eucaliptoides Cookson \& Pike 1954

Lámina 11, figuras G-H

Dimensiones: diámetro ecuatorial: $13-16 \mu \mathrm{m}$; espesor de la exina: $1 \mu \mathrm{m}$ (2 ejs.).

Procedencia: Miembro Inferior y Miembro Superior de la FRT.

Observaciones: estos ejemplares coinciden plenamente con la diagnosis de Thornhill \& Macphail (2012). 
Registros previos: Mioceno a Plioceno inferior de Argentina (Macphail \& Cantrill, 2006). Desde el Eoceno medio en Australia (ver citas en Thornhill \& Macphail, 2012). Neógeno de Burundi (Sah, 1967).

Afinidad botánica: Eucalyptus, Corymbia, Angophora, Syncarpia, Metrosideros, Melaleuca y Syzygium (Thornhill \& Macphail, 2012).

Familia Nothofagaceae

Nothofagidites Potonié 1960

Nothofagidites flemingii Potonie 1960

Nothofagidites acromegacanthus Menéndez y Caccavari 1975

Lámina 11, figuras I-J

Dimensiones: diámetro ecuatorial: 18 (20,5) $23 \mu \mathrm{m}$; número de colpos: 6-7; engrosamiento de colpos "a" (sensu Romero, 1977): 0,5 (1) 1,7 $\mu \mathrm{m}$; profundidad de colpos: $1,3(2,2) 2,6 \mu \mathrm{m}$. (12 ejs.).

Procedencia: Miembro Inferior y Miembro Superior de la FRT.

Observaciones: las formas observadas en la FRT son muy semejantes a las publicadas por Romero (1977). Los individuos estudiados presentan contorno en vista polar circular, raramente subpoligonal. El engrosamineto de las aberturas apenas protruye. En general, las espinas no son visibles en corte óptico.

Registros previos: Cretácico superior a Mioceno de Argentina (Menéndez et al. 1975; Dettmann et al., 1990; Barreda, 1997c; Barreda et al., 1998; Barreda \& Palamarczuk, 2000a,b; Palamarczuk \& Barreda, 2000).

Afinidad botánica: género Nothofagus subgénero Nothofagus. 
Nothofagidites americanus Zamaloa 1992

\section{Lámina 11, figuras K-L. Lámina 23, figura B}

Dimensiones: diámetro ecuatorial: 35 (40) $50 \mu \mathrm{m}$; número de colpos: 6-7; profundidad de colpos: 7-8 $\mu \mathrm{m}$. (10 ejs.).

Procedencia: Miembro Inferior y Miembro Superior de la FRT.

Observaciones: las formas observadas en la FRT son muy semejantes a las publicadas por Romero (1977). Los individuos estudiados presentan contorno en vista polar poligonal a subpoligonal. En general, las espinas son epenas visibles en corte óptico.

Registros previos: Cretácico superior al Mioceno de Argentina (Menéndez \& Caccavari, 1975; Dettmann et al., 1990; Barreda, 1997c; Barreda et al., 1998; Barreda \& Palamarczuk, 2000a,b; Palamarczuk \& Barreda, 2000; Zamaloa, 2000). Mioceno inferior de Antártida (Macphail \& Truswell, 2004).

Afinidad botánica: género Nothofagus subgénero Lophozonia.

Nothofagidites dorotensis Romero 1977

Lámina 12, figuras A-B. Lámina 23, figura C

Dimensiones: diámetro ecuatorial: 35 (40) $45 \mu \mathrm{m}$; número de colpos: 6-7; engrosamiento de colpos: 0,5-1 $\mu \mathrm{m}$; profundidad de colpos: 3 (4) $6 \mu \mathrm{m}$. (10 ejs.).

Procedencia: Miembro Inferior y Miembro Superior de la FRT.

Observaciones: las formas observadas en la FRT son muy semejantes a las publicadas por Romero (1977). Los individuos estudiados presentan contorno en vista polar poligonal a subpoligonal. Las espinas no son visibles en corte óptico. 
Registros previos: Cretácico superior a Mioceno de Argentina (Menéndez \& Caccavari, 1975; Dettmann et al., 1990; Barreda, 1997c; Palamarczuk \& Barreda, 2000; Zamaloa, 2000). Cretácico superior a Eoceno de Antártida (Dettmann, 1989; Askin, 1992a; Dolding, 1992). Cretácico superior a Eoceno de Chile (Romero, 1973; Troncoso \& Barrera, 1980).

Afinidad botánica: género Nothofagus.

Nothofagidites flemingii (Couper) Potonié 1960

Lámina 12, figuras C-D

Dimensiones: diámetro ecuatorial: 36 (40) $44 \mu \mathrm{m}$; número de colpos: 6-8; engrosamiento de colpos “a” (sensu Romero, 1977): 2-3; profundidad de colpos: 3 (4) 5 $\mu \mathrm{m}$. (10 ejs.).

Procedencia: Miembro Inferior y Miembro Superior de la FRT.

Observaciones: las formas observadas en la FRT son muy semejantes a las publicadas por Romero (1977), aunque corresponde a los tamaños menores de los rangos de medidas publicados en dicha contribución. Los individuos estudiados presentan contorno en vista polar poligonal a subpoligonal. Las espinas no son visibles en corte óptico.

Registros previos: especie ampliamente distribuida en Gondwana desde el Campaniano hasta el Pleistoceno superior (ver citas en Raine et al., 2011).

Afinidad botánica: género Nothofagus subgénero Nothofagus. 
Nothofagidites fortispinulosus Menendez \& Caccavari 1975

\section{Lámina 12, figuras E-F}

Dimensiones: diámetro ecuatorial: 23 (25) $27 \mu \mathrm{m}$; número de colpos: 6-8; engrosamiento de colpos "a" (sensu Romero, 1977): 2-3; profundidad de colpos: 3-4 $\mu \mathrm{m}$. (10 ejs.).

Procedencia: Miembro Inferior de la FRT.

Observaciones: las formas observadas en la FRT son muy semejantes a las publicadas por Romero (1977). Espinas fuertes, ca. 1 um de largo, visibles en corte óptico.

Registros previos: Formación Arroyo de los Mineros, Eoceno medio en Patagonia austral.

Afinidad botánica: género Nothofagus subgénero Nothofagus.

Nothofagidites nanus Romero 1977

Láminas 12, figuras G-H

Dimensiones: diámetro ecuatorial: 22 (25) $28 \mu \mathrm{m}$; número de colpos: 5 (6) 7; profundidad de colpos: 2-3 $\mu$ m. (10 ejs.).

Procedencia: Miembro Inferior y Miembro Superior de la FRT.

Observaciones: las formas observadas en la FRT son muy semejantes a las publicadas por Romero (1977). Los individuos estudiados presentan contorno en vista polar circular. Las espinas no son visibles en corte óptico.

Registros previos: Cretácico superior a Eoceno de Argentina (Dettmann et al., 1990). Cretácico superior a Paleógeno de Antártida (Stuchlik, 1981; Dettmann \& Thomson 1987; Cao, 1989; Dettmann, 1989; Shen et al., 1990; Dolding, 1992). 
Afinidad botánica: género Nothofagus.

\section{Nothofagidites rocaensis Romero 1973}

Lámina 12, figuras I-J. Lámina 23, figura D

Dimensiones: diámetro ecuatorial: 25 (30) $35 \mu \mathrm{m}$; número de colpos: 5 (6) 7; engrosamiento de colpos "a" (sensu Romero, 1977): 2 (2,7) 3; profundidad de colpos: 2 (2,3) $3 \mu \mathrm{m}$. (10 ejs.).

Procedencia: Miembro Inferior y Miembro Superior de la FRT.

Observaciones: las formas observadas en la FRT son muy semejantes a las publicadas por Menéndez \& Caccavari (1975). Los individuos estudiados presentan contorno en vista polar circular. Las espinas no son visibles en corte óptico.

Registros previos: Cretácico superior a Eoceno de Argentina (Menéndez \& Caccavari, 1975; Dettmann et al., 1990). Mioceno inferior de Antártida (Macphail \& Truswell, 2004).

Afinidad botánica: género Nothofagus subgénero Nothofagus.

Nothofagidites saraensis Menéndez \& Caccavari 1975

$$
\text { Lámina 12, figuras K-L }
$$

Dimensiones: diámetro ecuatorial: 27 (32) $37 \mu \mathrm{m}$; número de colpos: 5 (6) 7; engrosamiento de colpos "a" (sensu Romero, 1977): 1 (1,5) $2 \mu \mathrm{m}$; profundidad de colpos: 2,5 (3) 3,5 $\mu \mathrm{m}$. (10 ejs.).

Procedencia: Miembro Inferior y Miembro Superior de la FRT.

Observaciones: las formas observadas en la FRT son muy semejantes a las publicadas por Romero (1977), aunque corresponden a los tamaños menores de los rangos de 
medidas publicados en dicha contribución. Los individuos estudiados presentan contorno en vista polar circular. Las espinas no son visibles en corte óptico.

Registros previos: Cretácico superior a Mioceno de Argentina (Menéndez \& Caccavari, 1975; Dettmann et al., 1990; Prámparo et al., 1995; Barreda, 1997c; Barreda et al., 1998; Barreda \& Palamarczuk, 2000a,b; Palamarczuk \& Barreda, 2000; Zamaloa, 2000). Maastrichtiano a Mioceno inferior de Antártida (Baldoni \& Barreda, 1986; Askin, 1992a; Macphail \& Truswell, 2004).

Afinidad botánica: género Nothofagus subgénero Nothofagus.

Nothofagidites tehuelchesii Zamaloa \& Barreda 1992

\section{Lámina 13, figuras A-B}

Dimensiones: diámetro ecuatorial: 25 (35) $45 \mu \mathrm{m}$; número de colpos: 6-8; profundidad de colpos: 6-7 $\mu \mathrm{m}$. (10 ejs.).

Procedencia: Miembro Inferior y Miembro Superior de la FRT.

Observaciones: las formas observadas en la FRT son muy semejantes a las publicadas por Menéndez \& Caccavari (1975). Los individuos estudiados presentan contorno en vista polar poligonal a subpoligonal. Las espinas son visibles en corte óptico.

Registros previos: Paleoceno a Mioceno de Argentina (Zamaloa, 1992; Barreda, 1996; Barreda \& Palamarczuk, 2000a,b; Palamarczuk \& Barreda, 2000; Zamaloa, 2000). Mioceno inferior de Antártida (Macphail \& Truswell, 2004).

Afinidad botánica: género Nothofagus subgénero Lophozonia.

Familia Olacaceae

Especie tipo: Anacolosidites efflatus (Potonié) Ertman 1954 
Anacolosidites diffusa Archangelsky 1973

Lámina 13, figuras C-D

Dimesiones: diámetro ecuatorial: $10 \mu \mathrm{m}$ (1 ejemplar).

Procedencia: Miembro Superior de la FRT.

Observaciones: las formas observadas en la FRT son muy semejantes a las de la diagnosis original. Este es el primer registro para el Eoceno.

Registros previos: Cretácico superior a Paleoceno de Argentina (Archangelsky, 1976; Papú, 1989; Ruiz \& Quattrocchio, 1993, 1996, 1997b).

Afinidad botánica: géneros Anacolosa, Cathera y Ptychopetalum.

Familia Onagraceae

Corsinipollenites Nakoman 1965

Especie tipo: Corsinipollenites oculusnoctis (Thiergart) Nakoman 1965

Corsinipollenites atlantica Barreda 1997

\section{Lámina 13, figuras E-F}

Dimesiones: diámetro ecuatorial: 34-38 $\mu \mathrm{m}$; diámetro ectoporo: 4-5 $\mu \mathrm{m}$; espesor de la exina: $1 \mu \mathrm{m}(3$ ejs.).

Procedencia: Miembro Inferior de la FRT.

Observaciones: registro más antiguo de la especie. Las formas observadas en la FRT son muy semejantes a las la diagnosis original.

Registros previos: Oligoceno superior a Mioceno de Argentina (Barreda \& Palamarczuk, 2000 a,b; Leanza et al. 2002). 
Familia Polygalaceae

Polycolporopollenites Kedves 1965

Especie tipo: Polycolporopollenites esobalteus Pocknall \& Mildenhall 1984

Polycolporopollenites esobalteus Pocknall \& Mildenhall 1984

Lámina 13, figuras G-H

Dimensiones: diámetro polar: 16-30 $\mu \mathrm{m}$. (5 ejs.).

Procedencia: Miembro Inferior y Miembro Superior de la FRT.

Observaciones: especie de dimensiones y número de aberturas variable. El material estudiado presenta 6-7 colporos.

Registros previos: distribuida ampliamente en depósitos del Eoceno inferior al Plestoceno de Gondwana (White, 2006).

Afinidad botánica: Polygala stricta, Comesperma (Macphail \& Cantrill 2006).

Familia Proteaceae

Granodiporites Varma \& Rawat 1963

Especie tipo: Granodiporites erdtmanii Varma \& Rawat 1963

Granodiporites nebulosus Stover \& Partridge 1973

Láminas 13, figuras I-J

Dimensiones: diámetro ecuatorial: 35 (42,2) $50 \mu \mathrm{m}$; diámetro polar: $17(24,3) 29 \mu \mathrm{m}$; diámetro de poro: 4 (5) $7 \mu \mathrm{m}$ (20 ejs.).

Procedencia: Miembro Inferior y Miembro Superior de la FRT. 
Observaciones: las formas observadas en la FRT son muy semejantes a las la diagnosis original. En general presentan una ectosexina muy delgada rodeando el grano a modo de halo. En algunos ejemplares la ornamentación granulosa, típica de la especie, es difíciles de observar.

Registros previos: Oligoceno superior a Mioceno medio de Argentina (Zamaloa, 2000). Eoceno superior a Mioceno medio de Australia (Harris \& Morgan, 1976; Macphail \& Truswell, 1989; Nott \& Owen, 1992; Macphail, 1993, 1999; Macphail \& Hill, 1994; Martin, 1995).

Afinidad botánica: Embothrium coccineum.

Lewalanipollis Dettman \& Jarzen 1996

Especie tipo: Lewalanipollis senectus Dettmann \& Jarzen 1996

Lewalanipollis senectus Dettmann \& Jarzen 1996

\section{Láminas 13, figuras K-L}

Dimensiones: diámetro ecuatorial: $13(16,4) 19 \mu \mathrm{m}$; diámetro de poro: $2,2(2,6) 2,8 \mu \mathrm{m}$; espesor de la exina: 0,6 - $11 \mu \mathrm{m}$. (10 ejs.).

Procedencia: Miembro Inferior y Miembro Superior de la FRT.

Observaciones: las formas observadas en la FRT son muy semejantes a las la diagnosis original. Aunque el material aquí estudiado presenta dimensiones menores.

Registros previos: Australia: Santoniano al Paleoceno de Australia (Stoian, 2002). Maastrichtiano tardío a Paleógeno de Argentina (Baldoni et al. 1993; Prámparo \& Papú, 2003). 
Afinidad botánica: Proteaceae subfamilias Persoonioideae y Proteoideae (Dettmann \& Jarzen, 1996).

Peninsulapollis Dettmann \& Jarzen 1988

Especie tipo: Peninsulapollis gillii Dettmann \& Jarzen 1988

Peninsulapollis gillii Dettmann \& Jarzen 1988

Lámina 14, figuras A-B

Dimesiones: diámetro ecuatorial: $23(27,3) 31,5 \mu \mathrm{m}$; espesor de la exina: 0,5 - $1 \mu \mathrm{m}(6$ ejs.).

Procedencia: Miembro Inferior y Miembro Superior de la FRT.

Registros previos: distribuida ampliamente en depósitos del Cretácico superior al Oligoceno inferior de Gondwana (White, 2006).

Propylipollis Martin \& Harris 1975

Especie tipo: Propylipollis reticuloscabratus (Harris) Martin \& Harris 1974

Propylipollis ambiguus (Stover) Dettmann \& Jarzen 1996

Lámina 14, figuras C-D

Dimensiones: diámetro ecuatorial: 16 (18) $20 \mu \mathrm{m}$; diámetro de poro: 2 - 2,7 $\mu \mathrm{m}$; espesor de la exina: $0,8-1 \mu \mathrm{m}$ (5 ejs.).

Procedencia: Miembro Inferior y Miembro Superior de la FRT.

Observaciones: estos ejemplares coinciden con los descriptos por Dettmann \& Jarzen (1996). Se asignan a esta morfoespecie a formas triporadas afines a Embothrium 
coccineum, caracterizada por presentar microespinas y gránulos en la superficie de la exina.

Registros previos: Oligoceno a Mioceno inferior de Antártida (Askin \& Raine, 2000). Argentina: Maastrichtiano (Papú 1989; Baldoni \& Askin 1993). CampanianoMaastrichtiano a Eoceno de Australia (Stover \& Partridge 1973, 1982; Truswell et al. 1985; Milne 1988; Truswell \& Owen 1988; Alley \& Broadbridge, 1992; Alley \& Beecroft, 1993).

Afinidad botánica: Embothrium coccineum.

Propylipollis annularis (Cookson) Martin \& Harris 1974

\section{Lámina 14, figuras E-F}

Dimensiones: diámetro ecuatorial: 15 - $18 \mu \mathrm{m}$; diámetro de ectoporo: $3 \mu \mathrm{m}$; espesor de la exina: $<1 \mu \mathrm{m}(2$ ejs. $)$.

Procedencia: Miembro Inferior de la FRT.

Observaciones: estos ejemplares coinciden con los descriptos por Martin \& Harris (1974) aunque presentan poros de bordes netos.

Registros previos: amplio registro en Australia y Nueva Zelanda desde el Cretácico inferior (ver citas en Raine et al. 2011).

Afinidad botánica: géneros Xylomelum y Lambertia.

Propylipollis pseudomoides (Stover) Dettmann \& Jarzen 1996

Lámina 14, figuras G-H

Dimensiones: diámetro ecuatorial: 23 (30) $43 \mu \mathrm{m}$; diámetro de poro: 2 (3) 3,5 $\mu \mathrm{m}$; espesor de la exina: $1-1,5 \mu \mathrm{m}$ (20 ejs.). 
Procedencia: Miembro Inferior y Miembro Superior de la FRT.

Observaciones: esta especie se caracteriza por presentar un retículo cuyos lúmenes disminuyen su diámetro hacia los poros.

Registros previos: distribuida ampliamente en depósitos desde el Cretácico superior de Gondwana (ver citas en White, 2006).

Afinidad botánica: géneros Lomatia y Gevuina.

Propylipollis reticuloscabratus (Harris) Martin \& Harris 1974

\section{Lámina 14, figuras I-J}

Dimensiones: diámetro ecuatorial: $18(20,7) 23 \mu \mathrm{m}$; diámetro de poro: 1,7 - 2,2 $\mu \mathrm{m}$; espesor de la exina: $1,1-1,7 \mu \mathrm{m}(5$ ejs.).

Procedencia: Miembro Superior de la FRT.

Observaciones: primer registro para Sudamérica. Estos ejemplares coinciden con los descriptos por Dettmann \& Jarzen (1996). Aunque el material aquí estudiado tiene dimensiones menores. Se diferencia de Propylipollis pseudomoides por presenter microretículo, poros de menor diámetro y exina más gruesa.

Registros previos: Campaniano al Eoceno superior de Antártida (Dettmann, 1989; Askin, 2000). Desde el Campaniano en Australia: (ver citas en White, 2006).

Afinidad botánica: géneros Bleasdalea y Hicksbeachia (Dettmann \& Jarzen 1996).

Proteacidites Cookson y Couper 1953

Especie tipo: Proteacidites adenanthoides Cookson 1950 (Couper 1953)

Proteacidites obscurus Cookson 1950 
Lámina 14, figuras K-L

Dimensiones: diámetro ecuatorial: $24 \mu \mathrm{m}$; diámetro de poro: $3,5 \mu \mathrm{m}$; espesor de la sexina: $1 \mu \mathrm{m}$; espesor de la nexina: $2 \mu \mathrm{m}$ (1 ejs.).

Procedencia: Miembro Superior de la FRT.

Observaciones: esta especie se caracteriza por presentar una relación sexina/nexina $=$ $1 / 2$ o incluso menor.

Registros previos: especie ampliamente distribuida en Gondwana desde el Paleoceno (White, 2006).

Afinidad botánica: géneros Agastachys y Telopea.

Proteacidites rectus Pocknall \& Mildenhall 1984

Lámina 15, figuras A-B

Dimensiones: diámetro ecuatorial: 27 (29) $32 \mu \mathrm{m}$; diámetro de poro: 2,5 - 2,8 $\mu \mathrm{m}$; espesor de la exina: $1 \mu \mathrm{m}$ (10 ejs.).

Procedencia: Miembro Superior de la FRT.

Observaciones: las formas observadas en la FRT son muy semejantes a la descripción original de Pocknall \& Mildenhall (1984), particularmente por presentar un contorno en visra ecuatorial triangular de lados rectos y superficie escabrada.

Registros previos: Paleoceno a Eoceno de Argentina (Baldoni, 1987; Diaz et al., 1987). Eoceno superior a Mioceno inferior de Nueva Zelanda (Pocknall \& Mildenhall, 1984; Pocknall, 1985; Pocknall \& Turnbull, 1989). Eoceno medio a Mioceno inferior de Australia (Milne, 1988; Macphail, 1999). 
Dimensiones: diámetro ecuatorial: 11 (14) $18 \mu \mathrm{m}$; diámetro de poro: 1,5 - $2 \mu \mathrm{m}$; espesor de la exina: $<1 \mu \mathrm{m}(10$ ejs. $)$.

Procedencia: Miembro Inferior y Miembro Superior de la FRT.

Observaciones: las formas observadas en la FRT son muy semejantes a la descripción original de Couper (1960), presentando poros de márgenes netos a ligeramente engrosados y superficie psilada, aunque los ejemplares aquí estudiados alcanzan tamaños menores.

Registros previos: Cretácico superior a Mioceno inferior de Argentina (Ruiz \& Quattrocchio, 1997b; Povilauskas, 2013; Nañez et al. 2009). Paleoceno a Eoceno deAntártida (Baldoni \& Barreda, 1986; Pross et al. 2012). Oligoceno de Chile (Hebel \& Torres, 2009). Paleoceno a Oligoceno de Nueva Zelanda (ver citas en Raine et al., 2011). Desde el Paleoceno en Australia (Milne, 1988; Milne \& Martin, 1998).

Familia Sapindaceae

Cupanieidites Cokson y Pike 1954

Especie tipo: Cupaneidites mayor Cokson \& Pike 1954

Cupaneidites insulares Mindelhall \& Pocknall 1989

\section{Lámina 15, figuras E-F}

Dimensiones: diámetro ecuatorial: $15(15,7) 18 \mu \mathrm{m}$; espesor de la exina: 0,6-1 $\mu \mathrm{m}(10$ ejs.).

Procedencia: Miembro Inferior y Miembro Superior de la FRT. 
Observaciones: registro más antiguo de la especie, el primero para Sudamérica. El material estudiado se caracteriza por ser tricolporado, parasincolporado, colpos estrechos que se bifurcan a $1 / 2$ del radio ecuatorial para coalescer con colpos adyacentes delimitando una amplia isla polar de lados rectos a ligeramente cóncavos y superficie psilada.

Registros previos: Mioceno inferior a medio de Nueva Zelanda (Mildenhall \& Pocknall, 1989).

Afinidad botánica: Tribu Cupaniae (género Cupania).

Cupanieidites reticularis Cookson \& Pike 1954

$$
\text { Lámina 15, figuras G-H }
$$

Dimensiones: diámetro ecuatorial: 21 (24) $26 \mu \mathrm{m}$; exina $<1 \mu \mathrm{m}$ (10 ejs.).

Procedencia: Miembro Inferior y Miembro Superior de la FRT.

Registros previos: especie cosmopolita ampliamente distribuida desde el Paleoceno al Pleistoceno (citas en White, 2006).

Afinidad botánica: Tribu Cupaniae (género Cupania).

Dicotiledóneas de afinidad desconocida

Bysmapollis Partridge en Stover \& Partridge 1973

Especie tipo: Bysmapollis emaciatus Partridge en Stover \& Partridge 1973

Bysmapollis verrucatus Romero \& Zamaloa 1985

Lámina 15, figuras I-J 
Dimesiones: diámetro de la tétrade: $27(33,3)$ 47; diámetro ecuatorial del grano individual: 17,5 (22) $35 \mu \mathrm{m}$; diámetro de poro: 4-5 $\mu \mathrm{m}$ (6 ejs.).

Procedencia: Miembro Inferior y Miembro Superior de la FRT.

Observaciones: granos dispuesotos en tétrades tetraédricas, con tres poros lolongados y superficie de la exina verrucosa.

Registros previos: Paleoceno inferior de Argentina (Zamaloa \& Andreis, 1995).

Periporopollenites Pflug \& Thomson 1953

Especie tipo: Periporopollenites stigmosus Thomson \& Pflug 1953

Periporopollenites demarcatus Stover 1973

Lámina 15, figuras K-L. Lámina 24, figura B

Dimesiones: diámetro ecuatorial: $28,5(31,2) 36 \mu \mathrm{m}$. (10 ejs.).

Procedencia: Miembro Inferior y Miembro Superior de la FRT.

Observaciones: las formas estudiadas coindicen con las descriptas por Romero \& Zamaloa (1985) para la FRT aunque el material aquí estudiado presenta frecuentemente menos poros $(8-10)$.

Afinidad botánica: Trimeniaceae con dudas (Sampson \& Endress, 1984).

Registros previos: especie ampliamente distribuida en Gondwana desde el Maastrichtiano al Mioceno inferior (White, 2006).

Psilatricolpites Van der Hammen \& Wijmstra 1964

Especie tipo: Psilatricolpites clarissimus (Van der Hammen, 1954) 
Dimensiones: diámetro ecuatorial: 18 (20) $22 \mu \mathrm{m}$; diámetro polar: 17 (20) $21 \mu \mathrm{m}$. (10 ejs.).

Procedencia: Miembro Inferior y Miembro Superior de la FRT.

Observaciones: las formas observadas son muy semejantes a las la diagnosis original de González-Guzmán (1967) para el Eoceno de Colombia.

Psilatricolporites Pierce 1961

Especie tipo: Psilatricolporites inornatus (Van der Hammen) Pierce 1961

Psilatricolporites costatus Dueñas 1980

Lámina 16, figuras C-D

Dimensiones: diámetro ecuatorial: $12-14 \mu \mathrm{m}$. (3 ejs.).

Procedencia: Miembro Superior de la FRT.

Observaciones: las formas estudiadas se caracterizan por tener forma subromboidal ser tricolporadas, con endoaperturas circulares evidentes y colpos engrosados, y la superficie de la exina psilada.

Registros previos: Oligoceno superior de Brasil (Lima et al., 1985). Eoceno superiorMioceno inferior de Colombia (Dueñas-Jimenez, 1983, 1986; Hoorn et al., 1994). Mioceno medio de Perú (Hoorn, 1994).

Afinidad botánica: asignada con dudas a la familia Salicaceae (Moreno, 2014).

Psilatricolporites divisus Regali, 1974

Lámina 16, figuras E-F 
Dimensiones: diámetro polar: $28-30 \mu \mathrm{m}$. (3 ejs.).

Procedencia: Miembro Inferior y Miembro Superior de la FRT.

Observaciones: se caracteriza por presentar un surco en el plano ecuatorial donde se ubican las endoaperturas, por lo que el grano parece dividido en dos hemisferios.

Registros previos: Maastrichtiano superior de Bolivia (Vajda-Santivanez, 1999). Eoceno medio a superior de Brasil (de Lima \& Salard-Cheboldaeff, 1981). Mioceno inferior a medio de Colombia (Hoorn et al., 1994). Mioceno medio a superior de Perú (Hoorn et al., 1994).

Psilatricolporites pachydermatus Lorente 1986

Lámina 16, figuras G-H

Dimensiones: diámetro polar: 20-30 $\mu \mathrm{m}$. (5 ejs.).

Procedencia: Miembro Inferior de la FRT.

Observaciones: las formas observadas son muy semejantes a las la diagnosis original. Se diferencia de las otras especies del género presentes en la FRT por presentar una exina gruesa $(2-2,5 \mu \mathrm{m})$.

Registros previos: Venezuela: Mioceno inferior (Rull, 2001).

Psilatricolporites aff. P. protrudens Palazzesi 2010

\section{Lámina 16, figuras I-J}

Descripción: grano de polen suboblato, contorno rómboidal en vista ecuatorial tricolporado. Colpos cortos, extremos redondeados. Endoapertura lalongada (2 $\mu \mathrm{m})$. . Exina tectada $(1,2 \mu \mathrm{m})$, psilada, estratificación indistinguible. Área ecuatorial protruida a la altura de la endoapertura. 
Dimensiones: diámetro ecuatorial: $12-14 \mu \mathrm{m}$. (1 ejs.).

Procedencia: Miembro Superior de la FRT.

Observaciones: formas muy similares a la descripción original. Se cuenta sólo con un ejemplar en el que no se observa la estratificación de la exina, por lo que la asignación a P. protrudens no se puede realizar con certeza.

Afinidad botánica: Calyceraceae con dudas.

Psilatricolporites vanus González-Guzmán 1967

$$
\text { Lámina 16, figuras K-L }
$$

Dimensiones: diámetro polar: 16 (18) $20 \mu \mathrm{m}$. (10 ejs.).

Procedencia: Miembro Inferior y Miembro Superior de la FRT.

Observaciones: las formas observadas son muy semejantes a las la diagnosis original. Es una forma muy frecuente en la FRT (pico máximo en la muestra 3, 5,5 \%, tabla 3) y de morfología muy común entre las dicotiledóneas, probablemente represente a varias especies naturales.

Registros previos: Paleoceno a Eoceno medio de Colombia (Porta, 1974). Mioceno de Senegal (Medus, 1975).

Psilatricolporites varius Dueñas-Jimenez 1983

Lámina 17, figuras A-B

Dimensiones: diámetro polar: $11(13,5) 15 \mu \mathrm{m}$. (10 ejs.).

Procedencia: Miembro Inferior y Miembro Superior de la FRT. 
Observaciones: las formas observadas son muy semejantes a la diagnosis original. Es una forma muy frecuente en la FRT (pico máximo en la muestra 3, 19,9\%, tabla 3) y de morfología muy común entre las dicotiledóneas, probablemente represente a varias especies naturales. Se diferencia de las otras especies del género presentes en este estudio por su menor tamaño.

Registros previos: Mioceno medio a superior de Brasil (Hoorn et al., 1993). Oligoceno a Mioceno medio de Colombia (Dueñas-Jimenez, 1986; Hoorn et al., 1994). Mioceno medio a superior de Perú (Hoorn et al., 1994).

Rhoipites Wodehouse 1933

Especie tipo: Rhoipites bradleyi Wodehouse 1933

Rhoipites alveolatus (Couper 1953) Pocknall \& Crosbie 1982

\section{Lámina 17, figuras C-D}

Dimensiones: diámetro ecuatorial: 21 (23) $25 \mu \mathrm{m}$; diámetro polar: 27 (32) $41 \mu \mathrm{m}$; engrosamientos de los colpos: 1,3-3,5 $\mu \mathrm{m}$; diámetro de lúmen: 1-1,3 $\mu \mathrm{m}$; espesor de la exina: $0,6(1,3) 2,2 \mu \mathrm{m}$. (5 ejs.).

Procedencia: Miembro Inferior y superior de la FRT.

Observaciones: las formas observadas en la FRT son muy semejantes a las la diagnosis original. Es una especie de registro muy amplio y dimensiones variables.

Registros previos: especie ampliamente distribuida en Gondwana desde el Paleoceno (White, 2006).

Afinidad botánica: Avicenniaceae (Avicennia), ?Euphorbiaceae (Excoecaria), ?Caesalpiniaceae - Macphail 1998. Euphorbiaceae (Mautino \& Anzotegui, 2002b). 
Rhoipites baculatus Archangelsky 1973

\section{Lámina 17, figuras E-F}

Dimensiones: diámetro ecuatorial: 19 (22,5) 32,6 $\mu \mathrm{m}$; diámetro polar: 23 (28) $33 \mu \mathrm{m}$; engrosamientos de los colpos: 1,5 (2) 2,2 $\mu \mathrm{m}$; diámetro de lúmen: $<1 \mu \mathrm{m}$; espesor de la exina: $0,6(1,3) 1,7 \mu \mathrm{m}$. (10 ejs.).

Procedencia: Miembro Inferior y superior de la FRT.

Observaciones: las formas observadas en la FRT son muy semejantes a las la diagnosis original. Se diferecnias de $R$. alveolatus por presentar un microretículo y exina más delgada.

Registros previos: registro amplio en el Neógeno de Argentina y Antártida (citas en White, 2006).

Rhoipites cf. hawkdunensis Mildenhall \& Pocknall 1989

Lámina 17, figuras G-H

Dimensiones: diámetro ecuatorial: 10-11 $\mu \mathrm{m}$; diámetro polar: 20-22 $\mu \mathrm{m}$ (3 ejs.).

Procedencia: Miembro Inferior y superior de la FRT.

Observaciones: las formas observadas en la FRT son muy semejantes a las ilustradas por Mildenhall \& Pocknall (1989) para el Mioceno inferior a medio de Nueva Zelanda, aunque en el material aquí estudiado las endoaperturas son menos evidentes.

Rhoipites rhomboidaliformis? (Mc Intyre 1968) Mildenhall \& Pocknall 1989

Lámina 17, figuras I-J

Dimensiones: diámetro ecuatorial: $15-17 \mu \mathrm{m}$; diámetro polar: 15-17 $\mu \mathrm{m}$ (2 ejs.). 
Procedencia: Miembro Superior de la FRT.

Observaciones: las formas observadas en la FRT son muy semejantes a las la diagnosis original, aunque en los ejemplares aquí estudiados el microretículo es poco evidente.

Registros previos: Oligoceno de Antártida (Mildenhall, 1989). Oligoceno a Pleistoceno de Nueva Zelanda (Mildenhall \& Pocknall, 1989; Mildenhall, 2001).

Afinidad botánica: Araliaceae, Apiaceae.

Rhoipites sphaerica (Cookson 1947) Pocknall \& Crosbie 1982

\section{Lámina 17, figuras J-K}

Dimensiones: diámetro ecuatorial: $28(31,4) 34 \mu \mathrm{m}(8$ ejs. $)$.

Procedencia: Miembro Superior de la FRT.

Observaciones: los ejemplares estudiados se caracterizan por presentar forma subesférica, colpos engrosados y retículo homobrocado, de lúmenes densa y uniformemente distribuidos, subpoligonales, de $<1 \mu \mathrm{m}$ de ancho y muros angostos.

Registros previos: distribuida ampliamente en depósitos del Paleógeno y Neógeno de Gondwana (Raine et al., 2011).

Striatricolporites Leidelmeyer 1966

Especie tipo: Striatricolporites pimulis Leidelmeyer 1966

Striatricolporites pseudostriatus (Mc Intyre) Mildenhall \& Pocknall 1989

Lámina 18, figuras A-B

Dimensiones: diámetro ecuatorial: 27-29 $\mu \mathrm{m}$; diámetro polar: 32 (36) $42 \mu \mathrm{m}$; diámetro de endoapertura: 2-3 $\mu \mathrm{m}$; espesor de la exina: $1 \mu \mathrm{m}$ (6 ejs.). 
Procedencia: Miembro Superior de la FRT.

Observaciones: primer registro para Sudamérica. Las formas observadas en la FRT son muy semejantes a las la diagnosis original.

Registros previos: Eoceno medio a Mioceno medio de Australia (Alley \& Broadbridge, 1992).

Afinidad botánica: Anacardiaceae con dudas.

Tetracolporopollenites Pflug \& Thomson en Thomson \& Pflug 1953

Especie tipo: Tetracolporopollenites sapotoides Pflug \& Thomson en Thomson \& Pflug 1953

Tetracolporopollenites sp. 1 Jaramillo \& Dilcher 2001

Lámina 18, figuras C-D

Dimensiones: diámetro ecuatorial: 15-17 $\mu \mathrm{m}$; diámetro polar: 18-20 $\mu \mathrm{m}$; espesor de la exina: $1 \mu \mathrm{m}(2$ ejs. $)$.

Procedencia: Miembro Inferior de la FRT.

Observaciones: las formas observadas en la FRT son muy semejantes a las descriptas por Jaramillo y Dilcher (2001) para el Paleoceno de Colombia. Aunque el material allí estudiado tiene dimensiones mayores (diámetro polar: $37 \mu \mathrm{m}$ ).

Tricolpites Cookson ex Couper 1953 emend. Potonié 1960

Especie tipo: Tricolpites reticulatus Cookson 1947

Tricolpites bathyreticulatus Stanley 1965

Lámina 18, figuras E-F. Lámina 24, figura C 
Descripción: las formas observadas en la FRT son muy semejantes a las reportadas por McIntyre (1968) para el Neógeno de Nueva Zelanda.

Dimensiones: diámetro ecuatorial: $26(29,2) 32 \mu \mathrm{m}$ (10 ej.).

Procedencia: Miembro Inferior y Miembro Superior de la FRT.

Registros previos: especie cosmopolita distribuida ampliamente en depósitos del Cenomaniano al Mioceno inferior (ver citas en White, 2006 y Raine et al., 2011).

Afinidad botánica: Lamiaceae, con dudas.

\section{Tricolpites brevicolpus Couper 1960}

\section{Lámina 18, figuras G-H}

Dimensiones: diámetro ecuatorial: $17-19 \mu \mathrm{m}$; espesor de la exina: $1 \mu \mathrm{m}$ (2 ej.).

Procedencia: Miembro Inferior de la FRT.

Observaciones: las formas observadas en la FRT son muy semejantes a los ilustrados por Mildenhall (1994) para el Paleógeno de Nueva Zelanda. Se caracterizan por presentar colpos cortos, de márgenes difusos, y microretículo.

Registros previos: Mioceno superior a Pleistoceno de Burundi (Sah, 1967). Eoceno medio de Estados Unidos (Potter, 1976). Jurásico medio a Plioceno de India (Venkatachala \& Rawat, 1972,1977; Venkatachala, 1973; Sastri et al., 1977; Venkatachala \& Chowdhary, 1977; Venkatachala \& Sharma, 1984; Salujha et al., 1985; Mehrotra et al., 2002). Paleoceno de Nueva Zelanda (Norris, 1962; Hornibrook et al., 1978).

Triorites Couper 1953

Especie tipo: Triorites magnificus Cookson 1950 
Triorites fragilis Couper 1953

Lámina 18, figuras I-J

Dimesiones: diámetro ecuatorial: 18 (21,3) $26 \mu \mathrm{m}$ (10 ejs.).

Procedencia: Miembro Inferior y Miembro Superior de la FRT.

Observaciones: las formas observadas en la FRT son muy semejantes a las de la diagnosis original. Se diferencia de Triorites minor por su mayor tamaño, poros de mayor diámetro y superficie escabrada.

Registro previo: distribuida ampliamente en depósitos del Cretácico superior al Paleógeno de Gondwana (Raine et al., 2011).

Triorites minor Couper 1953

Lámina 18, figuras K-L

Dimesiones: diámetro ecuatorial: $8(11,8) 15,8 \mu \mathrm{m}$; diámetro de poro: $1,6(1,9) 2,6 \mu \mathrm{m}$ (20 ejs.).

Procedencia: Miembro Inferior y Miembro Superior de la FRT.

Observaciones: especie frecuente a lo largo de toda la FRT. Se diferencia de Triorites fregilis por su menor tamaño, contorno en vista ecuatorial triangular de lados cóncavos, poros de menor diámetro y superficie psilada.

Registro previo: distribuida ampliamente en depósitos del Cretácico superior al Neógeno de Gondwana (Raine et al., 2011).

Triorites subspinosus Couper 1960

Lámina 19, figuras A-B 
Dimesiones: diámetro ecuatorial: $18,5 \mu \mathrm{m}$; diámetro de poro: $2,6 \mu \mathrm{m}$; espesor de la exina: $<1 \mu \mathrm{m}$; microespinas: 0,5-1 (1 ej.).

Procedencia: Miembro Inferior de la FRT.

Observaciones: primer registro para Sudamérica. Se diferencia de las otras especies del género presentes en la FRT por presentar microespinas.

Registros previos: Nueva Zelanda: Paleoceno (Raine, 1984).

Monocotiledóneas

Familia Araceae

Monocotiledónea sp. 1

Lámina 19, figuras C-D

Descripción: grano de polen subesférico a prolato, inaperturado. Exina con carenas longitudinales, lisas, de bordes nítidos que culminan en los polos. En ocasiones las carenas se bifurcan. De 10 a 12 carenas por lado. Ancho de las carenas de $1 \mu \mathrm{m}$. Exina de $1 \mu \mathrm{m}$ de espesor, estratificación indistinguible.

Dimesiones: diámetro ecuatorial: $22-24 \mu \mathrm{m}$; diámetro polar: $28-30 \mu \mathrm{m}$ (3 ejs.).

Procedencia: Miembro Inferior y Miembro Superior de la FRT.

Observaciones: el material de la FRT presenta la mayoría de los rasgos diagnósticos propuestos por Hesse \& Zetter (2007) para el género Spathiphyllum: grado de esfericidad, carenas delgadas y bifurcadas; aunque no presenta más de 15 carenas por lado. Dicha contribución no presenta microfotografías al MO, por lo que se requiere una comparación más exhaustiva para confirmar la asignación al género Spathiphyllum.

Afinidad botánica: género Spathiphyllum. 
Familia Arecaceae

Arecipites Nichols et al. 1973

Especie tipo: Arecipites punctatus Wodehouse 1958

Arecipites minutiscabratus (McIntyre 1968) Milne 1988

Lámina 19, figura E-F

Dimesiones: diámetro ecuatorial mayor: 47 (52) $58 \mu \mathrm{m}$; diámetro ecuatorial menor: 31 (35) $39 \mu \mathrm{m}(10$ ejs.).

Procedencia: Miembro Inferior y Miembro Superior de la FRT.

Observaciones: las formas observadas en la FRT son muy semejantes a las de la diagnosis original, aunque presenta dimensiones mayores que en los registros previos para Argentina.

Registro previo: distribuida ampliamente en depósitos del Paleógeno de Gondwana (Raine et al., 2011).

Arecipites sp. 1 (nueva especie)

\section{Lámina 19, figura G-H}

Descripción: grano de polen, bilateral, anisopolar, contorno en vista polar elíptico, extremos romos, monosulcado. Largo de sulco / diámetro ecuatorial mayor del cuerpo 0,6, márgenes rectos, extremos agudos, margo no bien definido, en ocasiones indistinguible, $<0,1 \mu \mathrm{m}$, área polar pequeña, de $2 \mu \mathrm{m}$ de ancho. Exina de 0,5 a $2 \mu \mathrm{m}$ de espesor, tectado, columelada. Escultura microreticulada, homobrocada, de distribución uniforme y densa, muros $<1 \mu \mathrm{m}$. 
Dimesiones: diámetro ecuatorial mayor: $20(25,4) 33 \mu \mathrm{m}$; diámetro ecuatorial menor: $12(16,5) 18 \mu \mathrm{m}$ (10 ejs.).

Procedencia: Miembro Inferior y Miembro Superior de la FRT.

Comparaciones: Arecipites regio (Van der Hammen \& Garcia, 1966) Jaramillo \& Dilcher (2001), presenta mayor diámetro ecuatorial mayor $(30-53 \mu \mathrm{m})$, sulco de longitud mayor, ligeramente marginado, superficie microperforada (diámetro de lúmen: $0,4-0,8 \mu \mathrm{m})$.

Monosulcites Cookson \& Couper 1953

Especie tipo: Monosulcites minimus Cookson 1947

Monosulsites perspinosus Couper 1953

Lámina 19, figuras I-J

Dimesiones: diámetro ecuatorial mayor: 18 (22,8) $32 \mu \mathrm{m}$ (20 ejs.); diámetro ecuatorial menor: 14 (17) $22 \mu \mathrm{m}$ (10 ejs.); diámetro polar: 10 (11) $12 \mu \mathrm{m}$ (5 ejs.).

Procedencia: Miembro Inferior y Miembro Superior de la FRT.

Observaciones: formas caracterizadas por ser monocolpadas, de escultura equinada, espinas cónicas de expremos agudos, en ocasiones curvadas, distribuidas densamente sobre la superficie del grano.

Registros previos: especie cosmopolita ampliamente distribuída desde el Maastrichtiano (ver citas en White, 2006).

Psilamonocolpites Van der Hammen \& Garcia de Mutis 1966

Especie tipo: Psilamonocolpites medius Van der Hammen 1954 


\section{Lámina 19, figuras K-L}

Dimesiones: diámetro ecuatorial mayor: 15 (26,8) $40 \mu \mathrm{m}$ (20 ejs.); diámetro ecuatorial menor: 5,5 (13) $28 \mu \mathrm{m}$ (10 ejs.); diámetro polar: $6(16,8) 22 \mu \mathrm{m}$; espesor de la exina: < $1-1 \mu \mathrm{m}(5$ ejs.).

Procedencia: Miembro Inferior y Miembro Superior de la FRT.

Observaciones: se diferencia de Arecipites minutiscabratus por presentar un menor diámetro ecuatorial mayor, abertura de menor longitud y superficie psilada.

Registros previos: especie ampliamente distribuida en Sudamérica y África desde el Aptiano al Pleistoceno (ver citas en White, 2006).

Familia Poaceae

Graminidites Potonie 1960

Especie tipo: Graminidites media Cookson 1947

Graminidites media Cookson 1947

Lámina 20, figuras A-B

Descripción: grano de polen monoporado, anisopolar, subesferoidal, de contorno circular. Os de 2-3 $\mu \mathrm{m}$ de diámetro, anulado. Exina tectada de $<1-1 \mu \mathrm{m}$ de espesor. Estratificación indistinguible.

Dimesiones: diámetro: $22(28,7) 36 \mu \mathrm{m}$; diámetro de poro: $2-3 \mu \mathrm{m}$; anulus: 1,7 $\mu \mathrm{m}$; espesor de la exina: $<1-1 \mu \mathrm{m}(3$ ejs. $)$.

Procedencia: Miembro Inferior y Miembro Superior de la FRT. 
Observaciones: especie poco frecuente en el presente estudio. Se caracteriza por su forma esférica, diámetro menor a $40 \mu \mathrm{m}$ y poro anulado.

Registros previos: especie cosmopolita distribuida ampliamente en depósitos desde el Paleógeno (ver citas en White, 2006 y Raine et al., 2011).

Monocotiledóneas de afinidad desconocida

Liliacidites Couper 1953

Especie tipo: Liliacidites kaitangataensis Couper 1953

Liliacidites regularis Archangelsky 1973

Lámina 20, figuras C-D. Lámina 24, figura D

Dimesiones: diámetro ecuatorial mayor: 22 (29) $41 \mu \mathrm{m}$; diámetro ecuatorial menor: 14 $(18,6) 22 \mu \mathrm{m}$; espesor de la exina: $1 \mu \mathrm{m}$ (15 ejs.).

Procedencia: Miembro Inferior y Miembro Superior de la FRT.

Observaciones: primeros registros para el Eoceno de Sudamérica. Las formas observadas en la FRT son muy semejantes a las la diagnosis original.

Registros previos: Maastrichtiano a Paleoceno de Argentina (Archangelsky \& Zamaloa, 1986; Scafati et al., 2009; Barreda et al., 2012; Povilauskas, 2013).

Sparganiaceaepollenites Thiergart 1937

Especie tipo: Sparganiaceaepollenites polygonalis Thiergart 1937 (designada por Potonié, 1960).

Sparganiaceaepollenites barungensis Harris 1972

Lámina 20, figuras E-F 
Dimesiones: diámetro: $22(28,8) 33 \mu \mathrm{m}$; diámetro de lúmen: 1-3 $\mu \mathrm{m}$ (20 ejs.).

Procedencia: Miembro Inferior y Miembro Superior de la FRT.

Observaciones: estos ejemplares coinciden plenamente con los reportados por Barreda (1997) para la Fm. Chenque.

Registros previos: especie ampliamente distribuida en Gondwana desde el Cretácico superior al Pleistoceno (Raine et al., 2011).

Afinidad botánica: Sparganiaceae, Typhaceae. 


\section{Comparación con otras asociaciones paleógenas}

Se comparó de forma cualitativa la asociación registrada en la FRT con palinofloras del Paleógeno de Patagonia, Islas Malvinas y Antártida, como así también del norte de Colombia. Las primeras fueron seleccionadas por su proximidad geográfica, las segundas por haber sido comparadas también en cuanto a su diversidad (ver Resultados de rarefacción). Los aspectos considerados fueron: linajes principales reconocidos en la FRT (Nothofagaceae, Podocarpaceae, Araucariaceae, Myrtaceae, Proteaceae y Pteridofitas), otros taxa relevantes, edad de las asociaciones y ambiente de depositación (Tablas 2-5).

Las comparaciones se realizaron con las asociaciones registradas en las unidades: Fm Ligorio Márquez tanto en sus afloramientos en territorio chileno (Paleoceno superior de la XI Región, Troncoso et al., 2002), como argentino (Paleoceno-Eoceno inferior medio del NW de Santa Cruz, Macphail et al., 2013), Fm Agua Fresca (Eoceno inferior-Eoceno medio de la Región de Magallanes, Chile, Carrillo-Berumen et al., 2013), Fm Cheuquemó (Eoceno de Osorno, Chile, Troncoso \& Barrera, 1980), Fm Leña Dura (Eoceno de Punta Arenas, Chile, Cookson \& Cranwell, 1967), Fm Loreto (Eoceno superior-Oligoceno de la Región de Magallanes, Chile, Fasola, 1969), Fm Huitrera (Eoceno del NW de Patagonia, Argentina, Melendi et al., 2003), Fm Salto del Macho (Eoceno medio - Oligoceno inferior del SW de Río Negro, Argentina, Cornou et al., 2014), Fm Sloggett (Oligoceno inferior del SE de Tierra del Fuego, Argentina, Olivero et al., 1998) Fm San Julián (Oligoceno de Santa Cruz, Argentina, Barreda, 1997d, Náñez et al., 2009), Forest Bed (Mioceno medio? a Plioceno inferior de las Islas Malvinas, Macphail \& Cantrill, 2006), Fm La Meseta (Eoceno medio de la Isla Marambio, Antártida, Zamaloa et al., 1987), Fm Cerrajón 
(Paleoceno superior del norte de Colombia, Jaramillo et al., 2007), Fm Arenas del Limbo - San Fernando (Eoceno medio-bajo de los Andes orientales de Colombia, Jaramillo \& Dilcher, 2000) y Fm Riecito Mache - Gonzales (Eoceno medio inferior del noreste de Colombia, Jaramillo et al., 2010) (Figuras 9 y 10).

Entre las palinofloras del Paleógeno de Argentina (Tablas 2 y 3), las que presentan una mayor similitud con la de la FRT son las de la Fm La Meseta y Fm San Julián debido a la dominancia de Nothofagus y la presencia de representantes de las familias Araucariaceae, Myrtaceae, Podocarpaceae y Proteaceae. La Fm La Meseta se diferencia de la FRT principalmente por la ausencia de linajes meso/megatérmicos (Arecaceae, Araceae, Sapindaceae, Aquifoliaceae, Bombacaceae y Malpighiaceae). Por su parte, la Fm San Julián muestra tendencias distintas en los linajes: Nothofagus se hace dominante en la sección superior, mientras que en la FRT domina prácticamente a lo largo de toda la unidad; Podocarpaceae es más abundante en el nivel superior, mientras que en la FRT su frecuencia fluctúa; Myrtaceae, presenta un comportamiento opuesto a Podocarpaceae, mientras que en la FRT es poco frecuente en la base y luego fluctúa mostrando picos de dominancia; las Araucariaceae están presentes en el nivel inferior y ausente en el superior, mientras que en la FRT están presentes a lo largo de toda la formación siendo más frecuentes en los niveles superiores; las Proteaceae son un componente poco frecuente, mientras que en la FRT son frecuentes y abundantes; las pteridofitas son relativamente menos diversas; finalmente, Arecaceae es el único componente meso/megatérmico registrado en la Fm San Julián mientras que en la FRT también se registran las familias de afinidad subtropical/ tropical mencionadas anteriormente. La palinoflora de la Fm Salto del Macho es similar a la FRT por la presencia de Araucariaceae, Myrtaceae, Podocarpaceae, Proteaceae y representantes de la familia Arecaceae y Bombacaceae, pero no por su abundancia y diversidad. 
Nothofagus no es dominante y los otros linajes considerados son menos diversos. La Fm Ligorio Márquez se diferencia de la FRT principalmente por la ausencia de Nothofagus y Myrtaceae. Comparte con la FRT la presencia de Araucariaceae, Proteaceae, Cyatheaceae, Dicksoniaceae y de componentes meso/megatérmico como Bombacaceae y Arecaceae. La Fm La Huitrera, por su parte, en líneas generales también se diferencia de la FRT por la ausencia de Nothofagus y Myrtaceae, aunque el primero domina en los niveles superiores. La principal diferencia con la FRT es la dominancia de Podocarpaceae. La Fm Sloggett se diferencia de la FRT por la dominancia de Podocarpaceae, principalmente Dacrydium, y pteridofitas y la ausencia de componentes meso/megatérmicos. En dicha formación Nothofagus está representado sólo por el tipo fusca. La palinoflora de Forest Bed se diferencia de la de la FRT principalmente en la dominancia de Podocarpaceae. Comparten la presencia de Nothofagaceae, Araucariaceae y Myrtaceae y los géneros de afinidad meso/megatérmica Arecipites e Ilexpollenites.

En cuanto a las asociaciones registradas en el Paleógeno de Chile (Tabla 4) la que muestra una mayor similitud con la de la FRT es la asociación de la Fm Cheuquemó, principalmente por la dominancia y alta diversidad de Nothofagus a lo largo de toda la unidad, la alta diversidad de pteridofitas, la presencia de Myrtaceae, Podocarpaceae y Proteaceae. Difiere de la FRT en la ausencia de Araucariaceae, la baja frecuencia de Podocarpaceae y la ausencia de componentes meso/megatérmicos con excepción del morfogénero Cupaneidites.

Finalmente, la comparación con las floras polínicas del norte de Colombia (Tabla 5) muestra que su similitud con la FRT es menor. Esto se debe a la ausencia de Nothofagus, la muy escasa representación de Podocarpaceae y Araucariaceae y la 
dominancia (en algunos niveles) de Arecaceae. La Fm Riecito Mache - Gonzales es la que presenta una mayor similitud con la FRT por la presencia de Myrtaceae, Proteaceae, Arecaceae, Araceae, Bombacaceae, Fabaceae, Poaceae y Convolvulaceae.



Figura 9. Ubicación geográfica de las palinofloras del Paleógeno de Patagonia e Islas Malvinas comparadas. 1. Fm Río Turbio. 2. Fm Fm Ligorio Márquez (afloramiento en territorio argentino). 3. Fm Huitrera. 4. Fm Salto del Macho. 5. Fm San Julián. 6. Fm Sloggett. 7. Forest Bed. 8. Fm Ligorio Márquez (afloramiento en territorio chileno). 9. Fm Agua Fresca. 10. Fm Cheuquemó. 11. Fm Leña Dura. 12. Fm Loreto. 




Figura 10. Ubicación geográfica de las palinofloras del Paleógeno de Colombia y Antártida comparadas. 1. Fm Río Turbio. 2. Fm Cerrajón. 3. Fm Arenas del Limbo San Fernando. 4. Fm Riecito Mache - Gonzales. 5. Fm La Meseta. 


\begin{tabular}{|c|c|c|c|c|c|}
\hline Unidad & $\begin{array}{c}\text { Fm Río } \\
\text { Turbio }\end{array}$ & $\begin{array}{c}\text { Fm Ligorio } \\
\text { Márquez }\end{array}$ & Fm Huitrera & $\begin{array}{c}\text { Fm Salto del } \\
\text { Macho }\end{array}$ & Fm San Julián \\
\hline $\begin{array}{l}\text { Edad / } \\
\text { Ubicación }\end{array}$ & $\begin{array}{l}\text { Eoceno medio } \\
\text { - Eoceno } \\
\text { superior } \\
\text { (Oligoceno?) }\end{array}$ & $\begin{array}{l}\text { Paleoceno- } \\
\text { Eoceno inferior } \\
\text { medio / NW de } \\
\text { Santa Cruz }\end{array}$ & $\begin{array}{c}\text { Eoceno / NW de } \\
\text { Patagonia, } \\
\text { Argentina }\end{array}$ & $\begin{array}{c}\text { Eoceno medio - } \\
\text { Oligoceno } \\
\text { inferior / SW de } \\
\text { Río Negro, } \\
\text { Argentina }\end{array}$ & $\begin{array}{c}\text { Oligoceno / } \\
\text { Santa Cruz, } \\
\text { Argentina }\end{array}$ \\
\hline Ambiente & $\begin{array}{l}\text { marino } \\
\text { somero }\end{array}$ & pantano costero & continental & marino & $\begin{array}{c}\text { pantano costero, } \\
\text { escasa } \\
\text { influencia } \\
\text { marina }\end{array}$ \\
\hline Nothofagaceae & $\begin{array}{l}\text { abundantes y } \\
\text { diversas } \\
(\mathrm{S}=9), \\
\text { genralmente } \\
\text { dominantes. } \\
\text { Tipos, fusca y } \\
\text { menziesii }\end{array}$ & ausentes & $\begin{array}{l}\text { ausentes en } \\
\text { niveles } \\
\text { inferiores, } \\
\text { dominante en } \\
\text { superiores. } \\
\text { Tipos brassi y } \\
\text { fusca, el } \\
\text { primero más } \\
\text { frecuente }\end{array}$ & $\begin{array}{l}\text { diversas. Tipos } \\
\text { brassi, fusca y } \\
\text { menziesii }\end{array}$ & $\begin{array}{l}\text { menos } \\
\text { frecuentes en } \\
\text { nivel inferior, } \\
\text { tipo brassi más } \\
\text { frecuente. } \\
\text { Dominantes en } \\
\text { nivel superior, } \\
\text { tipo fusca más } \\
\text { frecuente }\end{array}$ \\
\hline Podocarpaceae & $\begin{array}{l}\text { en ocasiones } \\
\text { dominantes. } \\
\text { Diversas } \\
(\mathrm{S}=8)\end{array}$ & presentes & dominantes & presentes $(S=4)$ & $\begin{array}{c}\text { más abundantes } \\
\text { en nivel } \\
\text { superior. }\end{array}$ \\
\hline Araucariaceae & $\begin{array}{c}\text { Araucariacites } \\
\text { australis }\end{array}$ & $\begin{array}{c}\text { Dilwynites sp. } \\
\text { cf. } \mathrm{D} . \\
\text { tuberculatus } \\
\text { W.K. Harris } \\
1965\end{array}$ & $\begin{array}{c}\text { Araucariacifes } \\
\text { australis }\end{array}$ & $\begin{array}{c}\text { Araucariacites } \\
\text { australis }\end{array}$ & $\begin{array}{l}\text { presentes en } \\
\text { nivel inferior, } \\
\text { ausente en el } \\
\text { superior }\end{array}$ \\
\hline Myrtaceae & $\begin{array}{l}\text { en ocasiones } \\
\text { dominantes. }\end{array}$ & ausentes & ausentes & presentes & $\begin{array}{l}\text { abundante en } \\
\text { nivel inferior, } \\
\text { poco frecuente } \\
\text { en el superior }\end{array}$ \\
\hline Proteaceae & $\begin{array}{c}\text { frecuentes y } \\
\text { diversas } \\
(\mathrm{S}=10)\end{array}$ & presentes & presentes & presentes $(S=4)$ & poco frecuentes \\
\hline Pteridofitas & $\begin{array}{c}\text { abundantes y } \\
\text { diversas }\end{array}$ & $\begin{array}{c}\text { Cyatheaceae, } \\
\text { Dicksoniaceae, } \\
\text { Aytoniaceae }\end{array}$ & $\begin{array}{c}\text { Frecuentes. } \\
\text { Dicksoniaceae } \\
\text { Matoniaceae } \\
\text { Lycopodiaceae } \\
\text { y Polypodiaceae }\end{array}$ & presentes & $\begin{array}{c}\text { presentes } \\
(\mathrm{S}=16)\end{array}$ \\
\hline Otros & $\begin{array}{c}\text { Arecaceae, } \\
\text { Araceae, } \\
\text { Aquifoliaceae, } \\
\text { Bombacaceae, } \\
\text { Malpighiace, } \\
\text { Olacaceae, } \\
\text { Sapindaceae } \\
\end{array}$ & $\begin{array}{l}\text { Bombacaceae, } \\
\text { Arecaceae, } \\
\text { Asteraceae }\end{array}$ & $\begin{array}{l}\text { Cupanieidites } \\
\text { reticularis } \\
\text { (Sapindaceae), } \\
\text { Juglandaceae }\end{array}$ & $\begin{array}{l}\text { algas y } \\
\text { microplancton } \\
\text { marino. Índice } \\
\text { de similitud con } \\
\text { FRT } 0,375 . \\
\text { Arecaceae y } \\
\text { Bombacaceae } \\
\end{array}$ & $\begin{array}{c}\text { Arecaceae } \\
\text { dominantes en } \\
\text { el nivel inferior. }\end{array}$ \\
\hline
\end{tabular}

Tabla 2. Comparación cualitativa entre la asociación registrada en la FRT y las de formaciones paleógenas del sur de Argentina continental. S: número de especies. Para la Fm Salto del Macho Cornou et al. (2014) calcularon el índice de similitud con la FRT. 


\begin{tabular}{|c|c|c|c|c|}
\hline Unidad & Fm Río Turbio & Fm Sloggett & Forest Bed & Fm La Meseta \\
\hline $\begin{array}{l}\text { Edad / } \\
\text { Ubicación }\end{array}$ & $\begin{array}{l}\text { Eoceno medio - } \\
\text { Eoceno superior } \\
\text { (Oligoceno?) }\end{array}$ & $\begin{array}{c}\text { Oligoceno } \\
\text { inferior / SE de } \\
\text { Tierra del Fuego }\end{array}$ & $\begin{array}{c}\text { (Mioceno } \\
\text { medio? a } \\
\text { Plioceno infeiror } \\
\text { / Islas Malvinas) }\end{array}$ & $\begin{array}{l}\text { Eoceno medio / Isla } \\
\text { Marambio, Antártida }\end{array}$ \\
\hline Ambiente & marino somero & continental & marino costero & $\begin{array}{c}\text { ambientes } \\
\text { deltaicos, estuáricos y } \\
\text { de plataforma mareal }\end{array}$ \\
\hline Nothofagaceae & $\begin{array}{c}\text { abundantes y } \\
\text { diversas }(\mathrm{S}=9) \\
\text { genralmente } \\
\text { dominantes. } \\
\text { Tipos, fusca y } \\
\text { menziesii }\end{array}$ & $\begin{array}{l}\text { poco diversas, } \\
\text { tipo fusca }\end{array}$ & diversas & $\begin{array}{c}\text { dominantes } 43,8 \% \text {. } \\
\text { Principalmente, tipos } \\
\text { brassi y fusca. Tipo } \\
\text { menziesii presente }\end{array}$ \\
\hline Podocarpaceae & $\begin{array}{c}\text { en ocasiones } \\
\text { dominantes. } \\
\text { Diversas }(S=8)\end{array}$ & $\begin{array}{l}\text { dominantes, } \\
\text { principalmente } \\
\text { Dacrydium sp. }\end{array}$ & $\begin{array}{c}\text { dominantes } 65- \\
66 \%\end{array}$ & presentes \\
\hline Araucariaceae & $\begin{array}{l}\text { Araucariacites } \\
\text { australis }\end{array}$ & presentes & $\begin{array}{l}\text { Araucariacites } \\
\text { australis }\end{array}$ & presentes \\
\hline Myrtaceae & $\begin{array}{l}\text { en ocasiones } \\
\text { dominantes. }\end{array}$ & presentes & presentes & presentes \\
\hline Proteaceae & $\begin{array}{c}\text { frecuentes y } \\
\text { diversas }(S=10)\end{array}$ & $\begin{array}{c}\text { presentes, poco } \\
\text { diversas }\end{array}$ & diversas & presentes \\
\hline Pteridofitas & $\begin{array}{l}\text { abundantes y } \\
\text { diversas }\end{array}$ & $\begin{array}{l}\text { Abundantes. } \\
\text { Lophosoriaceae, } \\
\text { Dicksoniaceae, } \\
\text { Schizaeaeceae. }\end{array}$ & diversas & abundantes \\
\hline Otros & $\begin{array}{c}\text { Arecaceae, } \\
\text { Araceae, } \\
\text { Aquifoliaceae, } \\
\text { Bombacaceae, } \\
\text { Malpighiace, } \\
\text { Olacaceae, } \\
\text { Sapindaceae }\end{array}$ & $\begin{array}{l}\text { Cunoniaceae, } \\
\text { Gunnera. }\end{array}$ & $\begin{array}{l}\text { Arecipites } s p ., \\
\text { Bromeliaceae, } \\
\text { Ilexpollenites } s p .\end{array}$ & $\begin{array}{l}\text { Dilleniaceae, } \\
\text { Myricaceae y } \\
\text { Lauraceae. }\end{array}$ \\
\hline
\end{tabular}

Tabla 3. Comparación cualitativa entre la asociación registrada en la FRT y las de formaciones paleógenas de Tierra del Fuego, Antártida e Islas Malvinas. S: número de especies. 


\begin{tabular}{|c|c|c|c|c|c|c|}
\hline Formación & Río Turbio & $\begin{array}{c}\text { Ligorio } \\
\text { Márquez }\end{array}$ & Agua Fresca & Cheuquemó & $\begin{array}{l}\text { Leña } \\
\text { Dura }\end{array}$ & Loreto \\
\hline $\begin{array}{l}\text { Edad / } \\
\text { Ubicación }\end{array}$ & $\begin{array}{l}\text { Eoceno medio - } \\
\text { Eoceno superior } \\
\text { (Oligoceno?) }\end{array}$ & $\begin{array}{l}\text { Paleoceno } \\
\text { superior / XI } \\
\text { Región, } \\
\text { Chile }\end{array}$ & $\begin{array}{l}\text { Eoceno inferior- } \\
\text { Eoceno medio / } \\
\text { Región de } \\
\text { Magallanes, } \\
\text { Chile }\end{array}$ & $\begin{array}{l}\text { Eoceno / } \\
\text { SSW de la } \\
\text { ciudad de } \\
\text { Osorno, } \\
\text { Chile }\end{array}$ & $\begin{array}{l}\text { Eoceno / } \\
\text { Punta } \\
\text { Arenas, } \\
\text { Chile }\end{array}$ & $\begin{array}{c}\text { Eoceno } \\
\text { superior- } \\
\text { Oligoceno / } \\
\text { Región de } \\
\text { Magallanes, } \\
\text { Chile }\end{array}$ \\
\hline Ambiente & marino somero & fluvial & $\begin{array}{c}\text { marino con } \\
\text { aporte terrígeno }\end{array}$ & continental & marino & $\begin{array}{l}\text { escasa } \\
\text { influencia } \\
\text { marina }\end{array}$ \\
\hline Nothofagaceae & $\begin{array}{c}\text { abundantes y } \\
\text { diversos }(\mathrm{S}=9) \text {, } \\
\text { generalmente } \\
\text { dominantes. } \\
\text { Tipos, fusca y } \\
\text { menziesii }\end{array}$ & ausentes & $\begin{array}{c}35 \% \text { de las } \\
\text { angiospermas. } \\
\text { Decrece hacia el } \\
\text { techo }\end{array}$ & $\begin{array}{c}\text { frecuentes, } \\
\text { diversas } \\
(\mathrm{S}=10) \mathrm{y} \\
\text { dominantes. } \\
\text { Tipos brassi, } \\
\text { fusca y } \\
\text { menziesii }\end{array}$ & $\begin{array}{l}\text { frecuente } \\
\text { s. Tipos } \\
\text { brassi y } \\
\text { fusca }\end{array}$ & $\begin{array}{l}\text { frecuentes. } \\
\text { Nunca } \\
\text { dominantes }\end{array}$ \\
\hline Podocarpaceae & $\begin{array}{c}\text { en ocasiones } \\
\text { dominantes. } \\
\text { Diversos }(S=8)\end{array}$ & $\begin{array}{l}\text { presentes } \\
(\mathrm{S}=2)\end{array}$ & $\begin{array}{c}\text { frecuentes y } \\
\text { diversas }(S=10)\end{array}$ & $\begin{array}{l}\text { presentes } \\
(\mathrm{S}=6), \text { muy } \\
\text { escasas }\end{array}$ & $\begin{array}{l}\text { presentes } \\
\text { y poco } \\
\text { diversas } \\
(\mathrm{S}=3) \\
\end{array}$ & $\begin{array}{l}\text { frecuentes. } \\
\text { En ocasiones } \\
\text { dominantes }\end{array}$ \\
\hline Araucariaceae & $\begin{array}{c}\text { Araucariacites } \\
\text { australis }\end{array}$ & ausentes & presentes & ausentes & ausentes & $\begin{array}{c}\text { frecuentes. } \\
\text { En ocasiones } \\
\text { dominantes } \\
\end{array}$ \\
\hline Myrtaceae & $\begin{array}{l}\text { en ocasiones } \\
\text { dominantes. }\end{array}$ & ausentes & ausentes & $\begin{array}{l}\text { presentes } \\
(\mathrm{S}=2)\end{array}$ & ausentes & presentes \\
\hline Proteaceae & $\begin{array}{c}\text { frecuentes y } \\
\text { diversas }(S=10)\end{array}$ & $\begin{array}{c}\text { presentes. } \\
\text { Proteacidites } \\
\text { parvus }\end{array}$ & $\begin{array}{l}\text { menos diversa. } \\
\text { Decrecen hacia } \\
\text { el techo }\end{array}$ & $\begin{array}{l}\text { presentes } \\
(\mathrm{S}=3)\end{array}$ & $\begin{array}{l}\text { sólo una } \\
\text { sp. indet }\end{array}$ & $\begin{array}{c}\text { Proteacidites } \\
\text { cf. } \\
\text { Symphynemoi } \\
\text { des y } \\
\text { Proteacidites } \\
\text { sp. }\end{array}$ \\
\hline Pteridofitas & $\begin{array}{c}\text { abundantes y } \\
\text { diversas }(S=28)\end{array}$ & $\begin{array}{l}\text { presentes } \\
(\mathrm{S}=6)\end{array}$ & $\begin{array}{c}\text { abundantes. } \\
\text { Principalmente } \\
\text { Schizaeaceae, } \\
\text { Polypodiaceae y } \\
\text { Dicksoniaceae }\end{array}$ & $\begin{array}{l}\text { frecuentes y } \\
\text { diversas } \\
(S=23)\end{array}$ & presentes & $\begin{array}{c}\text { frecuentes. } \\
\text { En ocasiones } \\
\text { dominantes }\end{array}$ \\
\hline Otros & $\begin{array}{c}\text { Arecaceae, } \\
\text { Araceae, } \\
\text { Aquifoliaceae, } \\
\text { Bombacaceae, } \\
\text { Malpighiace, } \\
\text { Olacaceae, } \\
\text { Sapindaceae }\end{array}$ & $\begin{array}{l}\text { dos muestras } \\
\text { estudiadas }\end{array}$ & $\begin{array}{c}\text { Arecaceae. } \\
\text { Índice de } \\
\text { similitud con } \\
\text { FRT bajo }(0,26 \\
\text { y } 0,24)\end{array}$ & $\begin{array}{c}\text { Cupaneidites } \\
\text { major. }\end{array}$ & $\begin{array}{l}\text { Paleomic } \\
\text { ro- } \\
\text { plancton } \\
70-80 \%\end{array}$ & $\begin{array}{l}\text { Tricolpites } \\
\text { reticulatus y } \\
\text { Rhoipites sp. }\end{array}$ \\
\hline
\end{tabular}

Tabla 4. Comparación cualitativa entre la asociación registrada en la FRT y las de formaciones paleógenas del sur de Chile. S: número de especies. Para la Fm Agua Fresca Carrillo-Berumen et al. (2013) calcularon el índice de similitud con la FRT. 


\begin{tabular}{|c|c|c|c|c|}
\hline Formación: & Río Turbio & Cerrajón & $\begin{array}{l}\text { Arenas del Limbo - } \\
\text { San Fernando }\end{array}$ & $\begin{array}{l}\text { Riecito Mache - } \\
\text { Gonzales }\end{array}$ \\
\hline $\begin{array}{l}\text { Edad / } \\
\text { Ubicación }\end{array}$ & $\begin{array}{l}\text { Eoceno medio - } \\
\text { Eoceno superior } \\
\text { (Oligoceno?) }\end{array}$ & $\begin{array}{l}\text { Paleoceno superior / } \\
\text { norte de Colombia }\end{array}$ & $\begin{array}{c}\text { Eoceno medio-bajo / } \\
\text { Andes orientales de } \\
\text { Colombia }\end{array}$ & $\begin{array}{c}\text { Eoceno medio inferior } \\
\text { del noreste de } \\
\text { Colombia }\end{array}$ \\
\hline Ambiente & marino somero & $\begin{array}{c}\text { llanura costera con } \\
\text { influencia estuarina } \\
\text { en la base. Llanura } \\
\text { costera de } \\
\text { influencia fluvial en } \\
\text { la parte superior }\end{array}$ & $\begin{array}{c}\text { planicie fluvial a } \\
\text { llanura costera- } \\
\text { estuario }\end{array}$ & $\begin{array}{l}\text { fluvial a planicie } \\
\text { costera }\end{array}$ \\
\hline Nothofagaceae & $\begin{array}{c}\text { abundantes y } \\
\text { diversos }(\mathrm{S}=9) \text {, } \\
\text { genralmente } \\
\text { dominantes. Tipos, } \\
\text { fusca y menziesii }\end{array}$ & ausentes & $\mathrm{NE}$ & ausentes \\
\hline Podocarpaceae & $\begin{array}{c}\text { en ocasiones } \\
\text { dominantes. } \\
\text { Diversos }(S=8)\end{array}$ & raras & $\mathrm{NE}$ & presentes \\
\hline Araucariaceae & $\begin{array}{c}\text { Araucariacites } \\
\text { australis }\end{array}$ & raras & $\mathrm{NE}$ & ausentes \\
\hline Myrtaceae & $\begin{array}{l}\text { en ocasiones } \\
\text { dominantes. }\end{array}$ & ausentes & $\mathrm{NE}$ & presentes \\
\hline Proteaceae & $\begin{array}{c}\text { frecuentes y } \\
\text { diversas }(S=10)\end{array}$ & presente con dudas & $\mathrm{NE}$ & $\begin{array}{c}\text { decrecen en } \\
\text { diversidad hacia el } \\
\text { tope de la unidad } \\
\end{array}$ \\
\hline Pteridofitas & $\begin{array}{c}\text { abundantes y } \\
\text { diversas }\end{array}$ & $\begin{array}{l}\text { abundantes y } \\
\text { diversas }\end{array}$ & $\begin{array}{c}\text { Foveotricolpites } \\
\text { perforatus entre otras }\end{array}$ & abundantes y diversas \\
\hline Otros & $\begin{array}{c}\text { Arecaceae, } \\
\text { Araceae, } \\
\text { Aquifoliaceae, } \\
\text { Bombacaceae, } \\
\text { Malpighiace, } \\
\text { Olacaceae, } \\
\text { Sapindaceae }\end{array}$ & $\begin{array}{c}\text { dominan Arecaceae } \\
\text { y Araceae }\end{array}$ & $\begin{array}{l}\text { Arecaceae (en } \\
\text { ocasiones } \\
\text { dominantes) } \\
\text { Bombacaceae, } \\
\text { Poaceae, } \\
\text { Malpighiaceae }\end{array}$ & $\begin{array}{c}\text { Arecaceae, } \\
\text { Bombacaceae, } \\
\text { Fabaceae, Araceae, } \\
\text { Poaceae y } \\
\text { Convolvulaceae }\end{array}$ \\
\hline
\end{tabular}

Tabla 5. Comparación cualitativa entre la asociación registrada en la FRT y las de formaciones paleógenas del norte de Colombia. NE: no especificado, S: número de especies. 


\section{Estudios palinológicos complementarios vinculados a esta tesis}

Esta tesis doctoral ha motivado la publicación de tres trabajos. Dos de ellos tratan sobre la morfología polínica de Nothofagaceae y Proteaceae, dos de las principales familias presentes en la FRT (Fernández et al. 2016; Fernández, 2017). El tercero, da a conocer la presencia de la familia Malpighiaceae en dicha unidad, un componente importante desde el punto de vista de las interpretaciones paleoclimáticas por su afinidad meso/megatérmica (Fernández et al. 2012).

Nothofagidites, el morfogénero utilizado para referirse a los granos de polen fósiles afines a Nothofagus, es uno de los componentes más importantes de las palinofloras paleógenas de Patagonia (Palazzesi \& Barreda, 2007). Obtener la mayor información posible de su abundante registro es crucial para comprender la evolución de la flora del extremo sur de Sudamérica (Manos, 1997). Dicho objetivo se abordó desde un enfoque actuopalinológico: se estudió la morfología polínica y estratificación de detalle de las especies sudamericanas actuales del género Nothofagus utilizando microscopía electrónica de barrido (SEM), microscopía electrónica de transmisión (TEM) y microscopía óptica (LM), y se reconstruyeron estados de carácter ancestrales sobre un árbol filogenético de la familia. De esta manera, se comprobó que la morfología polínica permite reconocer sólo los subgéneros de Nothofagus y no sus especies. Se establecieron caracteres polínicos como sinapomorfías de los subgéneros. La reconstrucción de los estados de caracteres del nodo correspondiente al ancestro común del género Nothofagus permitió concluir que la forma ancestral de Nothofagaceae debería haber tenido: diámetro ecuatorial $<40 \mu \mathrm{m}$, contorno circular en la vista polar, microespinas distinguibles en corte óptico, colpos cortos engrosados hacia adentro, y una endexina delgada. Estas características son totalmente consistentes con 
las presentes en Nothofagidites senectus Dettmann \& Playford, la especie fósil más antigua de Nothofagaceae registrada en sedimentos del Campaniano-Maastrichtiano de Gondwana (Fernández et al. 2016).

Otro importante linaje de la asociación esporopolínica de la FRT es la familia Proteaceae. Esta familia se considera un clado relictual de Gondwana debido a su actual distribución disyunta en Australia, África, América Central y del Sur, y en áreas restringidas de Asia e Islas del Pacífico (Johnson \& Briggs, 1963, 1975, 1981; Weston \& Crisp, 1994). La familia tiene un rico registro fósil que se remonta al Cretácico superior. Se conocen macro y micro fósiles en el Hemisferio Sur, incluida la Antártida. Por esta razón, Proteaceae es otra familia clave para comprender la biogeografía de Gondwana (Askin \& Baldoni, 1998; González et al., 2007; Carpenter, 2012). De esta manera, también se estudió la morfología polínica de las especies argentinas de la familia. Fue interesante observar que las especies de las selvas del norte argentino, Roupala meisneri y $R$. montana var. brasiliensis, presentan granos con una escultura simple, típicamente escabrada; mientras que las especies patagónicas muestran una escultura más diversa, nunca escabrada. Estas diferencias morfológicas podrían apoyar la hipótesis de Johnson \& Briggs (1975), que distingue dos grandes grupos de Proteaceae en función de cómo y cuándo se dispersaron a América del Sur. Dichos autores proponen que el grupo tropical, al que pertenecen las especies del género Roupala, llegó desde África en el Turoniano (93-89 Ma), mientras que el grupo del sur habría llegado a la Patagonia a través de la Antártida durante el Paleoceno temprano (66-56 Ma). Por lo tanto, la morfología del polen más simple de las Proteaceae tropicales puede ser el resultado de una larga historia evolutiva independiente en América (Fernández, 2017). La ausencia de especies afines a Roupala en la FRT apoya esta hipótesis. 
Finalmente, en la FRT se destaca la presencia de grupos afines a formas meso/megatérmicas como Arecaceae, Araceae, Aquifoliaceae, Bombacaceae, Olacaceae, Sapindaceae y Malpighiaceae. La presencia de esta última familia en la unidad estudiada se confirmó con el hallazgo de granos de polen (asignados a Perisyncolporites pokornyi) y una impronta foliar (Fernández et al., 2012). Los clados más afines a las formas fósiles de la FRT están actualmente distribuidos en zonas tropicales y subtropicales de Sudamérica, llegando sólo a latitudes de $35^{\circ} \mathrm{S}$. La única especie actual con mayor tolerancia a condiciones extremas, Gallardoa fischeri, que alcanza una latitud de $42^{\circ} \mathrm{S}$, se aparta morfológicamente del material estudiado. Estos registros estarían sustentando previas hipótesis sobre una importante penetración de linajes neotropicales en altas latitudes durante el Eoceno. Por otro lado, la presencia de Malpighiaceae en el extremo más austral de Patagonia sustentaría la hipótesis propuesta por Martin (2002) sobre una posible ruta migratoria de la familia desde Sudamérica hacia Australia a través de Antártida, al menos para las formas perisincolporadas, que son típicamente americanas. Las condiciones climáticas imperantes en el sur de Sudamérica habrían favorecido la ruta migratoria planteada. A comienzos del Neógeno, la aridización y el enfriamiento climático trajeron aparejados la extinción local de géneros tropicales en Patagonia (Barreda \& Palazzesi, 2007), haciendo que algunos de éstos se desplacen hacia latitudes más bajas. En el caso de las Malpighiaceae, el registro polínico durante el Neógeno se localiza hacia el norte y noreste de Argentina (Anzótegui \& Aceñolaza, 2008; Mautino, 2010) lo que podría estar indicando una posible ruta migratoria desde el Eoceno al Mioceno condicionada por el deterioro climático (Fernández et al., 2012).

Es así como esta serie de contribuciones abordaron el estudio de la morfología polínica de grupos actuales presentes en las asociaciones de la FRT, con el objetivo de 
interpretar su registro fósil, ganar resolución en la afinidad botánica del mismo y sumar datos para contrastar hipótesis paleobiogeográficas previamente propuestas. 


\section{Análisis palinológico cuantitativo}

7.1 Análisis de agrupamiento

Se identificaron 116 morfoespecies de polen y esporas provenientes de muestras de afloramiento de la FRT, las cuales fueron asignadas a morfogéneros y morfoespecies aceptadas previamente (Apéndice 1, Tablas 2-4). El análisis de agrupamiento muestra dos grupos principales de muestras estratigráficamente bien delimitados y con una composición esporopolínica diferencial: el grupo A comprende a las muestras eocenas (9-53), con dos subgrupos, A1 (muestras 31-53, Miembro inferior de la FRT) y A2 (muestras 9-28, Miembro superior de la FRT). El grupo B está conformado en su totalidad por muestras oligocenas? (muestras 1-5) (Figuras 11-15).

El grupo A (Eoceno) está dominado por Nothofagus (aprox. 50\%), seguido por esporas de helechos (aprox. 30\%) y por podocarpáceas (aprox. 20\%). Nothofagus es diverso, registrándose los tres subgéneros actuales presentes en Sudamérica, de los cuales Nothofagus subgénero Nothofagus es el más abundante. Otras angiospermas bien representadas son Myrtaceae y Proteaceae. También se registran otras dicotiledóneas (Aquifoliaceae, Bombacaceae, Sapindaceae, Malpighiaceae, Fabaceae, Euphorbiaceae y Malvaceae) y diversas monocotiledóneas (Araceae, Arecaceae, Poaceae, entre otras). Los helechos son diversos, están representados principalmente por Deltoidospora minor (afinidad incierta), Dicksoniaceae (género Lophosoria) y Osmundaceae (Apéndice 1, Figura 1). La familia Podocarpaceae está representada principalmente por Podocarpidites elegans (sin afinidad actual conocida) y formas afines a los géneros Podocarpus, Dacrydium, Lagarostrobos, Dacrycarpus, y Microcachrys (Apéndice 1, Figura 2). 
El subgrupo A1 se caracteriza por la presencia de Nothofagidites fortispinulosus, Corsinipolenites atlantica, Psilatricolporites pachydermatus, Psilatricolporites protrudens, Tricolpites brevicolpis, Triorites subespinosus, Verrucosisporites sp. 1 y V. sp. 2; y por la abundancia de Nothofagidites flemingii (pico máximo en la muestra 45, 38\%), N. nanus (pico máximo en la muestra 50, 27\%), N. acromegacanthus (pico máximo en la muestra 49,36\%), Deltoidospora minor (pico máximo en la muestras 38 y 39, 7\%), Trilites parvalatus (pico máximo en la muestra 53, 6,5\%), Cyatheacidites annulatus (pico máximo en la muestra 34, 5,4\%), Myrtaceidites verrucosus (pico máximo en la muestra 34,12\%), Propylipollis ambiguus (pico máximo en la muestra 35, 6\%), Proteacidites rectus (pico máximo en la muestra 37, 4\%), Psilamonocolpites medius (pico máximo en la muestra 41, 8,5\%) y Bombacacidites isoreticulatus (pico máximo en la muestra 39, 4,8\%) (Apéndice 1, Tabla 3; Figuras 11-15). El subgrupo A2 se divide en dos grupos menores, A2a y A2b (Figuras 11-15), las cuales se diferencian entre sí y del subgrupo A1 principalmente por la presencia de Podocarpidites microreticulatus, Proteacidites obscurus, Rhoipites romboidaliformis y Closterium sp. (A2a); Cingutriletes australis, Matonisporites sp. 1, Foveotriletes sp. 1, Verrucosisporites sp. 3 (A2b); y la abundancia de ciertos grupos de plantas. Por ejemplo, el subgrupo A2a presenta una mayor abundancia de Nothofagidites rocaensis (pico máximo en la muestra 28, 35,7\%), N. dorotensis (pico máximo en la muestra 19, 26,4\%), N. acromegacanthus (pico máximo en la muestra 28, 16\%), Podocarpidites marwikii (pico máximo en la muestra 27, 5\%), Myrtaceidites parvus (pico máximo en la muestra 18, 22\%), Ilexpollenites clifdenensis (pico máximo en la muestra 25, 5\%). Por su parte el subgrupo A2b presenta una mayor abundancia de $N$. americanus (pico máximo en la muestra 10, 14\%) y Trilites parvalatus (pico máximo en la muestra 14, 7\%) (Apéndice 1, Tabla 3). 
Finalmente el grupo B se caracteriza por la presencia de Cyatheacidites minor, Araucariacites australis, Phyllocladidites mawsonii, Podocarpidites elegans, Nothofagidites dorotensis, N. rocaensis, N. americanus y Psilamonocolpites medius y por la abundancia de Nothofagidites rocaensis (pico máximo en la muestra 2, 28,6\%), Araucariacites australis (pico máximo en la muestra 3, 8,3\%) y Cyatheacidites minor (pico máximo en la muestra 1, 10,3\%). Anacolosidites difusa, Myrtaceidites eucalyptoides y cf. Perfotricolpites sp. están presenten sólo en este grupo, aunque no en todas sus muestras (Apéndice 1, Tabla 3; Figuras 11-15).

\subsection{Tendencias principales}

El análisis de los palinogramas permitió reconocer tres tendencias principales: la predominancia de formas arbóreas a lo largo de la FRT, la coincidencia de picos de alta frecuencia de helechos-podocarpáceas y picos de baja frecuencia de mirtáceasproteaceas, y la mayor frecuencia de formas meso/megatérmicas (cálidas) en el Miembro inferior de la FRT.

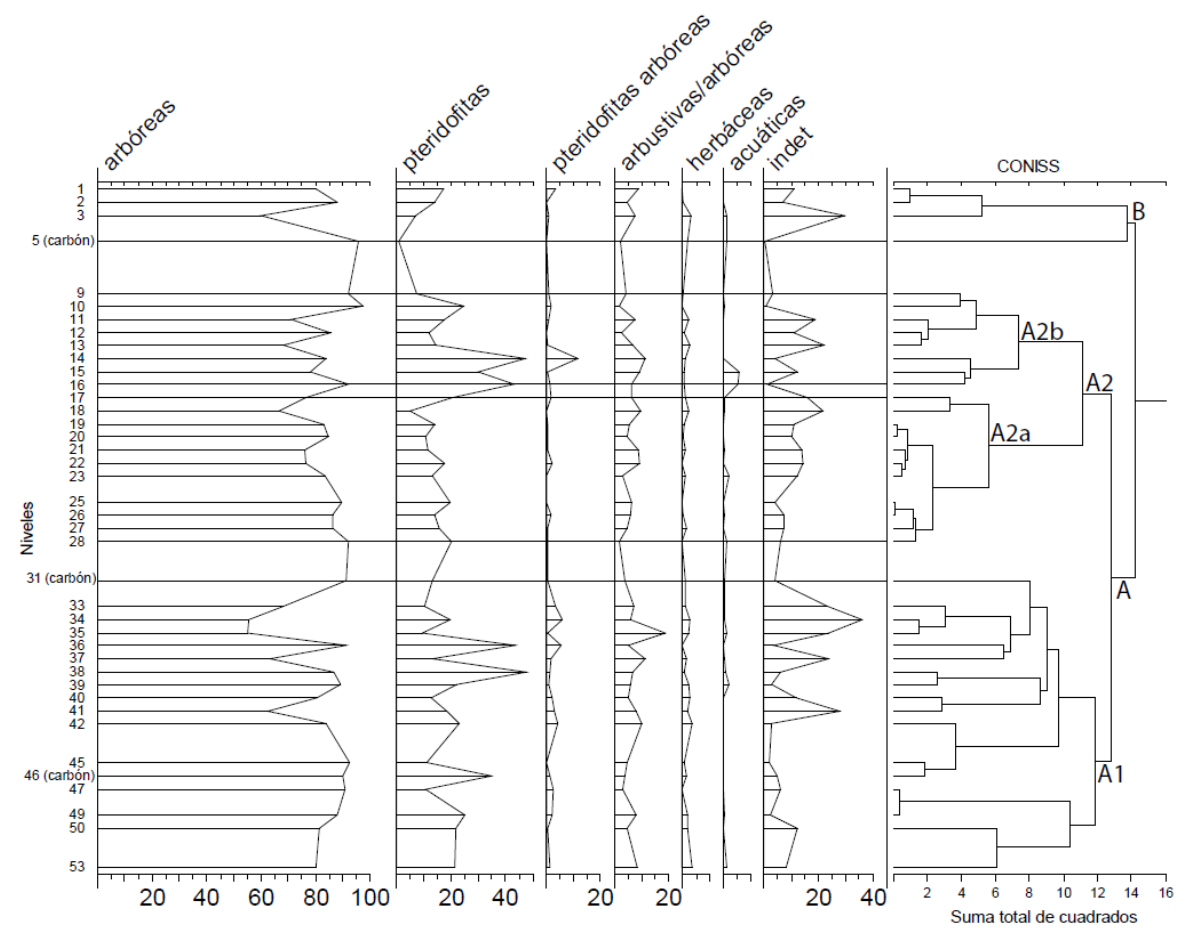

Figura 11. Palinograma de porcentajes de los tipos biológicos principales en la FRT. 
Nothofagaceae, Podocarpaceae, Araucariaceae, Arecaceae y Dicksoniaceae, son linajes casi exclusivamente arbóreos. Los mismos dominan a lo largo de la FRT (Figura 11).

El palinograma de frecuencias de las principales familias de angiospermas, gimnospermas y helechos (Figura 12) muestra que los picos de alta frecuencia de helechos coinciden con picos de alta frecuencia de podocarpáceas (muestras 10, 14, 16, 36, 38 y 46). Así mismo, dichos picos de alta frecuencia coinciden con picos de baja frecuencia de mirtáceas $\mathrm{y} / \mathrm{o}$ proteáceas. También se observa el comportamiento complementario, picos positivos de mirtáceas y/o proteáceas junto a picos negativos de helechos, podocarpáceas y Nothofagus (muestras 18, 35, 37 y 41). En cuanto a las especies de Nothofagus (Nothofagidites), se destaca la presencia de N. fortispinulosus solo en la base de la FRT (muestras 46 y 53); mayor frecuencia de $N$. flemingii en el Miembro inferior (muestras 31, 46 y 47); mayor frecuencia de $N$. americanus en el Miembro superior (muestras 10, 11 y 12); $N$. dorotensis, $N$. rocaensis y $N$. saraensis con frecuencias altas a lo largo de toda la secuencia (Figura 13).

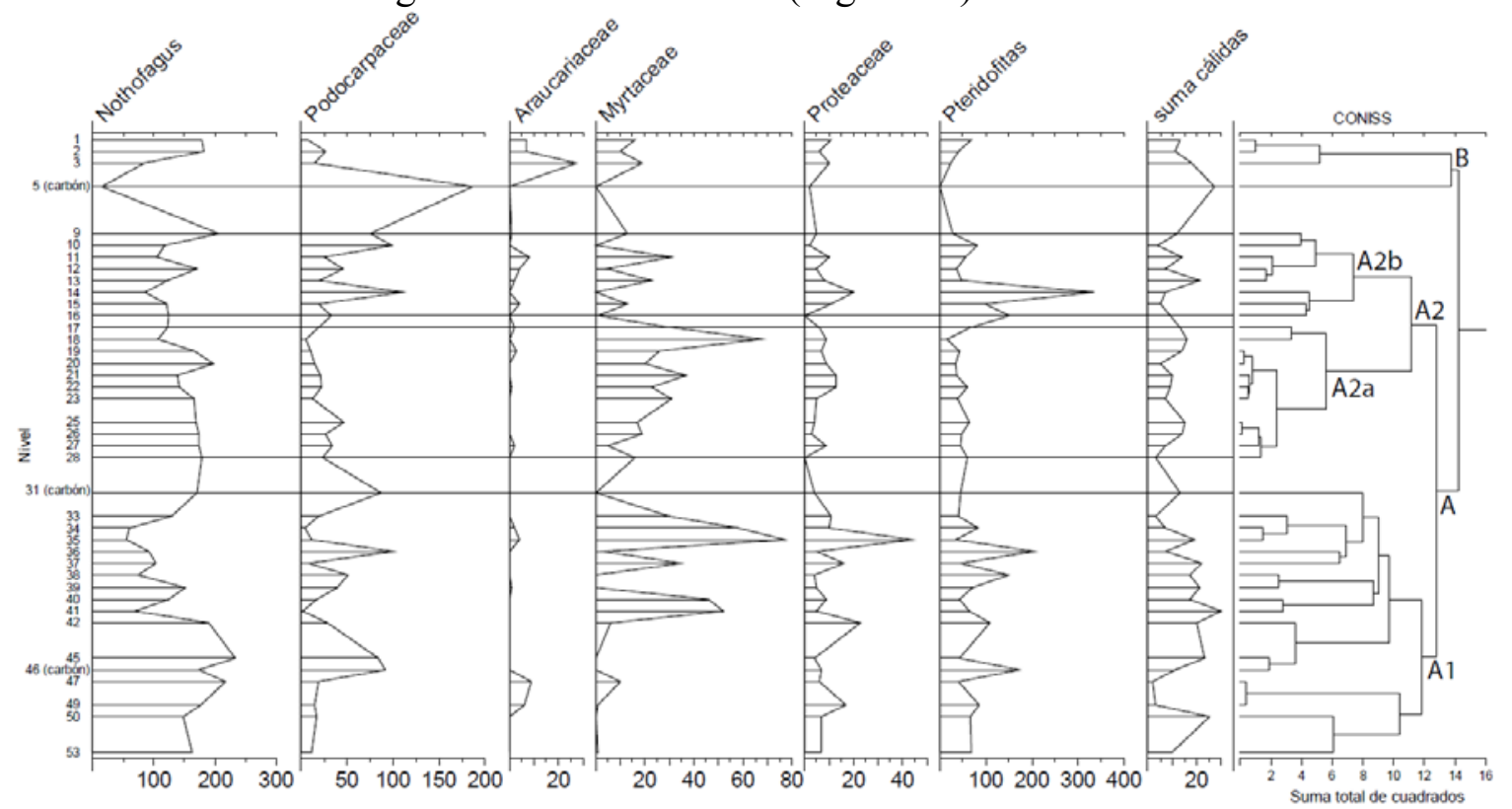

Figura 12. Palinograma de frecuencias absolutas de los linajes principales. 







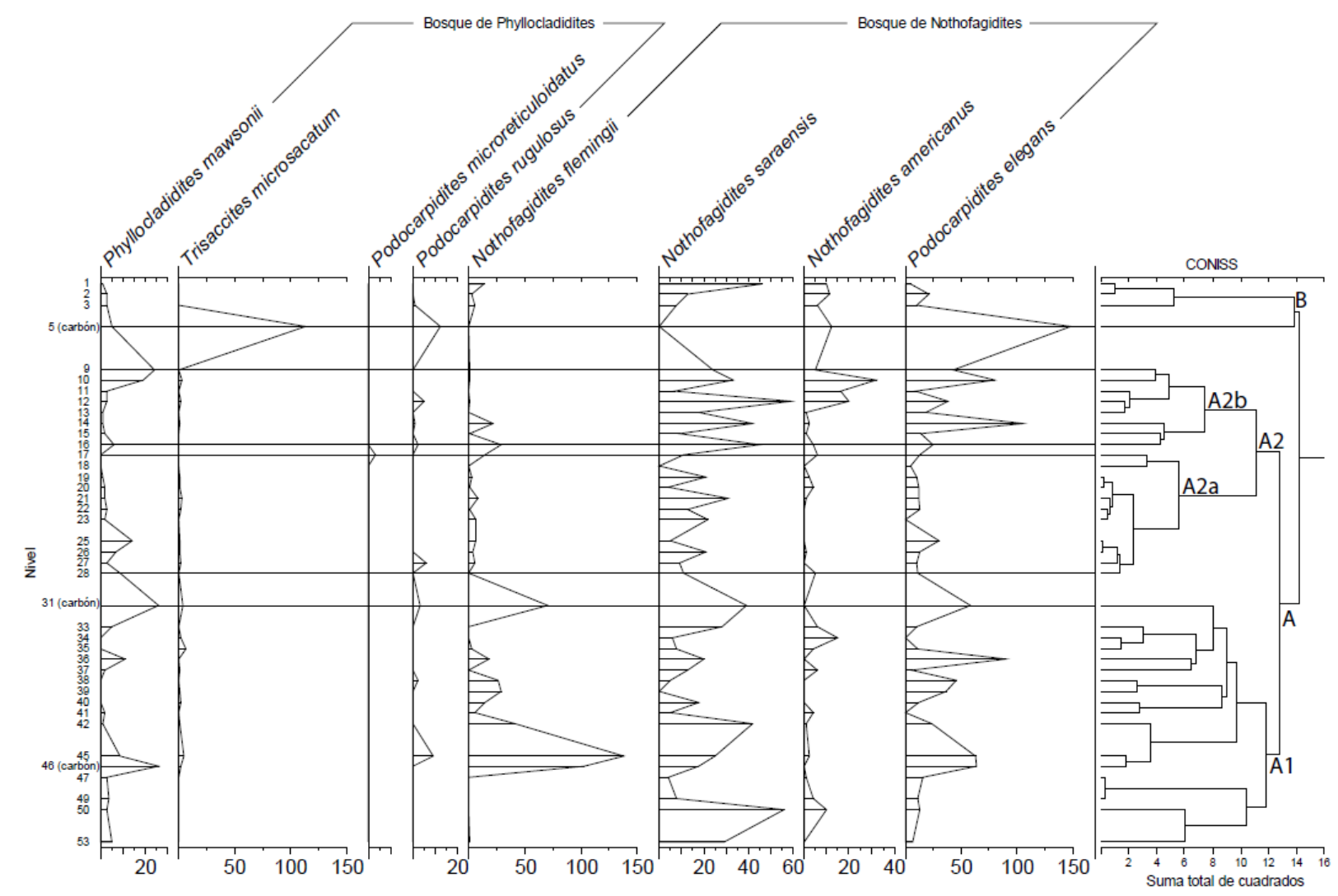

Figura 14. Frecuencias absolutas de los componentes del Bosque de Phyllocladidites y el de Nothofagidites sensu Romero (1977).

Se comparó las frecuencias absolutas de los componentes del bosque de Phyllocladidites y el de Nothofagidites definidos por Romero (1977). El bosque de Nothofagidites presenta mayores frecuencias absolutas a lo largo de toda la columna. Se observan tres variantes, que corresponden a los 3 carbones muestreados (muestras 5, 31, 46). En la muestra 5, dominan Podocarpidites elegans y Trisaccites microsacatum, el primero componente del Bosque de Nothofagidites y el segundo de el de Phyllocladidites. En las muestra 31y 46, se registran picos de Phyllocladidites mawsonii, pero los componentes del Bosque de Nothofagidites siguen siendo mayoritarios (Figura 14). 
El palinograma de frecuencia de formas cálidas muestra que las mismas se encuentran a lo largo de toda la FRT, pero son más frecuentes en el Miembro inferior, con excepción de Ilexpollenites clifdenensis, que presenta frecuencias relativamente altas en el Miembro superior (Figura 15).

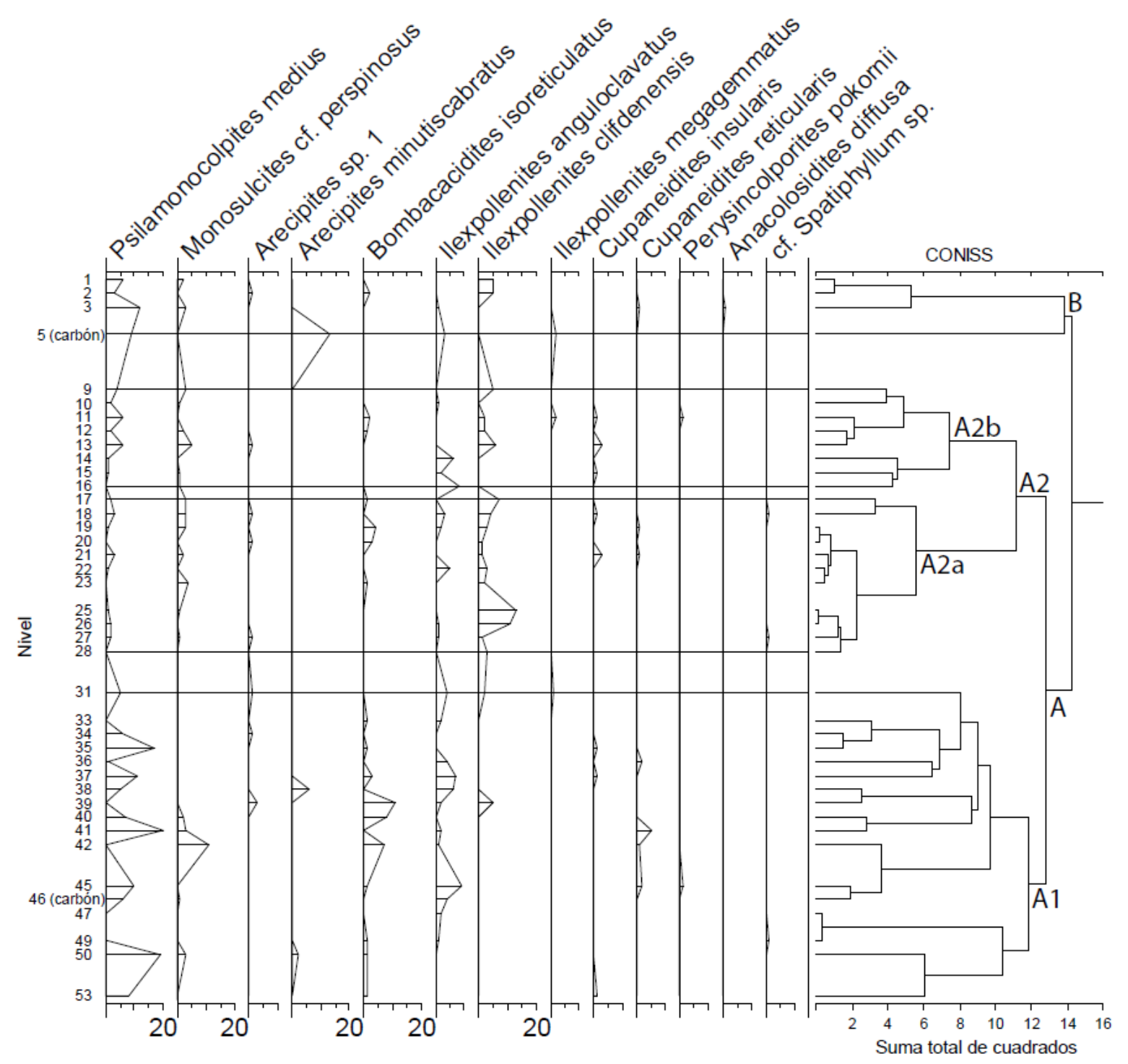

Figura 15. Palinograma de frecuencias absolutas de las especies vinculadas a climas cálidos. 
7.3 Resultados de rarefacción

El análisis de rarefacción (Figura 16; Apéndice 1, Tabla 5) indica que las asociaciones polínicas de muestras seleccionadas representando al Miembro inferior de la FRT (Subgrupo A1) son más diversas que aquellas del Miembro superior (Subgrupo A2), con dos excepciones: las muestras 15 y 47 . La primera pertenece al Miembro superior y presenta una diversidad relativamente alta (rarefacción a 300 especímenes, S = 45). La segunda pertenece al Miembro inferior y presenta una diversidad relativamente baja (rarefacción a 300 especímenes, $\mathrm{S}=30$ ), encontrándose hiperdominada por Nothofagidites acromegacanthus (32,2\%). Entre las muestras eocenas (grupo A), el mayor valor de diversidad lo presenta la muestra 37 (subgrupo A1, rarefacción a 300 especímenes, $\mathrm{S}=49$ ), mientras que el menor valor de diversidad lo presenta la muestra 15 (subgrupo A2b, rarefacción a 300 especímenes, $\mathrm{S}=27$ ). En el caso de las muestras oligocenas? (grupo B), la muestra 1 presenta un valor moderado de diversidad (rarefacción a 300 especímenes, $\mathrm{S}=37$ ), mientras que la muestra 3 presenta la mayor diversidad del análisis (rarefacción a 300 especímenes, $\mathrm{S}=52$ ). Las muestras con altos valores de diversidad $(19,21,33$ y 37) presentan frecuencias relativamente bajas de Nothofagus y helechos.

Se calculó el promedio de la diversidad polínica de todas las muestras rarificado a $100(\mathrm{~S}=25), 115(\mathrm{~S}=27)$ y $150(\mathrm{~S}=30)$ especímenes para su comparación gráfica con la diversidad de otras asociaciones paleógenas del norte de Sudamérica, seleccionadas por ser las únicas sobre las cuales se realizaron análisis de diversidad. Dichas unidades son la Fm Cerrajón (Paleoceno tardío del norte de Colombia, rarefacción a 150 especímenes, S = 20, Jaramillo et al., 2007); Fm Arenas del Limbo - San Fernando (Eoceno Medio-Bajo de los Andes orientales de Colombia, rarefacción a 115 
especímenes, S = 32, Jaramillo \& Dilcher, 2000); y Fm Riecito Mache - Gonzales (Eoceno Medio Inferior del noreste de Colombia, rarefacción a 100 especímenes, S = 31,5, Jaramillo et al., 2010) (Figura 16). La FRT presenta una diversidad promedio mayor que la de la Fm Carrajón, y aproximadamente un 20\% menor que la de las formaciones Arenas del Limbo - San Fernando y Fm Riecito Mache - Gonzales.



Figura 16. Curvas de rarefacción de 15 muestras seleccionadas. Azul: muestras del Miembro superior; rojo: muestras del Miembro inferior; verde: muestras del Subgrupo A2a; fucsia: muestras del grupo B. Estrellas: valores medios de diversidad de la FRT rarificados a 100, 115 y 150 especímenes. A: diversidad media rarificada a 115 especímenes de la Fm Arenas del Limbo - San Fernando (Eoceno medio-bajo de los Andes orientales de Colombia); C: diversidad media rarificada a 150 especímenes Fm Cerrajón (Paleoceno superior del norte de Colombia); R: diversidad media rarificada a 100 especímenes Fm Riecito Mache - Gonzales (Eoceno medio inferior del noreste de Colombia). 


\section{Discusión y conclusiones}

Las asociaciones de esporomorfos recuperadas en la FRT presentan una gran abundancia y diversidad. En general están dominadas por especies de Nothofagidites, Podocarpidites y Myrtaceidites. Las esporas de helechos son frecuentes, al igual que las cutículas de vegetales que están presentes a lo largo de toda la unidad, con buena preservación. Todas las muestras (con una excepción, muestra 5) presentan dinoquistes, siendo en general más frecuentes los Gonyaulacoideos en detrimento de los Peridinoideos. Se contaron un total de 22.805 especímenes de esporomorfos y 9.486 especímenes de paleomicroplancton. Los primeros se agruparon en 116 morfoespecies, de las cuales 77 se reconocieron por primera vez para la FRT, 3 son nuevas para la ciencia, 4 representan el primer registro para Sudamérica y una lo es para Argentina.

La abundancia de paleomicroplancton, principalmente de dinoquistes apoya la reconstrucción de un ambiente de depositación marino somero propuesta por Malumián \& Caramés (1997). Estos autores distinguen el relleno de un valle inciso inicial (Miembro Inferior) de la sedimentación en ambientes marinos y marginales posteriores a la colmatación del valle (Miembro Superior).

Los dos miembros de la FRT fueron reconocidos por su contenido palinoflorístico mediante un análisis de agrupamiento. Se observó también un tercer grupo de muestras en el tope de la secuencia que presenta una asociación particular, con formas cálidas y alta diversidad, las cuales podrían ser de edad Oligocena, coincidiendo con la propuesta de Fosdick et al. (2015).

Se llevó a cabo el primer análisis de diversidad para la FRT, mediante la confección de curvas de rarefacción. Su análisis indica que las asociaciones polínicas del Miembro Inferior son más diversas que aquellas del Miembro Superior (aunque se 
observan excepciones); la muestra más diversa proviene de un nivel del tope de la secuencia (Oligoceno?). Esto sugiere que a lo largo de la FRT se habría reducido la diversidad, pero no de manera drástica. Las muestras oligocenas? no corresponderían a un período de deterioro ambiental y empobrecimiento de la diversidad, quizás coincidiendo con las estimaciones de edad de Fosdick et al. (2015) para los términos superiores de la formación. Los datos sugieren también que los cambios en la diversidad son de una magnitud tal que un conteo de 200 a 300 individuos excluyendo a las especies hiperdominantes podría mejorar la resolución del análisis de diversidad.

Se confirmó la presencia de un bioma de bosque, diverso y con componentes meso/megatérmicos coincidiendo con las reconstrucciones previas realizadas en base a estudios paleopalinológicos (Archangelsky, 1972; Archangelsky \& Romero, 1974, Romero, 1973, 1977, 1978; Romero \& Zamaloa, 1985) y de macrofósiles de plantas (Panti, 2010; Pujana, 2008). La fisonomía de bosque se evidencia en la predominancia de los linajes de hábito arbóreo (Nothofagaceae, Podocarpaceae, Araucariaceae, Arecaceae y Dicksoniaceae) a lo largo de toda la unidad. Todas las muestras presentan una diversidad relativamente alta. Las comparaciones realizadas con otras asociaciones eocenas del norte de Sudamérica muestran que la FRT es un 20\% menos diversa, lo que podría evidenciar un gradiente latitudinal de diversidad, con su máximo en la región ecuatorial, disminuyendo hacia el sur, como proponen Jaramillo \& Cárdenas (2013).

Algunas de las formas identificadas en la FRT tienen una afinidad desconocida o incierta con grupos de plantas modernas. Ciertos taxones probablemente hayan cambiado sus rangos ecológicos. También cabe considerar que se desconoce la importancia de la producción relativa de polen para todos los casos, así como el transporte y preservación diferencial de palinomorfos en los componentes de la flora en 
el Paleógeno. Sin embargo, la palinología de la mayoría de los grupos presentes en la FRT está ampliamente estudiada y su afinidad botánica se conoce con buena resolución.

Siguiendo los lineamientos paleoecológicos para asociaciones boscosas del paleógeno de Patagonia de Romero (1977), Melendi et al. (2003) y Volkheimer (2011), puede concluirse que el bioma registrado en la FRT corresponde a un bosque dominado por Nothofagus, acompañado por Podocarpaceae, Araucariaceae, Dicksoniaceae y Arecaceae, con un estrato arbóreo de menor porte o arbustivo conformado por Myrtaceae, Proteaceae y Aquifoliaceae, y un sotobosque conformado por gran diversidad de pteridofitas. Epífitas como Loranthaceae, Misodendraceae, Sapindaceae y Polypodiaceae también estaban presentes. En cuanto a las relaciones entre helechospodocarpáceas y mirtáceas-proteáceas descriptas anteriormente, los primeros son indicadores de alta humedad (Romero, 1977), mientras que los segundos lo son de condiciones de menor humedad (Thornhill y Macphail, 2012). Esto es apoyado por el registro de niveles complementarios, con picos positivos de mirtáceas y/o proteáceas en detrimento de helechos, podocarpáceas y Nothofagus. Esta tendencia fue señalada por Romero (1977) como una relación antagónica de Nothofagus con respecto a los otros grupos de angiospermas, que podría explicarse por competencia. Dichas alternancias pueden mostrar cambios cíclicos en la composición del bosque mixto relacionados con la disponibilidad de agua.

En coincidencia con las conclusiones de Fasola (1969) y Romero (1977), no se observa un comportamiento opuesto entre Nothofagus y Podocarpaceae. La predominancia del Bosque de Nothofagidites sobre el de Phyllocladidites (sensu Romero, 1977) en las muestras estudiadas indicaría que el primero se encontraba más próximo al depocentro, en las tierras bajas, y el segundo tierra adentro, a mayor altitud. 
Dentro del componente dominante del bosque, Nothofagidites (Nothofagus), se destaca la presencia de $N$. fortispinulosus solo en la base de la FRT, la mayor frecuencia de $N$. flemingii en el Miembro Inferior, la mayor frecuencia de $N$. americanus en el Miembro Superior y $N$. dorotensis, $N$. rocaensis y $N$. saraensis con frecuencias altas a lo largo de toda la secuencia. Estas tendencias concuerdan con las descriptas por Romero (1977), aunque en dicha contribución N. fortispinulosus está ausente a lo largo de todo el perfil. $N$. dorotensis merece un análisis particular, pudiendo ser una especie clave en las interpretaciones ambientales del Paleógeno de Patagonia. Esta es la única morfoespecie sudamericana asignada al tipo polínico brassii a, al que pertenecen todas las especies actuales de Nothofagus subgénero Brassospora (Dettmann et al., 1990). De acuerdo con Couper (1960) el predominio del polen del tipo brassii por sobre el tipo fusca indica condiciones algo más cálidas. Actualmente, el subgénero Brassospora crece en Nueva Caledonia (600 - $900 \mathrm{msnm})$ y en Nueva Guinea (2.400 msnm), en áreas de lluvias moderadas a altas; en un clima de humedad constante y más cálido en relación al clima donde se desarrollan los subgéneros productores de polen tipo fusca (Hos, 1975). Por otra parte, Fernández et al. (2016) mediante el mapeo de caracteres polínicos del género Nothofagus en un árbol filogenético bien soportado, concluyeron que las sinapomorfías polínicas del subgénero Brassospora son: presencia de contorno en vista polar en forma de estrella y endexina relativamente gruesa (relación de espesor ectenxina / endexina 1:2). Estos rasgos no se observan en Nothofagidites dorotensis. Por ello, su afinidad al subgénero Brassospora debe ser revisada. El estudio de estas formas fósiles utilizando MET permitiría comprender la naturaleza de la estratificación de la exina y someter a prueba la presencia del subgénero Brassospora en Sudamérica.

Entre las gimnospermas, Podocarpus es en la región austral el componente principal de la selva templado-fría. Podocarpidites elegans, la especie más abundante 
en las asociaciones recuperadas, se asigna al género Podocarpus pero no se asemeja a ninguna de las especies vivientes (Romero, 1977). Polen asignable a Trisaccites microsaccatum fue encontrado por Gamerro (1965) en conos de la gimnosperma de afinidad desconocida Trisacocladus ligrensis junto a hojas en conexión orgánica (Formación Baqueró, Cretácico Inferior, Provincia de Santa Cruz). Microcachryidites antarcticus se ha relacionado con la podocarpácea viviente Microcachrys tetragona endémica de Tasmania y Phyllocladidiles mawsonii se relaciona comúnmente con la especie viviente también de Tasmania Dacrydium franklinii (Cooksoon \& Cranwell, 1967). Dichas especies crecen actualmente en bosques templados húmedos en partes bajas del relieve. Araucariacites australis, la única especie representante de Araucariaceae en este estudio, tendría requisitos más amplios. En la actualidad, los bosques de Araucaria araucana y Nothofagus pumilio constituyen una comunidad clímax en la Provincia Subantártica (Cabrera, 1976).

Entre las angiospermas se destacan componentes meso/megatérmicos por su abundancia y diversidad. Algunos de ellos están presentes en otras unidades paleógenas de Patagonia e Islas Malvinas, pero en menor frecuencia y riqueza específica. La más frecuente es la familia Arecaceae (Fm Ligorio Márquez, Fm Salto del Macho, Fm San Julián, Forest Bed, Fm Agua Fresca) seguida por registros puntuales de Bombacaceae (Fm Ligorio Márquez, Fm Salto del Macho), Sapindaceae (Fm Huitrera, Cheuquemó) y Aquifoliaceae (Forest Bed). En la FRT a dichas familias se les suma Malpighiaceae, Olacaceae y Araceae (asignación que requiere confirmación). La familia Arecaceae, (Psilamonocolpites medius, Arecipites sp. 1, A. minutiscabratus y Monosulcites cf. perspinosus), actualmente está ampliamente distribuidas en regiones tropicales a templadas, pero principalmente en regiones cálidas (Harley, 1996). Aquifoliaceae (Ilexpollenites anguloclavatus, I. clifdenensis e I. megagemmatus) es una familia de 
arbustos y árboles propias de regiones subtropicales y tropicales, principalmente de América. Bombacaceae (Bombacacidites isoreticulatus) es una familia de árboles pantropical. Las Sapindaceae (Cupameidites relicularis y $C$. insularis) crecen en ambientes húmedos, el morfogénero Cupanieidites es afín a Cupania, un género principalmente neotropical con un representante en Argentina, Cupania vernalis, que pudo haber estado representado por lianas en el Eoceno y Oligoceno (Frederiksen, 1985). Malpighiaceae (Perysincolporites pokornii) es una familia de árboles, arbustos y lianas. Su principal centro de diversidad se encuentra en la zona tropical de Sudamérica, región propuesta como el centro de origen de la familia (Anderson, 2004). Olacaceae (Anacolosidites diffusa) está representada por árboles, arbustos y lianas, algunas de las cuales parasitan las raíces de sus hospedadores; habitan regiones tropicales y subtropicales de todo el mundo.

Las Gunneraceae (Tricolpites reticulatus) actualmente presentan una distribución relíctica disyunta, principalmente en el hemisferio sur, con escasos representantes en el hemisferio norte. Crecen en hábitats, húmedos o anegados, desde el nivel del mar a alturas superiores a los $3.000 \mathrm{~m}$, siendo en muchos casos pioneras. Presentan una amplia tolerancia térmica. Tricolpites reticulatus muestra una gran similitud con Gunnera chilensis y G. masajuerae (Romero \& Castro, 1986). Dentro del bosque de Nothofagus actual, Roig et al. (1985) distinguen una asociación de gran desarrollo denominada Gunnero-Nothofagetum antarcticae que representa el estrato más bajo de dicho bosque.

Loranthaceae y Misodendraceae pertenecen al Orden Santalales, cuyos miembros son parásitos (Vidal-Russell \& Nickrent, 2008). Las Loranthaceae se habrían originado hace 81 Ma siendo sus formas basales parásitas de raíces. Esta familia habría 
adquirido el parasitismo aéreo hace 28 Ma (Vidal-Russell \& Nickrent, 2008). Actualmente comprende plantas arbustivas parásitas o hemiparasíticas, no específicas, aunque se ha registrado una asociación más recurrente con dicotiledóneas arbóreas (Abbiatti, 1946). Pese a ser una familia zoófila produce una cantidad sorprendentemente grande de polen (Frederiksen, 1985). Entre las formas fósiles afines a esta familia, Gothanipollis bassensis presenta una gran similitud morfológica con la especie actual Ligaria cuneifolia, la cual es epífita, hemiparásita, con distribución en Argentina, Chile, Brasil y Uruguay. Gothanipollis sp. 1 es afín a Struthanthus acuminatus, epífita, hemiparásita, distribuida en América. Por su parte, Misodendraceae (Compositoipollenites sp. 1) es una familia monotípica representada por Misodendron, endémica del sur de Chile y Argentina. Este género es holoporásito exclusivo de Nothofagus, ambos géneros habrían coevolucionado desde la divergencia de Misodendron hace 80 Ma (Vidal-Russell y Nickrent, 2008). En el presente estudio no hay evidencia de covariación en la frecuencia de este posible par de coacción hospedador-parásito.

Dicksoniaceae (Cyatheacidites annulatus, Matonisporites sp.1) actualmente comprende tres géneros de helechos arborescentes, de los cuales dos se encuentran representados en Argentina: Dicksonia con un representante en Misiones ( $D$. sellowiana), y Lophosoria con un representante en Neuquén y Río Negro ( $L$. quadripinnata) (Zuloaga \& Belgrano, 2008). La mayoría de las especies de Polypodiaceae (Polypodiisporites perverrucatus, Polypodiisporites speciosus) actuales son epifítas que crecen en regiones cálidas y húmedas, aunque se pueden encontrar en áreas de alta montaña. Los representantes de la familia Lycopodiaceae (Concavosporites sp., Retitriletes austroclavatidites) son plantas terrestres o epífitas, y se desarrollan principalmente en bosques montanos de regiones tropicales. Frederiksen 
(1985) considera a las pteridofinas como el componente principal del sotobosque durante el Paleoceno-Eoceno.

La presencia de esporas de la familia de algas verdes Zygnemataceae (Catinipollis geiseltalensis, muestra 15) es indicadora de hábitats de agua dulce estancados, poco profundos, relativamente mesotróficos, que sufrirían rápidos aumentos de temperatura. Su registro en los sedimentos indica autoctonía (Van Geel, 1976).

Es así como, en base a los posibles requerimientos de los elementos de las asociaciones encontradas en FRT, se puede concluir que el bosque se habría desarrollado en condición de clima templado-cálido, húmedo y marítimo, sin extremos de temperatura y con fluctuaciones menores en el régimen de precipitaciones. Lo que concuerda con la reconstrucción propuesta por Romero (1977).

La FRT conserva una flora que combinó elementos neotropicales (Arecaceae, Araceae, Aquifoliaceae, Bombacaceae, Sapindaceae, Malpighiaceae, Olacaceae), gondwanicos de clima frío (Nothofagus, Podocarpaceae, Myrtaceae, Proteaceae) y endémicos del bosque chaqueño (Prosopis) (Jaramillo \& Cárdenas, 2013). Romero (1978, 1986, 1993) denominó a esta asociación Paleoflora Mixta. Esta Paleoflora se registra desde el Paleoceno en las latitudes más australes $\left(\sim 44^{\circ} \mathrm{S}\right)$ de la Patagonia y en el Eoceno medio se habría expandido hacia el norte para ocupar toda la región al sur de $\sim 24^{\circ} \mathrm{S}$ (Romero, 1986). Se desarrolló bajo un clima templado a cálido (temperatura media anual $18 \pm 1,5^{\circ} \mathrm{C}$, Panti, 2010). La variación latitudinal de la temperatura media anual era menor a la actual (Ecuador a Río Turbio, $19^{\circ} \mathrm{C}$ vs $25^{\circ} \mathrm{C}$ ). La precipitación media anual era elevada $(1000-1800 \mathrm{~mm})$. Al igual que en la actualidad, la insolación era baja (1606 langleys), con la misma variación en la cantidad de horas de luz del día a lo largo del año (verano=18 hs, invierno=8 hs) (Jaramillo \& Cárdenas, 2013). De esta 
manera, la Paleoflora Mixta se desarrolló en condiciones físicas únicas, sin análogos modernos.

Entre los factores climáticos antes mencionadas, la temperatura media anual es la que varía a lo largo de la FRT (Zachos et al., 2001). De acuerdo a la curva propuesta por Zachos et al. (2001) desde el Paleoceno medio hasta el Eoceno temprano existió una tendencia hacia un pronunciado aumento de las paleotemperaturas globales, alcanzando su pico hace aproximadamente 52-50 Ma, aumento conocido como "el óptimo climático del Eoceno temprano" (EEOC, sigla en inglés). Hasta ese momento, las biotas del sur de Sudamérica, Australia y Nueva Zelanda permanecían conectadas a través de la Antártida (Palazzesi \& Barreda, 2007). En consecuencia, las biotas de estas regiones muestran una fuerte relación histórica. Esto se evidencia en la gran cantidad de especies compartidas entre las floras Paleógenas de dichas regiones, entre las que se destacan miembros de las familias Proteaceae, Myrtaceae, Nothofagaceae y Podocarpaceae (Drinnan \& Crane, 1990).

Luego del EEOC se produjo una tendencia general hacia condiciones más frías, iniciada en el Eoceno medio temprano (50 a $48 \mathrm{Ma}$ ) y que alcanzaría su clímax en el límite Eoceno/Oligoceno (glaciación del Oligoceno temprano) (Zachos et al. 2001). Estos cambios fueron determinados por importantes factores externos particularmente ligados a la fragmentación del Gondwana (la separación de Antártida de Australia y Sudamérica) con el consiguiente aislamiento térmico de Antártida. En este lapso de tiempo se habrían depositado los sedimentso de la FRT. Estas condiciones relativamente frías habrían sido el mayor factor de selección de la flora y habrían causado la dominancia del género Nothofagus (Romero, 1977). En esta tesis se puso a 
prueba la hipótesis de que dicha disminución de la temperatura media anual habría determinado también una progresiva disminución de la diversidad florística.

De esta manera, la hipótesis de trabajo se sometió a prueba desde dos puntos de vista, composicional y de la diversidad palinoflorística, siendo aceptada en parte. Según los análisis realizados, a lo largo de toda la FRT las formas cálidas están presentes y la diversidad florística es alta. Sin embargo, las formas cálidas son más abundantes y la diversidad es ligeramente mayor en el Miembro Inferior. Esto sugiere que el lapso abarcado por las muestras eocenas de la FRT se correspondería con una disminución de la temperatura media anual, pero no se alcanzarían niveles de marcado empobrecimiento ambiental y de la diversidad florística.

La Formación Río Turbio encierra una flora única, testimonio de un bioma extinto, pero clave para entender las leyes naturales que actualmente relacionan a la vegetación con su entorno. Esta tesis es un aporte en nuestro intento de conocer y comprender este importante capítulo de la historia de la flora del sur de Sudamérica. 


\section{Bibliografía}

Abbiatti, D. 1946. Las eriocaulaceas argentinas. Universidad de la Plata, Instituto del Museo.

Alley, N.F. \& Beecroft, A. 1993. Foraminiferal and palynological evidence from the Pidinga Formation and its bearing on Eocene sea level events and palaeochannel activity, eastern Eucla Basin, South Australia. Memoir of the Association of Australasian Palaeontologists, 15: 375-393.

Alley, N.F. \& Benbow, M. C. 1989. Late Eocene palynofloras from the Pidinga Formation SADME Ooldea Range 6, eastern Eucla Basin. Geological Survey of South Australia Quarterly Geological Notes, 111: 2-12.

Alley, N.F. \& Broadbridge, L. M. 1992. Middle Eocene palynofloras from the One Tree Hill area, St Vincent Basin, South Australia. Alcheringa, 16(3): 241-267.

Ancibor, E. 1990. Anatomía de las especies argentinas de Podostemum Mich. Parodiana, 6: 31-47.

Anderson, W.R. 2004. Malpighiaceae (Malpighia family). Flowering plants of the neotropics, 229-232.

Anzótegui, L.M. \& Aceñolaza, P.G. 2008. Macrofloristic assemblage of the Paraná Formation (Middle-Upper Miocene) in Entre Ríos (Argentina). Neues Jahrbuch für Geologie und Paläontologie-Abhandlungen, 248(2): 159-170.

Anzótegui, L.M. \& Acevedo, T.L. 1995. Revisión de Ilexpollenites Thiergart y una nueva especie del Plioceno superior (Formación Ituzaingó) de Corrientes, Argentina. VI Congreso Argentino de Paleontología y Bioestratigrafía, Trelew, Argentina. Actas: 15-21. 
Archangelsky, S. 1968. On the genus Tomaxellia (Coniferae) from the Lower Cretaceous of Patagonia (Argentina) and its male and female cones. Botanical Journal of the Linnean Society, 61(384):153-165.

Archangelsky, S. 1972. Esporas de la Formación Río Turbio Eoceno, Provincia de Santa Cruz. Museo, Facultad de Ciencias Naturales, Universidad Nacional.

Archangelsky, S. 1973. Palinología del Paleoceno de Chubut. 1. Descripciones sistemáticas. Ameghiniana, 10: 339-399.

Archangelsky, S. 1976. Palinología del Paleoceno de Chubut. II. Diagramas polínicos. Ameghiniana, 13: 43-55.

Archangelsky, S. 1996. Aspects of Gondwana paleobotany: gymnosperms of the Paleozoic-Mesozoic transition. Review of Palaeobotany and Palynology, 90(34): $287-302$.

Archangelsky, S. \& Fasola, A. 1971. Algunos elementos del paleomicroplancton del Terciario inferior de Patagonia Argentina y Chile. Museo, Facultad de Ciencias Naturales, Universidad Nacional.

Archangelsky, S., Petriella, B. \& Romero, E. J. 1969. Nota sobre el bosque petrificado del Cerro Bororó (Terciario inferior), provincia de Chubut. Revista de la Asociación Paleontológica Argentina, 6.

Archangelsky, S. \& Romero, E. J. 1974a. Polen de gimnospermas (coníferas) del Cretácico superior y Paleoceno de Patagonia. Ameghiniana, 11 (3): 217-236.

Archangelsky, S. \& Romero, E.J. 1974b. Los registros más antiguos del polen de Nothofagus (Fagaceas) de Patagonia (Argentina y Chile). Boletín de la Sociedad de Botánica de México, 33: 13-30. 
Archangelsky, S. \& Zamaloa, M. del, C. 1986. Nuevas descripciones palinológicas de las formaciones Salamanca y Bororó, Paleoceno de Chubut (República Argentina). Ameghiniana, 23.

Arguijo, M.H. \& Romero, E.J. 1981. Análisis Bioestratigráfico de Formaciones portadoras de Tafofloras Terciarias. VIII Congreso Geológico Argentino, San Luis, Argentina. Actas IV: 691-717.

Askin, R.A. 1990a. Campanian to Paleocene spore and pollen assemblages of Seymour Island, Antarctica. Review of Palaeobotany and Palynology, 65(1-4): 105-113.

Askin, R.A. \& Baldoni, A.M. 1998. The Santonian through Paleogene record of Proteaceae in the southern South America-Antarctic peninsula region. Australian Systematic Botany, 11(4): 373-390.

Askin, R.A. \& Raine, J.I. 2000. Oligocene and Early Miocene terrestrial palynology of the Cape Roberts Drillhole CRP-2/2A, Victoria Land Basin, Antarctica. Terra Antartica, 7(4): 493-501.

Baldoni, A.M. 1987. Nuevas descripciones palinológicas en el área de Collón Curá (Terciario inferior) Provincia del Neuquén. En Argentina. IV. Congreso Latinoamericano de Paleontología, Bolivia, 1: 399-414.

Baldoni, A.M. \& Askin, R.A. 1993. Palynology of the lower Lefipan Formation (Upper Cretaceous) of Barranca de los Perros, Chubut province, Argentina part II angiosperm pollen and discussion. Palynology, 17(1), 241-264.

Baldoni, A.M. \& Barreda, V. 1986. Estudio palinológico de las formaciones Lõpez de Bertodano y sobral, Isla Vicecomodoro Marambio, Antártida. Boletim IG-USP. Série Cientifica, 17: 89-96.

Baldoni, A.M., \& Medina, F. 1989. Fauna y microflora del Cretácico, en bahia Brandy, isla James Ross, Antártida. Serie Científica INACH, 39(4). 
Balme, B.E. 1957. Spores and pollen grains from the Mesozoic of Western Australia. Commonwealth Scientific and Industrial Research Organization, Coal Research Section, 25: 1-48.

Barreda, V.D. 1997a. Palynomorph assemblage of the Chenque Formation, Late Oligocene?-Miocene from golfo San Jorge basin, Patagonia, Argentina. Part 1: terrestrial algae, trilete and monolete spores. Ameghiniana, 34(1), 69-80.

Barreda, V.D. 1997b. Palynomorph assemblage of the Chenque Formation, Late Oligocene?-Miocene from golfo San Jorge basin. Patagonia, Argentina. Part 2: gymnosperm and colpate pollen. Ameghiniana, 34(1), 81-92.

Barreda, V.D. 1997c. Palynomorph assemblage of the Chenque Formation, Late Oligocene?-Miocene from Golfo San Jorge basin, Patagonia, Argentina. Part 3. Polycolpate and tricolporate pollen. Ameghiniana, 34(2): 131-144.

Barreda, V.D. 1997d. Palynomorph assemblage of the Chenque Formation, Late Oligocene?-Miocene from Golfo San Jorge basin, Patagonia, Argentina. Part 4. Polycotporate and porate pollen. Ameghiniana, 34(2): 145-154.

Barreda, V.D., Cúneo, N.R., Wilf, P., Currano, E.D., Scasso, R.A. \& Brinkhuis, H. 2012. Cretaceous/Paleogene floral turnover in Patagonia: drop in diversity, low extinction, and a Classopollis spike. PLoS One, 7(12): e52455.

Barreda, V.D., Gutiérrez, P.R. \& Limarino, C.O. 1998. Edad y paleoambiente de la "Serie del Yeso", valle del Cura, provincia de San Juan: evidencias palinológicas. Ameghiniana, 35(3): 321-335.

Barreda, V. \& Palamarczuk, S. 2000a. Estudio palinoestratigráfico del Oligoceno tardío-Mioceno en secciones de la costa patagónica y plataforma continental argentina. Correlación Geológica, 14: 103-138. 
Barreda, V. \& Palamarczuk, S. 2000b. Palinoestratigrafía de depósitos del Oligoceno tardío-Mioceno en el área sur del Golfo San Jorge, provincia de Santa Cruz, Argentina. Ameghiniana, 37(1): 103-117.

Berry, E.W. 1925a. A Miocene flora from Patagonia. Johns Hopkins University Studies in Geology, 6:183-251.

Berry, E.W. 1925b. The Tertiary flora of the island Trinidad. BWI John Hopkins University Studies in Geology, 6: 71-161.

Berry, E.W. 1928. Tertiary fossil plants from the Argentine Republic. US Government Printing Office.

Berry, E.W. 1932. Fossil plants from Chubut territory collected by the Scarritt Patagonian expedition. American Museum of Natural History. ISO 690

Berry, E.W. 1935a. A fossil Cochlospermum from northern Patagonia. Bulletin of the Torrey Botanical Club, 65-67.

Berry, E.W. 1935b. The Monimiaceae and a new Laurelia. Botanical Gazette, 96: 751754.

Berry, E.W. 1935c. A tertiary Ginkgo from Patagonia. Torreya, 35(1): 11-13.

Berry, E.W. 1937. Eocene plants from Rio Turbio in the territory of Santa Cruz, Patagonia. Contribution to Paleobotany of South America. John Hopkins Studies in Geolology, Baltimore, 12: 91-97.

Berry, E.W. 1938. Tertiary flora from the rio Pichileufu, Argentina. Geological Society of America Special Papers, 12: 1-198.

Blow, W.H. 1979. The cainozoic Globigerinida: a study of the morphology, taxonomy, evolutionary relationships and the stratigraphical distribution of some Globigerinida (mainly Globigerinacea). Text: P. 1/2: Sect. 1. Brill. 
Borrello, A.V. 1956. Recursos minerales de la República Argentina. III. Combustibles sólidos minerales. Revista del Instituto Nacional de Investigación de las Ciencias Naturales, Ciencias Geológicas, 5: 665.

Brandmayr, J. 1945. Contribución al conocimiento geológico del extremo sud-sudoeste del Territorio de Santa Cruz (Región Cerro Cazador - Alto Río Turbio). Boletín de Informaciones Petroleras, 256: 415-437.

Brea, M. 1993. Inferencias paleoclimáticas a partir del estudio de los anillos de crecimiento de leños fósiles de la Formación Río Turbio, Santa Cruz, Argentina. I. Nothofagoxylon paraprocera Ancibor 1990. Ameghiniana, 30: 135-141.

Cabrera, A.L. 1976. Regiones fitogeográficas argentinas. Enciclopedia Argentina de Agricultura y Jardinería. ACME (Ed.). Buenos Aires, Argentina, 2 (1): 1-85

Calegari, R., Baldi, M.J. \& Pioli, O. 1993. Sismoestratigrafía del Terciario de cuenca Austral. Aplicación en proyectos exploratorios. Boletín de Informaciones Petroleras, 10:2-23.

Cao, L. 1989. Discovery of Late Cretaceous palynoflora from Fildes Peninsula, King George Island, Antarctica and its significance. Acta Palaeontologica Sinica (Gushengwu Xuebao), 29: 140- 146.

Carpenter, R.J. 2012. Proteaceae leaf fossils: phylogeny, diversity, ecology and austral distributions. The Botanical Review, 78(3): 261-287.

Carrillo-Berumen, R., Quattrocchio, M.E. \& Helenes, J. 2013. Palinomorfos continentales del Paleógeno de las formaciones Chorrillo Chico y Agua Fresca, Punta Prat, Región de Magallanes, Chile. Andean geology, 40(3): 539-560.

Carrizo, R., Malumián, N., Náñez, C., Caramés, A. \& Concheyro, A. 1990. Micropaleontología y correlación del Terciario del área carbonífera de Río 
Turbio, provincia de Santa Cruz, Argentina. $2^{\circ}$ Simposio sobre el Terciario de Chile, Actas, 1: 29-50.

Casadío, S., Griffin, M., Marenssi, S., Net, L., Parras, A., Rodríguez Raising, M. \& Santillana, S. 2009. Paleontology and sedimentology of Middle Eocene rocks in Lago Argentino area, Santa Cruz Province, Argentina. Ameghiniana, 46: 27-47.

Colmenares, O.A. \& Teran, L. 1993. A biostratigraphic study of Paleogene sequences in southwestern Venezuela. Palynology, 17(1): 67-89.

Concheyro, A. 1991. Nanofósiles calcáreos de la Formación Man Aike (Eoceno, sudeste del Lago Cardiel) Santa Cruz, Argentina. Ameghiniana, 28: 385-399.

Cookson I.C. 1947 Fossil fungi from Tertiary deposits in the southern hemisphere. Proceeding of the Linnean Society of New South Wales. 72: 207-214.

Cookson, I.C. 1953. Difference in microspore composition of some samples from a bore at Comaum, South Australia. Australian Journal of Botany, 1(3): 462-473.

Cookson, I.C. \& Cranwell, L. M. 1967. Lower Tertiary microplankton, spores and pollen grains from southernmost Chile. Micropaleontology, 204-216.

Cookson, I.C. \& Pike, K.M. 1954a. Some dicotyledonous pollen types from Cainozoic deposits in the Australian region. Australian journal of botany, 2(2): 197-219.

Cookson, I.C. \& Pike, K.M. 1954b. The fossil occurrence of Phyllocladus and two other podocarpaceous types in Australia. Australian Journal of Botany, 2(1): 60-68.

Couper, R.A. 1953.Upper Mesozoic and Cenozoic spores and pollen grains from New Zealand. Doweld A. (Ed.). New Zealand Geological Survey palaeontological bulletin. 22: 1- 77 .

Couper, R.A. 1960. New Zealand Mesozoic and Cenozoic plant microfossils. Doweld A. (Ed.). New Zealand Geological Survey palaeontological bulletin, 32: 87. 
Cranwell, L.M. \& Srivastava, S.K. 2009. An Early Cretaceous (Hauterivian) SporePollen Assemblage from Southern Chile. Palynology, 33(1): 241-280.

Dettmann, M.E. 1963. Upper Mesozoic microfloras from south-eastern Australia. Royal Society of Victoria, 77 (1): 1-149.

Dettmann, M.E. 1989. Antarctica: Cretaceous cradle of austral temperate rainforests? Origins and evolution of the Antarctica biota. Crame, J.A. (Ed.). Geological Society Special Publication, Londres, 47(1): 89-105.

Dettmann, M.E. \& Jarzen, D.M. 1990. The Antarctic/Australian rift valley: Late cretaceous cradle of northeastern Australasian relicts? Review of palaeobotany and palynology, 65(1-4): 131-144.

Dettmann, M.E., Pocknall, D.T., Romero, E.J. \& Zamaloa, M. 1990. Nothofagidites Erdtman ex Potonié, 1960; a catalogue of species with notes on the paleogeographic distribution of Nothofagus B1. (Southern Beech). New Zealand Geological Survey, Palaeontological Bulletin, Wellington, 60:1-52.

Dettmann, M.E., \& Thomson, M.R.A. 1987. Cretaceous palynomorphs from the James Ross Island area, Antarctica. A pilot study. Bulletin-British Antarctic Survey, 77: $13-59$.

Diaz, E.F.G., Riggi, J.C \& Ostera, H. 1987. Hallazgo del Terciario Inferior con flora fósil, sobre el Bloque Oriental de la Depresión del Colon Cura, sureste del Neuquén, Argentina. Congreso Geológico Argentino, 10th, San Miguel de Tucumán, 3rd Actas, 3: 159- 162.

Drinnan, A.N. \& Crane, P.R. 1990. Cretaceous paleobotany and its bearing on the biogeography of austral angiosperms. En: Antarctic paleobiology, Springer New York, 192-219. 
Dueñas-Jimenez, H. 1983. Fluctuaciones del Nivel del Mar Durante la depositación de los sedimentos Basales de la Formación Ciénaga de Oro. Revista de la Academia Colombiana de Ciencias Exactas, Físicas y Naturales, 15(58): 67- 76

Dueñas-Jimenez, H. 1986. Geología y palinología de la formación ciénago de oro, región Caribe Colombiana. República de Colombia, Ministerio de Minas y Energía Instituto Nacional de Investigaciones Geológico-Mineras, 18.

Dueñas-Jimenez, H. 1999. Sequence analysis of Western Venezuelan Cretaceous to Eocene sediments using palynology: Chrono-paleoenvironmental and paleovegetational approaches: Discussion and reply. Discussion. Palynology, 23: 31- 33 .

ENADIMSA (Equipos Técnicos de la Empresa Nacional ADARO de Investigaciones Mineras, S.A). 1986. La minería andaluza. Libro Blanco. Consejería de Economía y Fomento, Dirección General de Industria, Energía y Minas. Madrid, Tomos I y II.

Erdtman, G. 2003. An introduction to pollen analysis. Read Books Ltd.

Erdtman, G. \& Straka, H. 1961. Cormophyte Spore Classification: An Outline Based on the Apertures (Tremata). Geologiska Föreningen i Stockholm Förhandlingar, 83(1): $65-78$.

Escobar, L.E. 1984. Estudio palinológico de la Formación Amaga. Boletín de Ciencias de la Tierra, Universidad Nacional de Colombia, Bogotá,7: 117- 129.

Estebenet, M.S.G., Espinosa, M.A., Guerstein, G.R., \& Raising, M.R. 2012. Diatomeas de la Formación Río Turbio (Eoceno Medio), Sudoeste de Santa Cruz, Argentina. Ameghiniana, 49(3): 389-394.

Faegri, K. \& Iversen, J. 1989. Textbook of Pollen Analysis (4ta edición). En: K. Faegri, P.E. Kalana, Krzywinski, K. (Eds.), John Willey and Sons, Londres, 328 pp. 
Fasola, A. 1969. Estudio palinológico de la Formación Loreto (Terciario medio), provincia de Magallanes, Chile. Ameghiniana, 6(1): 3-49.

Fasola, A. \& Paredes De Ramos, I. 1991. Late Cretaceous palynological assemblages from El Furrial area wells. Revista Técnica Intevec, 11: 3-3.

Fernández D.A. 2017. Pollen morphology of Proteaceae native to Argentina: a new dichotomus key for their identification. Revista del Museo Argentino de Ciencias Naturales., nueva serie. 19(1): 25-37.

Fernández D.A., Panti C., Palazzasi L. \& Barreda V.D. 2012. La presencia de una familia neotropical (Malpighiaceae) en el extremo más austral Sudamérica en el Eoceno. Revista brasileira de paleontologia., 15: 386-391.

Fernández D.A., Santamarina P.E., Tellería M.C., Palazzesi L. \& Barreda V.D. 2016. Pollen morphology of Nothofagus (Nothofagaceae, Fagales) and its phylogenetic significance. Acta Palaeobotanica 56(2): 223-245.

Fosdick J.C., Bostelmann J.E., Leonard J., Ugalde R., Oyarzún J.L. \& Griffin M. 2015. Timing and rates of foreland sedimentation: New detrital zircon $\mathrm{U} / \mathrm{Pb}$ geochronology of the Cerro Dorotea, Río Turbio, and Río Guillermo formations, Magallanes basin. XIV Congreso Geológico Chileno, La Serena, Chile.

Fossa Mancini, E., Feruglio, E. \& de Campana, J.Y. 1938. Una reunión de geólogos de YPF y el problema de la terminología estratigráfica. Boletín de Informaciones Petroleras, 15(171): 1-67.

Frederiksen, N.O. 1985. Review of early Tertuary sporomorph paleoecology. American Association of Stratigraphic Palinologists. Contribution Series, Virginia, 15: 192.

Furque, G. \& Caballé, M. 1993. Estudio geológico y geomorfológico de la cuenca superior del Río Turbio, provincia de Santa Cruz. Consejo Federal de 
Inversiones, Serie Investigaciones aplicadas, Colección Hidrología subterránea $6,8-39$.

Gamerro, J.C. 1965. Morfología del polen de Apterocladus lanceolatus Archang. (Coniferae) de la Formación Baqueró, provincia de Santa Cruz. Ameghiniana, 4: 133-136.

González Díaz, F.E. 1979, Estratigrafía del área de la Cordillera Patagónica entre los paralelos 40 $30^{\prime}$ y $41^{\circ}$ de latitud sur (Provincia del Neuquén): Actas VII Congreso Geológico Argentino, Neuquén, 1: 525-537.

González, C.C., Gandolfo M.A., Cúneo N.R., Wilf P. \& Johnson K.R. 2007. Revision of the Proteaceae macrofossil record from Patagonia, Argentina. Botanical Review, 73(3): 235-266.

González-Guzman, A.E. 1967. A palynological study on the Upper Los Cuervos and Mirador Formations (Lower and Middle Eocene; Tibu area, Colombia). Brill E.J. (Ed.), Leiden, 68 pp.

Grimm, E. 2015. Tilia software 2.0.41. Illinois State Museum Research and Collection Center Springfield.

Groeber, P. 1957. Chile, pt. 7 of Amerique Latine. Hoffstetter and others, Lexique Stratigraphique International: Paris, France. Comm. Stratigraphy, Internat. Geol. Cong, 5: 195.

Guerstein, G.R. 1990. Palinología estratigráfica del Terciario de la Cuenca del Colorado, República Argentina. Parte 1: especies terrestres de la perforación Nadir No. 1. Revista Española de micropaleontología, 22: 33-61.

Guerstein, G.R., Estebenet, M.S.G., Alperín, M.I., Casadío, S.A. \& Archangelsky, S. 2014. Correlation and paleoenvironments of middle Paleogene marine beds based on dinoflagellate cysts in southwestern Patagonia, Argentina. Journal of South American Earth Sciences, 52: 166-178. 
Guerstein, G.R., Guler, M.V., Brinkhuis, H. \& Warnaar, J. 2010. Mid Cenozoic Palaeoclimatic and Palaeoceanographic trends in the Southwest Atlantic Basins, a Dinoflagellate view. The Paleontology of Gran Barranca. En: The Paleontology of Gran Barranca: Evolution and Environmental Change through the Middle Cenozoic of Patagonia. Madden R.H., Carlini A.A., Vucetich M.G., Kay R.F. (Eds.), Cambridge, Cambridge University Press. p. 398-409

Guerstein, G.R., Guler, M.V., Williams, G.L., Fensome, R.A. \& Chiesa, J.O. 2008. Mid Palaeogene dinoflagellate cysts from Tierra del Fuego, Argentina: biostratigraphy and palaeoenvironments. Journal of Micropalaeontology, 27: 75-94.

Guerstein, G.R. \& Quattrocchio, M. 1988. Palinozonas e interpretación estratigráfica mediante análisis de agrupamiento del Terciario de la Cuenca del Colorado, República Argentina. II Jornadas Geológicas Bonaerenses, Actas 2:27-35.

Guerstein, G.R. \& Quattrocchio, M. 1991. Datos paleoambientales basados en el estudio estadístico de las palinofloras de la perforación Nadir N1 (Eoceno-Mioceno) Cuenca del Colorado. Revista de la Asociación Geológica Argentina, 46: 136149.

Harley, M.M. 1996. Pollen morphology of recent palms and the fossil record: some comparisons. Ninth International Palynological Congress, Program and Abstracts, Houston.

Harris, W.K. \& Morgan, R. 1976. Eocene microfloras from the eastern Murray Basin, New South Wales. Quarterly notes of the Geological Survey of New South Wales, 24: 1-6. 
Hebel, I. \& Torres, T. 2009. Polen fósil de isla Rey Jorge (Antártica) y Chile continental, afin a Proteaceae chilenas. Anales del Instituto de la Patagonia, Universidad de Magallanes, 37(1): 7-22.

Herbst, R., Anzótegui, L. M., Esteban, G., Mautino, L. R., Morton, S. \& Nasif, N. 2000. Síntesis paleontológica del Mioceno de los valles Calchaquíes, noroeste argentino. El Neógeno de Argentina. INSUGEO, Serie Correlación Geológica, 14: 263-288.

Hesse, M., \& Zetter, R. 2007. The fossil pollen record of Araceae. Plant Systematics and Evolution, 263(1): 93-115.

Hoorn,C. 1994. An environmental reconstruction of the palaeo-Amazon River system (Middle - Late Miocene, northwest Amazonia). Palaeogeography, Palaeoclimatology, Palaeoecology, 112 (3): 187- 238.

Hoorn, C., Raghubanshi, A.S. \& Singh, J.S. 1994. Fluvial palaeoenvironments in the intracratonic Amazonas Basin (Early Miocene - Early Middle Miocene, Colombia). Palaeogeography, Palaeoclimatology, Palaeoecology, 109 (1): 154.

Hornibrook, N.D.B. 1978. Globoquadrina debiscens (Foraminiferida) in the Otekaike Limestone (Waitakian Stage), New Zealand (Note). New Zealand journal of geology and geophysics, 21(5): 657-659.

Hos, D. 1975. Preliminary investigation of the palynology of the upper Eocene Wirillup Formation, Western Australia. Journal of the Royal Society of Western Australia.

Hünicken, M. 1955. Depósitos Neocretácicos y Terciarios del Extremo SSW de Santa Cruz (Cuenca carbonífera de Río Turbio). Revista del Instituto Nacional de 
Investigaciones de las Ciencias Naturales (Museo Argentino de Ciencias Naturales "Bernardino Rivadavia”). Ciencias Geológicas 4: 1-164.

Hünicken, M. 1967. Flora Terciaria de los Estratos de Río Turbio, Santa Cruz (Niveles plantíferos del arroyo Santa Flavio). Rev. Fac. Cienc. Exact., Fis. y Nat. Univ. Córdoba, S. Cs. Nat., 27(3-4): 139-227. Córdoba.

Hünicken, M. 1995. Floras Cretácicas y Terciarias. En: Revisión y actualización de la obra paleobotánica de Kurtz en la República Argentina, P.N. Stipanicic y M.A. Hünicken (eds.), Actas de la Academina Nacional de Ciencias, 11: 199-219.

Iversen, J. \& Troels Smith, J. 1950. Pollenmorfologiske definitioner og typer. Danmarks geol. unders, 3(8): 54.

Jaramillo, C.A, Bayona, G., Pardo-Trujillo, A., Rueda, M., Torres, V., Harrington, G. J., \& Mora, G. 2007. The palynology of the Cerrejón Formation (upper Paleocene) of northern Colombia. Palynology, 31: 153-189.

Jaramillo, C.A. \& Cárdenas, A. 2013. Global warming and neotropical rainforests: A historical perspective. Annual Review of Earth and Planetary Sciences, 41, 741766.

Jaramillo, C.A. \& Dilcher, D.L. 2000. Microfloral diversity patterns of the late Paleocene-Eocene interval in Colombia, northern South America. Geology, 28: 815-818.

Jaramillo, C.A., \& Dilcher, D.L. 2001. Middle Paleogene palynology of Central Colombia, South America: a study of pollen and spores from tropical latitudes. Palaeontographica Abteilung B, 87-213.

Jaramillo, C.A., Ochoa, D., Contreras, L., Pagani, M., Carvajal-Ortiz, H., Pratt, L. M., \& Rodriguez, G. 2010. Effects of rapid global warming at the Paleocene-Eocene boundary on neotropical vegetation. Science, 330(6006), 957-961. 
Johnson, L.A.S. \& Briggs, B.G. 1963. Evolution in the Proteaceae. Australian Systematic Botany 11(1): 21-61.

Johnson, L.A.S. \& Briggs, B.G. 1975. On the Proteaceae - the evolution and classification of a southern family. Botanical journal of the Linnean Society 70(2): 83-182.

Johnson, L.A.S. \& Briggs, B.G. 1981. Three old southern families Myrtaceae, Proteaceae and Restoniaceae. In: A. Keast (ed.), Ecological biogeography of Australia, pp. 429-469, Dr. W. Junk bv Publishers, The Hague.

Kemp. E.M. \& Harris, W.K. 1977. The palynology of early Tertiary sediments, Ninetyeast Ridge, Indian Ocean. The Palaeontological Association, London, Special papers in palaeontology 19: 1-70.

Kottek, M., Grieser, J., Beck, C., Rudolf, B., \& Rubel, F. 2006. World map of the Köppen-Geiger climate classification updated. Meteorologische Zeitschrift, 15(3), 259-263.

Krutzsch, W. 1959. Sporen vom "Schizaea-pusilla-Charakter" im Pliozan von Ruterburg (=Wendisch Wehningen). Archiv der Freude der Naturgeschichte in Mecklenburg 5: 36-55.

Lange, R.T. 1982. Australian Tertiary vegetation. Evidence and interpretation. Pp. 4489 in: Smith, J.M.B. (Ed.). "A history of Australasian vegetation". McGraw-Hill Book Company, Sydney.

Leanza, A.F. 1972. Geología Regional Argentina. En Simposio de Geologie Regional Argentina 1969: Cordoba). Argentina, Academia Nacional de Ciencas.

Leanza, H.A., Volkheimer, W., Hugo, C.A., Melendi, D.L. \& Rovere, E.I. 2002. Lutitas negras lacustres cercanas al límite Paleógeno-Neógeno en la región 
noroccidental de la provincia del Neuquén: Evidencias palinológicas. Revista de la Asociación Geológica Argentina, 57(3), 280-288.

Lima, M.R. \& Dino, R. 1984. Palinologia de amostras da Bacia de Bonfim, Terciário do Estado de São Paulo, Brasil. Boletim do Instituto de Geociências, 15:1-11.

Lima, M.R. \& Salard-Cheboldaeff, M. 1981. Palynologie des bassins de Gandarela et Fonseca (Eocene de l'etat de Minas Gerais, Bresil). Boletim do Instituto de Geociências, 12:33-54.

Lima, M.R., Salard-Cheboldaeff, M. \& Suguio, K. 1985. Étude palynologique de la Formation Tremembé, Tertiairie du Bassin de Taubaté, (Etat de São Paulo, Brésil), d'après les echantillons du sondage no. 42 du CNP. En: Campos, D.A.; Ferreira C.S., Brito I.M., Viana C.F. (Eds). Coletânea de Trabalhos Paleontológicos, Brasília, Departamento Nacional da Produção Mineral. Série Geologia 27, Seção Paleontologia e Estratigrafia, 2, 379-393.

Macphail, M.K., Kellett, J.R. Rexilius, J.P. \& O'Rorke, M.E. 1993: The "Geera Clay equivalent": a regressive marine unit in the Renmark Group that sheds new light on the age of the Mologa weathering surface in the Murray Basin. Australian Geological Survey Organisation journal of Australian geology and geophysics, 14: 47-63.

Macphail, M.K. 1999. Palynostratigraphy of the Murray Basin, inland southwestern Australia. Palynology, 23: 197-240.

Macphail, M. \& Cantrill, D.J. 2006. Age and implications of the Forest Bed, Falkland Islands, southwest Atlantic Ocean: evidence from fossil pollen and spores. Palaeogeography, Palaeoclimatology, Palaeoecology, 240(3): 602-629.

Macphail, M.K. \& Hill, R.S. 1994. K-Ar dated palynofloras in Tasmania 1: early oligocene, Proteacidites tuberculatus zone sediments, Wilmot Dam, 
northwestern Tasmania. Papers and Proceedings of the Royal Society of Tasmania, 128: 1-15.

Macphail, M.K., \& Stone, M.S. 2004. Age and palaeoenvironmental constraints on the genesis of the Yandi channel iron deposits, Marillana Formation, Pilbara, northwestern Australia. Australian Journal of Earth Sciences, 51(4), 497-520.

Macphail, M.K., \& Truswell, E.M. 1989. Palynostratigraphy of the central west Murray Basin. BMR Journal of Australian Geology and Geophysics, 11(2): 3.

Macphail, M. \& Truswell, E. 2004. Palynology of Site 1166, Prydz Bay, East Antarctica.

Malumián, N. 1990. Foraminíferos de la Formación Man Aike (Eoceno, sureste Lago Cardiel) provincia de Santa Cruz. Revista de la Asociación Geológica Argentina, 45(3-4), 365-385.

Malumián, N. 2002. El terciario marino: sus relaciones con el eustatismo. Geología y recursos naturales de Santa Cruz. Haller, M.J. (Ed.). En XV Congreso Geológico Argentino, Santa Cruz, Relatorio 1(15): 237-245.

Malumián, N., Ardolino, A.A., Franchi, M., Remesal, M. \& Salani, F. 1999. La sedimentación y el volcanismo terciarios en la Patagonia extraandina. Geología Argentina. Instituto de Geología y Recursos Minerales, Anales, 29(18):557-612.

Malumián, N. \& Caramés, A. 1997. Upper Campanian-Paleogene from the Río Turbio coal measures in southern Argentina: micropaleontology and the Paleocene/Eocene boundary. Journal of South American Earth Sciences, 10(2): 189-201.

Malumian, N. \& Nanez, C. 2011. The Late Cretaceous-Cenozoic transgressions in Patagonia and the Fuegian Andes: foraminifera, palaeoecology, and palaeogeography. Biological Journal of the Linnean Society, 103(2), 269-288. 
Malumián, N., Panza, J., \& Parisi, C. 2000, Yacimiento Rio Turbio: Instituto de Geologia y Recursos Minerales SEGEMAR (Argentina) Mapa 5172-III, escala, $1: 250.000$.

Manos P.S. 1997. Systematics of Nothofagus (Nothofagaceae) based on rDNA spacer sequences (ITS): taxonomic congruence with morphology and plastid sequences. American Journal of Botany, 84: 1137-1155.

Martin, H.A. 1973. Upper Tertiary palynology in southern New South Wales. Geological Society of Australia, special publication number, 4: 35-54.

Martin, H.A. 1977. The history of Ilex (Aquifoliaceae) with special reference to Australia: evidence from pollen. Australian journal of botany. 25: 655-673.

Martin, H.A. 1991. Tertiary stratigraphic palynology and palaeoclimate of the inland river systems in New South Wales. The Cainozoic in Australia: a re-appraisal of the evidence. Special Publication, 18: 181-194.

Martin, A.R.H. 1995. Palaeogene proteaceous pollen and phylogeny. Alcheringa, 19(1): $27-40$.

Martin, H.A. 2002. History of the family Malpighiaceae in Australia and its biogeographic implications: evidence from pollen. Australian Journal of Botany, $50: 171-182$

Martin, A.R. \& Harris, W.K. 1974. Reappraisal of Some Palynomorphs of Supposed Proteaceous Affinity: The Genus Proteacidites Cookson ex Couper. Grana, 14(2-3): 108-113.

Mautino, L.R. \& Anzotegui, L.M. 2000. Miocene spores and Mesozoic reworked spores from Chiquimil Formation, Vallecito, Catamarca Province. Amehiniana, 37: 1322. 
Mautino, L.R. \& Anzotegui, L.M. 2002a. Palinología de la Formación Chiquimil (Mioceno superior), Vallecito, provincia de Catamarca. Parte 2. Polen. Ameghiniana, 39: 257-270.

Mautino, L.R.; Anzotegui, L.M. 2002b. Palinología de la Formación Chiquimil (Mioceno Superior), en Río Vallecito, provincia de Catamarca, Argentina. Parte 3. Polen. Ameghiniana, 39: 271-284

Mautino, L.R. 2010. Palinofloras de las Formaciones San José y Chiquimil (MiocenoMedio y Superior), Noroeste de Argentina. Universidad Nacional del Nordeste, Tesis Doctoral, $444 \mathrm{pp}$.

Mazzoni, M.M., Kawashita, K., Harrison, S. \& Aragón, E. 1991. Edades radimétricas Eocenas. Borde occidental del Macizo Norpatagónico. Revista de la Asociación Geológica Argentina, 46: 150-158.

McIntyre, D.J. 1965. Some new pollen species from New Zealand Tertiary deposits. New Zealand Journal of Botany, 3: 204-214.

McIntyre, D.J. 1968. Further new pollen species from New Zealand Tertiary and uppermost Cretaceous deposits. New Zealand Journal of Botany, 6: 177-204.

McWhae, K.M. 1957. A note of the pollen of Whiteodendron and Kjellbergiodendron (Myrtaceae). Reinwardtia, 4: 189-191.

Medus, J. 1975. Palynologie de sediments Tertiaires du Senegal Meridional. Pollen et spores, 17: 545-608.

Mehrotra, N.C., Venkatachala, B.S., Swamy, S.N. \& Kapoor, P.N. 2002. Cauvery Basin. Mehrotra N.C., Venkatachala B.S., Swamy, S.N., Kapoor, P.N. (Eds.). Palynology in Hydrocarbon Exploration: The Indian Scenario Part 1: Category 1. Memoir of the Geological Society of India, 48: 43-60. 
Melendi, D.L., Scafati, L.H. \& Volkheimer, W. 2003. Palynostratigraphy of the Paleogene Huitrera Formation in N-W Patagonia, Argentina. Neues Jahrbuch für Geologie und Paläontologie Abhandlungen, Stuttgart, 228: 205-273.

Menéndez, C.A. \& Caccavari de Filice, M.A. 1975. Las especies de Nothofagidites (polen fósil de Nothofagus) de sedimentos Terciarios y Cretácicos de Estancia La Sara, Norte de Tierra del Fuego, Argentina. Ameghiniana, 12 (2): 165-183.

Mildenhall, D.C. 1978. Palynomorphs from Miocene-Pliocene sediments, Grey Valley (K31-Metric), South Island, New Zealand. New Zealand Geological Survey, Department of Scientific and Industrial Research.

Mildenhall, D.C. 1989. Summary of the age and paleoecology of the Miocene Manuherikia Group, Central Otago, New Zealand. Journal of the Royal Society of New Zealand, 19(1):19-29.

Mildenhall, D.C. 2001. Pollen analysis of Pliocene-Pleistocene Kowai Formation (Kurow Group), Mackenzie Basin, South Canterbury, New Zealand. New Zealand journal of geology and geophysics, 44(1): 97-104.

Mildenhall, D.C., \& Harris, W.F. 1971. Status of Haloragacidites (al. Triorites) harrisii (Couper) Harris comb. nov. and Haloragacidites trioratus Couper, 1953. New Zealand journal of botany, 9(2): 297-306.

Mildenhall, D.C. \& Pocknall, D.T. 1989: Miocene-Pleistocene spores and pollen from Central Otago, South Island, New Zealand. New Zealand Geological Survey paleontological bulletin, 59: 0-128.

Mildenhall, D.C. \& Suggate, R.P. 1981. Palynology and age of the Tadmor Group (Late Miocene-Pliocene) and Porika Formation (Early Pleistocene), South Island, New Zealand. New Zealand journal of geology and geophysics, 24: 515-528. 
Milne, L.A. 1988: Palynology of a late Eocene lignitic sequence from the western margin of the Eucla Basin, Western Australia. Memoir of the Association of Australasian Palaeontologists, 5: 285-310.

Milne, L.A. \& Martin, A.R.H., 1998. Conospermeae (Proteoideae) pollen morphology and its phylogenetic implications. Australian systematic botany, 11: 503-552.

Moore, P. D., Webb, J. A., \& Collison, M. E. 1991. Pollen analysis. Blackwell scientific publications.

Náñez, C., Quattrocchio, M. E. \& Ruiz, L. 2009. Palinología y micropaleontología de las Formaciones San Julián y Monte León (Oligoceno-Mioceno temprano) en el subsuelo de cabo Curioso, provincia de Santa Cruz, Argentina. Ameghiniana, 46(4), 669-693.

Norris, G., 1962. Type specimens of the New Zealand Mesozoic and Cainozoic spores and pollen grains. New Zealand journal of geology and geophysics, 5: 652-661.

Nott, J. F. \& Owen, J. A. 1992. An Oligocene palynoflora from the middle Shoalhaven catchment NSW and the Tertiary evolution of flora and climate in the southeast Australian highlands. Palaeogeography, palaeoclimatology, palaeoecology, 95 (1-2): 135-151.

Oksanen, J., Kindt, R. \& O'Hara, B. 2005. Community Ecology Package, Package VEGAN R for Statistical Computing.

Olivero, E., Barreda, V.D., Marensi, S., Santillana, S. \& Martinioni, D. 1998. Estratigrafía, sedimentología y palinología de la Formación Sloggett (Paleógeno continental) Tierra del Fuego, Argentina. Revista de la Asociación Geológica Argentina, 53: 504-516.

Olivero, E.B. \& Malumián, N. 1999. Eocene stratigraphy of southeastern Tierra del Fuego island, Argentina. AAPG bulletin, 83(2), 295-313. 
Olivero, E.B. \& Malumián, N. 2008. Mesozoic-Cenozoic stratigraphy of the Fuegian Andes, Argentina. Geologica Acta: an international earth science journal, 6(1).

Owen, J.A.K. 1988. Miocene palynomorph assemblages from Kiandra, New South Wales. Alcheringa, 12(4), 269-297.

Palamarczuk, S. \& Barreda, V. 2000. Palinología del Paleogeno tardío-Neogeno temprano, pozo Aries $\mathrm{x}-1$, plataforma continental Argentina, Tierra del Fuego. Ameghiniana, 37(2), 221-234.

Palamarczuk, S., Gamerro, J.C. \& Barreda, V.D. 2000. Estudio palinológico en el pozo Chiton MFJ8 x-1, plataforma continental argentina, cuenca Austral. 11 ${ }^{\mathrm{o}}$ Simposio Argentino de Paleobotánica y Palinología, (Tucumán), Ameghiniana 37 (4), Suplemento Resúmenes: 59R.

Palazzesi, L. 2008. Palinología de las Formaciones Gaiman y Puerto Madryn en el área de Península Valdés (noreste del Chubut): edad, correlación y ambiente de sedimentación. Tesis Doctoral, Universidad de Buenos Aires (FCEyN), Buenos Aires, Argentina, 197 pp.

Panti, C. 2010. Diversidad Florística durante el Paleógeno en Patagonia Austral. Tesis Doctoral, Universidad de Buenos Aires (FCEyN), Buenos Aires, Argentina, 210 pp.

Papú, O.H. 1988a. Estudio palinológico de la Formación Paso del Sapo (Cretácico Superior) en la localidad de "Los Fortines", Valle Medio del Río Chubut. Parte 1: Esporas Triletes, Laevigati y Apiculati. IV Congresso Argentino de Paleontologia y Biostratigrafia, actas 3: 63-73.

Papú, O.H. 1988b. Estudio palinológico de la Formación Paso del Sapo (Cretácico Superior) en la localidad de "Los Fortines", Valle Medio del Río Chubut. Parte 
II: Esporas Triletes, Murornati, Tricrassati y esporas Monoletes. IV Congresso Argentino de Paleontologia y Biostratigrafia, actas 3: 75-85.

Papú, O.H. 1989. Estudio palinológico de la Formación Paso del Sapo (Cretácico Superior), Valle Medio del Río Chubut. Granos de polen, consideraciones estadísticos, paleoecológicas y paleoambientales. Ameghiniana, 25: 193-202.

Pardo-Trujillo, A., Jaramillo, C.A. \& Oboh-Ikuenobe, F.E. 2003. Paleogene palynostratigraphy of the eastern middle Magdalena Valley, Colombia. Palynology, 27:155-178.

Partridge, A.D., 1978. Palynology of the Late Tertiary sequence at site 365, Leg 40, Deep Sea Drilling Project. Bolli H.M., Ryan W.B.F., et al. (Eds.). Initial reports of the Deep Sea Drilling Project, 40. Washington (U.S. Government Printing Office). 27: 953-961

Pearson, N.J., Gabriela Mángano, M., Buatois, L.A., Casadío, S. \& Raising, M.R. 2013. Environmental variability of Macaronichnus ichnofabrics in Eocene tidal-embayment deposits of southern Patagonia, Argentina. Lethaia, 46(3): 341354.

Pocknall, D.T. 1982. Palynology of late Oligocene Pomahaka Estuarine Bed sediments, Waikoikoi, Southland, New Zealand. New Zealand journal of botany, 20(3): 263-287.

Pocknall, D.T. 1985. Palynology of Waikato Coal Measures (Late Eocene-Late Oligocene) from the Raglan area, North Island, New Zealand. New Zealand journal of geology and geophysics, 28(2):329-349.

Pocknall, D.T. 1990. Palynological evidence for the early to middle Eocene vegetation and climate history of New Zealand. Review of palaeobotany and palynology, 65(1-4): 57-69. 
Pocknall, D.T. 1991. Palynostratigraphy of the Te Kuiti Group (late Eocene-Oligocene), Waikato Basin, New Zealand. New Zealand journal of geology and geophysics, 34(4): 407-417.

Pocknall, D.T. \& Mildenhall, D.C. 1984. Late Oligocene-early Miocene spores and pollen from Southland, New Zealand. New Zealand Dept. of Scientific and Industrial Research, 51.

Pocknall, D.T. \& Turnbull, I.M. 1989. Paleoenvironmental and stratigraphic significance of palynomorphs from Upper Eocene (Kaiatan) Beaumont Coal Measures and Orauea Mudstone, Waiau Basin, western Southland, New Zealand. New Zealand journal of geology and geophysics, 32(3): 371-378.

Porta, J.D. 1974. Colombie (deuxieme partie). Tertiare et Quaternaire. Lexique Stratigraphique International, Amerique Latine, V (4b). Centre National de la Recherche Scientifique, Pariss, 689 pp.

Potter, F.W. 1976: Investigations of Angiosperms from the Eocene of southeastern North America: pollen assemblages from Miller Pit, Henry County, Tennessee. Palaeontographica Abteilung B, 157: 44-96.

Povilauskas, L. 2013. Palinología de angiospermas de la Formación Monte Chico (Cretácico Superior) de la Provincia de Santa Cruz, Argentina. Revista brasileira de paleontologia, 16(11).

Prámparo, M., Papú, O. \& Milana, J.P. 1995. Estudio palinológico del miembro inferior de la Formación Pachaco, Terciario de la Provincia de San Juan. Análisis estadístico y conclusiones paleoecológicas. $6^{o}$ Congreso Argentino de Paleontología y Bioestratigrafia. Trelew, Actas 1: 207-212. 
Pross, J., Contreras, L., Bijl, P.K., Greenwood, D.R., Bohaty, S.M., Schouten, S. \& Huck, C.E. 2012. Persistent near-tropical warmth on the Antarctic continent during the early Eocene epoch. Nature, 488(7409), 73-77.

Pujana, R.R. 2008. Estudio paleoxilológico del Paleógeno de Patagonia austral (Formaciones Río Leona, Río Guillermo y Río Turbio) y Antártida (Formación La Meseta). Tesis Doctoral. Universidad de Buenos Aires (FCEyN), Buenos Aires, Argentina, 182 pp.

Pujana, R.R., Martínez, L. C. \& Brea, M. 2011. El registro de maderas fósiles de Leguminosae de Sudamérica. Revista del Museo Argentino de Ciencias Naturales, 13(2): 183-194.

Punt, W., Hoen, P.P., Blackmore, S., Nilsson, S. \& Le Thomas, A. 2007. Glossary of pollen and spore terminology. Review of Palaeobotany and Palynology, 143(1):1-81.

Quattrocchio, M.E., Guerstein, G.R. \& Deschamps, C. 1988. Fluctuaciones climáticas del Terciario de la Cuenca del Colorado, palinomorfos y vertebrados. II Jornadas Geológicas Bonaerenses, Actas, 55-64.

R Development Core Team. 2005. R: A language and environment for statistical computing. R Foundation for Statistical Computing, Vienna, Austria. ISBN 3900051-07-0, http://www.R-project.org.

Raine, J.I. 1984. Outline of a palynological zonation of Cretaceous to Paleogene terrestrial sediments in West Coast region South Island, New Zealand. Dept. of Scientific and Industrial Research New Zealand. (109).

Raine, J.I., Mildenhall, D.C. \& Kennedy, E. 2011. New Zealand fossil spores and pollen: an illustrated catalogue. GNS Science. 
Raine, J.I.; Wilson, G.J., 1988: Palynology of the Mt Somers (South Island, New Zealand) early Cenozoic sequence (note). New Zealand journal of geology and geophysics 31: 385-390.

Raising, M.R. 2010. Estratigrafía secuencial de los depósitos marinos y continentales del Eoceno-Oligoceno temprano de la cuenca Austral, suroeste de la provincia de Santa Cruz. Tesis Doctoral Publicada, Universidad Nacional del Sur, Buenos Aires, Argentina.

Ramos, V.A. 2002. Evolución tectónica. M.J. Haller (Ed.). Geología y Recursos naturales de Santa Cruz. Relatorio XV Congreso Geológico Argentino, Buenos Aires. 1(23): 365-387.

Rapela C.W \& Kay S.M. 1988. Late Paleozoic to Recent Magmatic Evolution of Northern Patagonia. Episodes, 11(3): 175-182.

Raup, D.M. 1975. Taxonomic diversity estimation using rarefaction. Paleobiology, 1(4): 333-342.

Rawat, M.S. 1977: Palynology of the Mesozoic sediments of Kutch, W. India: plant microfossils from Chawad River Traverse, District Kutch, Gujarat. Journal of palynology, 12: 19-42.

Regali, M.D.S. 1974. Palinologia dos sedimentos Meso-Cenozóicos do Brasil. Boletin. Tecnico Petrobras, 17: 263-301.

Riccardi, A.C. \& Rolleri, E.O. 1980. Cordillera patagónica austral. Simposio de Geología Regional Argentina, 2:1173-1306.

Roig, F.A. \& Faggi, A.M. 1985. Transecta Botánica de la Patagonia Austral. O. Boelcke, D.M. Moore y Roig, E.A. (Eds.). CONICET (Argentina), Instituto de la Patagonia (Chile) y Royal Society (Gran Bretaña). Buenos Aires, 187 pp

Romero, E.J. 1973. Polen fósil de Nothofagus (Nothofagidites) del Cretácico y Paleoceno de Patagonia. Revista del Museo. La Plata, 7: 291-293. 
Romero, E.J. 1977. Polen fósil de Gimnospermas y Fagáceas de la Formación Río Turbio (Eoceno), Santa Cruz, Argentina. FECIC, Buenos Aires. 219 pp.

Romero, E.J. 1986. El género Nothofagus en Antártida. VII Simposio Argentino de Palaeontología y Palinología, Actas, 81-185.

Romero, J.E. \& Castro, M.T. 1986. Material fúngico y granos de polen de angiospermas de la Formación Río Turbio (Eoceno), provincia de Santa Cruz, República Argentina. Ameghiniana 23: 101-118.

Romero, J.E. \& Zamaloa, M.C. 1985. Polen de angiospermas de la Formación Río Turbio (Eoceno), provincia de Santa Cruz, Argentina. Ameghiniana, 22: 43-51.

Rosenzweig, M.L. 1995. Species diversity in space and time. Cambridge University Press.

Royer, D.L. \& Chernoff, B. 2013. Diversity in neotropical wet forests during the Cenozoic is linked more to atmospheric $\mathrm{CO} 2$ than temperature. Proceedings of the Royal Society of London B: Biological Sciences, 280: 20131024.

Ruiz, L.C. \& Quattrocchio, M.E. 1993. Srivastavapollenites exoticus nov. Gen et sp. de la Formación Pedro Luro (Paleoceno), Cuenca del Colorado, Argentina. Ameghiniana, 30(3), 311-315.

Ruiz, L. \& Quattrocchio, M.E. 1996. Stratigraphic palynology of Pedro Luro Formation (? Maastrichtian-Paleocene), Colorado Basin. Argentine. Elf Aquitaine, 361-371.

Ruiz, L.C. \& Quattrocchio, M.E. 1997b. Estudio palinológico de la Formación Pedro Luro (?Maastrichtiano-Paleoceno), en la Cuenca del Colorado, República Argentina. Parte 2: Turma Saccites, Plicates, Poroses e Incertae Sedis. Revista Española de Micropaleontología, 29(2), 115-137. 
Rull, V. 1997. Sequence analysis of western Venezuelan Cretaceous to Eocene sediments using palynology: chronopaleoenvironmental and paleovegetational approaches. Palynology, 21(1), 79-90.

Rull, V. 2001. A quantitative palynological record from the early Miocene of western Venezuela, with emphasis on mangroves. Palynology, 25(1), 109-126.

Sah, S.C.D. 1967: Palynology of an Upper Neogene profile from Rusizi Valley (Burundi). Annales du Musee Royal de l'Afrique Centrale. Tervuren. Series 8vo, 57: 0-173.

Salard-Cheboldaeff, M., Mouton, J. \& Brunet, M. 1992. Paléoflore tertiaire du Bassin d'Anloua, plateau de l'Adamaoua, Cameroun. Revista Espanola de Micropaleontologia, 24: 131-62.

Salujha, S.K., Berry, C.M., Kindra,G.S. \& Murthy, M.S. 1985. Palynostratigraphic and source rock studies of the Well Lakhpat-1, Kutch. Bulletin of the Oil and Natural Gas Commission, Dehra Dun, India , 22 (2): 179-202.

Sampson, F.B. \& Endress, P.K. 1984. Pollen morphology in the Trimeniaceae. Grana, 23(3): 129-137.

Sastri, V.V., Raju, A.T.R., Sinha, R.N., Venkatachala, B.S. \& Banerji, R.K. 1977. Biostratigraphy and evolution of the Cauvery Basin, India. Journal of the Geological Society of India, 18: 355-377.

Scafati, L., Melendi, D.L. \& Volkheimer, W. 2009. A Danian subtropical lacustrine palynobiota from South America (Bororo Formation, San Jorge Basin, Patagonia - Argentina). Geological acta, 7: 35-61.

Shen, Z.Q., Tong, G.B., Zhang, J.P., Yu, S.F., \& Li, Y.L. 1990. Geological environments since Pliocene and accumulation process of saline deposit in west Chaidamu Basin, Qinghai, China. Mar Geol Quat Geol, 12(8999): 319-328. 
Sokal R.R., Rohlf F.J. 1995. Biometry: Third Edition. W.H. Freeman and Co, New York. 887 pp.

Songtham, W., Ratanasthien, B. \& Mildenhall, D.C. 2004. New species of algae Actinastrum lagerheim and Closterium nitzsch ex Ralfs from Middle Miocene Sediments of Chiang Muan basin, Phayao, Thailand, with tropical pollen composition. Science Asia, 30: 171-181.

Stanley, E.A., 1965. Upper Cretaceous and Paleocene plant microfossils and Paleocene dinoflagellates and hystrichosphaerids from northwestern South Dakota. Bulletin of American paleontology, 49: 179-384.

Stoian, L.M. 2002. Late Cretaceous-Late Eocene palynofloras from drillhole Troas 1, offshore Otway Basin, South Australia. Report Book, 10.

Stover, L.E., \& Partridge, A.D. 1973. Tertiary and Late Cretaceous spores and pollen from the Gippsland Basin, southeastern Australia. Proceedings of the Royal Society of Victoria, 85(2): 237-286.

Stover, L.E. \& Partridge, A.D. 1982. Eocene spore-pollen from the werillup formation, Western Australia. Palynology, 6(1): 69-96.

Stuchlik, L. 1981. Tertiary pollen spectra from the Ezcurra Inlet Group of Admiralty Bay, King George Island (South Shetland Islands, Antarctica). Studia Geologica Polonica, 72: 109-132.

Thornhill, A.H. \& Macphail, M. 2012. Fossil myrtaceous pollen as evidence for the evolutionary history of Myrtaceae: A review of fossil Myrtaceidites species. Review of Palaeobotany and Palynology, 176: 1-23.

Torre, E. 1993. Estudio de la Formación Río Turbio (miembro inferior): Microuleonfologk y Estrurigrufk, Trabajo Final de Licenciatura. Sin publicar. Universidad de Buenos Aires (FCEyN), Buenos Aires, Argentina. 
Troncoso, A. \& Barrera, E. 1980. Polen del Eoceno de Osorno (Chile). Boletín Museo Nacional de Historia Natural de Chile, 37: 179-203.

Troncoso, A. \& Muñoz, J. 1988. La edad de las tobas blanquecinas de Quinamavida y de las areniscas del puente Bullileo ( $7^{\circ}$ Región, Chile). V Congreso Geológico Chileno, 1:203-211.

Troncoso, A., Suárez, M., De la Cruz, R. \& Palma-Heldt, S. 2002. Paleoflora de la Formación Ligorio Márquez (XI Región, Chile) en su localidad tipo: sistemática, edad e implicancias paleoclimáticas. Revista geológica de Chile, 29(1): 113-135.

Troncoso, A. \& Romero, E. J. 1998. Evolución de las comunidades florísticas en el extremo sur de Sudamérica durante el Cenofítico. Monographs in Systematic Botany, 149-172.

Truswell, E.M. \& Owen, J.A., 1988: Eocene pollen from Bungonia, New South Wales. Memoir of the Association of Australasian Paleontologists, 5: 259-284.

Truswell, E.M., Sluiter, I.R. \& Harris, W.K. 1985. Palynology of the OligoceneMiocene sequence in the Oakvale-1 corehole, western Murray Basin, South Australia. Bureau of Mineral Resources journal of Australian geology and geophysics, 9: 267-295.

Tulip, J.R., Taylor, G. \& Truswell, E.M. 1982. Palynology of Tertiary Lake Bunyan, Cooma, New South Wales. Bureau of Mineral Resources journal of Australian geology and geophysics, 7: 255-268.

Vajda-Santivanez, V. 1999. Miospores from upper cretaceous-Paleocene strata in northwestern Bolivia. Palynology, 23(1): 181-196. 
Van Geel, B. 1976. Fossil spores of Zygnemataceae in ditches of a pre-historic settlement in Hoogkarspel (The Netherlands). Review of Palaeobotany and Palynology, 22(4): 337-344.

Van Geel, B., 1998: Are the resting eggs of the rotifer Hexarthra mira (Hudson 1871) the modern analog of Schizosporis reticulatus Cookson and Dettmann 1959? Palynology 22: 83-87.

Van Geel, B. \& Van der Hammen, T. 1978. Zygnemataceae in quaternary Columbian sediments. Review of Palaeobotany and Palynology, 25(5): 377-391.

Venkatachala, B.S. 1973. Palynological evidence on the age of Cuddalore Sandstone. Geophytology, 3(2): 145-149.

Venkatachala, B.S. \& Chowdhary, L.R. 1977. Palaeoecology of the Kadi Formation, Cambay Basin, India. Proceedings of the IVth Colloquium of Indian Micropalaentology and Stratigraphy, Dehradun, 259-277.

Venkatachala, B.S. \& Rawat, M.S. 1972. Palynology of the Tertiary sediments in the Cauvery basin. 1. Palaeocene-Eocene palynoflora from the subsurface. Proc. Seminar Paleopalynol. Indian Stratigr. (Calcutta), 229-335.

Venkatachala, B.S. \& Sharma, K.D. 1984. Palynological zonation in subsurface sediments in Narsapur well No. 1, Godavari-Krishna Basin, India. Proceedings of the X Indian Colloquim on Micropalaeontology and Stratigraphy, 445-466.

Vidal-Russell, R. \& Nickrent, D.L. 2008. The first mistletoes: origins of aerial parasitism in Santalales. Molecular phylogenetics and evolution, 47(2): 523-537.

Weston, P.H. \& Crisp, M.D. 1994. Cladistic biogeography of waratahs (Proteaceae, Embothrieae) and their allies across the pacific. Australian Systematic Botany, 7(3): $225-249$.

White, J.M. 2006. Palynodata Datafile: 2006 version. Canada. http://paleobotany.ru/ 
Wilf, P., Cúneo N.R., Johnson K.R., Hicks J.F., Wing S.L. \& Obradovich, J.D. 2003. High plant diversity in Eocene South America: Evidence from Patagonia. Science (in Reports), 300: 122-125.

Wilf, P., Johnson, K.R., Cúneo, N.R., Smith, M.E., Singer, B.S. \& Gandolfo, M.A. 2005. Eocene plant diversity at Laguna del Hunco and Río Pichileufú, Patagonia, Argentina. The American Naturalist, 165: 634-650.

Wood, G.D., Gabriel, A.M., \& Lawson, J.C. 1996, Palynological techniquesProcessing and microscopy. Jansonius, J., McGregor, D.C. (Eds.). Palynology: Principles and applications. American Association of Stratigraphic Palynologists Foundation, 29-50.

Zamaloa, M del C. 2000. Palinoflora y ambiente en el Terciario del nordeste de Tierra del Fuego, Argentina. Revista del Museo Argentino de Ciencias Naturales, nueva serie, 2(1), 43-51.

Zachos, J., Pagani, M., Sloan, L., Thomas, E. \& Billups, K. 2001. Trends, rhythms, and aberrations in global climate 65 Ma to present. Science, 292: 686-693.

Zamaloa, M. \& Andreis, R. 1995. Asociación palinológica del Paleoceno temprano (Formación Salamanca) en Ea. Laguna Manantiales, Santa Cruz, Argentina. VI Congreso Argentino de Paleontología y Bioestratigrafia, Actas, 301-305.

Zamaloa, M. del C. \& Romero, E.J., 1990: Some spores and pollen from the Cullen Formation (Upper Eocene to Middle Oligocene), Tierra del Fuego, Argentina. Palynology, 14: 123-133.

Zuloaga, F.O. \& Belgrano, M.J. 2008. Catálogo de las plantas vasculares del Cono Sur: Pteridophyta, gymnospermae y monocotyledoneae. Vol. 1. Missouri Botanical Garden. 
APÉNDICE 1 - Muestreo y análisis cuantitativo 
Tabla 1. Secciones analizadas y sus horizontes muestreados.

Tabla 2. Conteos, expresados en frecuencias absolutas, de las muestras analizadas.

Tabla 3. Conteos, expresados en porcentajes, de las muestras analizadas.

Tabla 4. Especies estudiadas y sus categorías para el análisis polínico.

Tabla 5. Valores de rarefacción, línea de corte en 100, 115 y 150 individuos. S=número de especies.

Figura 1. Palinograma de frecuencias absolutas de las especies de Pteridophyta.

Figura 2. Palinograma de frecuencias absolutas de las especies de Gymnospermae. 


\begin{tabular}{|c|c|c|c|c|}
\hline Perfil & GPS & $\begin{array}{c}\mathrm{N}^{\circ} \mathrm{de} \\
\text { campo/preparado }\end{array}$ & $\mathrm{N}^{\circ}$ de muestra & Resultado \\
\hline 1 & $\begin{array}{l}51^{\circ} 34^{\prime} 18.96 " \mathrm{~S} \\
72^{\circ} 20^{\prime} 37.14^{\prime \prime O}\end{array}$ & $\begin{array}{c}1 \\
2 \\
3 \\
4 \\
5 \\
6 \\
7 \\
8 \\
9 \\
10 \\
11 \\
12 \\
13 \\
14 \\
15 \\
16\end{array}$ & $\begin{array}{l}- \\
46 \\
45 \\
44 \\
43 \\
42 \\
41 \\
40 \\
39 \\
38 \\
37 \\
36 \\
35 \\
34 \\
33 \\
32\end{array}$ & $\begin{array}{l}\text { Estéril } \\
\text { Fértil } \\
\text { Fértil } \\
\text { Estéril } \\
\text { Estéril } \\
\text { Fértil } \\
\text { Fértil } \\
\text { Fértil } \\
\text { Fértil } \\
\text { Fértil } \\
\text { Fértil } \\
\text { Fértil } \\
\text { Fértil } \\
\text { Fértil } \\
\text { Fértil } \\
\text { Estéril }\end{array}$ \\
\hline 2 & $\begin{array}{l}51^{\circ} 32^{\prime} 29.40^{\prime \prime} \mathrm{S} \\
72^{\circ} 19^{\prime} 40.70^{\prime \prime O}\end{array}$ & $\begin{array}{l}21 \\
22\end{array}$ & $\begin{array}{l}31 \\
30\end{array}$ & $\begin{array}{l}\text { Fértil } \\
\text { Estéril }\end{array}$ \\
\hline 3 & $\begin{array}{l}51^{\circ} 30^{\prime} 37.00^{\prime \prime} \mathrm{S} \\
72^{\circ} 15^{\prime} 33.00^{\prime \prime} \mathrm{O}\end{array}$ & $\begin{array}{l}25 \\
26 \\
27 \\
28\end{array}$ & $\begin{array}{l}15 \\
16 \\
17 \\
18\end{array}$ & $\begin{array}{l}\text { Fértil } \\
\text { Fértil } \\
\text { Fértil } \\
\text { Fértil }\end{array}$ \\
\hline 4 & $\begin{array}{c}51^{\circ} 26^{\prime} 0.30^{\prime \prime} \mathrm{S} \\
72^{\circ} 13^{\prime} 41.30^{\prime \prime} \mathrm{O}\end{array}$ & $\begin{array}{l}29 \\
30 \\
31 \\
32 \\
33 \\
34 \\
35 \\
36 \\
37 \\
38\end{array}$ & $\begin{array}{c}3 \\
2 \\
1 \\
4 \\
5 \\
6 \\
7 \\
8 \\
9 \\
10\end{array}$ & $\begin{array}{c}\text { Fértil } \\
\text { Fértil } \\
\text { Fértil } \\
\text { Estéril } \\
\text { Fértil } \\
\text { Estéril } \\
\text { Estéril } \\
\text { Estéril } \\
\text { Fértil } \\
\text { Fértil }\end{array}$ \\
\hline 5 & $\begin{array}{l}51^{\circ} 29^{\prime} 24.10^{\prime \prime} \mathrm{S} \\
72^{\circ} 14^{\prime} 43.15^{\prime \prime} \mathrm{O}\end{array}$ & $\begin{array}{l}39 \\
40 \\
41 \\
42\end{array}$ & $\begin{array}{l}11 \\
12 \\
13 \\
14\end{array}$ & $\begin{array}{l}\text { Fértil } \\
\text { Fértil } \\
\text { Fértil } \\
\text { Fértil }\end{array}$ \\
\hline 6 & $\begin{array}{l}51^{\circ} 30^{\prime} 39.20^{\prime \prime} \mathrm{S} \\
72^{\circ} 15^{\prime} 38.40^{\prime \prime} \mathrm{O}\end{array}$ & $\begin{array}{l}43 \\
44\end{array}$ & $\begin{array}{l}19 \\
20\end{array}$ & $\begin{array}{l}\text { Fértil } \\
\text { Fértil }\end{array}$ \\
\hline 7 & $\begin{array}{l}51^{\circ} 31^{\prime} 39.30^{\prime \prime} \mathrm{S} \\
72^{\circ} 20^{\prime} 19.40^{\prime \prime} \mathrm{O}\end{array}$ & $\begin{array}{l}23 \\
24\end{array}$ & $\begin{array}{l}50 \\
51\end{array}$ & $\begin{array}{l}\text { Fértil } \\
\text { Estéril }\end{array}$ \\
\hline 8 & $\begin{array}{l}51^{\circ} 31 ' 57.60^{\prime \prime} \mathrm{S} \\
72^{\circ} 19^{\prime} 13.30^{\prime \prime O}\end{array}$ & $\begin{array}{l}45 \\
46 \\
47\end{array}$ & $\begin{array}{l}48 \\
47 \\
49\end{array}$ & $\begin{array}{l}\text { Estéril } \\
\text { Fértil } \\
\text { Fértil }\end{array}$ \\
\hline 9 & $\begin{array}{l}51^{\circ} 33^{\prime} 24.40^{\prime \prime} \mathrm{S} \\
72^{\circ} 21^{\prime} 5.90^{\prime \prime} \mathrm{O}\end{array}$ & $\begin{array}{l}49 \\
50 \\
51\end{array}$ & $\begin{array}{l}53 \\
54 \\
55\end{array}$ & $\begin{array}{l}\text { Fértil } \\
\text { Estéril } \\
\text { Estéril }\end{array}$ \\
\hline Mina 02 & $\begin{array}{l}51^{\circ} 32 ' 29.30 " \mathrm{~S} \\
72^{\circ} 19^{\prime} 40.40^{\prime \prime} \mathrm{O}\end{array}$ & $\begin{array}{l}\text { MI06 } \\
\text { MI07 } \\
\text { MI08 } \\
\text { MI09 } \\
\text { MI10 } \\
\text { MI11 } \\
\text { MI12 } \\
\text { MI13 } \\
\text { MI14 }\end{array}$ & $\begin{array}{l}29 \\
28 \\
27 \\
26 \\
25 \\
24 \\
23 \\
22 \\
21\end{array}$ & $\begin{array}{c}\text { Estéril } \\
\text { Fértil } \\
\text { Fértil } \\
\text { Fértil } \\
\text { Fértil } \\
\text { Estéril } \\
\text { Fértil } \\
\text { Fértil } \\
\text { Fértil }\end{array}$ \\
\hline
\end{tabular}


Closterium sp.

Especie

\begin{tabular}{|c|c|}
\hline 1 & 2 \\
\hline 0 & 0 \\
\hline 0 & 0 \\
\hline 0 & 0 \\
\hline 0 & 0 \\
\hline 0 & 0 \\
\hline 10 & 1 \\
\hline 0 & 0 \\
\hline 2 & 2 \\
\hline 0 & 0 \\
\hline 1 & 0 \\
\hline 11 & 0 \\
\hline 29 & 11 \\
\hline 0 & 0 \\
\hline 4 & 2 \\
\hline 0 & 0 \\
\hline 0 & 0 \\
\hline 0 & 3 \\
\hline 0 & 0 \\
\hline 0 & 0 \\
\hline 3 & 3 \\
\hline 0 & 0 \\
\hline 0 & 0 \\
\hline 0 & 0 \\
\hline 0 & 1 \\
\hline 0 & 0 \\
\hline 0 & 0 \\
\hline 2 & 0 \\
\hline 3 & 9 \\
\hline 5 & 10 \\
\hline 0 & 0 \\
\hline 0 & 0 \\
\hline 0 & 0 \\
\hline
\end{tabular}

Scenedesmaceae ind

Catinipollis geiseltalensis

Cingutriletes australis

Baculatisporites comaumensis

Baculatisporites turbioensis

Biretisporites sp. I Archangelsky

Concavisporites sp. II

Concavosporites sp.

Cyatheacidites annulatus

Cyathidites minor

Deltoidospora cf australis

Deltoidospora minor

Foveotriletes sp. 1

Gleichenidites circinidites

Gleichenidites senonicus

Klukisporites scaberis

Laevigatosporites ovatus

Leiotriletes minor

Leptolepidites densus

Matonisporites sp. 1

Peromonolites vellosus

Polypodiisporites speciosus

Polypodiumsporites perverrucatus

Pteridophyta indet.

Retitriletes austroclavatidites

Trilites fasolae

Trilites parvalatus

Verrucosisporites sp. 1

Verrucosisporites sp. 2

Verrucosisporites sp. 3

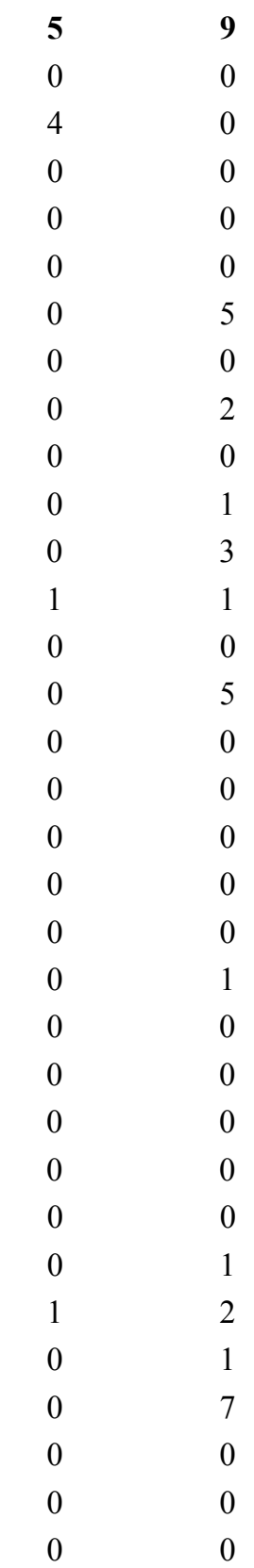

\begin{tabular}{|c|c|}
\hline 10 & 11 \\
\hline 0 & 0 \\
\hline 1 & 0 \\
\hline 0 & 0 \\
\hline 0 & 0 \\
\hline 0 & 0 \\
\hline 0 & 16 \\
\hline 14 & 2 \\
\hline 5 & 0 \\
\hline 0 & 0 \\
\hline 1 & 0 \\
\hline 5 & 3 \\
\hline 3 & 0 \\
\hline 0 & 1 \\
\hline 7 & 7 \\
\hline 0 & 0 \\
\hline 1 & 0 \\
\hline 1 & 0 \\
\hline 0 & 0 \\
\hline 0 & 0 \\
\hline 2 & 2 \\
\hline 0 & 0 \\
\hline 0 & 0 \\
\hline 2 & 0 \\
\hline 0 & 0 \\
\hline 0 & 0 \\
\hline 4 & 2 \\
\hline 0 & 0 \\
\hline 12 & 10 \\
\hline 25 & 13 \\
\hline 0 & 0 \\
\hline 0 & 0 \\
\hline 0 & 0 \\
\hline
\end{tabular}

\begin{tabular}{|c|c|}
\hline 12 & 13 \\
\hline 0 & 0 \\
\hline 0 & 0 \\
\hline 0 & 0 \\
\hline 0 & 0 \\
\hline 0 & 1 \\
\hline 12 & 2 \\
\hline 0 & 7 \\
\hline 0 & 3 \\
\hline 0 & 0 \\
\hline 0 & 0 \\
\hline 0 & 1 \\
\hline 11 & 6 \\
\hline 0 & 0 \\
\hline 1 & 9 \\
\hline 0 & 0 \\
\hline 0 & 0 \\
\hline 1 & 2 \\
\hline 0 & 0 \\
\hline 0 & 0 \\
\hline 4 & 3 \\
\hline 0 & 0 \\
\hline 0 & 0 \\
\hline 0 & 0 \\
\hline 0 & 0 \\
\hline 0 & 0 \\
\hline 1 & 2 \\
\hline 0 & 0 \\
\hline 2 & 4 \\
\hline 5 & 7 \\
\hline 0 & 0 \\
\hline 0 & 0 \\
\hline 0 & 0 \\
\hline
\end{tabular}


Especie

Dacrycarpites australiensis

Equisetosporites notensis

Microachrydites antarcticus

Phyllocladidites mawsonii

Podocarpidites elegans

Podocarpidites marwikii

Podocarpidites microreticuloidatus

Podocarpidites rugulosus

Araucariacites australis

Trisaccites microsacatum

Nothofagidites acromegacanthus

Nothofagidites americanus

Nothofagidites dorotensis

Nothofagidites flemingii

Nothofagidites fortispinulosus

Nothofagidites nanus

Nothofagidites rocaensis

Nothofagidites saraensis

Nothofagidites tehuelchesii

Myrtaceidites eucalyptoides

Myrtaceidites mesonesus

Myrtaceidites parvus

Myrtaceidites verrucosus

Granodiporites nebulosus

Lewalanipollis senectus

Peninsulapollis gilii

Propylipollis ambiguus

Propylipollis annularis

Propylipollis pseudomoides

Propylipollis reticuloscabratus

Proteacidites obscurus

Proteacidites rectus

\begin{tabular}{|c|c|c|}
\hline 1 & 2 & 3 \\
\hline 0 & 0 & 1 \\
\hline 0 & 1 & 0 \\
\hline 0 & 1 & 0 \\
\hline 1 & 3 & 3 \\
\hline 5 & 21 & 10 \\
\hline 1 & 0 & 0 \\
\hline 0 & 0 & 0 \\
\hline 0 & 0 & 1 \\
\hline 7 & 7 & 27 \\
\hline 0 & 0 & 0 \\
\hline 6 & 11 & 1 \\
\hline 10 & 11 & 6 \\
\hline 32 & 32 & 36 \\
\hline 13 & 2 & 5 \\
\hline 0 & 0 & 0 \\
\hline 34 & 38 & 5 \\
\hline 37 & 75 & 21 \\
\hline 46 & 13 & 8 \\
\hline 0 & 0 & 2 \\
\hline 2 & 0 & 0 \\
\hline 1 & 0 & 0 \\
\hline 13 & 10 & 16 \\
\hline 0 & 0 & 3 \\
\hline 0 & 0 & 4 \\
\hline 2 & 0 & 0 \\
\hline 0 & 0 & 0 \\
\hline 0 & 0 & 1 \\
\hline 0 & 0 & 0 \\
\hline 4 & 0 & 1 \\
\hline 0 & 0 & 1 \\
\hline 0 & 0 & 0 \\
\hline 0 & 0 & 3 \\
\hline
\end{tabular}

9
0
0
0
24
43
8
0
0
1
0
11
5
83
1
0
54
27
24
0
0
0
12
1
2
0
0
0
0
2
0
0
0

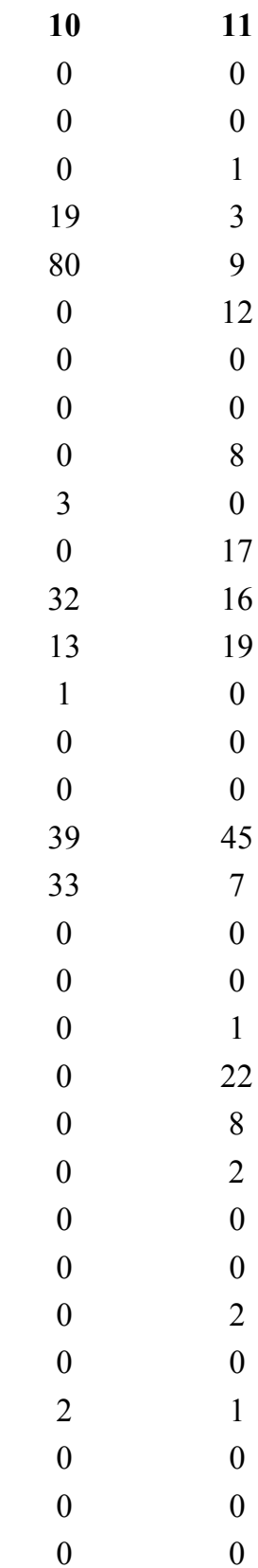

$$
12
$$


Especie

Proteacidites subscabratus

Anacolosidites diffusa

Bombacacidites isoreticulatus

Cupaneidites insularis

Cupaneidites reticularis

Ilexpollenites anguloclavatus

Ilexpollenites clifdenensis

Ilexpollenites megagemmatus

Perysincolporites pokornii

Bysmapollis verrucatus

Compositoipollenites sp. 1

Corsinipollenites atlantica

Dicolpopollis sp. 1

Ericipites sp.

Gothanipollis basensis

Gothanipollis sp. 1

Haloragacidites trioratus

Malvacearumpollis sp. 1

Malvacipollis sp. 1

Margocolporites sp 1 Tipo Prosopis $c f$. Perfotricolpites sp.

Periporopollenites demarcatus

Polycolporopollenites esobalteus

Psilatricolpites brevis

Psilatricolporites ef marginatus

Psilatricolporites costatus

Psilatricolporites divisus

Psilatricolporites pachydermatus

Psilatricolporites aff. P. protrudens

Psilatricolporites vanus

Psilatricolporites varius

Rhoipites alveolatus

$\begin{array}{ll}2 & 3 \\ 6 & 0 \\ 0 & 1 \\ 2 & 0 \\ 0 & 0 \\ 0 & 1 \\ 0 & 1 \\ 5 & 0 \\ 0 & 0 \\ 0 & 0 \\ 0 & 1 \\ 0 & 5 \\ 0 & 0 \\ 0 & 1 \\ 0 & 0 \\ 0 & 3 \\ 1 & 4 \\ 1 & 1 \\ 0 & 0 \\ 1 & 0 \\ 0 & 2 \\ 0 & 0 \\ 0 & 0 \\ 0 & 0 \\ 0 & 0 \\ 0 & 0 \\ 3 & 0 \\ 0 & 0 \\ 0 & 0 \\ 0 & 0 \\ 0 & 0 \\ 7 & 0 \\ 0 & 0 \\ 0 & 0 \\ 0 & 0 \\ 0 & 0 \\ 0 & 0 \\ 0 & 0 \\ 0 & 0 \\ 0 & 0 \\ 0 & 0 \\ 0 & 0 \\ 0 & 0 \\ 0 & 0\end{array}$



\begin{tabular}{|c|c|}
\hline 10 & 11 \\
\hline 0 & 5 \\
\hline 0 & 0 \\
\hline 0 & 2 \\
\hline 0 & 1 \\
\hline 0 & 0 \\
\hline 1 & 0 \\
\hline 0 & 2 \\
\hline 0 & 2 \\
\hline 0 & 1 \\
\hline 0 & 0 \\
\hline 0 & 0 \\
\hline 0 & 0 \\
\hline 0 & 0 \\
\hline 1 & 0 \\
\hline 0 & 0 \\
\hline 0 & 3 \\
\hline 0 & 0 \\
\hline 0 & 1 \\
\hline 2 & 7 \\
\hline 1 & 0 \\
\hline 0 & 0 \\
\hline 0 & 0 \\
\hline 0 & 0 \\
\hline 0 & 4 \\
\hline 0 & 0 \\
\hline 0 & 6 \\
\hline 0 & 0 \\
\hline 0 & 0 \\
\hline 0 & 0 \\
\hline 0 & 10 \\
\hline 0 & 14 \\
\hline 0 & 0 \\
\hline
\end{tabular}

0

0

0

0

0

0

0

0

1

0

0

0

0

0

0

0

0

0

0

0

0 


\section{Especie}

Rhoipites baculatus

Rhoipites cf. hawkdunensis

Rhoipites romboidaliformis

Rhoipites sphaerica

Striatricolporites pseudoestriatus

Tetracolporopollenites sp. 1

Tricolpites bathyreticulatus

Tricolpites brevicolpus

Tricolpites reticulatus

Triorites fragilis

Triorites minor

Triorites subespinosus

Arecipites minutiscabratus

Arecipites sp. 1

cf. Spatiphyllum sp.

Monosulcites ef perspinosus

Psilamonocolpites medius

Graminidites sp.

\section{Liliacidites regularis}

Sparganiaceaepollenites barungensis

Escolecodonte

Foraminifera

Uñas de ácaros

Gonyaulacoideos

Peridinoideos

Total dinoquistes

TOTAL

\begin{tabular}{|c|c|c|c|c|}
\hline 1 & 2 & 3 & 5 & 9 \\
\hline 0 & 3 & 2 & 0 & 0 \\
\hline 0 & 0 & 0 & 0 & 0 \\
\hline 0 & 0 & 0 & 0 & 0 \\
\hline 0 & 0 & 0 & 0 & 0 \\
\hline 1 & 1 & 0 & 0 & 0 \\
\hline 0 & 0 & 1 & 0 & 0 \\
\hline 1 & 0 & 2 & 0 & 0 \\
\hline 0 & 0 & 0 & 0 & 0 \\
\hline 0 & 0 & 1 & 0 & 1 \\
\hline 0 & 0 & 0 & 0 & 0 \\
\hline 11 & 2 & 3 & 0 & 0 \\
\hline 0 & 0 & 0 & 0 & 0 \\
\hline 0 & 0 & 0 & 13 & 0 \\
\hline 0 & 1 & 0 & 0 & 0 \\
\hline 0 & 0 & 0 & 0 & 0 \\
\hline 2 & 0 & 3 & 0 & 3 \\
\hline 6 & 3 & 12 & 9 & 4 \\
\hline 0 & 0 & 0 & 0 & 0 \\
\hline 0 & 1 & 1 & 0 & 0 \\
\hline 0 & 0 & 1 & 5 & 0 \\
\hline 0 & 1 & 0 & 0 & 0 \\
\hline 0 & 0 & 0 & 1 & 0 \\
\hline 1 & 0 & 5 & 0 & 7 \\
\hline 69 & 18 & 67 & 0 & 2 \\
\hline 44 & 22 & 34 & 0 & 29 \\
\hline 113 & 40 & 101 & 0 & 31 \\
\hline 343 & 311 & 305 & 369 & 383 \\
\hline
\end{tabular}

$\mathbf{1 0}$
0
0
0
0
0
0
0
0
0
0
0
0
0
0
0
1
2
0
0
0
0
0
2
349

06
0
0
0
0
0
0
0
0
0
0
0
0
0

11
0
0
0
0
0
0
1
0
2
0
4
0
0
0
0
0
6
0
0
4
9
0
0
764
337

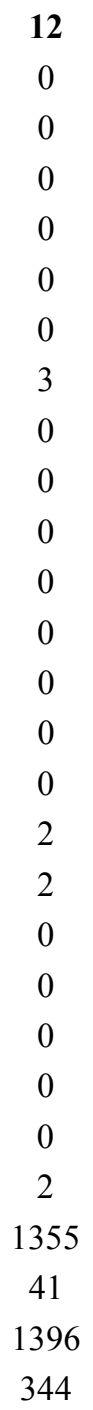

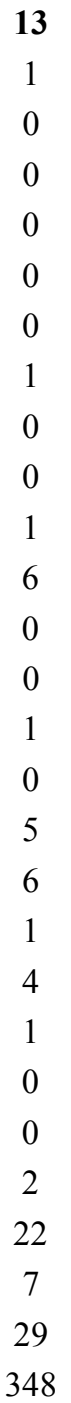


Especie

Closterium sp.

Botryococcus sp.

Scenedesmaceae indet

Catinipollis geiseltalensis

Cingutriletes australis

Baculatisporites comaumensis

Baculatisporites turbioensis

Biretisporites sp. I Archangelsky

Concavisporites sp. II

Concavosporites sp. I

Cyatheacidites annulatus

Cyathidites minor

Deltoidospora cf australis

Deltoidospora minor

Foveotriletes sp. 1

Gleichenidites circinidites

Gleichenidites senonicus

Klukisporites scaberis

Laevigatosporites ovatus

Leiotriletes minor

Leptolepidites densus

Matonisporites sp. 1

Peromonolites vellosus

Polypodiisporites speciosus

Polypodiumsporites perverrucatus

Pteridophyta indet.

Retitriletes austroclavatidites

Trilites fasolae

Trilites parvalatus

Verrucosisporites sp. 1

Verrucosisporites sp. 2

Verrucosisporites sp. 3

\section{5}

20
0
0
0
0
0
4
0
0
0
0
1
13
0
3
0
0
0
0
0
10
0
0
0
0
0
0
0
0
0
0
0
0
0
0
0
0
0
0
0
0
0
0
0
0
0
0
0
0
0
0

21
0
0
2
0
0
3
0
1
0
0
2
16
0
2
0
0
3
0
0
3
0
0
0
0
0
0
0
0
0
0
0
0
0
0
0
0
0
0
0
0
0
0
0
0
0
0
0
0
0
0
0
0
0
0
0

22
0
0
0
0
0
0
5
1
0
0
6
10
0
8
0
0
1
0
0
2
0
0
0
0
0
0
0
0
0
0
0
0
0
0
0
0
0
0
0
0
0
0
0
0
0
0
0
0
0
0
0
0
0
0
0
0
0
0
0
0
0
0
0
0
0




\section{Especie}

Dacrycarpites australiensis

Equisetosporites notensis

Microachrydites antarcticus

Phyllocladidites mawsonii

Podocarpidites elegans

Podocarpidites marwikii

Podocarpidites microreticuloidatus

Podocarpidites rugulosus

Araucariacites australis

Trisaccites microsacatum

Nothofagidites acromegacanthus

Nothofagidites americanus

Nothofagidites dorotensis

Nothofagidites flemingii

Nothofagidites fortispinulosus

Nothofagidites nana

Nothofagidites rocaensis

Nothofagidites saraensis

Nothofagidites tehuelchesii

Myrtaceidites eucalyptoides

Myrtaceidites mesonesus

Myrtaceidites parvus

Myrtaceidites verrucosus

Granodiporites nebulosus

Lewalanipollis senectus

Peninsulapollis gilii

Propylipollis ambiguus

Propylipollis annularis

Propylipollis pseudomoides

Propylipollis reticuloscabratus

Proteacidites obscurus

Proteacidites rectus

\begin{tabular}{|c|c|}
\hline 15 & 16 \\
\hline 1 & 0 \\
\hline 0 & 0 \\
\hline 0 & 0 \\
\hline 2 & 6 \\
\hline 14 & 25 \\
\hline 2 & 0 \\
\hline 0 & 0 \\
\hline 0 & 2 \\
\hline 4 & 0 \\
\hline 0 & 0 \\
\hline 6 & 0 \\
\hline 1 & 4 \\
\hline 56 & 13 \\
\hline 1 & 29 \\
\hline 0 & 0 \\
\hline 1 & 0 \\
\hline 47 & 33 \\
\hline 9 & 45 \\
\hline 0 & 0 \\
\hline 0 & 0 \\
\hline 0 & 0 \\
\hline 13 & 0 \\
\hline 0 & 1 \\
\hline 1 & 0 \\
\hline 2 & 0 \\
\hline 0 & 1 \\
\hline 0 & 0 \\
\hline 0 & 0 \\
\hline 3 & 0 \\
\hline 0 & 0 \\
\hline 0 & 0 \\
\hline 0 & 0 \\
\hline
\end{tabular}

17
0
0
0
0
13
3
3
0
2
0
0
6
18
14
0
10
63
11
0
0
0
30
1
4
1
0
0
0
0
0
0
0

0
0
0
0
0
0
0
0
0
0

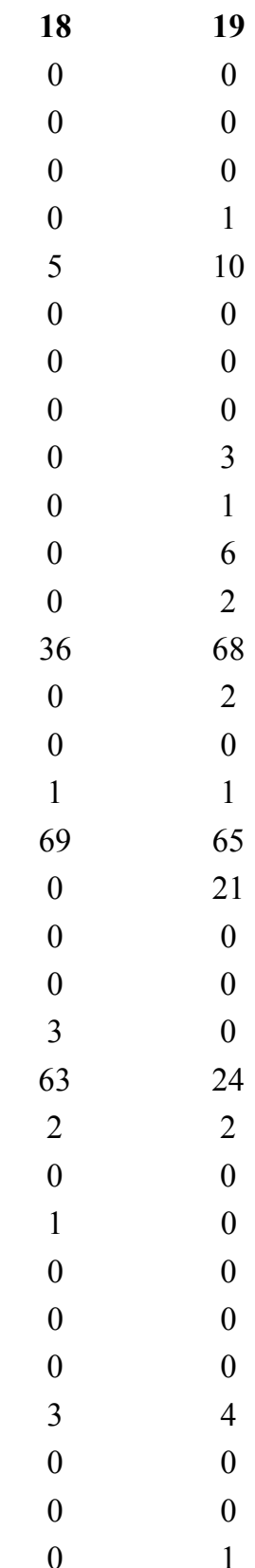

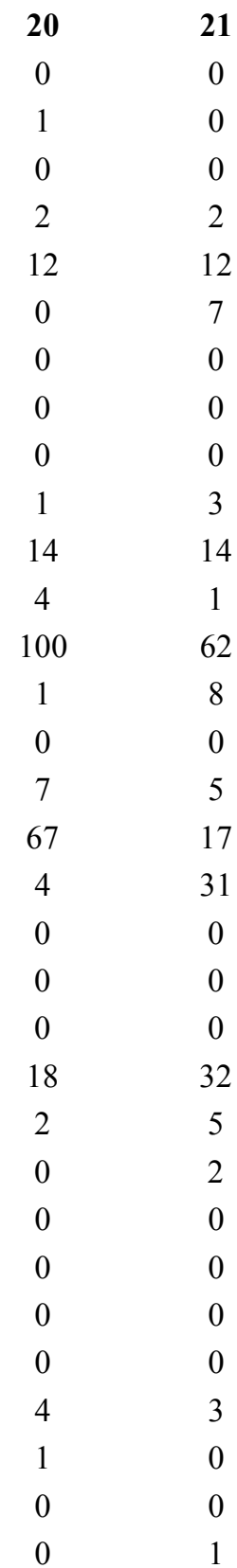

2




\section{Especie}

Proteacidites subscabratus

Anacolosidites diffusa

Bombacacidites isoreticulatus

Cupaneidites insularis

Cupaneidites reticularis

Ilexpollenites anguloclavatus

Ilexpollenites clifdenensis

Ilexpollenites megagemmatus

Perysincolporites pokornii

Bysmapollis verrucatus

Compositoipollenites sp. 1

Corsinipollenites atlantica

Dicolpopollis sp. 1

Ericipites sp.

Gothanipollis basensis

Gothanipollis sp. 1

Haloragacidites trioratus

Malvacearumpollis sp. 1

Malvacipollis sp. 1

Margocolporites sp 1 Tipo Prosopis

cf. Perfotricolpites sp.

Periporopollenites sp. 1

Polycolporopollenites esobalteus

Psilatricolpites brevis

Psilatricolporites cf marginatus

Psilatricolporites costatus

Psilatricolporites divisus

Psilatricolporites pachydermatus

Psilatricolporites protrudens

Psilatricolporites vanus

Psilatricolporites varius

Rhoipites alveolatus

$\begin{array}{ccccc}\mathbf{1 5} & \mathbf{1 6} & \mathbf{1 7} & \mathbf{1 8} & \mathbf{1 9} \\ 5 & 0 & 1 & 5 & 2 \\ 0 & 0 & 0 & 0 & 0 \\ 0 & 0 & 1 & 0 & 4 \\ 1 & 0 & 0 & 1 & 0 \\ 0 & 0 & 0 & 0 & 1 \\ 2 & 8 & 0 & 3 & 2 \\ 0 & 0 & 7 & 4 & 3 \\ 0 & 0 & 0 & 0 & 0 \\ 0 & 0 & 0 & 0 & 0 \\ 0 & 0 & 0 & 0 & 0 \\ 0 & 0 & 0 & 2 & 0 \\ 0 & 0 & 0 & 0 & 0 \\ 0 & 0 & 0 & 1 & 0 \\ 1 & 2 & 0 & 0 & 0 \\ 3 & 0 & 2 & 8 & 0 \\ 1 & 0 & 0 & 1 & 1 \\ 1 & 0 & 0 & 0 & 0 \\ 2 & 0 & 0 & 0 & 0 \\ 3 & 0 & 0 & 2 & 3 \\ 0 & 0 & 0 & 3 & 0 \\ 0 & 0 & 0 & 0 & 0 \\ 0 & 0 & 0 & 0 & 0 \\ 0 & 0 & 0 & 0 & 0 \\ 0 & 0 & 5 & 0 & 0 \\ 3 & 0 & 0 & 0 & 0 \\ 4 & 0 & 8 & 15 & 6 \\ 0 & 0 & 1 & 0 & 0 \\ 0 & 0 & 0 & 0 & 0 \\ 0 & 0 & 0 & 0 & 0 \\ 0 & 0 & 0 & 8 & 4 \\ 10 & 0 & 18 & 18 & 6 \\ 0 & 0 & 0 & 0 & 0\end{array}$

$\mathbf{2 0}$
4
0
3
0
0
0
1
0
0
0
0
0
0
1
2
0
0
3
0
1
0
3
0
0
0
0
0
0
0
1
14
0

0
0
0
0
0
0

21
7
0
0
3
1
0
1
0
0
0
0
0
1
0
4
1
0
1
0
0
0
1
1
0
0
7
0
0
0
0
23
0

10

25

0

0 
Especie

Rhoipites baculatus

Rhoipites cf. hawkdunensis

Rhoipites romboidaliformis

Rhoipites sphaerica

Striatricolporites pseudoestriatus

Tetracolporopollenites sp. 1

Tricolpites bathyreticulatus

Tricolpites brevicolpus

Tricolpites reticulatus

Triorites fragilis

Triorites minor

Triorites subespinosus

Arecipites minutiscabratus

Arecipites sp. 1

cf. Spatiphyllum sp.

Monosulcites ef perspinosus

Psilamonocolpites medius

Graminidites sp.

Liliacidites regularis

Sparganiaceaepollenites barungensis

Escolecodonte

Foraminifera

Uñas de ácaros

Gonyaulacales

Peridiniales

Total dinoquistes

TOTAL

20
0
1
0
0
1
0
1
0
0
0
4
0
0
1
0
0
0
0
1
0
0
0
0
0
0
0
0
0
0
0

21
0
1
0
0
0
0
0
0
0
1
2
0
0
0
0
2
3
0
3
3
0
0
0
0
0
0
0
0
0
0
0
0
0
0

22


Especie

Closterium sp.

Botryococcus sp.

Scenedesmaceae indet

Catinipollis geiseltalensis

Cingutriletes australis

Baculatisporites comaumensis

Baculatisporites turbioensis

Biretisporites sp. I Archangelsky

Concavisporites sp. II

Concavosporites sp. I

Cyatheacidites annulatus

Cyathidites minor

Deltoidospora cf australis

Deltoidospora minor

Foveotriletes sp. 1

Gleichenidites circinidites

Gleichenidites senonicus

Klukisporites scaberis

Laevigatosporites ovatus

Leiotriletes minor

Leptolepidites densus

Matonisporites sp. 1

Peromonolites vellosus

Polypodiisporites speciosus

Polypodiumsporites perverrucatus

Pteridophyta indet.

Retitriletes austroclavatidites

Trilites fasolae

Trilites parvalatus

Verrucosisporites sp. 1

Verrucosisporites sp. 2

Verrucosisporites sp. 3

\begin{tabular}{|c|c|c|}
\hline 26 & 27 & 28 \\
\hline 0 & 0 & 0 \\
\hline 0 & 0 & 0 \\
\hline 2 & 0 & 4 \\
\hline 0 & 0 & 0 \\
\hline 0 & 0 & 0 \\
\hline 5 & 0 & 0 \\
\hline 0 & 4 & 3 \\
\hline 0 & 1 & 1 \\
\hline 0 & 0 & 0 \\
\hline 0 & 0 & 0 \\
\hline 5 & 1 & 1 \\
\hline 8 & 14 & 13 \\
\hline 0 & 0 & 0 \\
\hline 6 & 3 & 3 \\
\hline 0 & 0 & 0 \\
\hline 1 & 1 & 0 \\
\hline 3 & 0 & 12 \\
\hline 0 & 0 & 0 \\
\hline 1 & 0 & 0 \\
\hline 2 & 5 & 3 \\
\hline 0 & 0 & 0 \\
\hline 0 & 0 & 0 \\
\hline 0 & 0 & 0 \\
\hline 0 & 0 & 0 \\
\hline 0 & 0 & 0 \\
\hline 0 & 0 & 0 \\
\hline 0 & 0 & 0 \\
\hline 2 & 3 & 0 \\
\hline 15 & 14 & 25 \\
\hline 0 & 0 & 0 \\
\hline 0 & 0 & 0 \\
\hline 0 & 0 & 0 \\
\hline
\end{tabular}

\begin{tabular}{|c|c|}
\hline 31 & 33 \\
\hline 0 & 0 \\
\hline 0 & 0 \\
\hline 1 & 1 \\
\hline 0 & 1 \\
\hline 0 & 0 \\
\hline 4 & 0 \\
\hline 2 & 0 \\
\hline 1 & 0 \\
\hline 0 & 0 \\
\hline 0 & 0 \\
\hline 1 & 10 \\
\hline 1 & 15 \\
\hline 0 & 0 \\
\hline 11 & 6 \\
\hline 0 & 0 \\
\hline 0 & 0 \\
\hline 11 & 1 \\
\hline 0 & 0 \\
\hline 0 & 0 \\
\hline 2 & 1 \\
\hline 0 & 0 \\
\hline 0 & 0 \\
\hline 0 & 0 \\
\hline 1 & 1 \\
\hline 0 & 2 \\
\hline 0 & 0 \\
\hline 1 & 3 \\
\hline 1 & 1 \\
\hline 9 & 2 \\
\hline 0 & 0 \\
\hline 0 & 0 \\
\hline 0 & 0 \\
\hline
\end{tabular}

\begin{tabular}{|c|c|}
\hline 34 & 35 \\
\hline 0 & 0 \\
\hline 0 & 0 \\
\hline 2 & 1 \\
\hline 0 & 4 \\
\hline 0 & 0 \\
\hline 4 & 1 \\
\hline 0 & 0 \\
\hline 0 & 4 \\
\hline 0 & 0 \\
\hline 0 & 0 \\
\hline 19 & 1 \\
\hline 33 & 7 \\
\hline 0 & 0 \\
\hline 19 & 16 \\
\hline 0 & 0 \\
\hline 0 & 0 \\
\hline 0 & 0 \\
\hline 0 & 0 \\
\hline 0 & 0 \\
\hline 6 & 1 \\
\hline 0 & 0 \\
\hline 0 & 0 \\
\hline 0 & 1 \\
\hline 0 & 0 \\
\hline 0 & 1 \\
\hline 1 & 0 \\
\hline 0 & 0 \\
\hline 2 & 0 \\
\hline 0 & 4 \\
\hline 0 & 0 \\
\hline 0 & 0 \\
\hline 0 & 0 \\
\hline
\end{tabular}

36

0
0
3
0
0
6
3
5
0
5
4
3
0
71
0
0
7
3
1
0
1
1
0
0
1
0
0
0
0
0
0
0
0
0
0
0
0




\section{Especie}

Dacrycarpites australiensis

Equisetosporites notensis

Microachrydites antarcticus

Phyllocladidites mawsonii

Podocarpidites elegans

Podocarpidites marwikii

Podocarpidites microreticuloidatus

Podocarpidites rugulosus

Araucariacites australis

Trisaccites microsacatum

Nothofagidites acromegacanthus

Nothofagidites americanus

Nothofagidites dorotensis

Nothofagidites flemingii

Nothofagidites fortispinulosus

Nothofagidites nana

Nothofagidites rocaensis

Nothofagidites saraensis

Nothofagidites tehuelchesii

Myrtaceidites eucalyptoides

Myrtaceidites mesonesus

Myrtaceidites parvus

Myrtaceidites verrucosus

Granodiporites nebulosus

Lewalanipollis senectus

Peninsulapollis gilii

Propylipollis ambiguus

Propylipollis annularis

Propylipollis pseudomoides

Propylipollis reticuloscabratus

Proteacidites obscurus

Proteacidites rectus

\begin{tabular}{|c|c|}
\hline 26 & 27 \\
\hline 0 & 0 \\
\hline 0 & 0 \\
\hline 0 & 2 \\
\hline 7 & 3 \\
\hline 13 & 10 \\
\hline 6 & 13 \\
\hline 0 & 0 \\
\hline 0 & 6 \\
\hline 0 & 2 \\
\hline 1 & 2 \\
\hline 17 & 29 \\
\hline 1 & 0 \\
\hline 82 & 94 \\
\hline 3 & 5 \\
\hline 0 & 0 \\
\hline 2 & 1 \\
\hline 48 & 36 \\
\hline 21 & 9 \\
\hline 0 & 0 \\
\hline 0 & 0 \\
\hline 0 & 0 \\
\hline 19 & 5 \\
\hline 0 & 0 \\
\hline 0 & 4 \\
\hline 0 & 0 \\
\hline 0 & 0 \\
\hline 0 & 0 \\
\hline 0 & 0 \\
\hline 0 & 4 \\
\hline 1 & 0 \\
\hline 0 & 0 \\
\hline 0 & 0 \\
\hline
\end{tabular}

\begin{tabular}{|c|c|}
\hline 31 & 33 \\
\hline 0 & 2 \\
\hline 0 & 0 \\
\hline 0 & 0 \\
\hline 26 & 5 \\
\hline 58 & 10 \\
\hline 0 & 2 \\
\hline 0 & 0 \\
\hline 3 & 0 \\
\hline 0 & 0 \\
\hline 4 & 0 \\
\hline 0 & 0 \\
\hline 0 & 6 \\
\hline 1 & 59 \\
\hline 70 & 0 \\
\hline 0 & 0 \\
\hline 2 & 0 \\
\hline 58 & 34 \\
\hline 39 & 28 \\
\hline 0 & 1 \\
\hline 0 & 0 \\
\hline 0 & 0 \\
\hline 0 & 27 \\
\hline 0 & 3 \\
\hline 0 & 1 \\
\hline 0 & 2 \\
\hline 0 & 0 \\
\hline 0 & 0 \\
\hline 0 & 0 \\
\hline 4 & 0 \\
\hline 0 & 0 \\
\hline 0 & 0 \\
\hline 0 & 4 \\
\hline
\end{tabular}

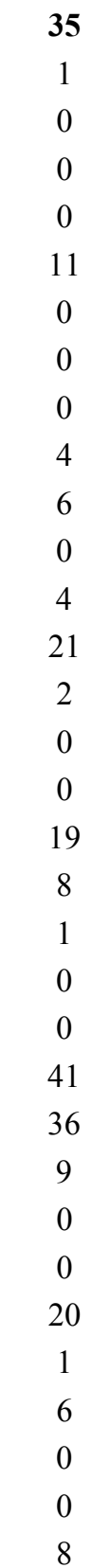

\begin{tabular}{|c|c|}
\hline 36 & 37 \\
\hline 0 & 0 \\
\hline 0 & 0 \\
\hline 0 & 0 \\
\hline 11 & 2 \\
\hline 90 & 6 \\
\hline 0 & 0 \\
\hline 0 & 0 \\
\hline 0 & 0 \\
\hline 0 & 0 \\
\hline 0 & 1 \\
\hline 0 & 0 \\
\hline 0 & 6 \\
\hline 13 & 41 \\
\hline 18 & 0 \\
\hline 0 & 0 \\
\hline 0 & 0 \\
\hline 41 & 43 \\
\hline 20 & 13 \\
\hline 0 & 0 \\
\hline 0 & 0 \\
\hline 0 & 2 \\
\hline 1 & 12 \\
\hline 2 & 21 \\
\hline 2 & 1 \\
\hline 0 & 3 \\
\hline 0 & 1 \\
\hline 0 & 0 \\
\hline 0 & 0 \\
\hline 3 & 2 \\
\hline 0 & 0 \\
\hline 0 & 0 \\
\hline 0 & 10 \\
\hline
\end{tabular}




\section{Especie}

Proteacidites subscabratus

Anacolosidites diffusa

Bombacacidites isoreticulatus

Cupaneidites insularis

Cupaneidites reticularis

Ilexpollenites anguloclavatus

Ilexpollenites clifdenensis

Ilexpollenites megagemmatus

Perysincolporites pokornii

Bysmapollis verrucatus

Compositoipollenites sp. 1

Corsinipollenites atlantica

Dicolpopollis sp. 1

Ericipites sp.

Gothanipollis basensis

Gothanipollis sp. 1

Haloragacidites trioratus

Malvacearumpollis sp. 1

Malvacipollis sp. 1

Margocolporites sp 1 Tipo Prosopis

cf. Perfotricolpites sp.

Periporopollenites sp. 1

Polycolporopollenites esobalteus

Psilatricolpites brevis

Psilatricolporites ef marginatus

Psilatricolporites costatus

Psilatricolporites divisus

Psilatricolporites pachydermatus

Psilatricolporites protrudens

Psilatricolporites vanus

Psilatricolporites varius

Rhoipites alveolatus

\begin{tabular}{|c|c|}
\hline 26 & 27 \\
\hline 2 & 1 \\
\hline 0 & 0 \\
\hline 0 & 0 \\
\hline 0 & 0 \\
\hline 0 & 0 \\
\hline 1 & 1 \\
\hline 11 & 1 \\
\hline 0 & 0 \\
\hline 0 & 0 \\
\hline 0 & 0 \\
\hline 0 & 0 \\
\hline 0 & 0 \\
\hline 0 & 0 \\
\hline 0 & 0 \\
\hline 0 & 0 \\
\hline 0 & 0 \\
\hline 0 & 0 \\
\hline 0 & 3 \\
\hline 1 & 1 \\
\hline 2 & 0 \\
\hline 0 & 0 \\
\hline 3 & 0 \\
\hline 0 & 0 \\
\hline 0 & 1 \\
\hline 0 & 0 \\
\hline 1 & 0 \\
\hline 0 & 0 \\
\hline 0 & 0 \\
\hline 0 & 0 \\
\hline 0 & 6 \\
\hline 12 & 5 \\
\hline 0 & 0 \\
\hline
\end{tabular}

\begin{tabular}{|c|c|c|}
\hline 31 & 33 & 34 \\
\hline 0 & 4 & 0 \\
\hline 0 & 0 & 0 \\
\hline 0 & 1 & 0 \\
\hline 0 & 0 & 0 \\
\hline 0 & 0 & 0 \\
\hline 4 & 2 & 0 \\
\hline 2 & 0 & 0 \\
\hline 1 & 0 & 0 \\
\hline 0 & 0 & 0 \\
\hline 0 & 0 & 0 \\
\hline 0 & 0 & 6 \\
\hline 0 & 0 & 0 \\
\hline 0 & 0 & 0 \\
\hline 0 & 2 & 0 \\
\hline 0 & 4 & 3 \\
\hline 0 & 0 & 1 \\
\hline 0 & 0 & 0 \\
\hline 0 & 0 & 0 \\
\hline 5 & 3 & 1 \\
\hline 0 & 3 & 3 \\
\hline 0 & 0 & 0 \\
\hline 2 & 0 & 0 \\
\hline 0 & 0 & 0 \\
\hline 0 & 1 & 2 \\
\hline 0 & 0 & 0 \\
\hline 0 & 3 & 10 \\
\hline 1 & 0 & 0 \\
\hline 0 & 0 & 0 \\
\hline 0 & 1 & 0 \\
\hline 0 & 0 & 0 \\
\hline 0 & 39 & 61 \\
\hline 0 & 0 & 0 \\
\hline
\end{tabular}




\section{Especie}

Rhoipites baculatus

Rhoipites cf. hawkdunensis

Rhoipites romboidaliformis

Rhoipites sphaerica

Striatricolporites pseudoestriatus

Tetracolporopollenites sp. 1

Tricolpites bathyreticulatus

Tricolpites brevicolpus

Tricolpites reticulatus

Triorites fragilis

Triorites minor

Triorites subespinosus

Arecipites minutiscabratus

Arecipites sp. 1

cf. Spatiphyllum sp.

Monosulcites cf perspinosus

Psilamonocolpites medius

Graminidites sp.

Liliacidites regularis

Sparganiaceaepollenites barungensis

Escolecodonte

Foraminifera

Uñas de ácaros

Gonyaulacales

Peridiniales

Total dinoquistes

TOTAL

\begin{tabular}{|c|c|c|c|}
\hline 26 & 27 & 28 & 31 \\
\hline 2 & 0 & 1 & 2 \\
\hline 0 & 1 & 0 & 0 \\
\hline 0 & 0 & 0 & 0 \\
\hline 0 & 0 & 0 & 0 \\
\hline 0 & 0 & 1 & 0 \\
\hline 0 & 0 & 0 & 0 \\
\hline 0 & 0 & 0 & 0 \\
\hline 0 & 0 & 0 & 0 \\
\hline 0 & 1 & 0 & 0 \\
\hline 0 & 0 & 0 & 1 \\
\hline 0 & 1 & 3 & 1 \\
\hline 0 & 0 & 0 & 0 \\
\hline 0 & 0 & 0 & 0 \\
\hline 0 & 1 & 0 & 1 \\
\hline 0 & 1 & 0 & 0 \\
\hline 0 & 1 & 0 & 0 \\
\hline 2 & 2 & 0 & 5 \\
\hline 0 & 0 & 0 & 0 \\
\hline 1 & 2 & 0 & 0 \\
\hline 0 & 0 & 0 & 3 \\
\hline 0 & 0 & 0 & 0 \\
\hline 0 & 0 & 0 & 0 \\
\hline 4 & 1 & 0 & 0 \\
\hline 19 & 13 & 19 & 7 \\
\hline 0 & 1 & 2 & 1 \\
\hline 19 & 14 & 21 & 8 \\
\hline 404 & 0 & 385 & 381 \\
\hline
\end{tabular}

33
11
0
0
0
0
0
0
2
3
0
1
1
0
0
0
0
0
0
0
0
0
8
6
389

07
0
0
0
0
0
0
0
0
0
0
0
0
0
0
0
0
0
0
0
0

\begin{tabular}{|c|c|}
\hline 34 & 35 \\
\hline 1 & 2 \\
\hline 0 & 0 \\
\hline 0 & 0 \\
\hline 0 & 0 \\
\hline 0 & 0 \\
\hline 0 & 1 \\
\hline 1 & 0 \\
\hline 0 & 0 \\
\hline 0 & 3 \\
\hline 0 & 1 \\
\hline 7 & 3 \\
\hline 0 & 0 \\
\hline 0 & 0 \\
\hline 1 & 0 \\
\hline 0 & 0 \\
\hline 0 & 0 \\
\hline 6 & 17 \\
\hline 1 & 0 \\
\hline 0 & 0 \\
\hline 0 & 2 \\
\hline 0 & 0 \\
\hline 0 & 0 \\
\hline 9 & 6 \\
\hline 12 & 5 \\
\hline 12 & 7 \\
\hline 24 & 12 \\
\hline 431 & 406 \\
\hline
\end{tabular}

\begin{tabular}{|c|c|c|}
\hline 36 & 37 & 38 \\
\hline 3 & 4 & 1 \\
\hline 0 & 1 & 0 \\
\hline 0 & 0 & 0 \\
\hline 0 & 0 & 1 \\
\hline 0 & 0 & 0 \\
\hline 0 & 0 & 0 \\
\hline 1 & 2 & 0 \\
\hline 0 & 0 & 0 \\
\hline 0 & 2 & 1 \\
\hline 0 & 3 & 1 \\
\hline 0 & 9 & 1 \\
\hline 0 & 0 & 0 \\
\hline 0 & 0 & 6 \\
\hline 0 & 0 & 0 \\
\hline 0 & 0 & 0 \\
\hline 0 & 0 & 0 \\
\hline 1 & 11 & 5 \\
\hline 0 & 0 & 0 \\
\hline 0 & 2 & 0 \\
\hline 0 & 0 & 0 \\
\hline 0 & 0 & 0 \\
\hline 1 & 0 & 0 \\
\hline 4 & 8 & 0 \\
\hline 623 & 179 & 771 \\
\hline 16 & 6 & 4 \\
\hline 639 & 185 & 775 \\
\hline 426 & 467 & 531 \\
\hline
\end{tabular}


Closterium sp.

Especie

Botryococcus sp.

Scenedesmaceae indet

Catinipollis geiseltalensis

Cingutriletes australis

Baculatisporites comaumensis

Baculatisporites turbioensis

Biretisporites sp. I Archangelsky

Concavisporites sp. II

Concavosporites sp. I

Cyatheacidites annulatus

Cyathidites minor

Deltoidospora cf australis

Deltoidospora minor

Foveotriletes sp. 1

Gleichenidites circinidites

Gleichenidites senonicus

Klukisporites scaberis

Laevigatosporites ovatus

Leiotriletes minor

Leptolepidites densus

Matonisporites sp. 1

Peromonolites vellosus

Polypodiisporites speciosus

Polypodiumsporites perverrucatus

Pteridophyta indet.

Retitriletes austroclavatidites

Trilites fasolae

Trilites parvalatus

Verrucosisporites sp. 1

Verrucosisporites sp. 2

Verrucosisporites sp. 3

40
0
0
0
0
0
0
6
0
0
0
6
6
8
10
0
0
2
0
0
1
0
0
0
0
0
0
0
0
0
0
0
0
0
0
0
0
0
0
0
0
0
0
0
0
0
0
0
0
0
0

41
0
0
0
0
0
0
15
3
1
0
9
11
1
16
0
0
2
0
0
0
1
0
1
1
1
0
0
0
0

0
0
0
0
0
0
0
0

42
0
0
0
0
0
1
8
0
0
0
16
4
0
39
0
2
1
0
9
4
2
0
12
0
1
1
1
7
0

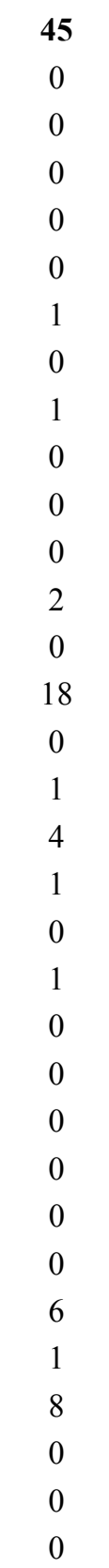

\begin{tabular}{|c|c|}
\hline 46 & 47 \\
\hline 0 & 0 \\
\hline 0 & 0 \\
\hline 0 & 0 \\
\hline 0 & 0 \\
\hline 0 & 0 \\
\hline 39 & 0 \\
\hline 10 & 0 \\
\hline 1 & 2 \\
\hline 0 & 0 \\
\hline 0 & 0 \\
\hline 7 & 8 \\
\hline 6 & 1 \\
\hline 0 & 0 \\
\hline 31 & 14 \\
\hline 0 & 0 \\
\hline 0 & 0 \\
\hline 16 & 1 \\
\hline 1 & 0 \\
\hline 0 & 0 \\
\hline 11 & 2 \\
\hline 1 & 0 \\
\hline 0 & 0 \\
\hline 3 & 0 \\
\hline 0 & 0 \\
\hline 0 & 0 \\
\hline 0 & 0 \\
\hline 3 & 1 \\
\hline 9 & 2 \\
\hline 36 & 11 \\
\hline 0 & 0 \\
\hline 0 & 0 \\
\hline 0 & 0 \\
\hline
\end{tabular}

49
0
0
2
0
5
0
0
7
14
0
0
2
0
0
0
0
0
0
41




\section{Especie}

Dacrycarpites australiensis

Equisetosporites notensis

Microachrydites antarcticus

Phyllocladidites mawsonii

Podocarpidites elegans

Podocarpidites marwikii

Podocarpidites microreticuloidatus

Podocarpidites rugulosus

Araucariacites australis

Trisaccites microsacatum

Nothofagidites acromegacanthus

Nothofagidites americanus

Nothofagidites dorotensis

Nothofagidites flemingii

Nothofagidites fortispinulosus

Nothofagidites nana

Nothofagidites rocaensis

Nothofagidites saraensis

Nothofagidites tehuelchesii

Myrtaceidites eucalyptoides

Myrtaceidites mesonesus

Myrtaceidites parvus

Myrtaceidites verrucosus

Granodiporites nebulosus

Lewalanipollis senectus

Peninsulapollis gilii

Propylipollis ambiguus

Propylipollis annularis

Propylipollis pseudomoides

Propylipollis reticuloscabratus

Proteacidites obscurus

Proteacidites rectus

\begin{tabular}{|c|c|c|}
\hline 39 & 40 & 41 \\
\hline 1 & 1 & 0 \\
\hline 0 & 0 & 0 \\
\hline 0 & 0 & 0 \\
\hline 0 & 0 & 2 \\
\hline 37 & 12 & 0 \\
\hline 1 & 4 & 0 \\
\hline 0 & 0 & 0 \\
\hline 0 & 0 & 0 \\
\hline 1 & 0 & 0 \\
\hline 1 & 2 & 0 \\
\hline 0 & 0 & 0 \\
\hline 0 & 0 & 4 \\
\hline 16 & 53 & 16 \\
\hline 29 & 14 & 5 \\
\hline 0 & 0 & 0 \\
\hline 6 & 13 & 1 \\
\hline 100 & 26 & 39 \\
\hline 0 & 18 & 5 \\
\hline 0 & 0 & 0 \\
\hline 0 & 0 & 0 \\
\hline 0 & 0 & 2 \\
\hline 0 & 27 & 47 \\
\hline 0 & 19 & 3 \\
\hline 0 & 2 & 5 \\
\hline 0 & 0 & 0 \\
\hline 1 & 0 & 0 \\
\hline 0 & 0 & 0 \\
\hline 0 & 0 & 0 \\
\hline 5 & 3 & 0 \\
\hline 0 & 0 & 0 \\
\hline 0 & 0 & 0 \\
\hline 0 & 4 & 0 \\
\hline
\end{tabular}

\begin{tabular}{|c|c|c|c|c|c|}
\hline 42 & 45 & 46 & 47 & 49 & 50 \\
\hline 4 & 3 & 1 & 0 & 0 & 1 \\
\hline 0 & 0 & 0 & 0 & 0 & 0 \\
\hline 0 & 0 & 0 & 0 & 0 & 0 \\
\hline 1 & 9 & 26 & 3 & 4 & 3 \\
\hline 24 & 63 & 64 & 16 & 11 & 13 \\
\hline 0 & 0 & 0 & 0 & 0 & 0 \\
\hline 0 & 0 & 0 & 0 & 0 & 0 \\
\hline 0 & 9 & 0 & 0 & 0 & 0 \\
\hline 0 & 0 & 0 & 9 & 6 & 0 \\
\hline 1 & 5 & 2 & 0 & 0 & 0 \\
\hline 0 & 1 & 0 & 104 & 82 & 0 \\
\hline 1 & 2 & 0 & 1 & 4 & 10 \\
\hline 25 & 5 & 20 & 43 & 14 & 15 \\
\hline 41 & 138 & 103 & 0 & 0 & 0 \\
\hline 0 & 27 & 0 & 0 & 0 & 0 \\
\hline 0 & 8 & 0 & 5 & 0 & 64 \\
\hline 79 & 27 & 31 & 59 & 69 & 0 \\
\hline 42 & 25 & 18 & 4 & 8 & 56 \\
\hline 2 & 0 & 1 & 0 & 0 & 2 \\
\hline 0 & 0 & 0 & 0 & 0 & 0 \\
\hline 0 & 0 & 0 & 0 & 0 & 0 \\
\hline 6 & 0 & 0 & 10 & 0 & 0 \\
\hline 0 & 0 & 0 & 0 & 1 & 0 \\
\hline 13 & 1 & 0 & 1 & 11 & 1 \\
\hline 1 & 1 & 0 & 0 & 0 & 0 \\
\hline 1 & 1 & 0 & 0 & 0 & 0 \\
\hline 0 & 1 & 0 & 0 & 0 & 0 \\
\hline 0 & 0 & 0 & 0 & 0 & 1 \\
\hline 0 & 1 & 4 & 0 & 4 & 4 \\
\hline 0 & 0 & 0 & 0 & 1 & 0 \\
\hline 0 & 0 & 0 & 0 & 0 & 0 \\
\hline 9 & 0 & 3 & 0 & 0 & 0 \\
\hline
\end{tabular}




\section{Especie}

Proteacidites subscabratus

Anacolosidites diffusa

Bombacacidites isoreticulatus

Cupaneidites insularis

Cupaneidites reticularis

Ilexpollenites anguloclavatus

Ilexpollenites clifdenensis

Ilexpollenites megagemmatus

Perysincolporites pokornii

Bysmapollis verrucatus

Compositoipollenites sp. 1

Corsinipollenites atlantica

Dicolpopollis sp. 1

Ericipites sp.

Gothanipollis basensis

Gothanipollis sp. 1

Haloragacidites trioratus

Malvacearumpollis sp. 1

Malvacipollis sp. 1

Margocolporites sp 1 Tipo Prosopis

cf. Perfotricolpites sp.

Periporopollenites sp. 1

Polycolporopollenites esobalteus

Psilatricolpites brevis

Psilatricolporites cf marginatus

Psilatricolporites costatus

Psilatricolporites divisus

Psilatricolporites pachydermatus

Psilatricolporites protrudens

Psilatricolporites vanus

Psilatricolporites varius

Rhoipites alveolatus

\begin{tabular}{|c|c|}
\hline 39 & 40 \\
\hline 0 & 0 \\
\hline 0 & 0 \\
\hline 11 & 8 \\
\hline 0 & 0 \\
\hline 0 & 0 \\
\hline 2 & 0 \\
\hline 5 & 0 \\
\hline 0 & 0 \\
\hline 0 & 0 \\
\hline 1 & 0 \\
\hline 0 & 0 \\
\hline 0 & 0 \\
\hline 0 & 0 \\
\hline 0 & 2 \\
\hline 1 & 2 \\
\hline 0 & 0 \\
\hline 0 & 0 \\
\hline 0 & 0 \\
\hline 0 & 1 \\
\hline 0 & 0 \\
\hline 0 & 0 \\
\hline 1 & 0 \\
\hline 0 & 1 \\
\hline 0 & 0 \\
\hline 0 & 0 \\
\hline 0 & 0 \\
\hline 0 & 0 \\
\hline 0 & 0 \\
\hline 0 & 0 \\
\hline 0 & 0 \\
\hline 0 & 19 \\
\hline 1 & 0 \\
\hline
\end{tabular}

\begin{tabular}{|c|c|c|c|c|c|}
\hline 42 & 45 & 46 & 47 & 49 & 50 \\
\hline 0 & 0 & 0 & 5 & 1 & 1 \\
\hline 0 & 0 & 0 & 0 & 0 & 0 \\
\hline 7 & 1 & 0 & 0 & 1 & 1 \\
\hline 0 & 0 & 0 & 0 & 0 & 0 \\
\hline 1 & 2 & 0 & 0 & 0 & 0 \\
\hline 1 & 9 & 4 & 2 & 1 & 0 \\
\hline 0 & 0 & 0 & 0 & 0 & 0 \\
\hline 0 & 0 & 0 & 0 & 0 & 0 \\
\hline 0 & 1 & 0 & 0 & 0 & 0 \\
\hline 0 & 0 & 2 & 0 & 0 & 0 \\
\hline 0 & 1 & 0 & 0 & 3 & 1 \\
\hline 1 & 0 & 0 & 0 & 0 & 0 \\
\hline 0 & 0 & 0 & 0 & 0 & 0 \\
\hline 3 & 0 & 1 & 0 & 0 & 0 \\
\hline 0 & 0 & 0 & 1 & 0 & 4 \\
\hline 0 & 0 & 0 & 0 & 0 & 0 \\
\hline 1 & 0 & 0 & 0 & 0 & 0 \\
\hline 0 & 0 & 1 & 4 & 1 & 0 \\
\hline 1 & 3 & 7 & 0 & 0 & 2 \\
\hline 1 & 1 & 3 & 0 & 0 & 1 \\
\hline 0 & 0 & 0 & 0 & 0 & 0 \\
\hline 1 & 0 & 0 & 1 & 0 & 0 \\
\hline 0 & 0 & 0 & 0 & 0 & 0 \\
\hline 0 & 1 & 0 & 0 & 0 & 1 \\
\hline 0 & 0 & 0 & 0 & 0 & 0 \\
\hline 0 & 0 & 0 & 0 & 1 & 0 \\
\hline 0 & 0 & 0 & 0 & 0 & 0 \\
\hline 0 & 0 & 0 & 0 & 0 & 0 \\
\hline 0 & 0 & 0 & 0 & 0 & 0 \\
\hline 2 & 3 & 0 & 3 & 1 & 4 \\
\hline 0 & 0 & 0 & 2 & 1 & 10 \\
\hline 1 & 0 & 0 & 1 & 1 & 0 \\
\hline
\end{tabular}




\section{Especie}

Rhoipites baculatus

Rhoipites cf. hawkdunensis

Rhoipites romboidaliformis

Rhoipites sphaerica

Striatricolporites pseudoestriatus

Tetracolporopollenites sp. 1

Tricolpites bathyreticulatus

Tricolpites brevicolpus

Tricolpites reticulatus

Triorites fragilis

Triorites minor

Triorites subespinosus

Arecipites minutiscabratus

Arecipites sp. 1

cf. Spatiphyllum sp.

Monosulcites cf perspinosus

Psilamonocolpites medius

Graminidites sp.

Liliacidites regularis

Sparganiaceaepollenites barungensis

Escolecodonte

Foraminifera

Uñas de ácaros

Gonyaulacales

Peridiniales

Total dinoquistes

TOTAL 


\begin{tabular}{|c|c|}
\hline 1 & 2 \\
\hline 0 & 0 \\
\hline 0 & 0 \\
\hline 0 & 0 \\
\hline 0 & 0 \\
\hline 2,7 & 0,3 \\
\hline 0 & 0 \\
\hline 0,5 & 0,7 \\
\hline 0 & 0 \\
\hline 0 & 0 \\
\hline 0,3 & 0 \\
\hline 2,9 & 0 \\
\hline 7,7 & 3,7 \\
\hline 0 & 0 \\
\hline 1,1 & 0,7 \\
\hline 0 & 0 \\
\hline 0 & 0 \\
\hline 0 & 1 \\
\hline 0 & 0 \\
\hline 0 & 0 \\
\hline 0,8 & 1 \\
\hline 0 & 0 \\
\hline 0 & 0 \\
\hline 0 & 0 \\
\hline 0 & 0,3 \\
\hline 0 & 0 \\
\hline 0 & 0 \\
\hline 0,5 & 0 \\
\hline 0,8 & 3 \\
\hline 1,3 & 3,4 \\
\hline 0 & 0 \\
\hline 0 & 0 \\
\hline 0 & 0 \\
\hline
\end{tabular}

Closterium sp.

Botryococcus sp.

Scenedesmaceae indet

Catinipollis geiseltalensis

Baculatisporites comaumensis

Baculatisporites turbioensis

Biretisporites sp. I Archangelsky

Cingutriletes australis

Concavisporites sp. II

Concavosporites sp. I

Cyatheacidites annulatus

Cyathidites minor

Deltoidospora cf australis

Deltoidospora minor

Foveotriletes sp. 1

Gleichenidites circinidites

Gleichenidites senonicus

Klukisporites scaberis

Laevigatosporites ovatus

Leiotriletes minor

Leptolepidites densus

Matonisporites sp. 1

Peromonolites vellosus

Polypodiisporites speciosus

Polypodiumsporites perverrucatus

Pteridophyta indet.

Retitriletes austroclavatidites

Trilites fasolae

Trilites parvalatus

Verrucosisporites sp. 1

Verrucosisporites sp. 2

Verrucosisporites sp. 3

5
0
1,6
0
0
0
0
0
0
0
0
0
0,4
0
0
0
0
0
0
0
0
0
0
0
0
0
0
0
0
0
0
0
0
0
0
0
0
0
0
0
0
0
0
0
0
0
0
0
0
0
0
0
0

$\mathbf{1 0}$
0
0,1
0
0
0
1,3
0,5
0
0
0,1
0,5
0,3
0
0,6
0
0,1
0,1
0
0
0,2
0
0
0,2
0
0
0,4
0
1,1
2,3
0
0
0


0

$\mathbf{1 1}$
0
0
0
0
1,6
0,2
0
0
0
0
0,3
0
0,1
0,7
0
0
0
0
0
0
0
0
0
0
0
0
0
0
0
0
0
0
0
0
0
0
0
0

12

13

0

0

2

0,5

0

0,3

0,8

0,3$$
0
$$$$
1,4
$$$$
0
$$$$
0
$$$$
0
$$$$
0
$$$$
0,3
$$$$
0
$$$$
0
$$$$
0
$$$$
0
$$$$
0
$$$$
0,3
$$$$
0,5
$$$$
0,3
$$$$
1,9
$$$$
0
$$$$
\begin{aligned}
& 0 \\
& 0 \\
& 0
\end{aligned}
$$

$\begin{array}{ccc}0 & 0 & 0 \\ 0 & 0 & 0 \\ 0 & 0 & 0 \\ 0 & 0 & 0 \\ 0,7 & 0,7 & 2 \\ 0 & 2,4 & 2,9 \\ 0 & 1 & 1 \\ 0 & 0,3 & 0 \\ 0 & 0 & 0 \\ 0 & 0 & 0,9 \\ 0 & 0,3 & 11,2 \\ 0,7 & 2,1 & 4,9 \\ 0 & 0 & 0 \\ 0,1 & 3,1 & 5,6 \\ 0 & 0 & 0 \\ 0 & 0 & 0 \\ 0,1 & 0,7 & 0,9 \\ 0 & 0 & 0,5 \\ 0 & 0 & 0 \\ 0,2 & 1 & 2,4 \\ 0 & 0 & 0,3 \\ 0 & 0 & 0,3 \\ 0 & 0 & 2,4 \\ 0 & 0 & 0,5 \\ 0 & 0 & 0 \\ 0,1 & 0,7 & 1 \\ 0 & 0 & 1 \\ 0,1 & 1,4 & 7,5 \\ 0,3 & 2,4 & 10,9 \\ 0 & 0 & 0 \\ 0 & 0 & 0 \\ 0 & 0 & 0,5\end{array}$


Especie

Dacrycarpites australiensis

Equisetosporites notensis

Microachrydites antarcticus

Phyllocladidites mawsonii

Podocarpidites elegans

Podocarpidites marwikii

Podocarpidites microreticuloidatus

Podocarpidites rugulosus

Araucariacites australis

Trisaccites microsacatum

Nothofagidites acromegacanthus

Nothofagidites americanus

Nothofagidites dorotensis

Nothofagidites flemingii

Nothofagidites fortispinulosus

Nothofagidites nanus

Nothofagidites rocaensis

Nothofagidites saraensis

Nothofagidites tehuelchesii

Myrtaceidites eucalyptoides

Myrtaceidites mesonesus

Myrtaceidites parvus

Myrtaceidites verrucosus

Granodiporites nebulosus

Lewalanipollis senectus

Peninsulapollis gili

Propylipollis ambiguus

Propylipollis annularis

Propylipollis pseudomoides

Propylipollis reticuloscabratus

Proteacidites obscurus

Proteacidites rectus

\begin{tabular}{|c|c|c|c|c|}
\hline 1 & 2 & 3 & 5 & 9 \\
\hline 0 & 0 & 0,4 & 6 & 0 \\
\hline 0 & 0,4 & 0 & 0 & 0 \\
\hline 0 & 0,4 & 0 & 0 & 0 \\
\hline 0,4 & 1,1 & 1,1 & 1,4 & 7,3 \\
\hline 1,9 & 8 & 3,7 & 42 & 13,1 \\
\hline 0,4 & 0 & 0 & 0 & 2,4 \\
\hline 0 & 0 & 0 & 0 & 0 \\
\hline 0 & 0 & 0,4 & 3,4 & 0 \\
\hline 2,6 & 2,7 & 9,9 & 0 & 0,3 \\
\hline 0 & 0 & 0 & 32,1 & 0 \\
\hline 2,2 & 4,2 & 0,4 & 0 & 3,4 \\
\hline 3,7 & 4,2 & 2,2 & 3,4 & 1,5 \\
\hline 11,9 & 12,2 & 13,2 & 0,3 & 25,4 \\
\hline 4,8 & 0,8 & 1,8 & 0 & 0,3 \\
\hline 0 & 0 & 0 & 0 & 0 \\
\hline 12,6 & 14,5 & 1,8 & 0 & 16,5 \\
\hline 13,7 & 28,6 & 7,7 & 0,3 & 8,3 \\
\hline 17 & 5 & 2,9 & 0 & 7,3 \\
\hline 0 & 0 & 0,7 & 0,6 & 0 \\
\hline 0,7 & 0 & 0 & 0 & 0 \\
\hline 0,4 & 0 & 0 & 0 & 0 \\
\hline 4,8 & 3,8 & 5,9 & 0 & 3,7 \\
\hline 0 & 0 & 1,1 & 0 & 0,3 \\
\hline 0 & 0 & 1,5 & 0,3 & 0,6 \\
\hline 0,7 & 0 & 0 & 0 & 0 \\
\hline 0 & 0 & 0 & 0 & 0 \\
\hline 0 & 0 & 0,4 & 0 & 0 \\
\hline 0 & 0 & 0 & 0 & 0 \\
\hline 1,5 & 0 & 0,4 & 0,3 & 0,6 \\
\hline 0 & 0 & 0,4 & 0 & 0 \\
\hline 0 & 0 & 0 & 0 & 0 \\
\hline 0 & 0 & 1,1 & 0 & 0 \\
\hline
\end{tabular}

\begin{tabular}{|c|c|c|c|c|}
\hline 10 & 11 & 12 & 13 & 14 \\
\hline 0 & 0 & 0 & 0 & 1,3 \\
\hline 0 & 0 & 0 & 0 & 0 \\
\hline 0 & 0,4 & 0 & 0 & 0 \\
\hline 8,3 & 1,2 & 1,1 & 0,4 & 0,4 \\
\hline 34,8 & 3,6 & 14 & 6,8 & 44,7 \\
\hline 0 & 4,8 & 0 & 0,4 & 0 \\
\hline 0 & 0 & 0 & 0 & 0 \\
\hline 0 & 0 & 1,8 & 0 & 0,4 \\
\hline 0 & 3,2 & 1,5 & 0,8 & 0 \\
\hline 1,3 & 0 & 0,7 & 0 & 0,4 \\
\hline 0 & 6,9 & 2,6 & 6,8 & 0 \\
\hline 13,9 & 6,5 & 7,4 & 0,4 & 0,9 \\
\hline 5,7 & 7,7 & 13,3 & 11 & 2,6 \\
\hline 0,4 & 0 & 0,4 & 0 & 8,9 \\
\hline 0 & 0 & 0 & 0 & 0 \\
\hline 0 & 0 & 2,6 & 6,8 & 0,4 \\
\hline 17 & 18,1 & 14,8 & 14,8 & 5,5 \\
\hline 14,3 & 2,8 & 21,8 & 6,8 & 17,9 \\
\hline 0 & 0 & 0 & 0 & 0 \\
\hline 0 & 0 & 0 & 0 & 0 \\
\hline 0 & 0,4 & 0 & 0 & 0 \\
\hline 0 & 8,9 & 1,8 & 6,5 & 0 \\
\hline 0 & 3,2 & 0 & 2,3 & 0 \\
\hline 0 & 0,8 & 0 & 0,4 & 8,1 \\
\hline 0 & 0 & 0 & 0 & 0 \\
\hline 0 & 0 & 0 & 0 & 0 \\
\hline 0 & 0,8 & 0,4 & 0,8 & 0 \\
\hline 0 & 0 & 0 & 0 & 0 \\
\hline 0,9 & 0,4 & 0 & 1,1 & 0 \\
\hline 0 & 0 & 0 & 0 & 0,4 \\
\hline 0 & 0 & 0 & 0 & 0 \\
\hline 0 & 0 & 0 & 0 & 0 \\
\hline
\end{tabular}


Especie

Proteacidites subscabratus

Anacolosidites diffusa

Bombacacidites isoreticulatus

Cupaneidites insularis

Cupaneidites reticularis

Ilexpollenites anguloclavatus

Ilexpollenites clifdenensis

Ilexpollenites megagemmatus

Perysincolporites pokornii

Bysmapollis verrucatus

Compositoipollenites sp. 1

Corsinipollenites atlantica

Dicolpopollis sp. 1

Ericipites sp.

Gothanipollis basensis

Gothanipollis sp. 1

Haloragacidites trioratus

Malvacearumpollis sp. 1

Malvacipollis sp. 1

Margocolporites sp 1 Tipo Prosopis

$c f$. Perfotricolpites sp.

Periporopollenites demarcatus

Polycolporopollenites esobalteus

Psilatricolpites brevis

Psilatricolporites cf marginatus

Psilatricolporites costatus

Psilatricolporites divisus

Psilatricolporites pachydermatus

Psilatricolporites aff. P. protrudens

Psilatricolporites vanus

Psilatricolporites varius

Rhoipites alveolatus

\begin{tabular}{|c|c|c|c|c|}
\hline 1 & 2 & 3 & 5 & 9 \\
\hline 1,9 & 2,3 & 0 & 0 & 0,3 \\
\hline 0 & 0 & 0,4 & 0 & 0 \\
\hline 0 & 0,8 & 0 & 0 & 0 \\
\hline 0 & 0 & 0 & 0 & 0 \\
\hline 0 & 0 & 0,4 & 0 & 0 \\
\hline 0 & 0 & 0,4 & 0,9 & 0 \\
\hline 1,9 & 1,9 & 0 & 0 & 1,5 \\
\hline 0 & 0 & 0 & 0,6 & 0 \\
\hline 0 & 0 & 0 & 0 & 0 \\
\hline 0 & 0 & 0,4 & 0 & 0 \\
\hline 0 & 0 & 1,8 & 0 & 0 \\
\hline 0 & 0 & 0 & 0 & 0 \\
\hline 0 & 0 & 0,4 & 0 & 0 \\
\hline 0 & 0 & 0 & 0,3 & 1,2 \\
\hline 3 & 0 & 1,1 & 0 & 0 \\
\hline 0 & 0,4 & 1,5 & 0 & 0 \\
\hline 0 & 0,4 & 0,4 & 0 & 0 \\
\hline 0 & 0 & 0 & 0 & 0 \\
\hline 0,4 & 0,4 & 0 & 0 & 0 \\
\hline 0 & 0 & 0,7 & 0 & 0 \\
\hline 0 & 0 & 0 & 0,3 & 0 \\
\hline 0 & 0 & 0 & 0,3 & 0 \\
\hline 0 & 0 & 0 & 0 & 0 \\
\hline 0 & 0 & 0 & 0 & 0,6 \\
\hline 0 & 0 & 0 & 0 & 0 \\
\hline 1,5 & 1,1 & 0,7 & 0 & 0 \\
\hline 0 & 0 & 0 & 0 & 0 \\
\hline 0 & 0 & 0 & 0 & 0 \\
\hline 0 & 0 & 0 & 0 & 0 \\
\hline 3,7 & 0 & 5,5 & 0 & 2,8 \\
\hline 0 & 2,7 & 19,9 & 0 & 0 \\
\hline 0,7 & 0 & 0 & 0 & 0 \\
\hline
\end{tabular}

$\mathbf{1 0}$
0
0
0
0
0
0,4
0
0
0
0
0
0
0
0,4
0
0
0
0
0,9
0,4
0
0
0
0
0
0
0
0
0
0
0
0

0
0
0
0
0
0
0
0
0
0
0
0
0
0
0
0
0
0
0
0
0
0
0

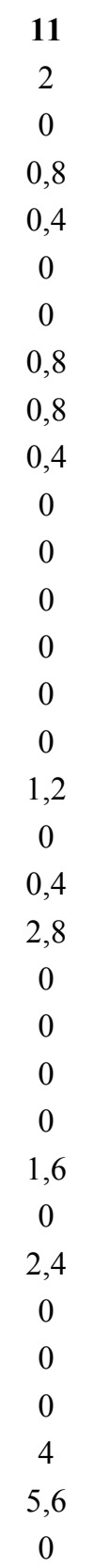

\begin{abstract}
12
\end{abstract}
13

1,5

0,8

0

0

0,4

0

0

0

$\begin{array}{ccc}0 & 0 & 0 \\ 0 & 0 & 2,6\end{array}$

0,7

0

0

0,4

0

0

0

0

0

0

0

0

0,4

0

0
0

0

0

0

0

0

0

0

$1,8 \quad 0,4 \quad 0$

$\begin{array}{ccc}1,8 & 0,4 & 0 \\ 3,7 & 10,3 & 0\end{array}$




\section{Especie}

Rhoipites baculatus

Rhoipites cf. hawkdunensis

Rhoipites romboidaliformis

Rhoipites sphaerica

Striatricolporites pseudoestriatus

Tetracolporopollenites sp. 1

Tricolpites bathyreticulatus

Tricolpites brevicolpus

Tricolpites reticulatus

Triorites fragilis

Triorites minor

Triorites subespinosus

Arecipites minutiscabratus

Arecipites sp. 1

Monocotiledónea sp. 1

Monosulcites perspinosus

Psilamonocolpites medius

Graminidites sp.

Liliacidites regularis

Sparganiaceaepollenites barungensis

Escolecodonte

Foraminifera

Uñas de ácaros

Gonyaulacoideos

Peridinoideos

$\begin{array}{ccc}\mathbf{1} & \mathbf{2} & \mathbf{3} \\ 0 & 1,1 & 0,7 \\ 0 & 0 & 0 \\ 0 & 0 & 0 \\ 0 & 0 & 0 \\ 0,4 & 0,4 & 0 \\ 0 & 0 & 0,4 \\ 0,4 & 0 & 0,7 \\ 0 & 0 & 0 \\ 0 & 0 & 0,4 \\ 0 & 0 & 0 \\ 4,1 & 0,8 & 1,1 \\ 0 & 0 & 0 \\ 0 & 0 & 0 \\ 0 & 0,4 & 0 \\ 0 & 0 & 0 \\ 0,7 & 0 & 1,1 \\ 2,2 & 1,1 & 4,4 \\ 0 & 0 & 0 \\ 0 & 0,4 & 0,4 \\ 0 & 0 & 0,4 \\ 0 & 0,3 & 0 \\ 0 & 0 & 0 \\ 0,3 & 0 & 1,4 \\ 18,3 & 6,1 & 18,9 \\ 11,7 & 7,4 & 9,6\end{array}$

$\begin{array}{cc}\mathbf{5} & \mathbf{9} \\ 0 & 0 \\ 0 & 0 \\ 0 & 0 \\ 0 & 0 \\ 0 & 0 \\ 0 & 0 \\ 0 & 0 \\ 0 & 0 \\ 0 & 0,3 \\ 0 & 0 \\ 0 & 0 \\ 0 & 0 \\ 3,7 & 0 \\ 0 & 0 \\ 0 & 0 \\ 0 & 0,9 \\ 2,6 & 1,2 \\ 0 & 0 \\ 0 & 0 \\ 1,4 & 0 \\ 0 & 0 \\ 0,4 & 0 \\ 0 & 1,9 \\ 0 & 0,5 \\ 0 & 8 \\ & 0 \\ 0 & 0 \\ 0 & 0 \\ 0 & 0 \\ 0 & 0 \\ 0 & 0 \\ 0 & 0 \\ 0 & 0 \\ 0 & 0 \\ 0 & 0 \\ 0 & 0 \\ 0 & 0\end{array}$

$\mathbf{1 0}$
0
0
0
0
0
0
0
0
0
0
0
0
0
0
0
0,4
0,9
0
0
0
0
0
0,2
73

0
0
0
0
0
0
0
0
0

$\mathbf{1 1}$
0
0
0
0
0
0
0,4
0
0,8
0
1,6
0
0
0
0
0
2,4
0
0
1,6
0,9
0
0
55,7
19,7

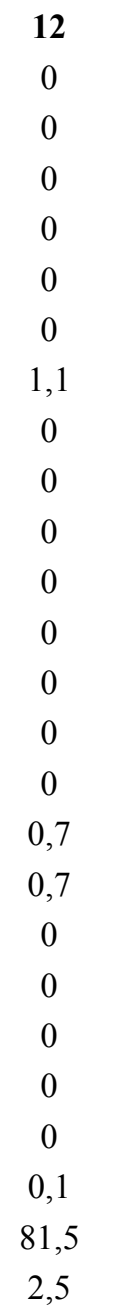

\begin{tabular}{|c|c|}
\hline 13 & 14 \\
\hline 0,4 & 3 \\
\hline 0 & 0 \\
\hline 0 & 0 \\
\hline 0 & 0 \\
\hline 0 & 0 \\
\hline 0 & 0 \\
\hline 0,4 & 0 \\
\hline 0 & 0 \\
\hline 0 & 0,4 \\
\hline 0,4 & 0 \\
\hline 2,3 & 0 \\
\hline 0 & 0 \\
\hline 0 & 0 \\
\hline 0,4 & 0 \\
\hline 0 & 0 \\
\hline 1,9 & 0 \\
\hline 2,3 & 0,4 \\
\hline 0,4 & 0 \\
\hline 1,5 & 0,9 \\
\hline 0,4 & 0 \\
\hline 0 & 0 \\
\hline 0 & 0 \\
\hline 0,7 & 0,2 \\
\hline 7,5 & 59,4 \\
\hline 2,4 & 0,7 \\
\hline
\end{tabular}


Especie

Closterium sp.

Botryococcus sp.

Scenedesmaceae indet

Catinipollis geiseltalensis

Baculatisporites comaumensis

Baculatisporites turbioensis

Biretisporites sp. I Archangelsky

Cingutriletes australis

Concavisporites sp. II

Concavosporites sp. I

Cyatheacidites annulatus

Cyathidites minor

Deltoidospora cf australis

Deltoidospora minor

Foveotriletes sp. 1

Gleichenidites circinidites

Gleichenidites senonicus

Klukisporites scaberis

Laevigatosporites ovatus

Leiotriletes minor

Leptolepidites densus

Matonisporites sp. 1

Peromonolites vellosus

Polypodiisporites speciosus

Polypodiumsporites perverrucatus

Pteridophyta indet.

Retitriletes austroclavatidites

Trilites fasolae

Trilites parvalatus

Verrucosisporites sp. 1

Verrucosisporites sp. 2

Verrucosisporites sp. 3

\begin{tabular}{|c|c|c|c|c|}
\hline 15 & 16 & 17 & 18 & 19 \\
\hline 0 & 0 & 0 & 0,3 & 0 \\
\hline 0 & 0 & 0 & 0 & 0 \\
\hline 0 & 4,5 & 0,3 & 0 & 0 \\
\hline 4,7 & 0 & 0 & 0 & 0 \\
\hline 2,2 & 0 & 3,1 & 0 & 0,3 \\
\hline 1,2 & 5,3 & 0 & 0 & 0,5 \\
\hline 1,2 & 1,5 & 0,7 & 0 & 0,3 \\
\hline 0 & 0 & 0 & 0 & 0 \\
\hline 0 & 0 & 0 & 0 & 0 \\
\hline 0 & 0 & 0 & 0 & 0 \\
\hline 0,5 & 1 & 1,7 & 0 & 0,3 \\
\hline 9,6 & 5,5 & 7,3 & 1,8 & 2,5 \\
\hline 0 & 0 & 0 & 0 & 0 \\
\hline 0,5 & 4 & 2,8 & 1,5 & 1,9 \\
\hline 0 & 1 & 0 & 0 & 0 \\
\hline 0 & 0 & 0 & 0 & 0 \\
\hline 0,2 & 1,3 & 0 & 0 & 0 \\
\hline 0 & 0 & 0 & 0 & 0 \\
\hline 0 & 0 & 0,7 & 0 & 0 \\
\hline 2 & 4 & 1 & 0 & 1,4 \\
\hline 0 & 0 & 0 & 0 & 0 \\
\hline 0 & 0 & 0 & 0 & 0 \\
\hline 0 & 0,5 & 0 & 0 & 0,5 \\
\hline 0 & 0 & 0,3 & 0 & 0 \\
\hline 0 & 4,3 & 0 & 0 & 0 \\
\hline 0,2 & 0 & 1 & 0 & 0 \\
\hline 0,2 & 0 & 0 & 0 & 0,8 \\
\hline 3,9 & 6,5 & 2,4 & 0,6 & 0,8 \\
\hline 2,5 & 3 & 2,1 & 0,6 & 2,5 \\
\hline 0 & 0 & 0 & 0 & 0 \\
\hline 0 & 0 & 0 & 0 & 0 \\
\hline 0 & 0 & 0 & 0 & 0 \\
\hline
\end{tabular}

\begin{tabular}{|c|c|c|c|c|}
\hline 20 & 21 & 22 & 23 & 25 \\
\hline 0 & 0 & 0 & 0 & 0 \\
\hline 0 & 0 & 0 & 0 & 0 \\
\hline 0 & 0,4 & 0 & 0 & 0 \\
\hline 0 & 0 & 0 & 1,4 & 0 \\
\hline 1,3 & 0,5 & 0 & 0 & 7,4 \\
\hline 0 & 0 & 0,5 & 0 & 0,4 \\
\hline 0 & 0,2 & 0,1 & 0 & 0 \\
\hline 0 & 0 & 0 & 0 & 0 \\
\hline 0 & 0 & 0 & 0 & 0,4 \\
\hline 0 & 0 & 0 & 0 & 0 \\
\hline 0,3 & 0,4 & 0,6 & 0 & 0 \\
\hline 4,3 & 2,8 & 1 & 2,4 & 2,6 \\
\hline 0 & 0 & 0 & 0 & 0 \\
\hline 1 & 0,4 & 0,8 & 2,2 & 0,4 \\
\hline 0 & 0 & 0 & 0 & 0 \\
\hline 0 & 0 & 0 & 0 & 0 \\
\hline 0 & 0,5 & 0,1 & 0,2 & 5,2 \\
\hline 0 & 0 & 0 & 0 & 0 \\
\hline 0 & 0 & 0 & 0 & 0 \\
\hline 3,3 & 0,5 & 0,2 & 1 & 1,9 \\
\hline 0 & 0 & 0 & 0 & 0 \\
\hline 0 & 0 & 0 & 0 & 0 \\
\hline 0 & 0 & 0 & 0,2 & 0 \\
\hline 0 & 0 & 0 & 0 & 0 \\
\hline 0 & 0 & 0,2 & 0 & 0 \\
\hline 0 & 0 & 0 & 0 & 0 \\
\hline 0,3 & 0,4 & 0 & 0 & 0 \\
\hline 0 & 0,2 & 0,7 & 1,2 & 0,4 \\
\hline 1 & 0,7 & 2 & 2,2 & 5,6 \\
\hline 0 & 0 & 0 & 0 & 0 \\
\hline 0 & 0 & 0 & 0 & 0 \\
\hline 0 & 0 & 0 & 0 & 0 \\
\hline
\end{tabular}

25

7,4

0

4

0

2,6

0,4

0

5,2

0

,9

0

5,6

0 


\section{Especie}

Dacrycarpites australiensis Equisetosporites notensis

Microachrydites antarcticus

Phyllocladidites mawsonii

Podocarpidites elegans

Podocarpidites marwikii

Podocarpidites microreticuloidatus

Podocarpidites rugulosus

Araucariacites australis

Trisaccites microsacatum

Nothofagidites acromegacanthus

Nothofagidites americanus

Nothofagidites dorotensis

Nothofagidites flemingii

Nothofagidites fortispinulosus

Nothofagidites nana

Nothofagidites rocaensis

Nothofagidites saraensis

Nothofagidites tehuelchesii

Myrtaceidites eucalyptoides

Myrtaceidites mesonesus

Myrtaceidites parvus

Myrtaceidites verrucosus

Granodiporites nebulosus

Lewalanipollis senectus

Peninsulapollis gilii

Propylipollis ambiguus

Propylipollis annularis

Propylipollis pseudomoides

Propylipollis reticuloscabratus

Proteacidites obscurus

Proteacidites rectus

$\begin{array}{cc}\mathbf{1 5} & \mathbf{1 6} \\ 0,5 & 0 \\ 0 & 0 \\ 0 & 0 \\ 1 & 3,5 \\ 6,8 & 14,5 \\ 1 & 0 \\ 0 & 0 \\ 0 & 1,2 \\ 2 & 0 \\ 0 & 0 \\ 2,9 & 0 \\ 0,5 & 2,3 \\ 27,3 & 7,5 \\ 0,5 & 16,8 \\ 0 & 0 \\ 0,5 & 0 \\ 22,9 & 19,1 \\ 4,4 & 26 \\ 0 & 0 \\ 0 & 0 \\ 0 & 0 \\ 6,3 & 0 \\ 0 & 0,6 \\ 0,5 & 0 \\ 1 & 0 \\ 0 & 0,6 \\ 0 & 0 \\ 0 & 0 \\ 1,5 & 0 \\ 0 & 0 \\ 0 & 0 \\ 0 & 0 \\ & \\ 0 & 0\end{array}$

$\mathbf{1 8}$
0
0
0
0
1,8
0
0
0
0
0
0
0
12,7
0
0
0,4
24,3
0
0
0
1,1
22,2
0,7
0
0,4
0
0
0
1,1
0
0
0

$\mathbf{1 9}$
0
0
0
0,4
3,9
0
0
0
1,2
0,4
2,3
0,8
26,4
0,8
0
0,4
25,2
8,1
0
0
0
9,3
0,8
0
0
0
0
0
1,6
0
0
0,4

$\mathbf{2 0}$
0
0,4
0
0,7
4,3
0
0
0
0
0,4
5
1,4
35,7
0,4
0
2,5
23,9
1,4
0
0
0
6,4
0,7
0
0
0
0
0
1,4
0,4
0
0

21
0
0
0
0,7
4,5
2,6
0
0
0
1,1
5,2
0,4
23,1
3
0
1,9
6,3
11,6
0
0
0
11,9
1,9
0,7
0
0
0
0
1,1
0
0
0,4

0
0
0
0
0
0
0
0
0
0
0
0

22
0
0
1
5
2
0
0
0
0
7
0
23
0
0
0
20
5
0
0
0
0
0
0
0
4
0
0
0
0
0
0

25

11,4

1,1

0

0

0,4

7,6

27,7

2,3

0

24,6

1,9

0

0

6,4

0

0,4

0,8

0

0

0 


\section{Especie}

Proteacidites subscabratus

Anacolosidites diffusa

Bombacacidites isoreticulatus

Cupaneidites insularis

Cupaneidites reticularis

Ilexpollenites anguloclavatus

Ilexpollenites clifdenensis

Ilexpollenites megagemmatus

Perysincolporites pokornii

Bysmapollis verrucatus

Compositoipollenites sp. 1

Corsinipollenites atlantica

Dicolpopollis sp. 1

Ericipites sp.

Gothanipollis basensis

Gothanipollis sp. 1

Haloragacidites trioratus

Malvacearumpollis sp. 1

Malvacipollis sp. 1

Margocolporites sp 1 Tipo Prosopis

$c f$. Perfotricolpites sp.

Periporopollenites sp. 1

Polycolporopollenites esobalteus

Psilatricolpites brevis

Psilatricolporites cf marginatus

Psilatricolporites costatus

Psilatricolporites divisus

Psilatricolporites pachydermatus

Psilatricolporites protrudens

Psilatricolporites vanus

Psilatricolporites varius

Rhoipites alveolatus

\begin{tabular}{|c|c|}
\hline 15 & 16 \\
\hline 2,4 & 0 \\
\hline 0 & 0 \\
\hline 0 & 0 \\
\hline 0,5 & 0 \\
\hline 0 & 0 \\
\hline 1 & 4,6 \\
\hline 0 & 0 \\
\hline 0 & 0 \\
\hline 0 & 0 \\
\hline 0 & 0 \\
\hline 0 & 0 \\
\hline 0 & 0 \\
\hline 0 & 0 \\
\hline 0,5 & 1,2 \\
\hline 1,5 & 0 \\
\hline 0,5 & 0 \\
\hline 0,5 & 0 \\
\hline 1 & 0 \\
\hline 1,5 & 0 \\
\hline 0 & 0 \\
\hline 0 & 0 \\
\hline 0 & 0 \\
\hline 0 & 0 \\
\hline 0 & 0 \\
\hline 1,5 & 0 \\
\hline 2 & 0 \\
\hline 0 & 0 \\
\hline 0 & 0 \\
\hline 0 & 0 \\
\hline 0 & 0 \\
\hline 4,9 & 0 \\
\hline 0 & 0 \\
\hline
\end{tabular}

$\begin{array}{cccc}\mathbf{1 7} & \mathbf{1 8} & \mathbf{1 9} & \mathbf{2 0} \\ 0,4 & 1,8 & 0,8 & 1,4 \\ 0 & 0 & 0 & 0 \\ 0,4 & 0 & 1,6 & 1,1 \\ 0 & 0,4 & 0 & 0 \\ 0 & 0 & 0,4 & 0 \\ 0 & 1,1 & 0,8 & 0 \\ 3 & 1,4 & 1,2 & 0,4 \\ 0 & 0 & 0 & 0 \\ 0 & 0 & 0 & 0 \\ 0 & 0 & 0 & 0 \\ 0 & 0,7 & 0 & 0 \\ 0 & 0 & 0 & 0 \\ 0 & 0,4 & 0 & 0 \\ 0 & 0 & 0 & 0,4 \\ 0,9 & 2,8 & 0 & 0,7 \\ 0 & 0,4 & 0,4 & 0 \\ 0 & 0 & 0 & 0 \\ 0 & 0 & 0 & 1,1 \\ 0 & 0,7 & 1,2 & 0 \\ 0 & 1,1 & 0 & 0,4 \\ 0 & 0 & 0 & 0 \\ 0 & 0 & 0 & 1,1 \\ 0 & 0 & 0 & 0 \\ 2,1 & 0 & 0 & 0 \\ 0 & 0 & 0 & 0 \\ 3,4 & 5,3 & 2,3 & 0 \\ 0,4 & 0 & 0 & 0 \\ 0 & 0 & 0 & 0 \\ 0 & 0 & 0 & 0 \\ 0 & 2,8 & 1,6 & 0,4 \\ 7,7 & 6,3 & 2,3 & 0 \\ 0 & 0 & 0 & \end{array}$

21
2,6
0
0
1,1
0,4
0
0,4
0
0
0
0
0
0,4
0
1,5
0,4
0
0,4
0
0
0
0,4
0,4
0
0
2,6
0
0
0
0
8,6
0

22
0,4
0
0
0
0
2
1,2
0
0
0
0
0
0
0
0,4
0,4
0
0,8
0
0
0
0
0
0
0
0
0
0
0
0
0
0
0
0
0
0
0
0
0

\section{3}

1,2

$0,4 \quad 0$

$0 \quad 0$

$0 \quad 0$

$0 \quad 0$

$0,8 \quad 4,9$

$0 \quad 0$

$0 \quad 0$

$0 \quad 0$

$0,4 \quad 0$

$0 \quad 0$

$0 \quad 0$

$0,4 \quad 0$

$0 \quad 0$

$0 \quad 0$

$0 \quad 0$

$0,8 \quad 0$

$0 \quad 0,8$

$0,4 \quad 0,4$

$0 \quad 0$

$0,8 \quad 0$

$0 \quad 0$

$\begin{array}{ll}0 & 0 \\ 0 & 0\end{array}$

$1,9 \quad 0,8$

$0 \quad 0$

$0 \quad 0$

$\begin{array}{ll}0 & 0\end{array}$

$\begin{array}{cc}0 & 0,4 \\ 5,1 & 0\end{array}$

$\begin{array}{cc}5,1 & 0 \\ 0 & 0\end{array}$ 


\section{Especie}

Rhoipites baculatus

Rhoipites cf. hawkdunensis

Rhoipites romboidaliformis

Rhoipites sphaerica

Striatricolporites pseudoestriatus

Tetracolporopollenites sp. 1

Tricolpites bathyreticulatus

Tricolpites brevicolpus

Tricolpites reticulatus

Triorites fragilis

Triorites minor

Triorites subespinosus

Arecipites minutiscabratus

Arecipites sp. 1

cf. Spatiphyllum sp.

Monosulcites cf perspinosus

Psilamonocolpites medius

Graminidites sp.

Liliacidites regularis

Sparganiaceaepollenites barungensis

Escolecodonte

Foraminifera

Uñas de ácaros

Gonyaulacales

Peridiniales

$\begin{array}{ccccc}\mathbf{1 5} & \mathbf{1 6} & \mathbf{1 7} & \mathbf{1 8} & \mathbf{1 9} \\ 0,5 & 1,2 & 0 & 1,1 & 0,8 \\ 0 & 0 & 0 & 0,4 & 0 \\ 0 & 0 & 0 & 0,7 & 0 \\ 0 & 0 & 0,9 & 0 & 0,4 \\ 0 & 0 & 0,9 & 0 & 0 \\ 0 & 0 & 0 & 0 & 0 \\ 0 & 0 & 0 & 0,7 & 0 \\ 0 & 0 & 0 & 0 & 0 \\ 0,5 & 0 & 0,4 & 0 & 0 \\ 0 & 0 & 0 & 0,4 & 0 \\ 1 & 0 & 0,4 & 3,5 & 2,3 \\ 0 & 0 & 0 & 0 & 0 \\ 0 & 0 & 0 & 0 & 0 \\ 0 & 0 & 0 & 0,4 & 0 \\ 0 & 0 & 0 & 0,4 & 0 \\ 0,5 & 0,6 & 1,3 & 1,1 & 1,2 \\ 0,5 & 0 & 0,9 & 1,1 & 0,4 \\ 0 & 0 & 0 & 0 & 0 \\ 0 & 0,6 & 0,9 & 0,7 & 0 \\ 0 & 0 & 0 & 0,4 & 0,8 \\ 0 & 0 & 0 & 0 & 0 \\ 0 & 0 & 0 & 0 & 0 \\ 0,5 & 0 & 1 & 1,5 & 0,8 \\ 41,4 & 45,1 & 15,3 & 10,7 & 27,8 \\ 4,2 & 7 & 2,4 & 3 & 2,2\end{array}$

$\begin{array}{ccccc}\mathbf{2 0} & \mathbf{2 1} & \mathbf{2 2} & \mathbf{2 3} & \mathbf{2 5} \\ 0 & 0 & 2,4 & 0,8 & 0,4 \\ 0,4 & 0,4 & 0 & 0 & 0 \\ 0 & 0 & 0 & 0 & 0 \\ 0 & 0 & 0 & 0 & 0 \\ 0,4 & 0 & 0 & 0 & 0 \\ 0 & 0 & 0 & 0 & 0 \\ 0,4 & 0 & 2 & 0 & 0 \\ 0 & 0 & 0 & 0 & 0 \\ 0 & 0 & 0 & 0 & 0 \\ 0 & 0,4 & 0,4 & 0 & 1,5 \\ 1,4 & 0,7 & 1,6 & 2,7 & 0 \\ 0 & 0 & 0 & 0 & 0 \\ 0 & 0 & 0 & 0 & 0 \\ 0,4 & 0 & 0 & 0 & 0 \\ 0 & 0 & 0 & 0 & 0 \\ 0 & 0,7 & 0 & 1,6 & 0,4 \\ 0 & 1,1 & 0,4 & 0 & 0,4 \\ 0 & 0 & 0 & 0 & 0 \\ 0,4 & 1,1 & 0 & 0,8 & 0 \\ 0 & 0 & 0 & 0 & 0 \\ 0 & 0 & 0 & 0 & 0 \\ 0 & 0 & 0 & 0 & 0 \\ 0,7 & 1,8 & 0,4 & 1,7 & 0 \\ 4,6 & 49,6 & 73,8 & 34,3 & 2,2 \\ 3,3 & 1,4 & 0,5 & 0,5 & 0,4\end{array}$


Especie

Closterium sp.

Botryococcus sp.

Scenedesmaceae indet

Catinipollis geiseltalensis

Baculatisporites comaumensis

Baculatisporites turbioensis

Biretisporites sp. I Archangelsky

Cingutriletes australis

Concavisporites sp. II

Concavosporites sp. I

Cyatheacidites annulatus

Cyathidites minor

Deltoidospora cf australis

Deltoidospora minor

Foveotriletes sp. 1

Gleichenidites circinidites

Gleichenidites senonicus

Klukisporites scaberis

Laevigatosporites ovatus

Leiotriletes minor

Leptolepidites densus

Matonisporites sp. 1

Peromonolites vellosus

Polypodiisporites speciosus

Polypodiumsporites perverrucatus

Pteridophyta indet.

Retitriletes austroclavatidites

Trilites fasolae

Trilites parvalatus

Verrucosisporites sp. 1

Verrucosisporites sp. 2

Verrucosisporites sp. 3

$\begin{array}{cccc}\mathbf{2 6} & \mathbf{2 7} & \mathbf{2 8} & \mathbf{3 1} \\ 0 & 0 & 0 & 0 \\ 0 & 0 & 0 & 0 \\ 0,7 & 0 & 1,5 & 0,3 \\ 0 & 0 & 0 & 0 \\ 1,8 & 0 & 0 & 1,3 \\ 0 & 1,5 & 1,2 & 0,7 \\ 0 & 0,4 & 0,4 & 0,3 \\ 0 & 0 & 0 & 0 \\ 0 & 0 & 0 & 0 \\ 0 & 0 & 0 & 0 \\ 1,8 & 0,4 & 0,4 & 0,3 \\ 2,8 & 5,3 & 5 & 0,3 \\ 0 & 0 & 0 & 0 \\ 2,1 & 1,1 & 1,2 & 3,7 \\ 0 & 0 & 0 & 0 \\ 0,4 & 0,4 & 0 & 0 \\ 1,1 & 0 & 4,6 & 3,7 \\ 0 & 0 & 0 & 0 \\ 0,4 & 0 & 0 & 0 \\ 0,7 & 1,9 & 1,2 & 0,7 \\ 0 & 0 & 0 & 0 \\ 0 & 0 & 0 & 0 \\ 0 & 0 & 0 & 0 \\ 0 & 0 & 0 & 0,3 \\ 0 & 0 & 0 & 0 \\ 0 & 0 & 0 & 0 \\ 0 & 0 & 0 & 0,3 \\ 0,7 & 1,1 & 0 & 0,3 \\ 5,3 & 5,3 & 9,6 & 3 \\ 0 & 0 & 0 & 0 \\ 0 & 0 & 0 & 0 \\ 0 & 0 & 0 & 0 \\ & & & \end{array}$

33
0
0
0,1
0,1
0
0
0
0
0
0
1,4
2,1
0
0,8
0
0
0,1
0
0
0,1
0
0
0
0,1
0,3
0
0,4
0,1
0,3
0
0
0

34
0
0
0,7
0
1,5
0
0
0
0
0
7
12,2
0
7
0
0
0
0
0
2,2
0
0
0
0
0
0
0
0

0
0
0
0
0
0
0
0
0
0
0
0
0
0
0
0
0
0
0
0
0
0
0

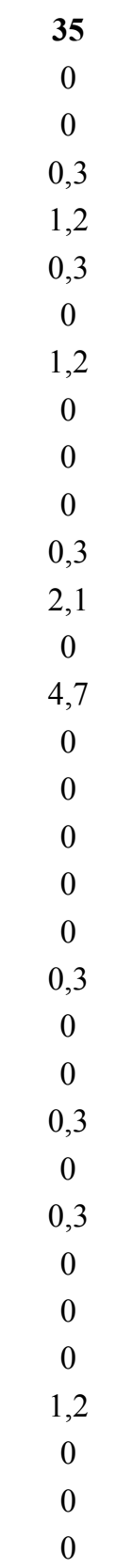

$\begin{array}{ccc}\mathbf{3 6} & \mathbf{3 7} & \mathbf{3 8} \\ 0 & 0 & 0 \\ 0 & 0 & 0 \\ 0 & 0 & 0,3 \\ 0 & 0,2 & 0 \\ 2,8 & 0 & 0,6 \\ 0,9 & 0,7 & 0,3 \\ 1 & 0,4 & 0,5 \\ 0 & 0 & 0 \\ 0 & 0 & 0 \\ 0 & 0 & 0,5 \\ 2,7 & 1,1 & 0,4 \\ 2,4 & 2,9 & 0,3 \\ 0 & 0,7 & 0 \\ 4,2 & 1,3 & 7,6 \\ 0 & 0 & 0 \\ 0,2 & 0,7 & 0 \\ 1,6 & 0 & 0,8 \\ 0 & 0 & 0,3 \\ 0 & 0 & 0,1 \\ 0,9 & 0,4 & 0 \\ 0 & 0,7 & 0,1 \\ 0 & 0 & 0 \\ 0,9 & 0 & 0,4 \\ 0 & 0,7 & 0,1 \\ 0,1 & 0,2 & 0 \\ 0,5 & 0 & 0 \\ 0,3 & 0 & 0 \\ 1,6 & 0 & 1,9 \\ 3,6 & 0,2 & 1,7 \\ 0,1 & 0 & 0 \\ 0 & 0 & 0,1 \\ 0 & 0 & 0\end{array}$




\section{Especie}

Dacrycarpites australiensis Equisetosporites notensis

Microachrydites antarcticus

Phyllocladidites mawsonii

Podocarpidites elegans

Podocarpidites marwikii

Podocarpidites microreticuloidatus

Podocarpidites rugulosus

Araucariacites australis

Trisaccites microsacatum

Nothofagidites acromegacanthus

Nothofagidites americanus

Nothofagidites dorotensis

Nothofagidites flemingii

Nothofagidites fortispinulosus

Nothofagidites nana

Nothofagidites rocaensis

Nothofagidites saraensis

Nothofagidites tehuelchesii

Myrtaceidites eucalyptoides

Myrtaceidites mesonesus

Myrtaceidites parvus

Myrtaceidites verrucosus

Granodiporites nebulosus

Lewalanipollis senectus

Peninsulapollis gilii

Propylipollis ambiguus

Propylipollis annularis

Propylipollis pseudomoides

Propylipollis reticuloscabratus

Proteacidites obscurus

Proteacidites rectus

\begin{tabular}{|c|c|c|}
\hline 26 & 27 & 28 \\
\hline 0 & 0 & 0 \\
\hline 0 & 0 & 0 \\
\hline 0 & 0,8 & 0 \\
\hline 2,7 & 1,2 & 3,8 \\
\hline 5 & 3,9 & 4,7 \\
\hline 2,3 & 5,1 & 1,3 \\
\hline 0 & 0 & 0 \\
\hline 0 & 2,4 & 0 \\
\hline 0 & 0,8 & 0 \\
\hline 0,4 & 0,8 & 0 \\
\hline 6,6 & 11,4 & 16,2 \\
\hline 0,4 & 0 & 2,1 \\
\hline 31,7 & 37 & 17 \\
\hline 1,2 & 2 & 0 \\
\hline 0 & 0 & 0 \\
\hline 0,8 & 0,4 & 0 \\
\hline 18,5 & 14,2 & 35,7 \\
\hline 8,1 & 3,5 & 4,7 \\
\hline 0 & 0 & 0 \\
\hline 0 & 0 & 0 \\
\hline 0 & 0 & 0 \\
\hline 7,3 & 2 & 6,8 \\
\hline 0 & 0 & 0 \\
\hline 0 & 1,6 & 0 \\
\hline 0 & 0 & 0 \\
\hline 0 & 0 & 0 \\
\hline 0 & 0 & 0 \\
\hline 0 & 0 & 0 \\
\hline 0 & 1,6 & 0 \\
\hline 0,4 & 0 & 0 \\
\hline 0 & 0 & 0 \\
\hline 0 & 0 & 0 \\
\hline
\end{tabular}

\begin{tabular}{|c|c|}
\hline 31 & 33 \\
\hline 0 & 0,8 \\
\hline 0 & 0 \\
\hline 0 & 0 \\
\hline 8,9 & 1,9 \\
\hline 19,8 & 3,8 \\
\hline 0 & 0,8 \\
\hline 0 & 0 \\
\hline 1 & 0 \\
\hline 0 & 0 \\
\hline 1,4 & 0 \\
\hline 0 & 0 \\
\hline 0 & 2,3 \\
\hline 0,3 & 22,3 \\
\hline 23,9 & 0 \\
\hline 0 & 0 \\
\hline 0,7 & 0 \\
\hline 19,8 & 12,8 \\
\hline 13,3 & 10,6 \\
\hline 0 & 0,4 \\
\hline 0 & 0 \\
\hline 0 & 0 \\
\hline 0 & 10,2 \\
\hline 0 & 1,1 \\
\hline 0 & 0,4 \\
\hline 0 & 0,8 \\
\hline 0 & 0 \\
\hline 0 & 0 \\
\hline 0 & 0 \\
\hline 1,4 & 0 \\
\hline 0 & 0 \\
\hline 0 & 0 \\
\hline 0 & 1,5 \\
\hline
\end{tabular}

$\begin{array}{cc}\mathbf{3 4} & \mathbf{3 5} \\ 0 & 0,3 \\ 0 & 0 \\ 0 & 0 \\ 0 & 0 \\ 0 & 3,4 \\ 1,7 & 0 \\ 0 & 0 \\ 0 & 0 \\ 0,8 & 1,2 \\ 0,8 & 1,8 \\ 0 & 0 \\ 6,3 & 1,2 \\ 6,7 & 6,4 \\ 0 & 0,6 \\ 0 & 0 \\ 0 & 0 \\ 8,8 & 5,8 \\ 2,5 & 2,5 \\ 0,8 & 0,3 \\ 0 & 0 \\ 0,4 & 0 \\ 12,1 & 12,6 \\ 11,7 & 11 \\ 1,3 & 2,8 \\ 0 & 0 \\ 0 & 0 \\ 1,3 & 6,1 \\ 0 & 0,3 \\ 0,4 & 1,8 \\ 0 & 0 \\ 0 & 0 \\ 1,3 & 2,5 \\ & \\ 0 & 0\end{array}$

$\begin{array}{ccc}\mathbf{3 6} & \mathbf{3 7} & \mathbf{3 8} \\ 0 & 0 & 0 \\ 0 & 0 & 2 \\ 0 & 0 & 0 \\ 5,1 & 0,8 & 0 \\ 41,7 & 2,4 & 30,1 \\ 0 & 0 & 0 \\ 0 & 0 & 0 \\ 0 & 0 & 1,3 \\ 0 & 0 & 0 \\ 0 & 0,4 & 0 \\ 0 & 0 & 0 \\ 0 & 2,4 & 0 \\ 6 & 16,1 & 17,6 \\ 8,3 & 0 & 17 \\ 0 & 0 & 0 \\ 0 & 0 & 1,3 \\ 19 & 16,9 & 9,2 \\ 9,3 & 5,1 & 3,3 \\ 0 & 0 & 0 \\ 0 & 0 & 0 \\ 0 & 0,8 & 0 \\ 0,5 & 4,7 & 0 \\ 0,9 & 8,2 & 0 \\ 0,9 & 0,4 & 0 \\ 0 & 1,2 & 0 \\ 0 & 0,4 & 0 \\ 0 & 0 & 0 \\ 0 & 0 & 0 \\ 1,4 & 0,8 & 2 \\ 0 & 0 & 0 \\ 0 & 0 & 0 \\ 0 & 3,9 & 0,7\end{array}$




\section{Especie}

Proteacidites subscabratus

Anacolosidites diffusa

Bombacacidites isoreticulatus

Cupaneidites insularis

Cupaneidites reticularis

Ilexpollenites anguloclavatus

Ilexpollenites clifdenensis

Ilexpollenites megagemmatus

Perysincolporites pokornii

Bysmapollis verrucatus

Compositoipollenites sp. 1

Corsinipollenites atlantica

Dicolpopollis sp. 1

Ericipites sp.

Gothanipollis basensis

Gothanipollis sp. 1

Haloragacidites trioratus

Malvacearumpollis sp. 1

Malvacipollis sp. 1

Margocolporites sp 1 Tipo Prosopis

$c f$. Perfotricolpites sp.

Periporopollenites sp. 1

Polycolporopollenites esobalteus

Psilatricolpites brevis

Psilatricolporites cf marginatus

Psilatricolporites costatus

Psilatricolporites divisus

Psilatricolporites pachydermatus

Psilatricolporites protrudens

Psilatricolporites vanus

Psilatricolporites varius

Rhoipites alveolatus

$\begin{array}{ccc}\mathbf{2 6} & \mathbf{2 7} & \mathbf{2 8} \\ 0,8 & 0,4 & 0 \\ 0 & 0 & 0 \\ 0 & 0 & 0 \\ 0 & 0 & 0 \\ 0 & 0 & 0 \\ 0,4 & 0,4 & 0 \\ 4,2 & 0,4 & 1,3 \\ 0 & 0 & 0 \\ 0 & 0 & 0 \\ 0 & 0 & 0 \\ 0 & 0 & 0 \\ 0 & 0 & 0 \\ 0 & 0 & 0 \\ 0 & 0 & 0 \\ 0 & 0 & 0,4 \\ 0 & 0 & 0 \\ 0 & 0 & 0 \\ 0 & 1,2 & 0 \\ 0,4 & 0,4 & 0,9 \\ 0,8 & 0 & 0 \\ 0 & 0 & 0 \\ 1,2 & 0 & 0 \\ 0 & 0 & 0 \\ 0 & 0,4 & 0 \\ 0 & 0 & 0 \\ 0,4 & 0 & 0 \\ 0 & 0 & 0 \\ 0 & 0 & 0 \\ 0 & 0 & 0 \\ 0 & 2,4 & 0 \\ 4,6 & 2 & 3 \\ 0 & 0 & 0\end{array}$

$\begin{array}{cccc}\mathbf{3 1} & \mathbf{3 3} & \mathbf{3 4} & \mathbf{3 5} \\ 0 & 1,5 & 0 & 0 \\ 0 & 0 & 0 & 0 \\ 0 & 0,4 & 0 & 0,3 \\ 0 & 0 & 0 & 0,3 \\ 0 & 0 & 0 & 0 \\ 1,4 & 0,8 & 0 & 0 \\ 0,7 & 0 & 0 & 0 \\ 0,3 & 0 & 0 & 0 \\ 0 & 0 & 0 & 0 \\ 0 & 0 & 0 & 0 \\ 0 & 0 & 2,5 & 0,3 \\ 0 & 0 & 0 & 0,3 \\ 0 & 0 & 0 & 0 \\ 0 & 0,8 & 0 & 0,9 \\ 0 & 1,5 & 1,3 & 2,1 \\ 0 & 0 & 0,4 & 1,8 \\ 0 & 0 & 0 & 0 \\ 0 & 0 & 0 & 0 \\ 1,7 & 1,1 & 0,4 & 0,3 \\ 0 & 1,1 & 1,3 & 2,5 \\ 0 & 0 & 0 & 0 \\ 0,7 & 0 & 0 & 0 \\ 0 & 0 & 0 & 0 \\ 0 & 0,4 & 0,8 & 0,9 \\ 0 & 0 & 0 & 0 \\ 0 & 1,1 & 4,2 & 0 \\ 0,3 & 0 & 0 & 0 \\ 0 & 0 & 0 & 0 \\ 0 & 0,4 & 0 & 0 \\ 0 & 0 & 0 & 17,8 \\ 0 & 14,7 & 25,4 & 0 \\ 0 & 0 & 0 & 0\end{array}$

$\begin{array}{ccc}\mathbf{3 6} & \mathbf{3 7} & \mathbf{3 8} \\ 0 & 0 & 0 \\ 0 & 0 & 0 \\ 0 & 1,2 & 0 \\ 0 & 0,4 & 0 \\ 0,9 & 0 & 0 \\ 1,9 & 2,7 & 3,9 \\ 0 & 0 & 0 \\ 0 & 0 & 0 \\ 0 & 0 & 0 \\ 0 & 0 & 0,7 \\ 0 & 0 & 0 \\ 0 & 0 & 0 \\ 0 & 0 & 0 \\ 0 & 0,4 & 0 \\ 0 & 0,8 & 0 \\ 0 & 0,4 & 0 \\ 0 & 0 & 0 \\ 0 & 0,4 & 0 \\ 1,9 & 0 & 0 \\ 0 & 0 & 0 \\ 0 & 0 & 0 \\ 0 & 0 & 0 \\ 0 & 0 & 0 \\ 0 & 0 & 0,7 \\ 0 & 0 & 0 \\ 0 & 3,5 & 0 \\ 0 & 0 & 0 \\ 0 & 0 & 0 \\ 0 & 0 & 0 \\ 0 & 0,8 & 0 \\ 0 & 11,8 & 0 \\ 0 & 0 & 0\end{array}$




\section{Especie}

Rhoipites baculatus

Rhoipites cf. hawkdunensis

Rhoipites romboidaliformis

Rhoipites sphaerica

Striatricolporites pseudoestriatus

Tetracolporopollenites sp. 1

Tricolpites bathyreticulatus

Tricolpites brevicolpus

Tricolpites reticulatus

Triorites fragilis

Triorites minor

Triorites subespinosus

Arecipites minutiscabratus

Arecipites sp. 1

cf. Spatiphyllum sp.

Monosulcites cf perspinosus

Psilamonocolpites medius

Graminidites sp.

Liliacidites regularis

Sparganiaceaepollenites barungensis

Escolecodonte

Foraminifera

Uñas de ácaros

Gonyaulacales

Peridiniales

\begin{tabular}{|c|c|c|c|c|}
\hline 26 & 27 & 28 & 31 & 33 \\
\hline 0,8 & 0 & 0,4 & 0,7 & 4,2 \\
\hline 0 & 0,4 & 0 & 0 & 0 \\
\hline 0 & 0 & 0 & 0 & 0 \\
\hline 0 & 0 & 0 & 0 & 0 \\
\hline 0 & 0 & 0,4 & 0 & 0 \\
\hline 0 & 0 & 0 & 0 & 0 \\
\hline 0 & 0 & 0 & 0 & 0 \\
\hline 0 & 0 & 0 & 0 & 0,8 \\
\hline 0 & 0,4 & 0 & 0 & 1,1 \\
\hline 0 & 0 & 0 & 0,3 & 0 \\
\hline 0 & 0,4 & 1,3 & 0,3 & 0,4 \\
\hline 0 & 0 & 0 & 0 & 0,4 \\
\hline 0 & 0 & 0 & 0 & 0 \\
\hline 0 & 0,4 & 0 & 0,3 & 0 \\
\hline 0 & 0,4 & 0 & 0 & 0 \\
\hline 0 & 0,4 & 0 & 0 & 0 \\
\hline 0,8 & 0,8 & 0 & 1,7 & 0 \\
\hline 0 & 0 & 0 & 0 & 0 \\
\hline 0,4 & 0,8 & 0 & 0 & 0 \\
\hline 0 & 0 & 0 & 1 & 0 \\
\hline 0 & 0 & 0 & 0 & 0 \\
\hline 0 & 0 & 0 & 0 & 1,1 \\
\hline 1,4 & 0,4 & 0 & 0 & 0,8 \\
\hline 6,7 & 4,9 & 7,3 & 2,3 & 39,3 \\
\hline 0 & 0,4 & 0,8 & 0,3 & 21 \\
\hline
\end{tabular}

34
0,4
0
0
0
0
0
0,4
0
0
0
2,9
0
0
0,4
0
0
2,5
0,4
0
0
0
0
3,3
4,4
4,4


0
0
0
0
0
0
0

35
0,6
0
0
0
0
0,3
0
0
0,9
0,3
0,9
0
0
0
0
0
5,2
0
0
0,6
0
0
1,8
1,5
2,1
0

$\begin{array}{ccc}\mathbf{3 6} & \mathbf{3 7} & \mathbf{3 8} \\ 1,4 & 1,6 & 0,7 \\ 0 & 0,4 & 0 \\ 0 & 0 & 0 \\ 0 & 0 & 0,7 \\ 0 & 0 & 0 \\ 0 & 0 & 0 \\ 0,5 & 0,8 & 0 \\ 0 & 0 & 0 \\ 0 & 0,8 & 0,7 \\ 0 & 1,2 & 0,7 \\ 0 & 3,5 & 0,7 \\ 0 & 0 & 0 \\ 0 & 0 & 3,9 \\ 0 & 0 & 0 \\ 0 & 0 & 0 \\ 0 & 0 & 0 \\ 0,5 & 4,3 & 3,3 \\ 0 & 0 & 0 \\ 0 & 0,8 & 0 \\ 0 & 0 & 0 \\ 0 & 0 & 0 \\ 0,1 & 0 & 0 \\ 0,5 & 1,8 & 0 \\ 72,4 & 40 & 82,8 \\ 1,9 & 1,3 & 0,4\end{array}$


Closterium sp

Botryococcus sp.

Scenedesmaceae indet

Catinipollis geiseltalensis

Baculatisporites comaumensis

Baculatisporites turbioensis

Biretisporites sp. I Archangelsky

Cingutriletes australis

Concavisporites sp. II

Concavosporites sp. I

Cyatheacidites annulatus

Cyathidites minor

Deltoidospora cf australis

Deltoidospora minor

Foveotriletes sp. 1

Gleichenidites circinidites

Gleichenidites senonicus

Klukisporites scaberis

Laevigatosporites ovatus

Leiotriletes minor

Leptolepidites densus

Matonisporites sp. 1

Peromonolites vellosus

Polypodiisporites speciosus

Polypodiumsporites perverrucatus

Pteridophyta indet.

Retitriletes austroclavatidites

Trilites fasolae

Trilites parvalatus

Verrucosisporites sp. 1

Verrucosisporites sp. 2

Verrucosisporites sp. 3

$\begin{array}{ccc}\mathbf{3 9} & \mathbf{4 0} & \mathbf{4 1} \\ 0 & 0 & 0 \\ 0 & 0 & 0 \\ 1 & 0 & 0 \\ 0,2 & 0 & 0 \\ 0,2 & 0 & 0 \\ 0,2 & 1,7 & 5,2 \\ 0 & 0 & 1 \\ 0 & 0 & 0 \\ 0,4 & 0 & 0,3 \\ 0 & 0 & 0 \\ 0,6 & 1,7 & 3,1 \\ 0 & 1,7 & 3,8 \\ 0 & 2,3 & 0,3 \\ 7,6 & 2,9 & 5,6 \\ 0 & 0 & 0 \\ 0,4 & 0 & 0 \\ 0 & 0,6 & 0,7 \\ 0,4 & 0 & 0 \\ 0 & 0 & 0 \\ 0 & 0,3 & 0 \\ 0 & 0 & 0,3 \\ 0 & 0 & 0 \\ 2,2 & 0,3 & 0,3 \\ 0,2 & 0 & 0,3 \\ 0,2 & 0 & 0,3 \\ 0 & 0,3 & 0 \\ 0,2 & 0,3 & 0 \\ 0,4 & 0,6 & 0 \\ 1,2 & 0 & 0,7 \\ 0 & 0 & 0 \\ 0 & 0 & 0 \\ 0 & 0 & 0 \\ & & \\ 0 & 0,3\end{array}$

$\begin{array}{ccccccc}\mathbf{4 2} & \mathbf{4 5} & \mathbf{4 6} & \mathbf{4 7} & \mathbf{4 9} & \mathbf{5 0} & \mathbf{5 3} \\ 0 & 0 & 0 & 0 & 0 & 0 & 0 \\ 0 & 0 & 0 & 0 & 0 & 0 & 0 \\ 0 & 0 & 0 & 0 & 0,3 & 0 & 0,4 \\ 0 & 0 & 0 & 0 & 0 & 0 & 0,4 \\ 0,1 & 0,3 & 9,4 & 0 & 0,8 & 0,4 & 0 \\ 1 & 0 & 2,4 & 0 & 0 & 0 & 0 \\ 0 & 0,3 & 0,2 & 0,5 & 0,5 & 0 & 0,2 \\ 0 & 0 & 0 & 0 & 0 & 0 & 0 \\ 0 & 0 & 0 & 0 & 0 & 0 & 0 \\ 0 & 0 & 0 & 0 & 0,2 & 0 & 0 \\ 2 & 0 & 1,7 & 2,1 & 1,1 & 0,4 & 0,9 \\ 0,5 & 0,5 & 1,4 & 0,3 & 0,6 & 6,9 & 2,2 \\ 0 & 0 & 0 & 0 & 0 & 0 & 0 \\ 4,8 & 4,8 & 7,5 & 3,7 & 2,2 & 6,9 & 3,7 \\ 0 & 0 & 0 & 0 & 0 & 0 & 0 \\ 0,2 & 0,3 & 0 & 0 & 0 & 0 & 0 \\ 0,1 & 1,1 & 3,9 & 0,3 & 0,3 & 1,1 & 0 \\ 0 & 0,3 & 0,2 & 0 & 0,3 & 0 & 0 \\ 1,1 & 0 & 0 & 0 & 0 & 0 & 0 \\ 0,5 & 0,3 & 2,7 & 0,5 & 0,2 & 0 & 0 \\ 0,2 & 0 & 0,2 & 0 & 0 & 0 & 0 \\ 0 & 0 & 0 & 0 & 0 & 0 & 0 \\ 1,5 & 0 & 0,7 & 0 & 0,2 & 0 & 0,2 \\ 0 & 0 & 0 & 0 & 0 & 0,4 & 0 \\ 0,1 & 0 & 0 & 0 & 0 & 0,4 & 0 \\ 0,1 & 0 & 0 & 0 & 0 & 0 & 0 \\ 0,1 & 1,6 & 0,7 & 0,3 & 0 & 0,4 & 0 \\ 0,1 & 0,3 & 2,2 & 0,5 & 0,6 & 0,4 & 0,4 \\ 0,9 & 2,1 & 8,7 & 2,9 & 6,4 & 8 & 7,5 \\ 0 & 0 & 0 & 0 & 0 & 0 & 0 \\ 0 & 0 & 0 & 0 & 0 & 0 & 0 \\ 0 & 0 & 0 & 0 & 0 & 0 & 0\end{array}$




\section{Especie}

Dacrycarpites australiensis Equisetosporites notensis

Microachrydites antarcticus

Phyllocladidites mawsonii

Podocarpidites elegans

Podocarpidites marwikii

Podocarpidites microreticuloidatus

Podocarpidites rugulosus

Araucariacites australis

Trisaccites microsacatum

Nothofagidites acromegacanthus

Nothofagidites americanus

Nothofagidites dorotensis

Nothofagidites flemingii

Nothofagidites fortispinulosus

Nothofagidites nana

Nothofagidites rocaensis

Nothofagidites saraensis

Nothofagidites tehuelchesii

Myrtaceidites eucalyptoides

Myrtaceidites mesonesus

Myrtaceidites parvus

Myrtaceidites verrucosus

Granodiporites nebulosus

Lewalanipollis senectus

Peninsulapollis gilii

Propylipollis ambiguus

Propylipollis annularis

Propylipollis pseudomoides

Propylipollis reticuloscabratus

Proteacidites obscurus

Proteacidites rectus

$\begin{array}{cc}\mathbf{3 9} & \mathbf{4 0} \\ 0,4 & 0,4 \\ 0 & 0 \\ 0 & 0 \\ 0 & 0 \\ 16 & 4,7 \\ 0,4 & 1,6 \\ 0 & 0 \\ 0 & 0 \\ 0,4 & 0 \\ 0,4 & 0,8 \\ 0 & 0 \\ 0 & 0 \\ 6,9 & 20,7 \\ 12,6 & 5,5 \\ 0 & 0 \\ 2,6 & 5,1 \\ 43,3 & 10,2 \\ 0 & 7 \\ 0 & 0 \\ 0 & 0 \\ 0 & 0 \\ 0 & 10,5 \\ 0 & 7,4 \\ 0 & 0,8 \\ 0 & 0 \\ 0,4 & 0 \\ 0 & 0 \\ 0 & 0 \\ 2,2 & 1,2 \\ 0 & 0 \\ 0 & 0 \\ 0 & 1,6\end{array}$

$\begin{array}{ccc}\mathbf{4 1} & \mathbf{4 2} & \mathbf{4 5} \\ 0 & 1,4 & 0,8 \\ 0 & 0 & 0 \\ 0 & 0 & 0 \\ 0,8 & 0,3 & 2,5 \\ 0 & 8,2 & 17,5 \\ 0 & 0 & 0 \\ 0 & 0 & 0 \\ 0 & 0 & 2,5 \\ 0 & 0 & 0 \\ 0 & 0,3 & 1,4 \\ 0 & 0 & 0,3 \\ 1,7 & 0,3 & 0,6 \\ 6,8 & 8,5 & 1,4 \\ 2,1 & 13,9 & 38,2 \\ 0 & 0 & 7,5 \\ 0,4 & 0 & 2,2 \\ 16,5 & 26,9 & 7,5 \\ 2,1 & 14,3 & 6,9 \\ 0 & 0,7 & 0 \\ 0 & 0 & 0 \\ 0,8 & 0 & 0 \\ 19,9 & 2 & 0 \\ 1,3 & 0 & 0 \\ 2,1 & 4,4 & 0,3 \\ 0 & 0,3 & 0,3 \\ 0 & 0,3 & 0,3 \\ 0 & 0 & 0,3 \\ 0 & 0 & 0 \\ 0 & 0 & 0,3 \\ 0 & 0 & 0 \\ 0 & 0 & 0 \\ 0 & 3,1 & 0\end{array}$

46
0,3
0
0
8,5
20,8
0
0
0
0
0,7
0
0
6,5
33,6
0
0
10,1
5,9
0,3
0
0
0
0
0
0
0
0
0
1,3
0
0
1

47
0
1,
5,7
3,2
37
0,4
15
1,8
21
1,4
0
3,6
0
0
0
0
0
0
0
0
0

$\begin{array}{ccc}\mathbf{4 9} & \mathbf{5 0} & \mathbf{5 3} \\ 0 & 0,4 & 0 \\ 0 & 0 & 0 \\ 0 & 0 & 0 \\ 1,8 & 1,3 & 2,2 \\ 4,8 & 5,6 & 3 \\ 0 & 0 & 0 \\ 0 & 0 & 0 \\ 0 & 0 & 0 \\ 2,6 & 0 & 0 \\ 0 & 0 & 0 \\ 36,1 & 0 & 0 \\ 1,8 & 4,3 & 0 \\ 6,2 & 6,4 & 1,7 \\ 0 & 0 & 0,4 \\ 0 & 0 & 28,3 \\ 0 & 27,4 & 0 \\ 30,4 & 0 & 26,1 \\ 3,5 & 23,9 & 12,6 \\ 0 & 0,9 & 1,3 \\ 0 & 0 & 0 \\ 0 & 0 & 0 \\ 0 & 0 & 0,4 \\ 0,4 & 0 & 0 \\ 4,8 & 0,4 & 1,7 \\ 0 & 0 & 0 \\ 0 & 0 & 0,4 \\ 0 & 0 & 0 \\ 0 & 0,4 & 0 \\ 1,8 & 1,7 & 1,3 \\ 0,4 & 0 & 0 \\ 0 & 0 & 0 \\ 0 & 0 & 0\end{array}$




\section{Especie}

Proteacidites subscabratus

Anacolosidites diffusa

Bombacacidites isoreticulatus

Cupaneidites insularis

Cupaneidites reticularis

Ilexpollenites anguloclavatus

Ilexpollenites clifdenensis

Ilexpollenites megagemmatus

Perysincolporites pokornii

Bysmapollis verrucatus

Compositoipollenites sp. 1

Corsinipollenites atlantica

Dicolpopollis sp. 1

Ericipites sp.

Gothanipollis basensis

Gothanipollis sp. 1

Haloragacidites trioratus

Malvacearumpollis sp. 1

Malvacipollis sp. 1

Margocolporites sp 1 Tipo Prosopis $c f$. Perfotricolpites sp.

Periporopollenites sp. 1

Polycolporopollenites esobalteus

Psilatricolpites brevis

Psilatricolporites ef marginatus

Psilatricolporites costatus

Psilatricolporites divisus

Psilatricolporites pachydermatus

Psilatricolporites protrudens

Psilatricolporites vanus

Psilatricolporites varius

Rhoipites alveolatus

$\begin{array}{ccc}\mathbf{3 9} & \mathbf{4 0} & \mathbf{4 1} \\ 0 & 0 & 0 \\ 0 & 0 & 0 \\ 4,8 & 3,1 & 0 \\ 0 & 0 & 0 \\ 0 & 0 & 2,1 \\ 0,9 & 0 & 0,8 \\ 2,2 & 0 & 0 \\ 0 & 0 & 0 \\ 0 & 0 & 0 \\ 0,4 & 0 & 0 \\ 0 & 0 & 0 \\ 0 & 0 & 0 \\ 0 & 0 & 1,7 \\ 0 & 0,8 & 0 \\ 0,4 & 0,8 & 0,8 \\ 0 & 0 & 0,4 \\ 0 & 0 & 0 \\ 0 & 0 & 0 \\ 0 & 0,4 & 0,4 \\ 0 & 0 & 0 \\ 0 & 0 & 0 \\ 0,4 & 0 & 0 \\ 0 & 0,4 & 0 \\ 0 & 0 & 0,8 \\ 0 & 0 & 0 \\ 0 & 0 & 0 \\ 0 & 0 & 0 \\ 0 & 0 & 3,8 \\ 0 & 0 & 0 \\ 0 & 0 & 6,8 \\ 0 & 7,4 & 11 \\ 0,4 & 0 & 0 \\ & & \end{array}$

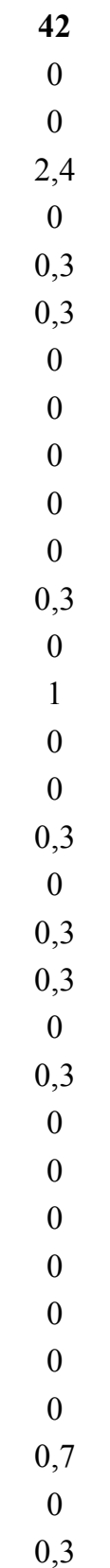

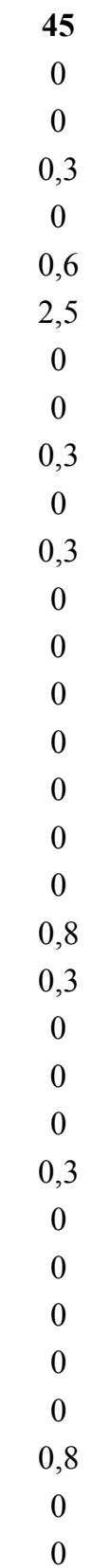



\begin{tabular}{|c|c|c|c|}
\hline 47 & 49 & 50 & 53 \\
\hline 1,8 & 0,4 & 0,4 & 0 \\
\hline 0 & 0 & 0 & 0 \\
\hline 0 & 0,4 & 0,4 & 0,4 \\
\hline 0 & 0 & 0 & 0,4 \\
\hline 0 & 0 & 0 & 0 \\
\hline 0,7 & 0,4 & 0 & 0 \\
\hline 0 & 0 & 0 & 0 \\
\hline 0 & 0 & 0 & 0 \\
\hline 0 & 0 & 0 & 0 \\
\hline 0 & 0 & 0 & 0 \\
\hline 0 & 1,3 & 0,4 & 2,2 \\
\hline 0 & 0 & 0 & 0,4 \\
\hline 0 & 0 & 0 & 0 \\
\hline 0 & 0 & 0 & 0,9 \\
\hline 0,4 & 0 & 1,7 & 3,5 \\
\hline 0 & 0 & 0 & 0 \\
\hline 0 & 0 & 0 & 0 \\
\hline 1,4 & 0,4 & 0 & 0 \\
\hline 0 & 0 & 0,9 & 0,4 \\
\hline 0 & 0 & 0,4 & 0 \\
\hline 0 & 0 & 0 & 0 \\
\hline 0,4 & 0 & 0 & 0 \\
\hline 0 & 0 & 0 & 1,3 \\
\hline 0 & 0 & 0,4 & 0 \\
\hline 0 & 0 & 0 & 0 \\
\hline 0 & 0,4 & 0 & 0 \\
\hline 0 & 0 & 0 & 0,4 \\
\hline 0 & 0 & 0 & 0 \\
\hline 0 & 0 & 0 & 0 \\
\hline 1,1 & 0,4 & 1,7 & 2,2 \\
\hline 0,7 & 0,4 & 4,3 & 3,5 \\
\hline 0,4 & 0,4 & 0 & 0 \\
\hline
\end{tabular}




\section{Especie}

Rhoipites baculatus

Rhoipites cf. hawkdunensis

Rhoipites romboidaliformis

Rhoipites sphaerica

Striatricolporites pseudoestriatus

Tetracolporopollenites sp. 1

Tricolpites bathyreticulatus

Tricolpites brevicolpus

Tricolpites reticulatus

Triorites fragilis

Triorites minor

Triorites subespinosus

Arecipites minutiscabratus

Arecipites sp. 1

cf. Spatiphyllum sp.

Monosulcites cf perspinosus

Psilamonocolpites medius

Graminidites sp.

Liliacidites regularis

Sparganiaceaepollenites barungensis

Escolecodonte

Foraminifera

Uñas de ácaros

Gonyaulacales

Peridiniales

\begin{tabular}{|c|c|c|c|c|}
\hline 39 & 40 & 41 & 42 & 45 \\
\hline 0,9 & 2 & 0,8 & 0 & 0 \\
\hline 0 & 0 & 0 & 0 & 0 \\
\hline 0 & 0 & 0 & 0 & 0 \\
\hline 0 & 0 & 0 & 0 & 0 \\
\hline 0 & 0 & 0 & 0 & 0 \\
\hline 0 & 0 & 0 & 0 & 0 \\
\hline 0 & 0 & 0 & 0,7 & 0 \\
\hline 0 & 0 & 0 & 0 & 0 \\
\hline 0,4 & 1,2 & 1,3 & 0 & 0,3 \\
\hline 0,4 & 0,4 & 0 & 0 & 0 \\
\hline 0 & 1,2 & 4,2 & 0,3 & 0 \\
\hline 0 & 0 & 0 & 0 & 0 \\
\hline 0 & 0 & 0 & 0 & 0 \\
\hline 1,3 & 0 & 0 & 0 & 0 \\
\hline 0 & 0 & 0 & 0 & 0 \\
\hline 0 & 0,8 & 1,3 & 3,7 & 0 \\
\hline 0 & 2,7 & 8,5 & 0 & 2,8 \\
\hline 0 & 0 & 0 & 0 & 0 \\
\hline 0 & 1,6 & 0,4 & 0 & 0 \\
\hline 1,7 & 0 & 0 & 3,4 & 0,3 \\
\hline 0 & 0 & 0 & 0 & 0 \\
\hline 0 & 0 & 0 & 0 & 0,3 \\
\hline 0,6 & 1,4 & 1,4 & 0 & 0,5 \\
\hline 51,7 & 19,8 & 3,1 & 53,3 & 5 \\
\hline 0,8 & 6 & 13,2 & 10,7 & 0 \\
\hline
\end{tabular}

\begin{tabular}{|c|c|}
\hline 46 & 47 \\
\hline 0,7 & 0,7 \\
\hline 0 & 0 \\
\hline 0 & 0 \\
\hline 0 & 0 \\
\hline 0 & 0 \\
\hline 0 & 0 \\
\hline 0,7 & 0 \\
\hline 0 & 0 \\
\hline 0 & 0 \\
\hline 0,3 & 0,4 \\
\hline 0 & 1,4 \\
\hline 0 & 0 \\
\hline 0 & 0 \\
\hline 0 & 0 \\
\hline 0 & 0 \\
\hline 0,3 & 0 \\
\hline 2 & 0 \\
\hline 0 & 0 \\
\hline 0 & 0 \\
\hline 1,3 & 0 \\
\hline 13,3 & 0 \\
\hline 0 & 0 \\
\hline 0 & 0,5 \\
\hline 13,3 & 9,8 \\
\hline 0 & 17,9 \\
\hline
\end{tabular}

$\begin{array}{ccc}\mathbf{4 9} & \mathbf{5 0} & \mathbf{5 3} \\ 0 & 3,8 & 0,4 \\ 0 & 0 & 0 \\ 0 & 0 & 0 \\ 0 & 0 & 0 \\ 0 & 0 & 0 \\ 0 & 0 & 0 \\ 0 & 0 & 0 \\ 0 & 0 & 0 \\ 0 & 1,3 & 0,4 \\ 0 & 0 & 0 \\ 0 & 1,3 & 0 \\ 0 & 0 & 0 \\ 0 & 0,9 & 0 \\ 0 & 0 & 0 \\ 0,4 & 0 & 0 \\ 0 & 1,3 & 0 \\ 0 & 8,1 & 3,5 \\ 0 & 0 & 0,4 \\ 0 & 0 & 0 \\ 0 & 0 & 0 \\ 0 & 0 & 0 \\ 0 & 0 & 0 \\ 0,3 & 2,7 & 0 \\ 15,4 & 3,4 & 10,8 \\ 49,5 & 4,2 & 37,8 \\ & & \\ 0 & & 0\end{array}$




\section{Especie}

Closterium sp.

Botryococcus sp.

Scenedesmaceae indet

Catinipollis geiseltalensis

Cingutriletes australis

Baculatisporites comaumensis

Baculatisporites turbioensis

Biretisporites sp. I Archangelsky

Concavisporites sp. II

Concavosporites sp. I

Cyatheacidites annulatus

Cyathidites minor

Deltoidospora cf australis

Deltoidospora minor

Foveotriletes sp. 1

Gleichenidites circinidites

Gleichenidites senonicus

Klukisporites scaberis

Laevigatosporites ovatus

Leiotriletes minor

Leptolepidites densus

Matonisporites sp. 1

Peromonolites vellosus

Polypodiisporites speciosus

Polypodiumsporites perverrucatus

Pteridophyta indet.

Retitriletes austroclavatidites

Trilites fasolae

Trilites parvalatus

Verrucosisporites sp. 1

Verrucosisporites sp. 2

Verrucosisporites sp. 3

Dacrycarpites australiensis

Equisetosporites notensis

Microachrydites antarcticus

Phyllocladidites mawsonii

Podocarpidites elegans

Podocarpidites marwikii

Podocarpidites microreticuloidatus

Podocarpidites rugulosus

Araucariacites australis

Trisaccites microsacatum

Nothofagidites acromegacanthus

Nothofagidites americanus

Nothofagidites dorotensis

Nothofagidites flemingii

Nothofagidites fortispinulosus

Nothofagidites nanus

Nothofagidites rocaensis
Grupos y familias

$$
\begin{aligned}
& \text { Algae } \\
& \text { Algae } \\
& \text { Algae } \\
& \text { Algae }
\end{aligned}
$$

Sphagnales

Pteridophyta

Pteridophyta

Pteridophyta

Pteridophyta

Pteridophyta

Pteridophyta

Pteridophyta

Pteridophyta

Pteridophyta

Pteridophyta

Pteridophyta

Pteridophyta

Pteridophyta

Pteridophyta

Pteridophyta

Pteridophyta

Pteridophyta

Pteridophyta

Pteridophyta

Pteridophyta

Pteridophyta

Pteridophyta

Pteridophyta

Pteridophyta

Pteridophyta

Pteridophyta

Pteridophyta

Podocarpaceae

Podocarpaceae

Podocarpaceae

Podocarpaceae

Podocarpaceae

Podocarpaceae

Podocarpaceae

Podocarpaceae

Araucariaceae

Gymnospermae

Nothofagus

Nothofagus

Nothofagus

Nothofagus

Nothofagus

Nothofagus

Nothofagus
Tipo biológico

acuático

acuático

acuático

acuático

briofita

pteridofita

pteridofita

pteridofita

pteridofita

pteridofita

pteridofita arbórea

pteridofita

pteridofita

pteridofita

pteridofita

pteridofita

pteridofita

pteridofita

pteridofita

pteridofita

pteridofita

pteridofita

pteridofita

pteridofita

pteridofita

pteridofita

pteridofita

pteridofita

pteridofita

pteridofita

pteridofita

pteridofita

arbóreo

arbóreo

arbóreo

arbóreo

arbóreo

arbóreo

arbóreo

arbóreo

arbóreo

arbóreo

arbóreo

arbóreo

arbóreo

arbóreo

arbóreo

arbóreo

arbóreo 
Nothofagidites saraensis

\section{Especie}

Nothofagidites tehuelchesii

Myrtaceidites eucalyptoides

Myrtaceidites mesonesus

Myrtaceidites parvus

Myrtaceidites verrucosus

Granodiporites nebulosus

Lewalanipollis senectus

Peninsulapollis gilii

Propylipollis ambiguus

Propylipollis annularis

Propylipollis pseudomoides

Propylipollis reticuloscabratus

Proteacidites obscurus

Proteacidites rectus

Proteacidites subscabratus

Anacolosidites diffusa

Bombacacidites isoreticulatus

Cupaneidites insularis

Cupaneidites reticularis

Ilexpollenites anguloclavatus

Ilexpollenites clifdenensis

Ilexpollenites megagemmatus

Perysincolporites pokornii

Bysmapollis verrucatus

Compositoipollenites sp. 1

Corsinipollenites atlantica

Dicolpopollis sp. 1

Ericipites sp.

Gothanipollis basensis

Gothanipollis sp. 1

Haloragacidites trioratus

Malvacearumpollis sp. 1

Malvacipollis sp. 1

Margocolporites sp 1 Tipo Prosopis

$c f$. Perfotricolpites sp.

Periporopollenites demarcatus

Polycolporopollenites esobalteus

Psilatricolpites brevis

Psilatricolporites cf marginatus

Psilatricolporites costatus

Psilatricolporites divisus

Psilatricolporites pachydermatus

Psilatricolporites aff. P. protrudens

Psilatricolporites vanus

Psilatricolporites varius

Rhoipites alveolatus

Rhoipites baculatus

Rhoipites cf. hawkdunensis
Nothofagus

\section{Grupos y familias}

Nothofagus

Myrtaceae

Myrtaceae

Myrtaceae

Myrtaceae

Proteaceae

Proteaceae

Proteaceae

Proteaceae

Proteaceae

Proteaceae

Proteaceae

Proteaceae

Proteaceae

Proteaceae

DicotiledoneaTropical/subtropical

DicotiledoneaTropical/subtropical

DicotiledoneaTropical/subtropical

DicotiledoneaTropical/subtropical

DicotiledoneaTropical/subtropical

DicotiledoneaTropical/subtropical

DicotiledoneaTropical/subtropical

DicotiledoneaTropical/subtropical

Dicotiledonea

Dicotiledonea

Dicotiledonea

Dicotiledonea

Dicotiledonea

Dicotiledonea

Dicotiledonea

Dicotiledonea

Dicotiledonea

Dicotiledonea

Dicotiledonea

Dicotiledonea

Dicotiledonea

Dicotiledonea

Dicotiledonea

Dicotiledonea

Dicotiledonea

Dicotiledonea

Dicotiledonea

Dicotiledonea

Dicotiledonea

Dicotiledonea

Dicotiledonea

Dicotiledonea

Dicotiledonea arbóreo

Tipo biológico

arbóreo

arbóreo

arbóreo

arbóreo

arbóreo

arbustivi/arbóreo

arbustivi/arbóreo

arbustivi/arbóreo

arbustivi/arbóreo

arbustivi/arbóreo

arbustivi/arbóreo

arbustivi/arbóreo

arbustivi/arbóreo

arbustivi/arbóreo

arbustivi/arbóreo

arbustivi/arbóreo

arbóreo

arbustivi/arbóreo

arbustivi/arbóreo

arbustivi/arbóreo

arbustivi/arbóreo

arbustivi/arbóreo

arbustivi/arbóreo

indet

herbáceo

herbáceo

arbustivi/arbóreo

arbustivi/arbóreo

arbustivi/arbóreo

arbustivi/arbóreo

arbóreo

indet

indet

arbóreo

herbáceo

indet

indet

indet

indet

indet

indet

indet

indet

indet

indet

indet

indet

indet 
Rhoipites romboidaliformis

Rhoipites sphaerica

\section{Especie}

Striatricolporites pseudoestriatus

Tetracolporopollenites sp. 1

Tricolpites bathyreticulatus

Tricolpites brevicolpus

Tricolpites reticulatus

Triorites fragilis

Triorites minor

Triorites subespinosus

Arecipites minutiscabratus

Arecipites sp. 1

cf. Spatiphyllum sp.

Monosulcites cf perspinosus

Psilamonocolpites medius

Graminidites sp.

Liliacidites regularis

Sparganiaceaepollenites barungensis

Escolecodonte

Foraminifera

Uñas de ácaros

Gonyaulacoideos

Peridinoideos
Dicotiledonea

Grupos y familias

Dicotiledonea

Dicotiledonea

Dicotiledonea

Dicotiledonea

Dicotiledonea

Dicotiledonea

Dicotiledonea

Dicotiledonea

Monocotiledonea Tropical/subtropical

Monocotiledonea Tropical/subtropical

Monocotiledonea Tropical/subtropical

Monocotiledonea Tropical/subtropical

Monocotiledonea Tropical/subtropical

Monocotiledonea

Monocotiledonea

Monocotiledonea

Paleomicroplancton

Paleomicroplancton

Paleomicroplancton

Paleomicroplancton

Paleomicroplancton indet

indet

Tipo biológico

indet

indet

indet

indet

herbáceo

indet

indet

indet

arbóreo

arbóreo

arbóreo

arbóreo

arbóreo

herbáceo

herbáceo

herbáceo

Paleomicroplancton

Paleomicroplancton

Paleomicroplancton

Paleomicroplancton

Paleomicroplancton 
Tabla 5

$\begin{array}{cccc}\text { Muestra } & \text { S (raref. 100) } & \text { S (raref. 115) } & \text { S (raref. 150) } \\ 1 & 27,41 & 28,77 & 31,27 \\ 3 & 24,8 & 26,16 & 28,81 \\ 14 & 23,67 & 24,87 & 27,2 \\ 15 & 28,64 & 30,49 & 34,2 \\ 16 & 21,9 & 22,66 & 24,08 \\ 19 & 27,68 & 29,56 & 33,18 \\ 21 & 29,24 & 31,18 & 34,97 \\ 23 & 22,91 & 24,1 & 26,35 \\ 33 & 26,7 & 28,52 & 32,11 \\ 37 & 31,09 & 33,05 & 36,82 \\ 39 & 23,34 & 23,94 & 27,23 \\ 40 & 27,54 & 28,95 & 31,61 \\ 47 & 20,16 & 21,39 & 23,82 \\ 49 & 21,68 & 23,38 & 26,15 \\ 53 & 23,41 & 24,87 & 27,73 \\ \text { S promedio } & 25,34 & 26,79 & 29,702\end{array}$


萄

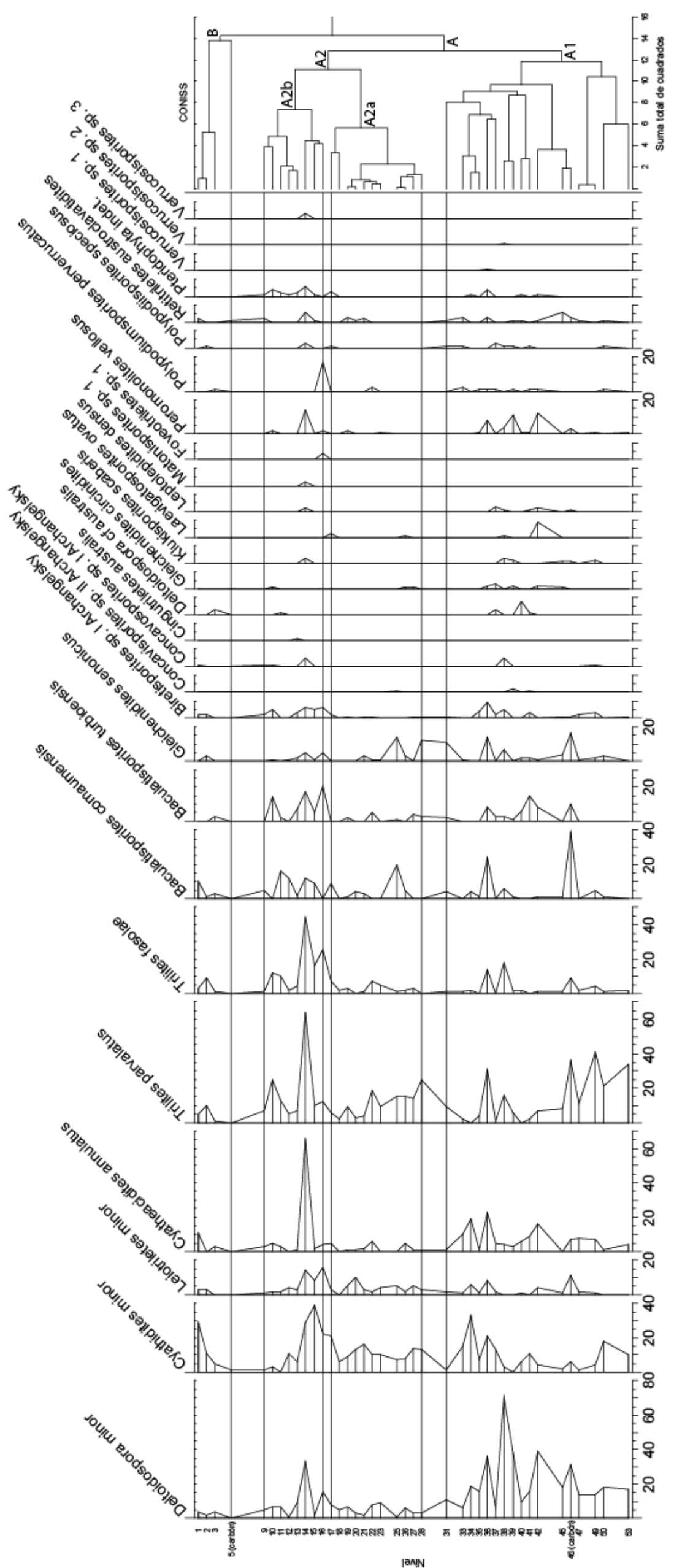


Figura 2

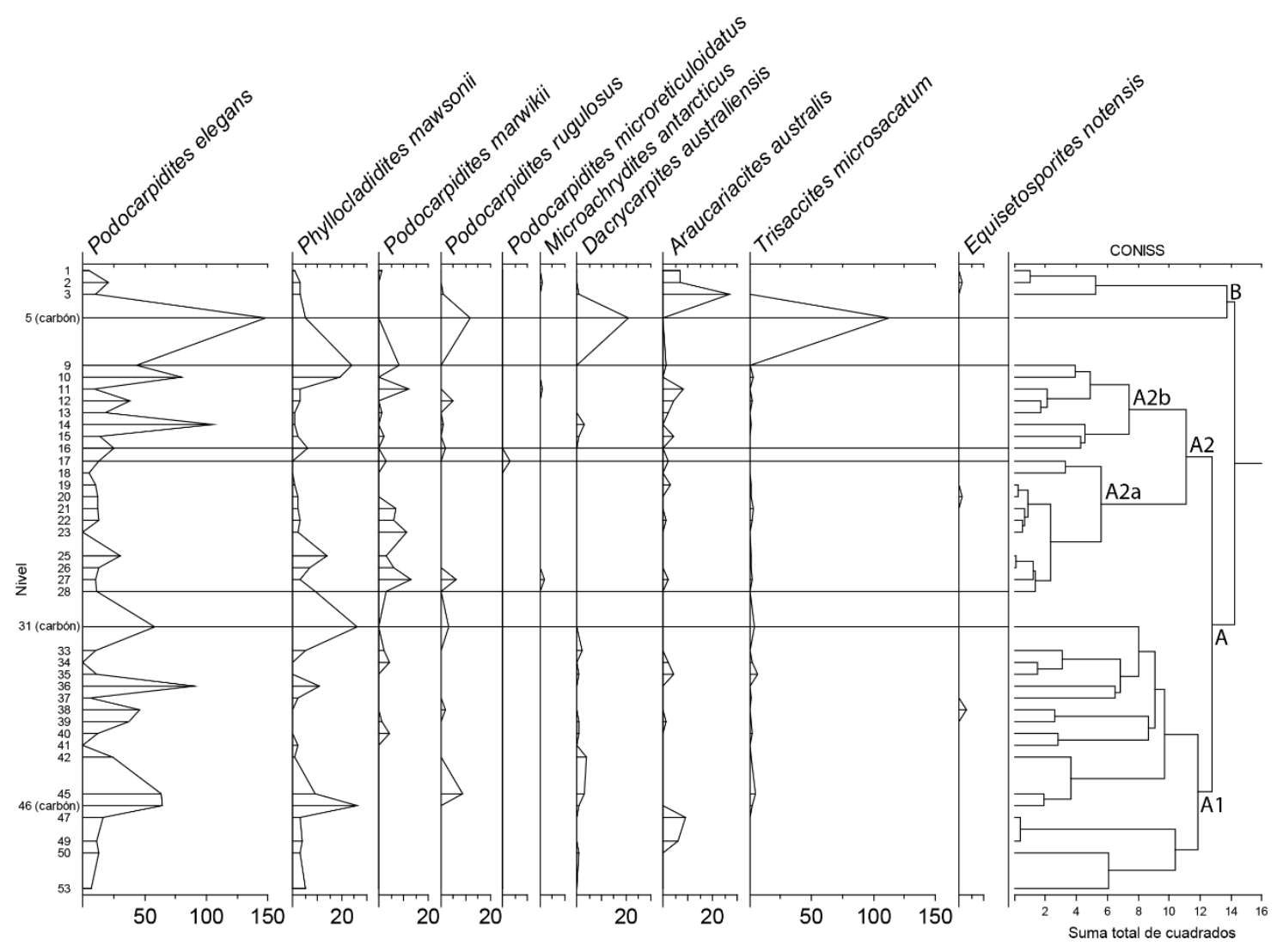


APÉNDICE 2 - Láminas 


\section{LÁMINA 1}
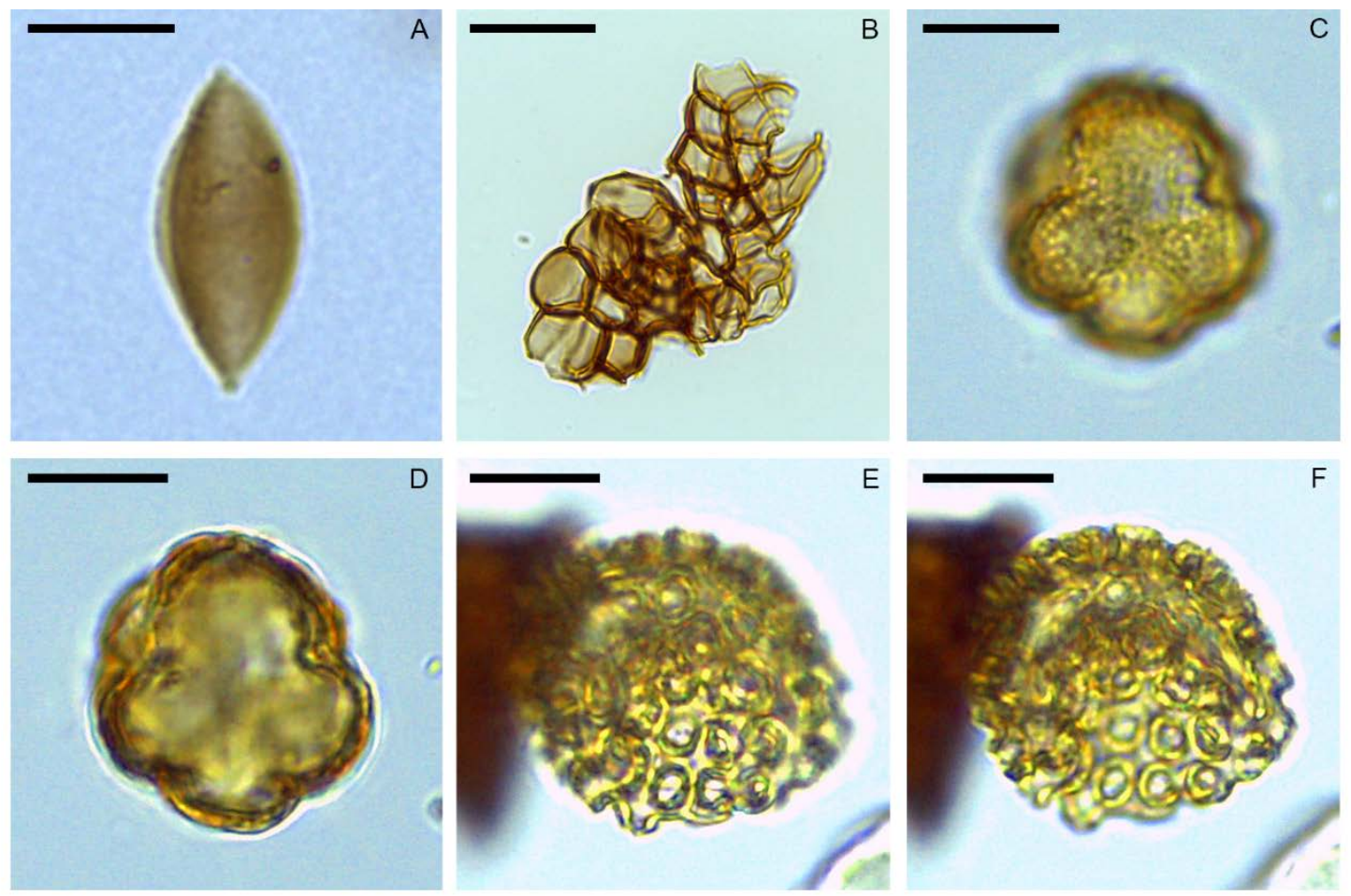

A. Closterium sp., muestra18 +10, 142/22.1, esc10. B. Botryococcus sp., muestra $5+10$, 156.3/10.4, esc20. C-D. Scenedesmaceae indet., muestra $28+10,143 / 22.9$. E-F. Catinipollis geiseltalensis, muestra $46+10,135.7 / 9.6$. A: escala $=10 \mu \mathrm{m}$. B-F: escala $=$ $20 \mu \mathrm{m}$. 


\section{LÁMINA 2}
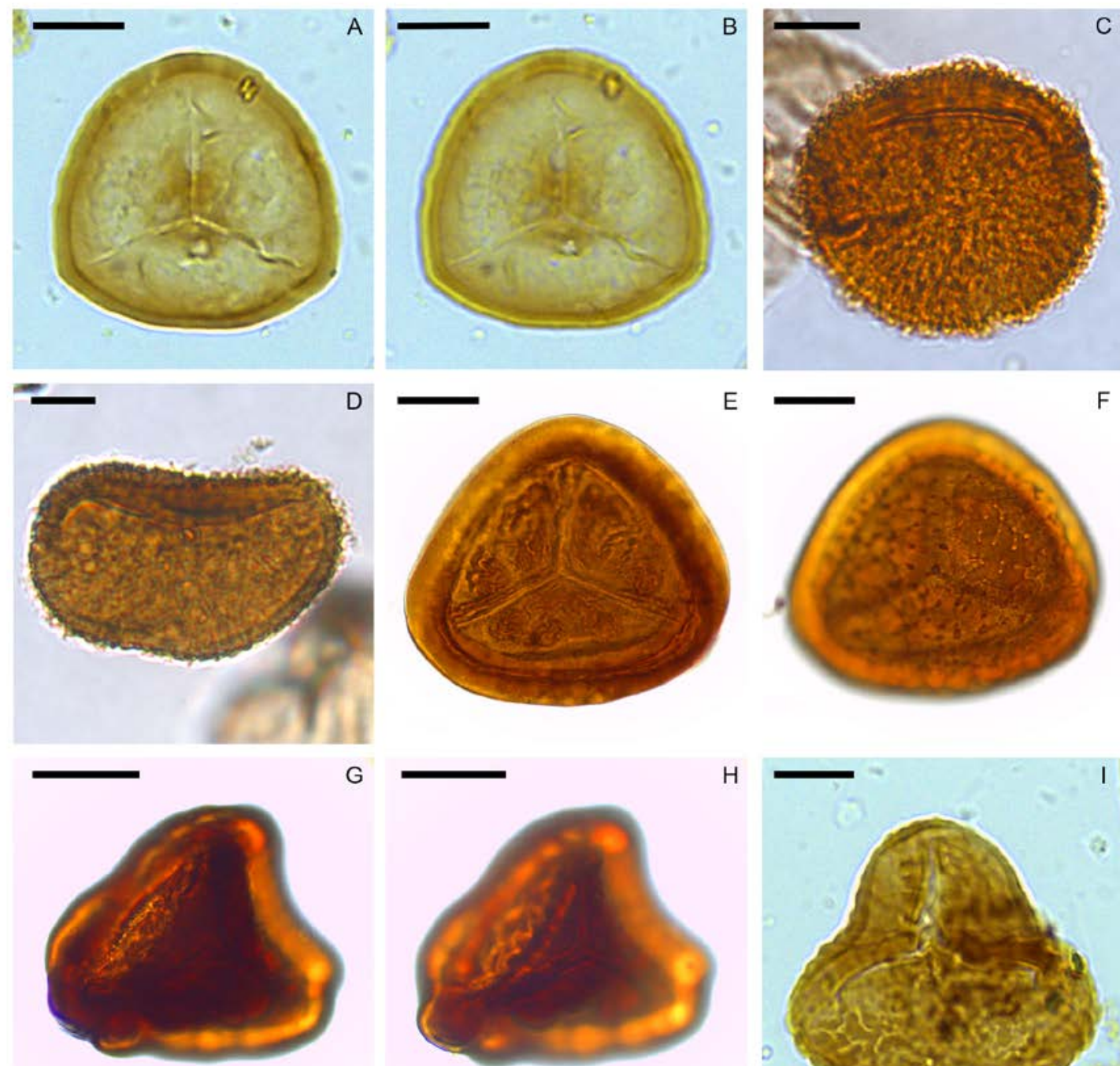

G
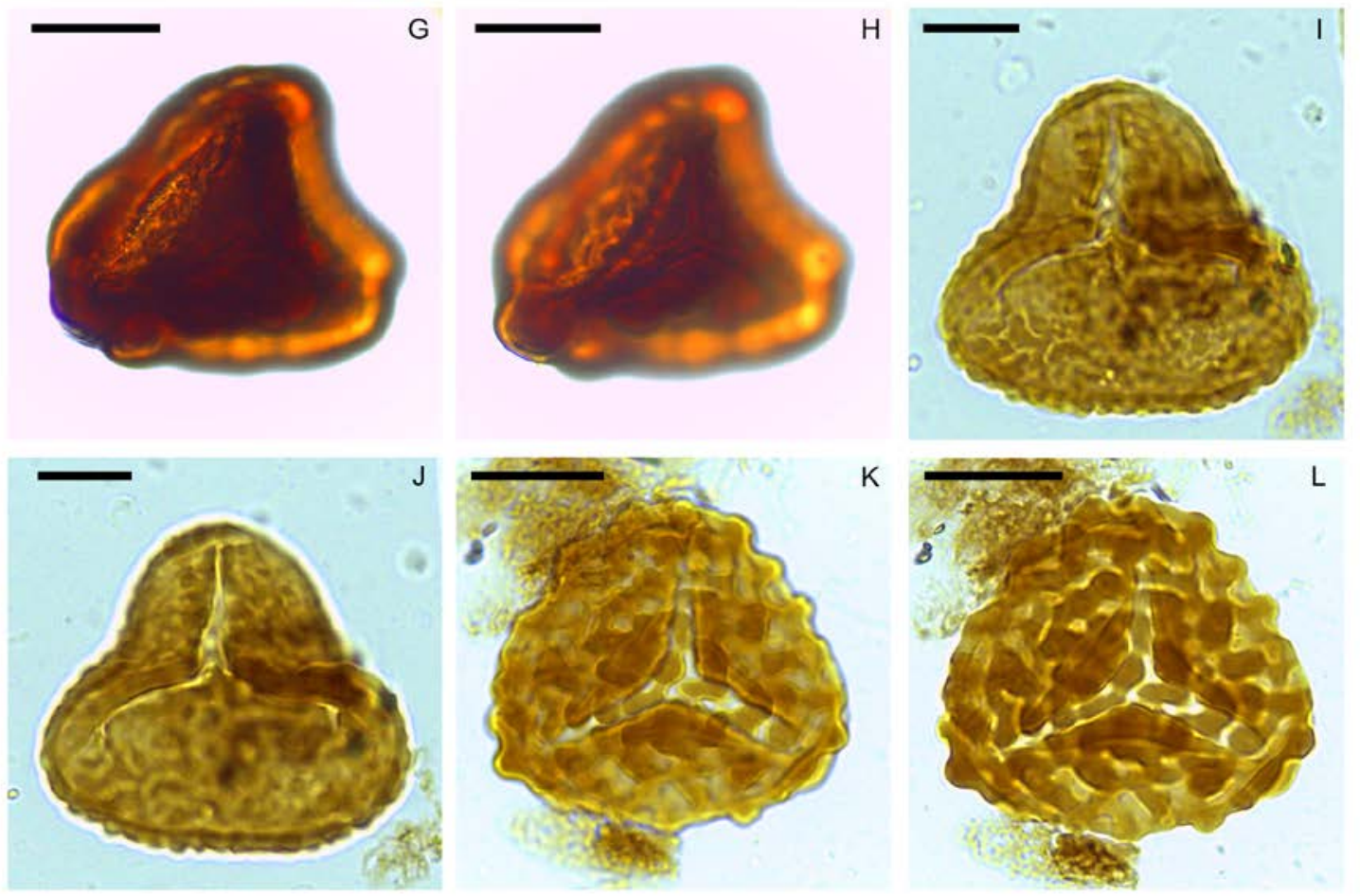

A-B. Cingutriletes australis, muestra $13+10,143.2 / 17.7$. C-D. Peromonolites vellosus, muestra $38+10,137 / 19.2$; muestra $46+10,149.8 / 13.2$. E-F. Cyatheacidites annulatus, muestra $1+25,125.9 / 11.6$. G-H. Matonisporites sp.1, muestra $14+10$, 147.3-8. I-J. Trilites fasolae, muestra 49, 145.7-3.8. K-L. Trilites parvallatus, muestra $49+10$, 140.4/3.8. A-B, D-E: escala $=10 \mu \mathrm{m}$. C-D, F-L: escala $=20 \mu \mathrm{m}$. 


\section{LÁMINA 3}
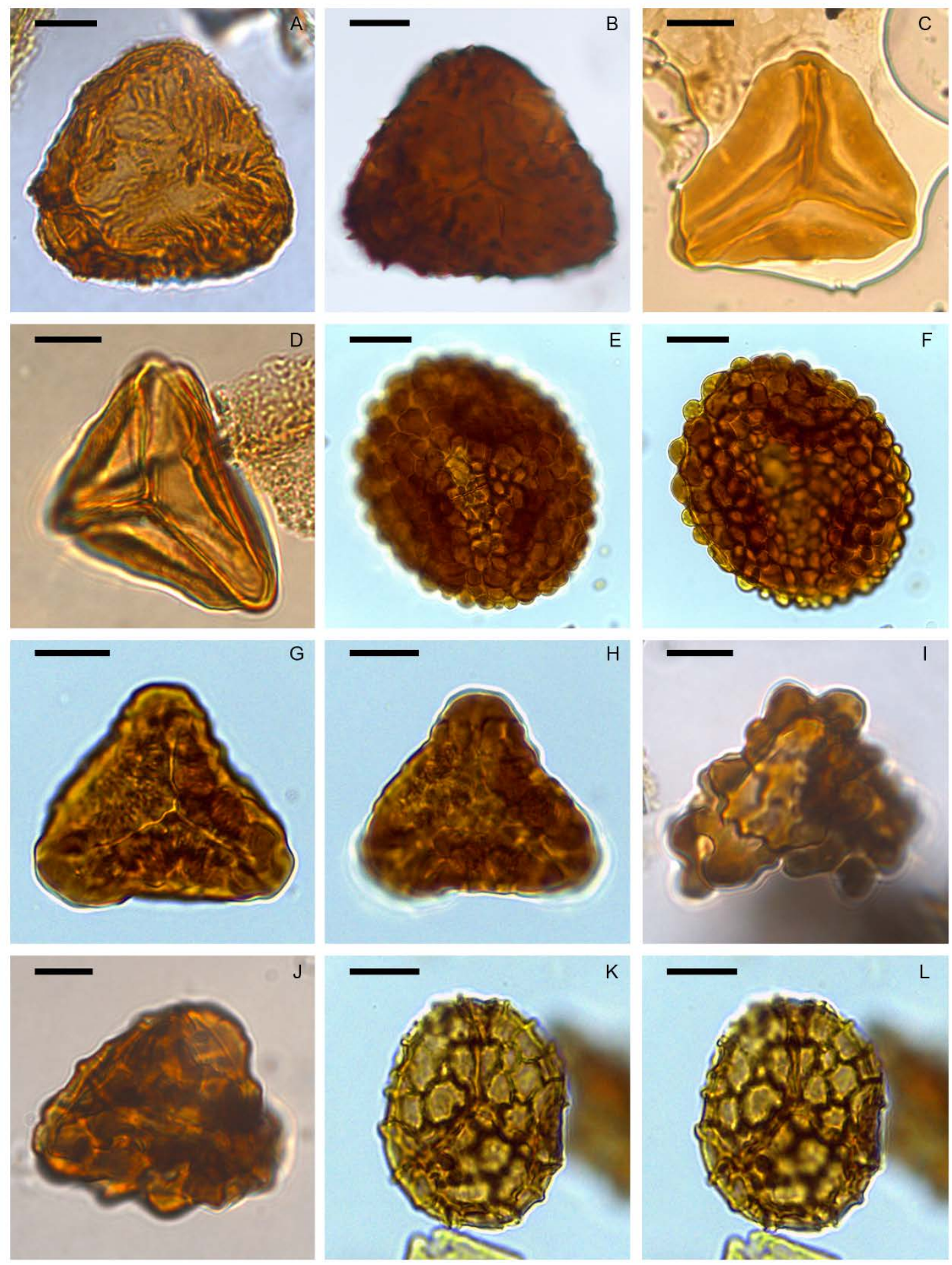

A-B. Gleicheniidites circinidites, muestra $38+10,143 / 22.4$; muestra $45+10$, 144.7/22.8. C-D. Gleicheniidites senonicus, muestra 46, 137.1/102; muestra $31+10$, 146/4.1. E-F. Leptolepidites densus, muestra $9+25$, 155.8-14.1. G-H. Concavosporites sp. I, muestra $14+10,155 / 10$. I-J. Concavosporites sp. II, muestra $9+10,125.2 / 14.2$; 139.2/21.7. K-L. Retitriletes austroclavatidites, muestra $46+10,133.2 / 11$. Escala $=10$ $\mu \mathrm{m}$. 


\section{LÁMINA 4}

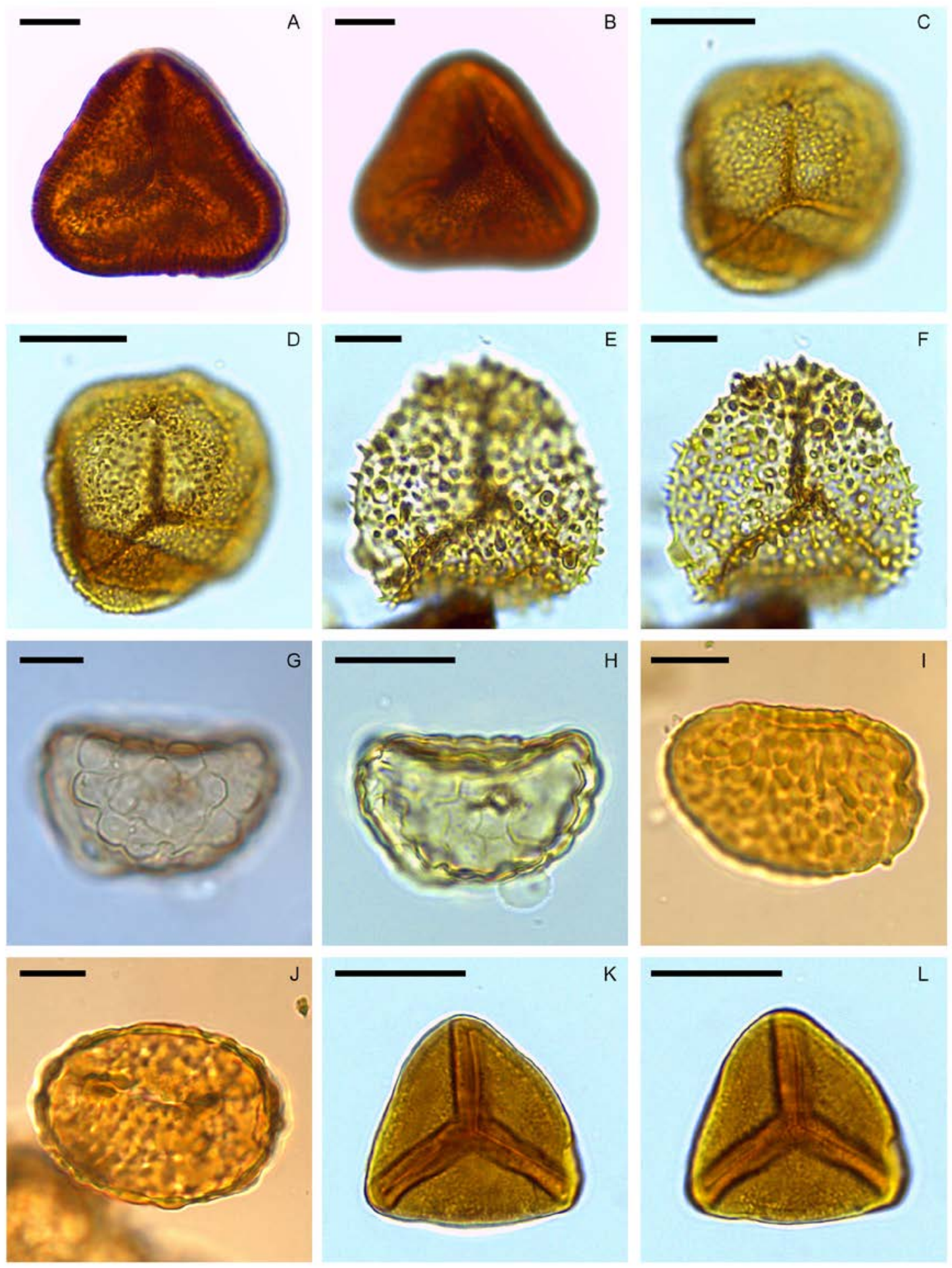

A-B. Foveotriletes sp. 1, muestra $26+10$, 139/10.8. C-D. Baculatisporites comaumensis, muestra $46+25,53.5 / 106.6$. E-F. Baculatisporites turbioensis, muestra $26+10,141.65 / 18.9$. G-H Polypodiisporites perverrucatus, muestra $9+10,154.1 / 24.2$. I-J. Polypodiisporites speciosus, muestra $9+10$, 135/9.9; muestra $14+10,36.7 / 110.4$. K-L. Biretisporites sp. I, muestra $36+10,131.6 / 9.4$. Escala $=10 \mu \mathrm{m}$. 


\section{LÁMINA 5}
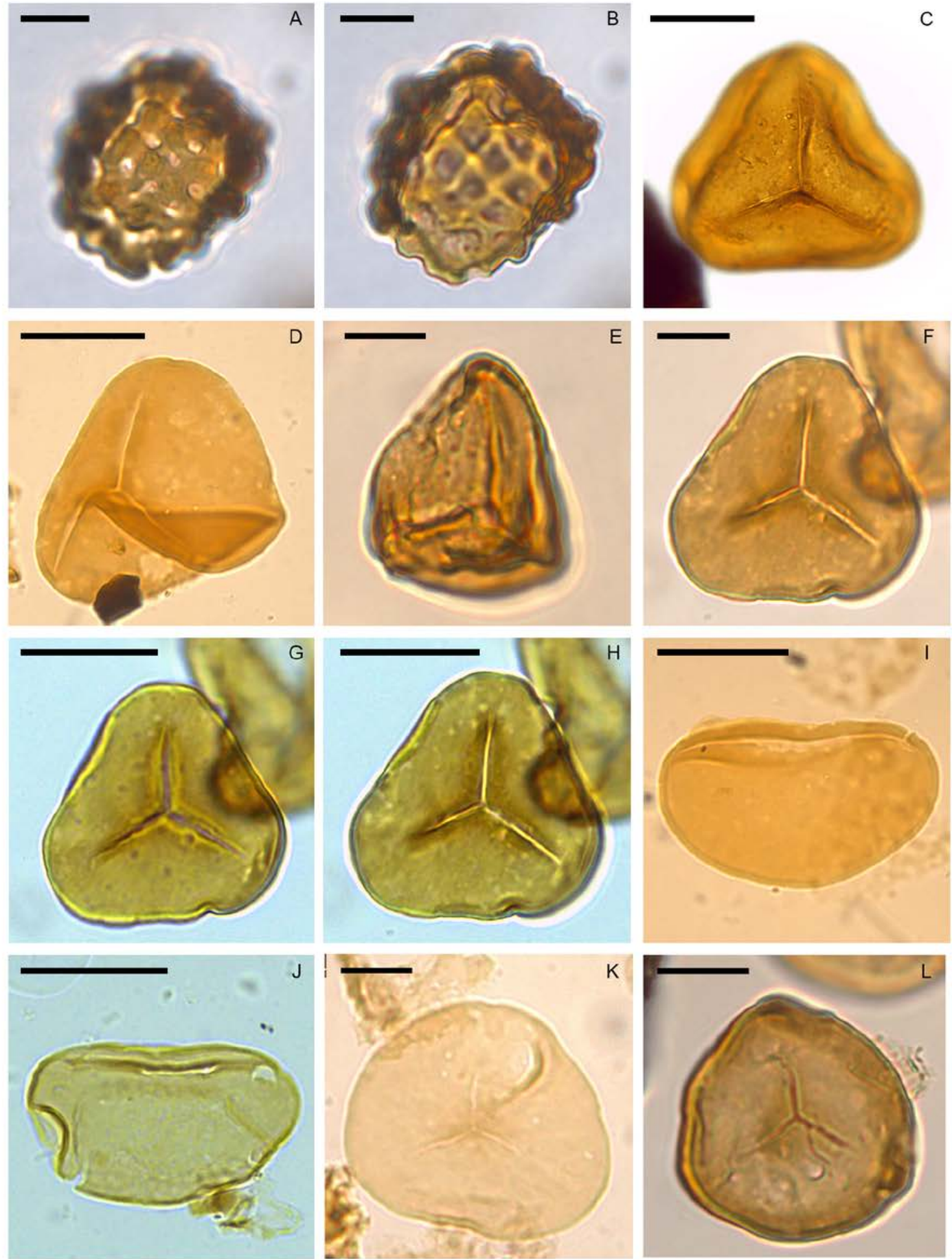

A-B. Klukisporites scaberis, muestra $46+10,146 / 14.2$. C-D. Cyathidites minor, muestra 1, +25, 153.5/17.6; muestra 50, 149.3/15.8. E-F. Deltoidospora cf australis, muestra $46+10,+10,109.4 / 20.3 ; 130.5 / 20.3$. G-H Deltoidospora minor, muestra $9+10$, 129.8/19.9. I-J. Laevigatosporites ovatus, muestra $46+10$, 148.5/17; muestra $42+10$, 152.3/15.6. K-L. Leiotriletes minor I, muestra $46+10$, 144/6.3; 140.4/19. A-B, K-L: escala $=10 \mu \mathrm{m} . \mathrm{C}-\mathrm{J}$ : escala $=20 \mu \mathrm{m}$. 


\section{LÁMINA 6}
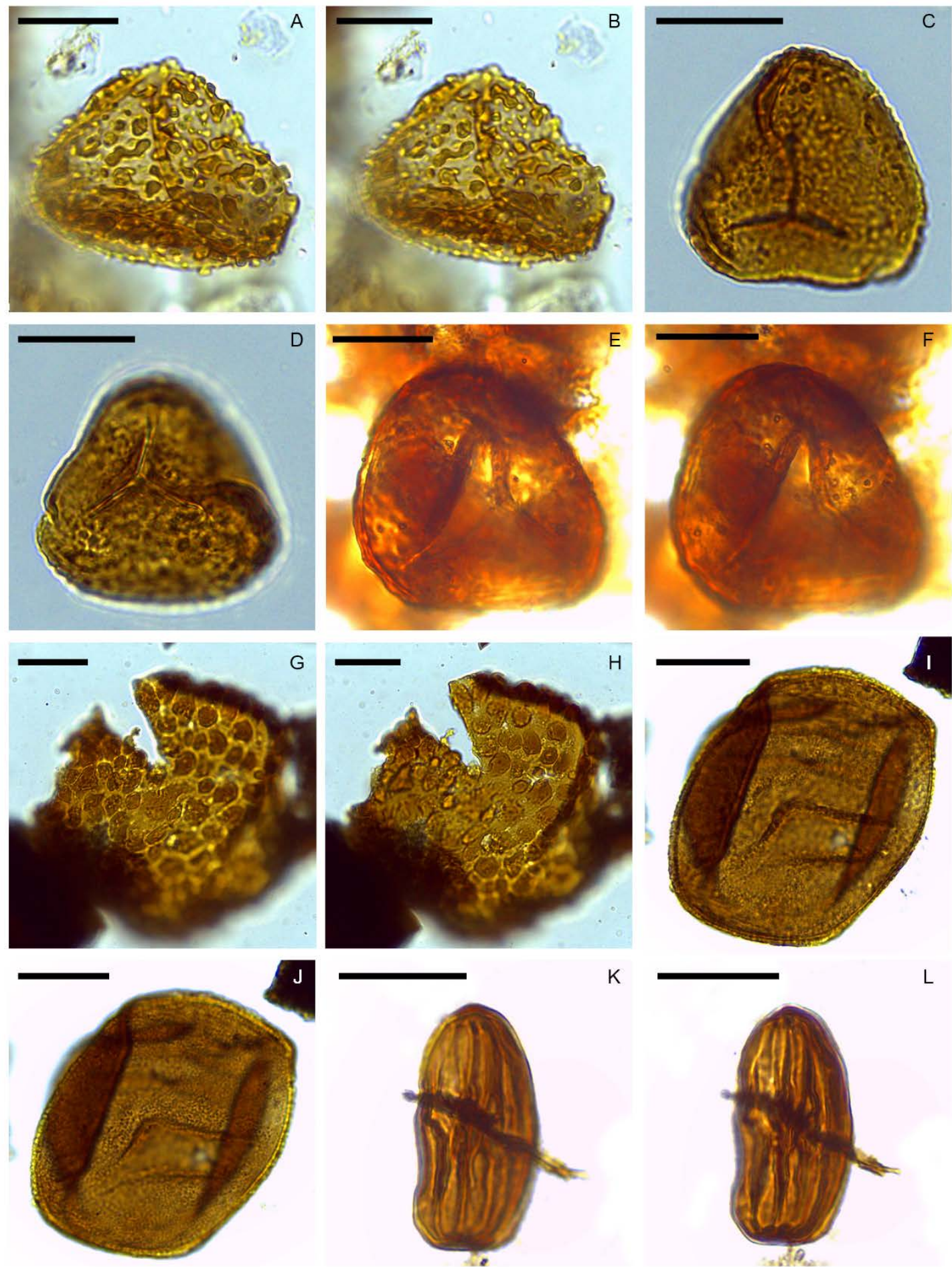

A-B. Verrucosisporites sp. 1, muestra $36+25,153.5 / 12$. C-D. Verrucosisporites sp. 2, muestra $38+10,139 / 15.2$. E-F. Verrucosisporites sp. 3, muestra $14+25,142.5 / 5.6$. GH. Pteridophyta indet. 1, muestra $36+25,139.8 / 9.3$. I-J. Araucariacites australis, muestra $3+25,123 / 12.1$. K-L. Equisetosporites notensis, muestra $2+10$, 139-13.8. Escala $=10 \mu \mathrm{m}$. 


\section{LÁMINA 7}
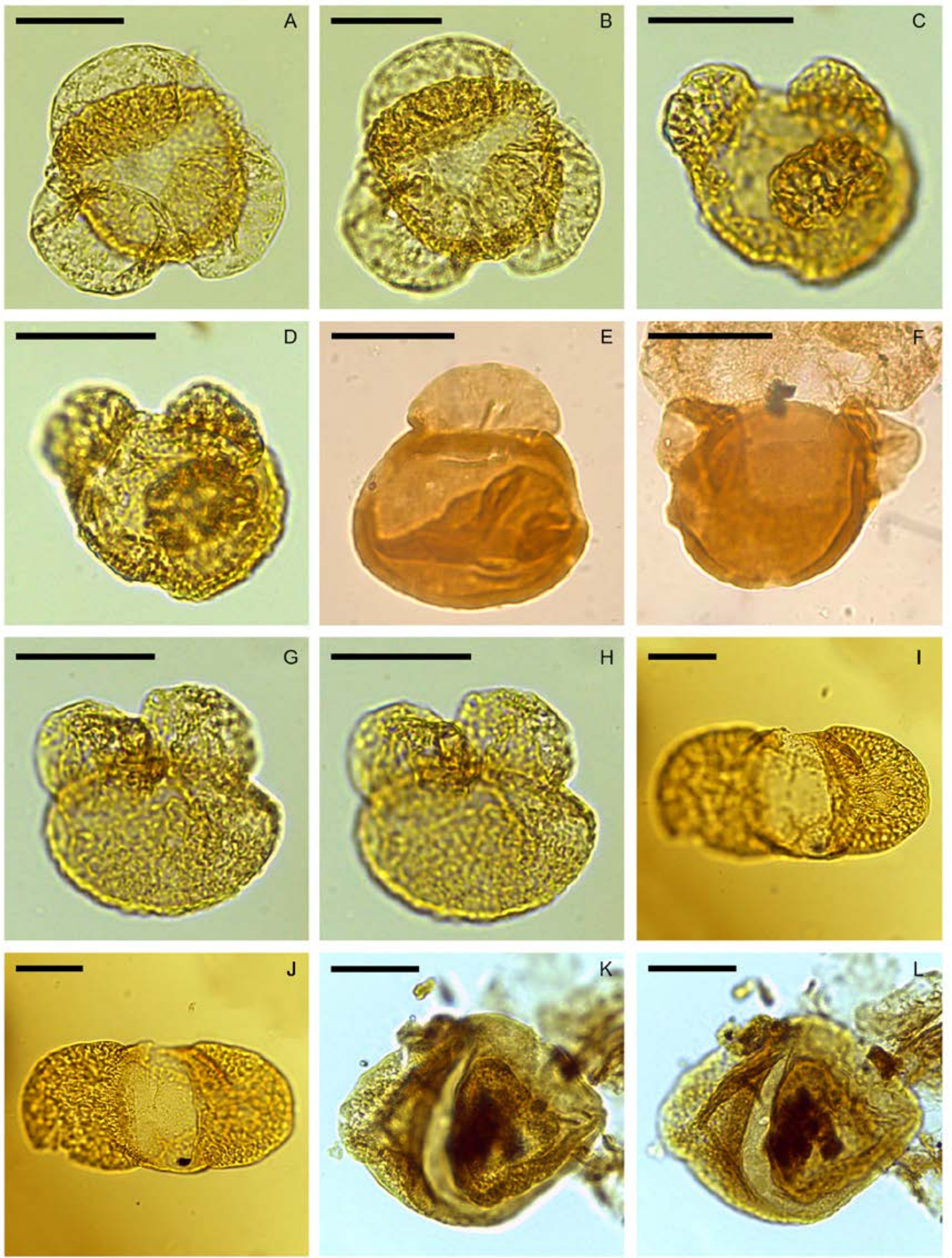

A-B. Dacrycarpites australiensis, muestra $5+10$, 132.7/14.4. C-D. Microcachrydites antarcticus, muestra $5+10,138.2-5.1$. E-F. Phyllocladidites mawsonii, muestra $9+10$ 133.3/12.5; 135.4/8.9. G-H. Podocarpidtes elegans, muestra $5+10,142.8 / 11.5$. I-J. Podocarpidites marwikii, muestra $5+10,138.8 / 14.8$. K-L. Podocarpidites microreticuloidatus, muestra $17+10,133.9 / 2.6$. Escala $=20 \mu \mathrm{m}$. 


\section{LÁMINA 8}
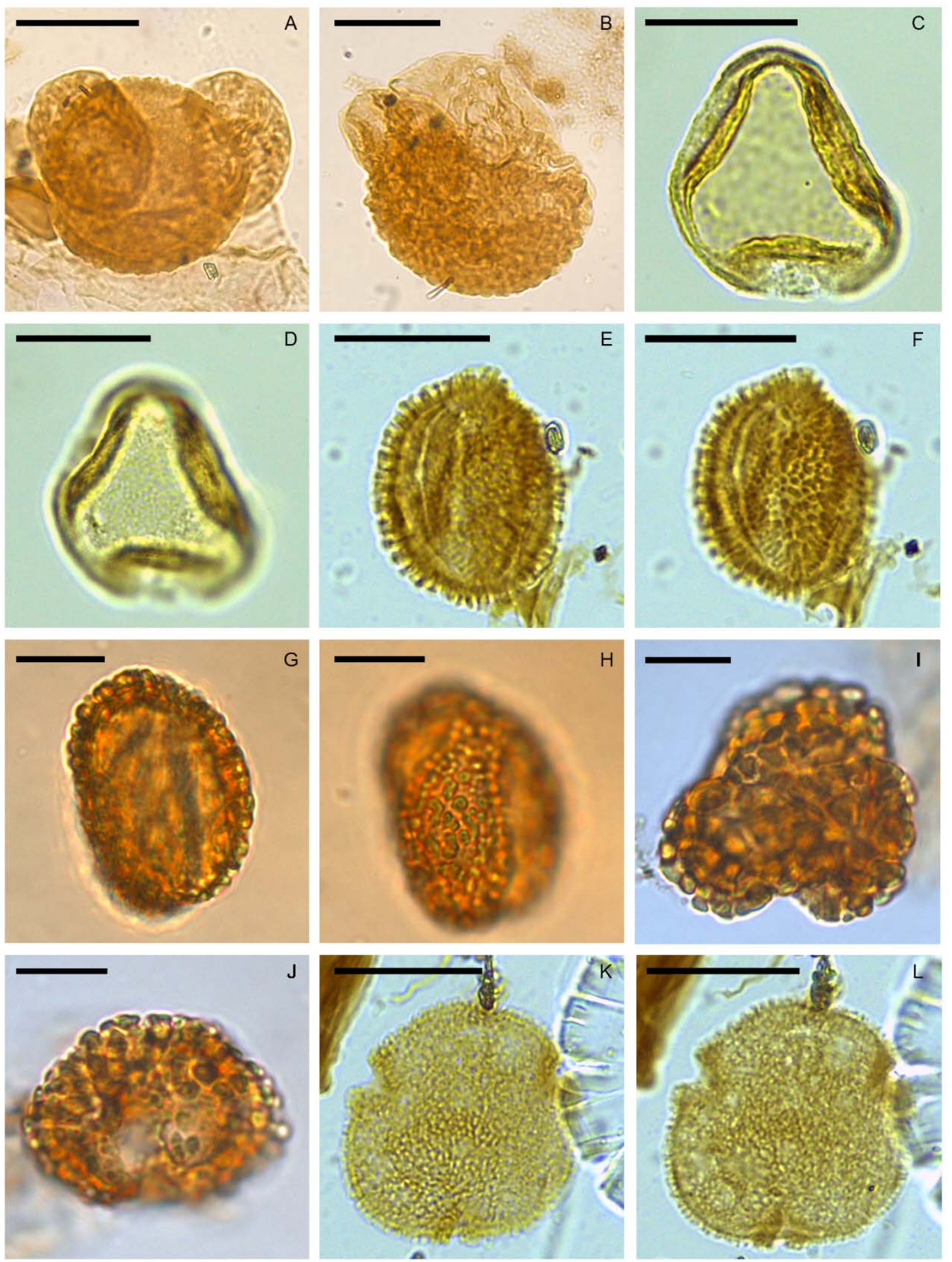

A-B. Podocarpidites rugulosus, muestra 45, 125.2/8.5; 131.2/12.1. C-D. Trisaccites microsaccatum, muestra $5+10,149.7-4.7$. E-F Ilexpollenites anguloclavatus, muestra $45+10$, 123.6-2. G-H. Ilexpollenites clifdenensis, muestra $25+10$, 144.3/5.5. I-J. Ilexpollenites megagemmatus, muestra $9+10,159.4 / 12 ; 136.7 / 23$. K-L. Bombacacidites isoreticulatus, muestra $42+10,136.7 / 3.4$. A-F, K-L: escala $=20 \mu \mathrm{m}$. G-J: escala $=10$ $\mu \mathrm{m}$. 


\section{LÁMINA 9}
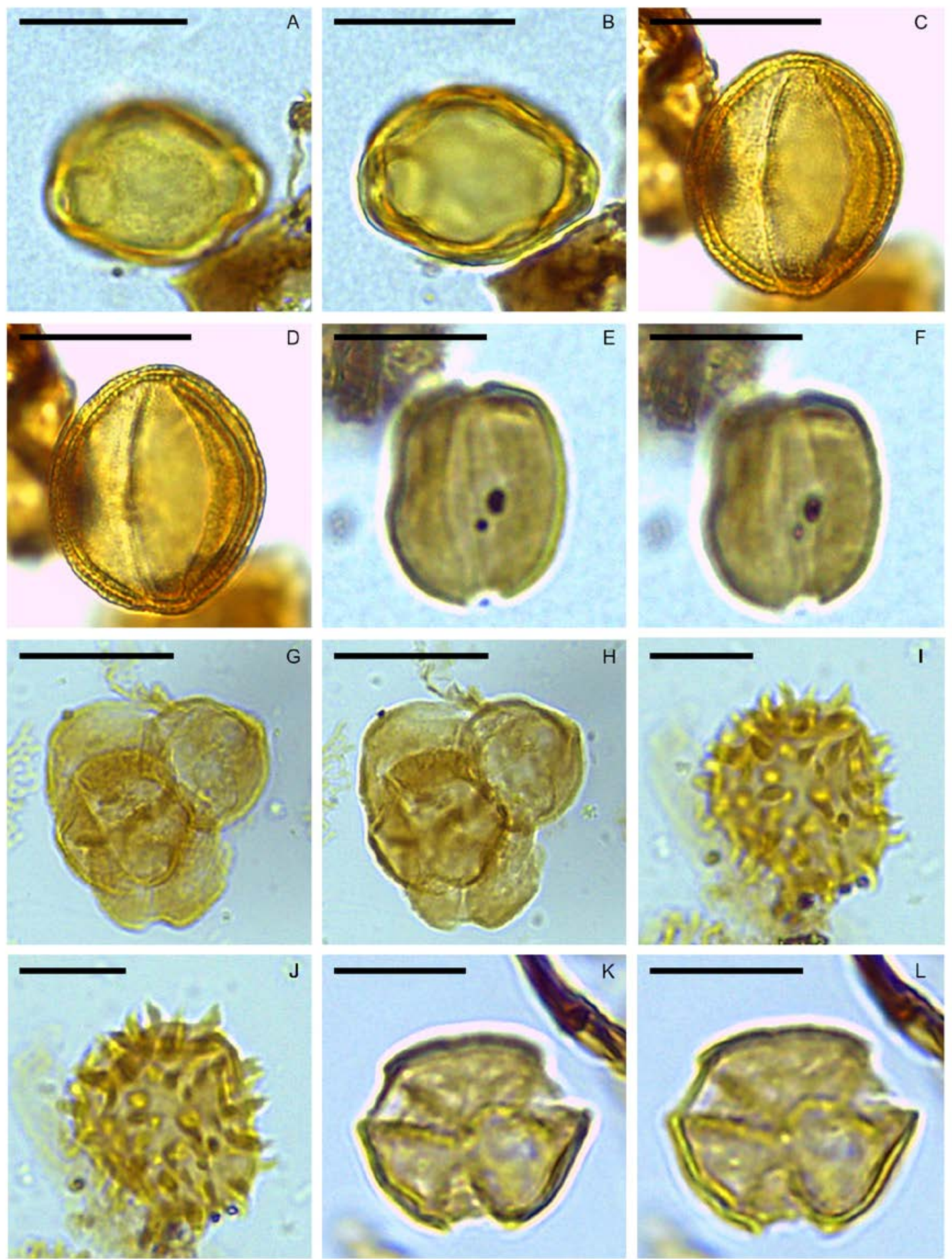

A-B. Haloragacidites trioratus, muestra $5+10$, 135/11.7. C-D. cf. Perfotricolpites sp., muestra $5+10,144.2 / 9.8$. E-F Dicolpopollis sp. 1, muestra $18+10,132 / 16.4$. G-H. Ericipites sp.1, muestra $9+10,130.6 / 10.6$. I-J. Malvacipollis sp.1, muestra $46+10$, 124.9/10.6. K-L. Margocolporites sp. 1, muestra $33+10$, 138.1/9.9. A-H, K-L: escala = $20 \mu \mathrm{m}$. I-J: escala $=10 \mu \mathrm{m}$ 


\section{LÁMINA 10}
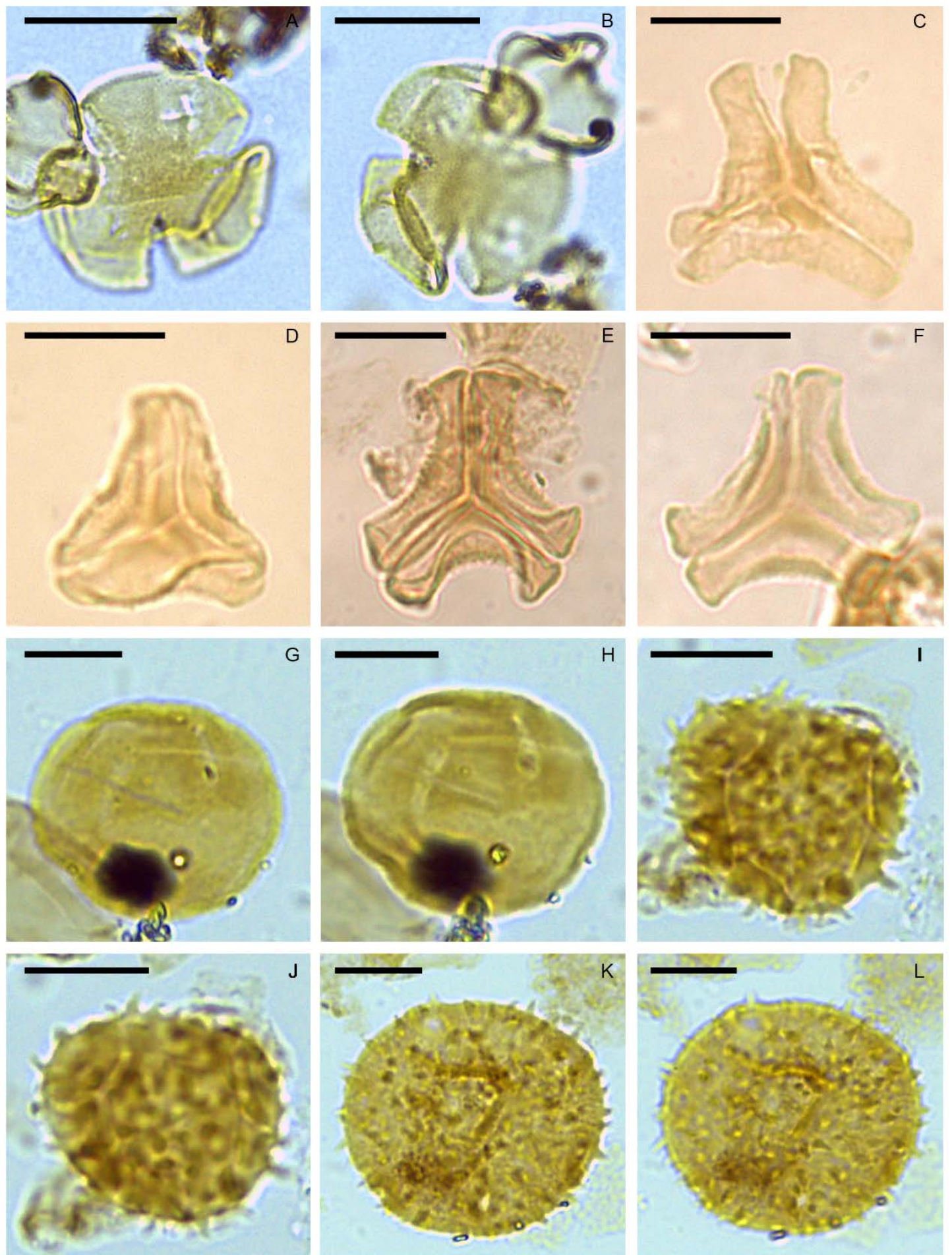

A-B. Tricolpites reticulatus, muestra $17+10,127 / 3.9$. C-D. Gothanipollis bassensis, muestra $53+10$, 132.9-17.1; muestra $50+10,151.8 / 12.9$. E-F Gothanipollis sp. 1, muestra $35+10,134 / 17.6$; muestra $3+10,144.3 / 20.2$. G-H. Perisyncolporites pokornyi, muestra $45+10$, 141-24.4. I-J. Malvacearumpollis sp. 1, muestra $47+10$, 150-8.5. K-L. Compositoipollenites sp. 1, muestra $53+10,122.7-10.95$. A-F, I-J: escala $=20 \mu \mathrm{m}$. G$\mathrm{H}, \mathrm{K}-\mathrm{L}$ : escala $=10 \mu \mathrm{m}$. 


\section{LÁMINA 11}


A-B. Myrtaceidites mesonesus, muestra $18+10,152.7 / 24.1$. C-D. Myrtaceidites parvus, muestra $18+10,154.3 / 6.3 ; 133.4 / 15.8$. E. Myrtaceidites verrucosus forma verrucosus, muestra $35+10$, 151.6/11.7. F. M. verrucosus forma rhodamnoides muestra $35+10$, 125.3/10.2. G-H. Myrtaceidites eucaliptoides, muestra $1+10,152.8-14.8$. I-J. Nothofagidites acromegacanthus, muestra $47+10$, 132.8/8.6. K-L. Nothofagidites americanus, muestra $10+10,135.7 / 17.9$. A-H, K-L: escala $=20 \mu \mathrm{m}$. I-J: escala $=10$ $\mu \mathrm{m}$. 


\section{LÁMINA 12}


A-B. Nothofagidites dorotensis, muestra $46+10$, 125.7/10.6. C-D. Nothofagidites flemingii, muestra $98+10,152.6 / 22.8$. E-F. Nothofagidites fortispinulosus, muestra 53 +10 , 149-20.1. G-H. Nothofagidites nanus, muestra $46+10,150.9-20.8$. I-J. Nothofagidites rocaensis, muestra $46+10,140.7 / 22.4 ; 145.7 / 24.3$. K-L. Nothofagidites saraensis, muestra $50+10,147.7-3.7$. A-H, K-L: escala $=20 \mu \mathrm{m}$. I-J: escala $=10 \mu \mathrm{m}$. 


\section{LÁMINA 13}
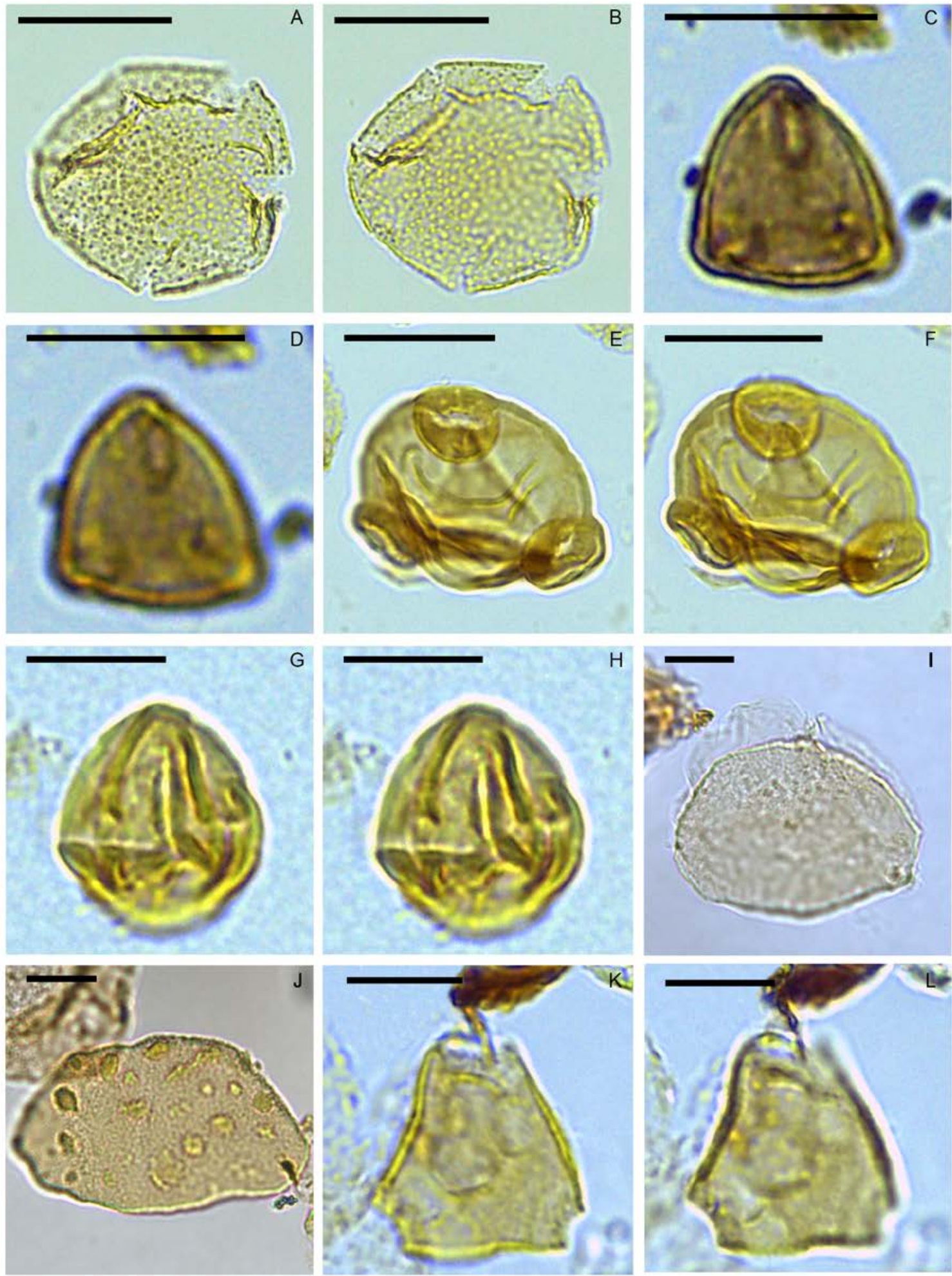

A-B. Nothofagidites tehuelchesii, muestra $5+10,154.8 / 10$. C-D. Anacolosidites diffusa, muestra $3+10,124.2 / 18$. E-F. Corsinipollenites atlantica, muestra $53+10,143.9-18.3$. G-H. Polycolporopollenites esobalteus, muestra $21+10$, 153.7/12.5. I-J. Granodiporites nebulosus, muestra $6+10,157.9 / 19.2 ; 125.8 / 16.2$. K-L. Lewalanipollis senectus, muestra $15+10,119.8 / 18.5$. A-F, I-J: escala $=20 \mu \mathrm{m}$. G-H, K-L: escala $=10 \mu \mathrm{m}$. 


\section{LÁMINA 14}



A-B. Peninsulapollis gillii, muestra $16+10,151.3 / 11.7$. C-D. Propylipollis ambiguus, muestra $3+10,157.9 / 21.3$. E-F. Propylipollis annularis, muestra 50 +10, 146.2-15.8. GH. Propylipollis pseudomoides, muestra $35+10$, 144.2/17.3. I-J. Propylipollis reticuloscabratus, muestra $17+10,126.2 / 4.1$. K-L. Proteacidites obscurus, muestra 22 $+10,130.4 / 11.8$. A-B, E-J: escala $=10 \mu \mathrm{m}$. C-D, K-L: escala $=20 \mu \mathrm{m}$. 


\section{LÁMINA 15}
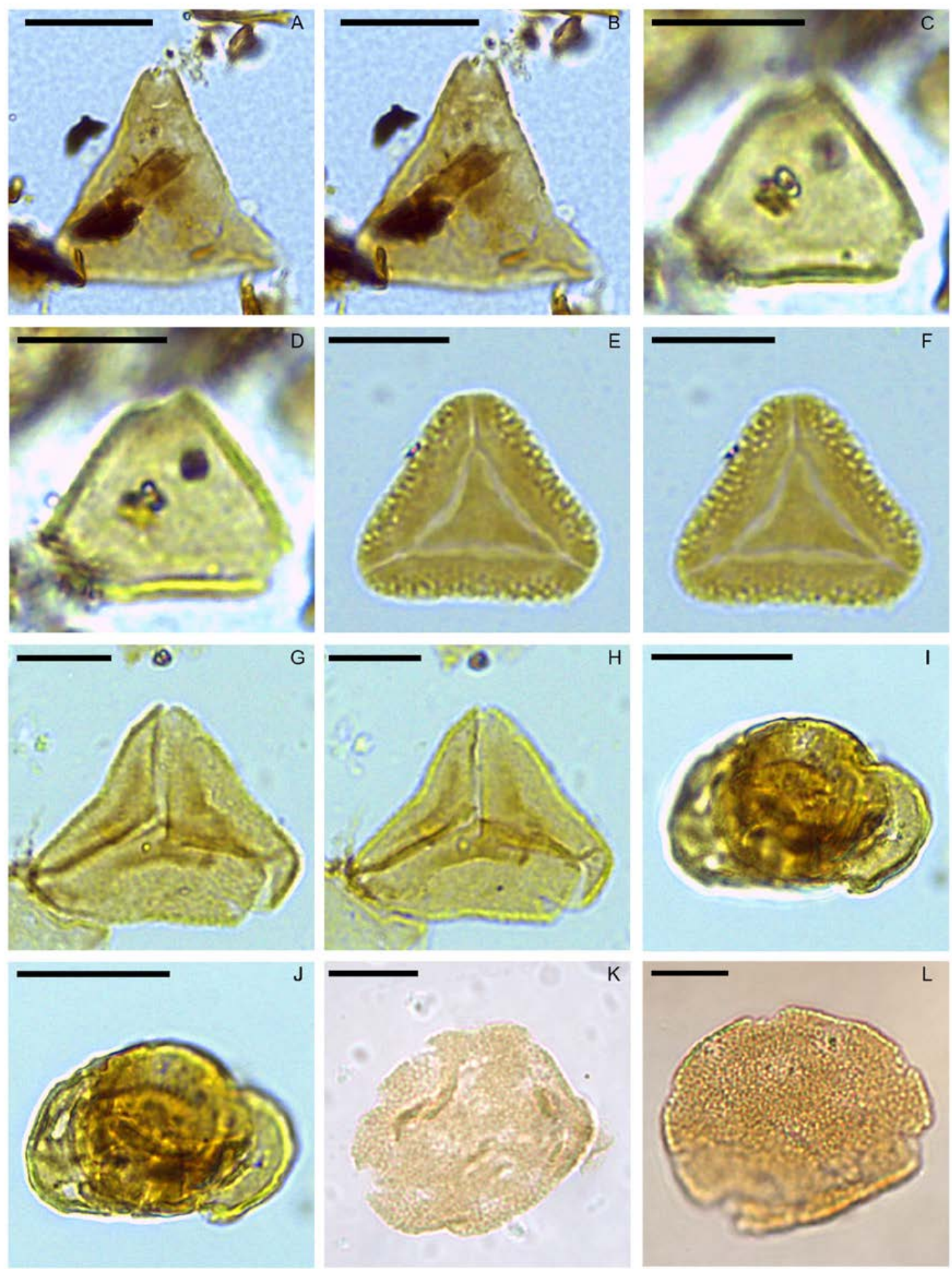

A-B. Proteacidites rectus, muestra $19+10$, 129.3/11.2. C-D. Proteacidites subscabratus, muestra $18+10,153.4-17.9$. E-F. Cupaneidites insulares, muestra 53 +10 , 147.7/13.7. G-H. Cupanieidites reticularis, muestra $41+10$, 148-18. I-J. Bysmapollis verrucatus, muestra $45+10$, 157.4-5.1. K-L. Periporopollenites demarcatus, muestra $26+10,117.5 / 22.5 ; 47+10,142 / 5$. A-D, G-H, K-L: escala $=20$ $\mu \mathrm{m}$. E-F, I-J: escala $=10 \mu \mathrm{m}$. 


\section{LÁMINA 16}

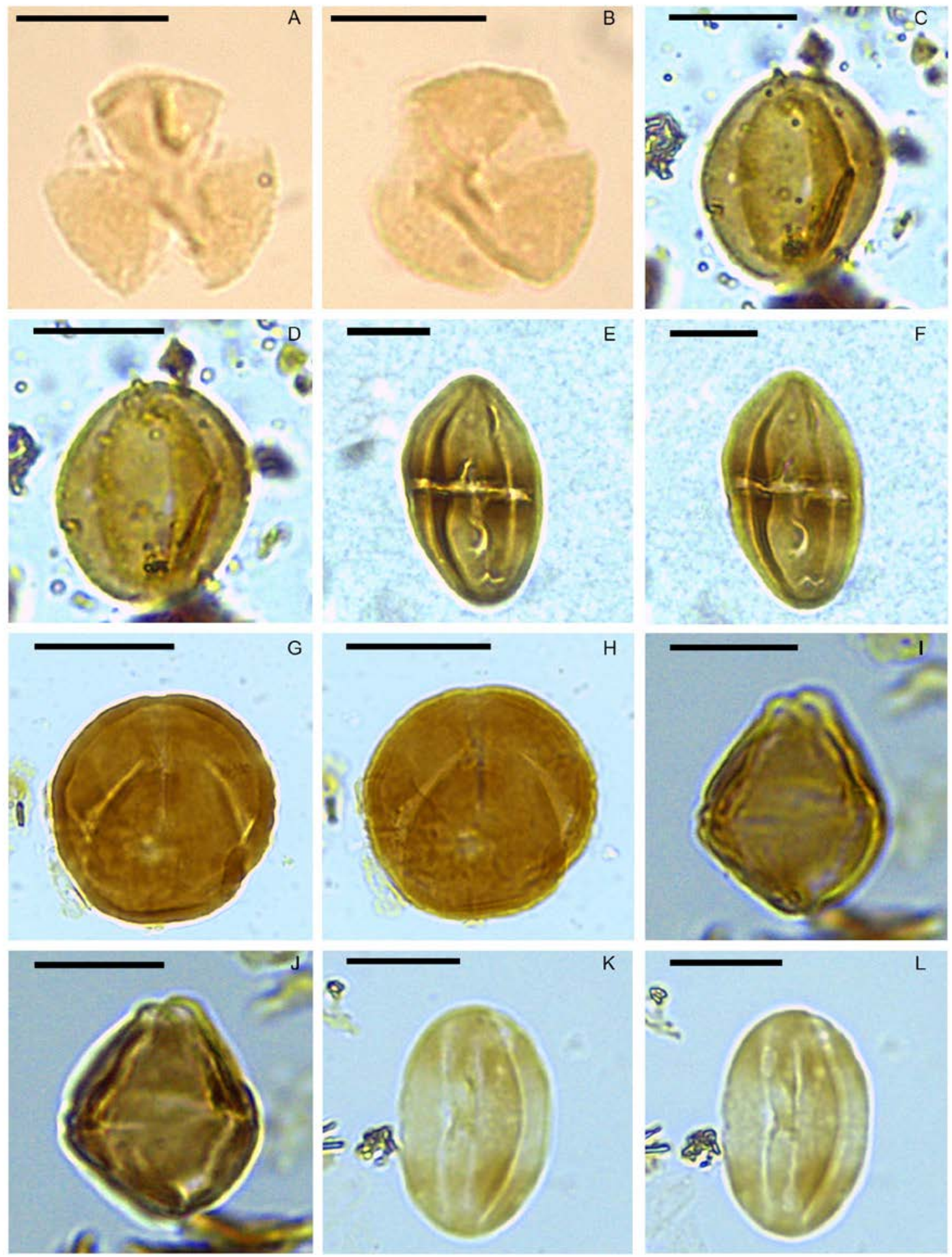

A-B. Psilatricolpites brevis, muestra $13+10,133.2 / 15.8 ; 134.7 / 14.6$. C-D. Psilatricolporites costatus, muestra $35+10,133 / 12$. E-F. Psilatricolporites divisus, muestra $17+10,152.3 / 0.9$. G-H. Psilatricolporites pachydermatus, muestra $41+10$, 128.4/10.2. I-J. Psilatricolporites aff. P. protrudens, muestra $33+10,127.1 / 10.1$. K-L. Psilatricolporites vanus, muestra $41+10,137.1 / 11.8$. A-B, E-L: escala $=20 \mu \mathrm{m}$. E-F, C-D: escala $=10 \mu \mathrm{m}$. 


\section{LÁMINA 17}
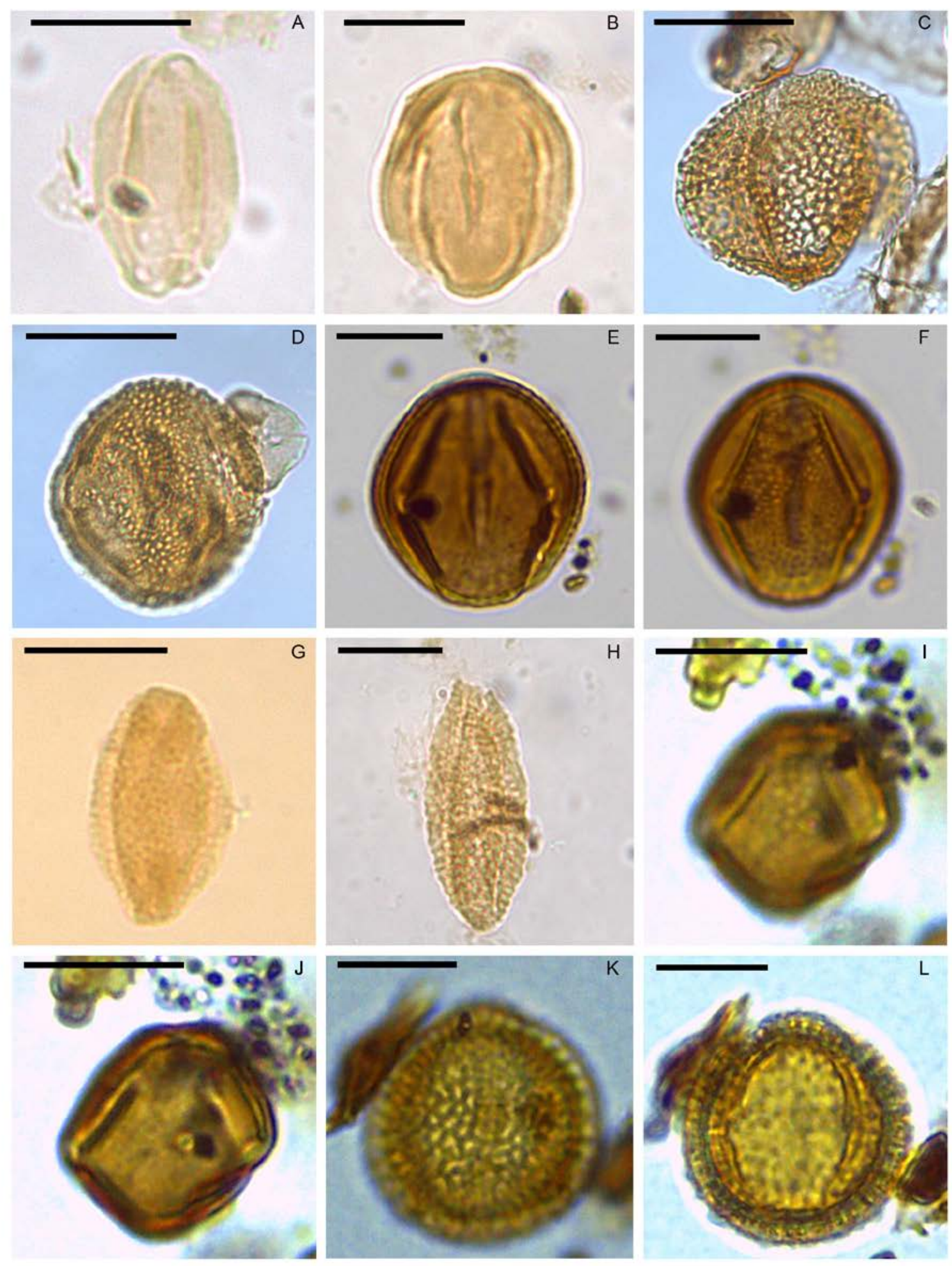

A-B. Psilatricolporites varius, muestra $3+10$, 132/4.6; 137.2/5. C-D. Rhoipites alveolatus, muestra 9, +10, 144.8/18.8; 147.5/19.8. E-F. Rhoipites baculatus, $3+10$, 152/14.4. G-H. Rhoipites cf. hawkdunensis, muestra $37+10,51.2 / 104.5$; muestra 37 +10, 49.9/114.2. I-J. Rhoipites rhomboidaliformis?, muestra $18+10,148.4 / 10.7$. K-L. Rhoipites sphaerica, muestra $19+10,137.3 / 11.9$. Escala $=20 \mu \mathrm{m}$. 


\section{LÁMINA 18}
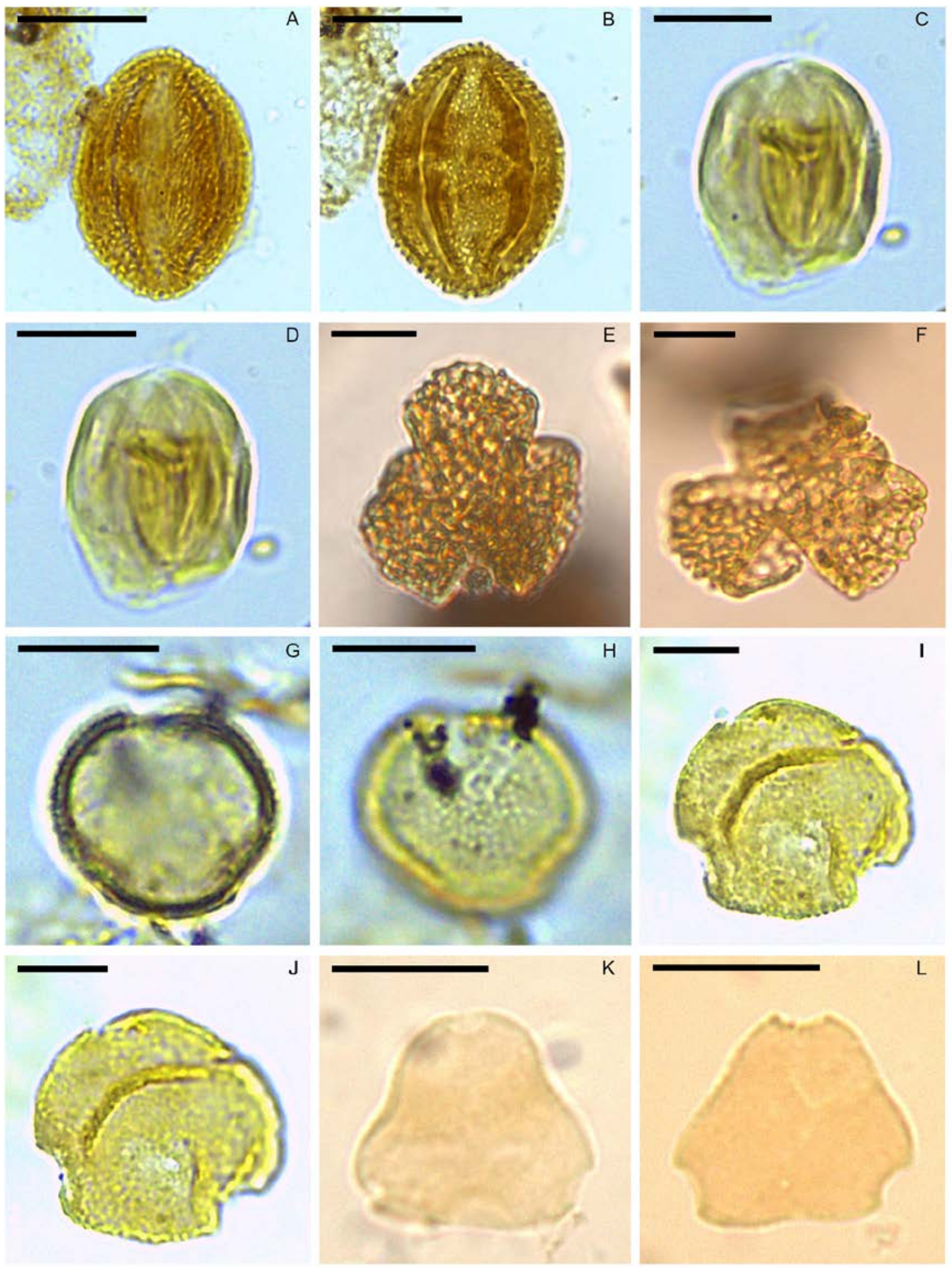

A-B. Striatricolporites pseudostriatus, muestra $28+10,127.3 / 11.7$. C-D. Tetracolporopollenites sp. 1, muestra $3+10$, 144.8/13.2. E-F. Tricolpites bathyreticulatus, muestra $46+10,137.5 / 4.7$; muestra $45+10,132.3 / 20.2$. G-H. Tricolpites brevicolpus, muestra $47+10,122 / 11.6$. I-J. Triorites fragilis, muestra 39 +10, 143.1-13.5. K-L. Triorites minor, muestra $41+10,153.5 / 10.2$; 135.9/14.6. A-B, EF, I-L: escala $=20 \mu \mathrm{m} . \mathrm{C}-\mathrm{D}, \mathrm{G}-\mathrm{H}$ : escala $=10 \mu \mathrm{m}$. 


\section{LÁMINA 19}
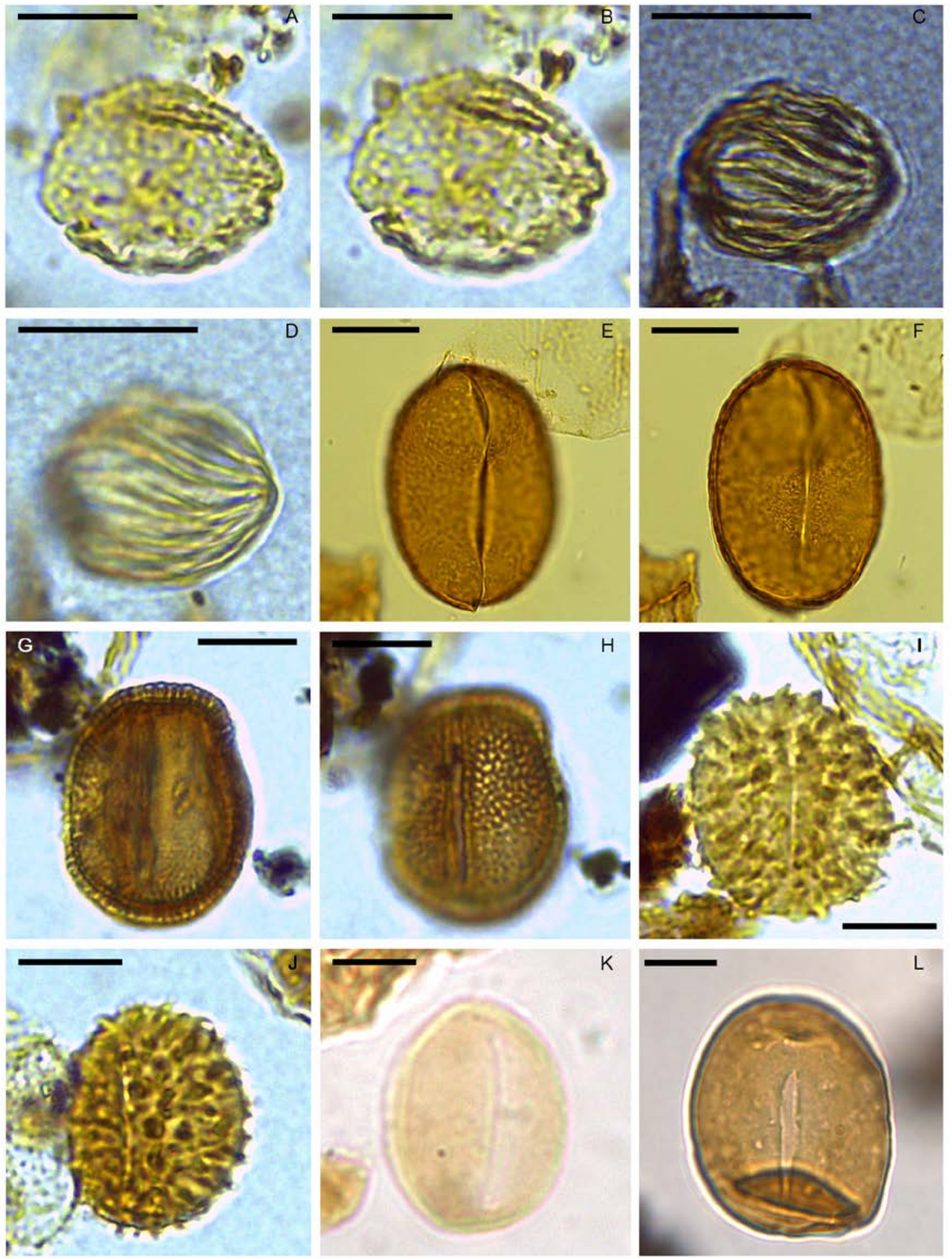

A-B. Triorites subspinosus, muestra $49+10,137.2 / 10$. C-D. Monocotiledónea sp. 1, muestra $18+10,146.9 / 24.1$. E-F. Arecipites minutiscabratus, muestra 5 +25, 149.1/10. G-H Arecipites sp. 1, muestra $18+10$, 149.6/17.6. I-J. Monosulsites perspinosus, muestra $17+10,139.2 / 2.1 ; 19+10,137.8 / 12$. K-L. Psilamonocolpites medius, muestra $46+10,135.6 / 16.9$; muestra $50+10,137.4 / 2.5$. A-B, E-L: escala $=10 \mu \mathrm{m}$. C-D: escala $=20 \mu \mathrm{m}$. 


\section{LÁMINA 20}
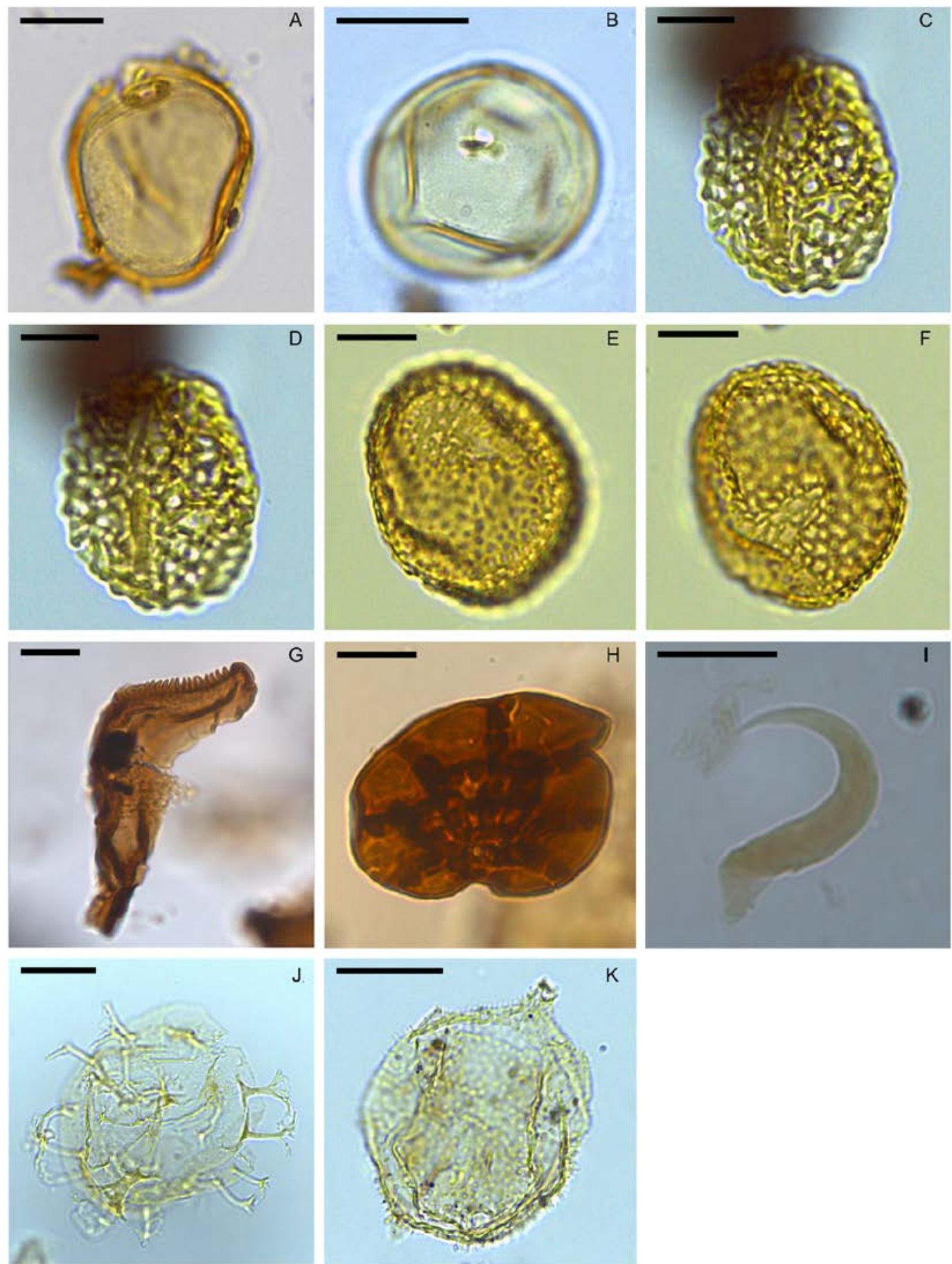

A-B. Graminidites media, muestra $13+10,40.4 / 19.5$; muestra $14+25,145.8 / 11.1$. C-B. Liliacidites regularis, muestra $39+10$, 151.5/21.6. E-F. Sparganiaceaepollenites barungensis, $42+10,142 / 10$. G. Escolecodonte indet., muestra $2+25,157.8 / 17.8$. H. Foraminífero indet., muestra $15+10,153.6 / 5.9$. I. Uña de ácaro, muestra $34+10$, 145.2/4.5. J. Ejemplo de Gonyaulacoideo frecuente en la FRT, Enneadocysta dictyostila, muestra $39+25,139 / 21.5$. K. Ejemplo de Peridinoideo frecuente en la FRT, Vozzhennikovia apertura, muestra $10+25,128.5 / 11.1$. A, C-D: escala $=10 \mu \mathrm{m}$. B, E-I: escala $=20 \mu \mathrm{m}$. 


\section{LÁMINA 21}
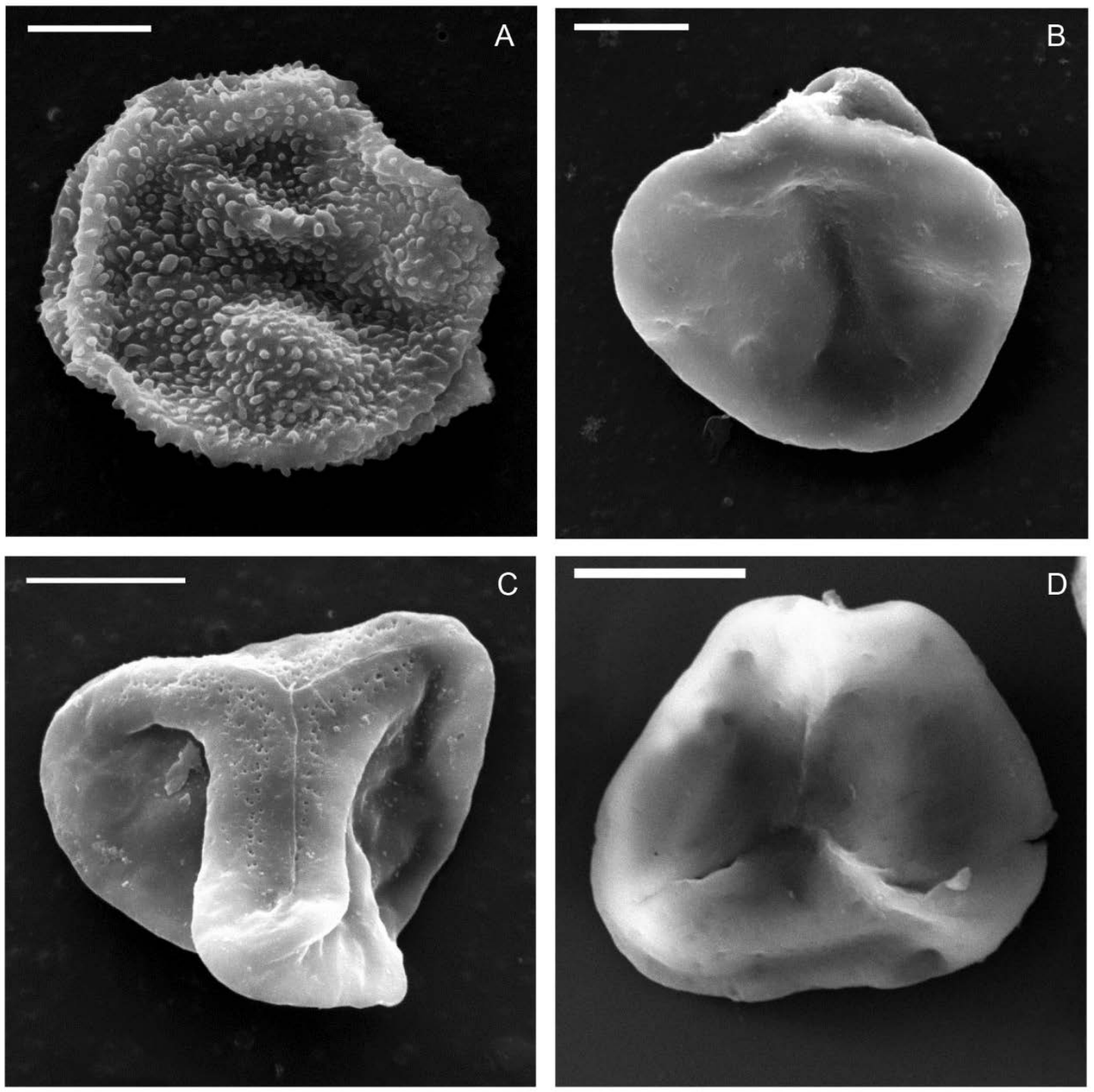

Imágenes al MEB de especies seleccionadas, muestra $46+10$. A. Baculatisporites comaumensis. B-C. Cyathidites minor. D. Deltoidospora minor. Escala $=10 \mu \mathrm{m}$. 


\section{LÁMINA 22}


Imágenes al MEB de especies seleccionadas, muestra $27+10$. A. Microcachrydites antarcticus. B. Trisaccites microsaccatum. C. Ilexpollenites anguloclavatus. D. Ilexpollenites clifdenensis. A-B, D: escala $=10 \mu \mathrm{m}$. C, escala $=5 \mu \mathrm{m}$. 


\section{LÁMINA 23}
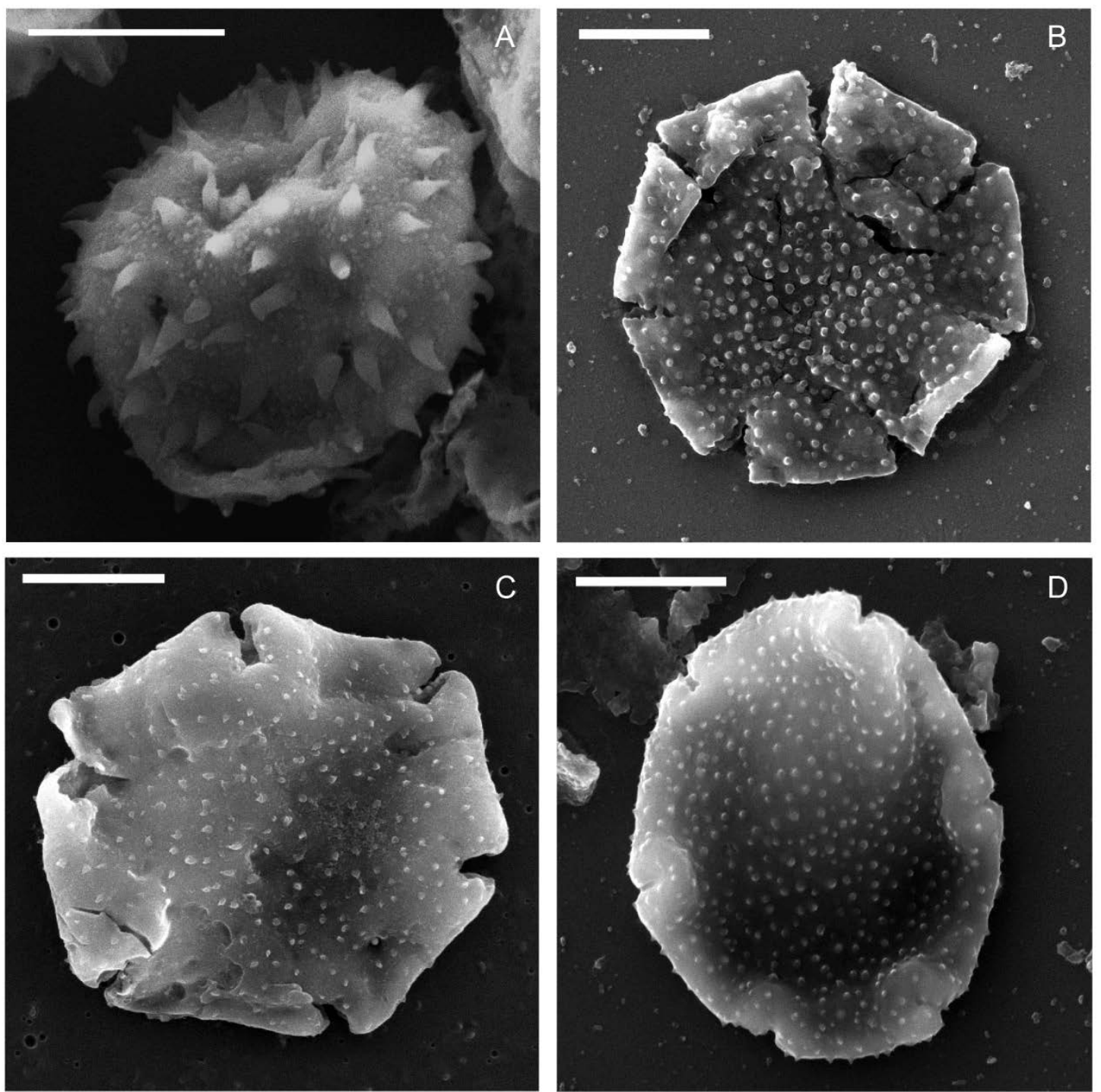

Imágenes al MEB de especies seleccionadas, muestra $11+10$. A. Malvacipollis sp.1. B. Nothofagidites americanus. C. Nothofagidites dorotensis. D. Nothofagidites rocaensis. Escala $=10 \mu \mathrm{m}$. 


\section{LÁMINA 24}
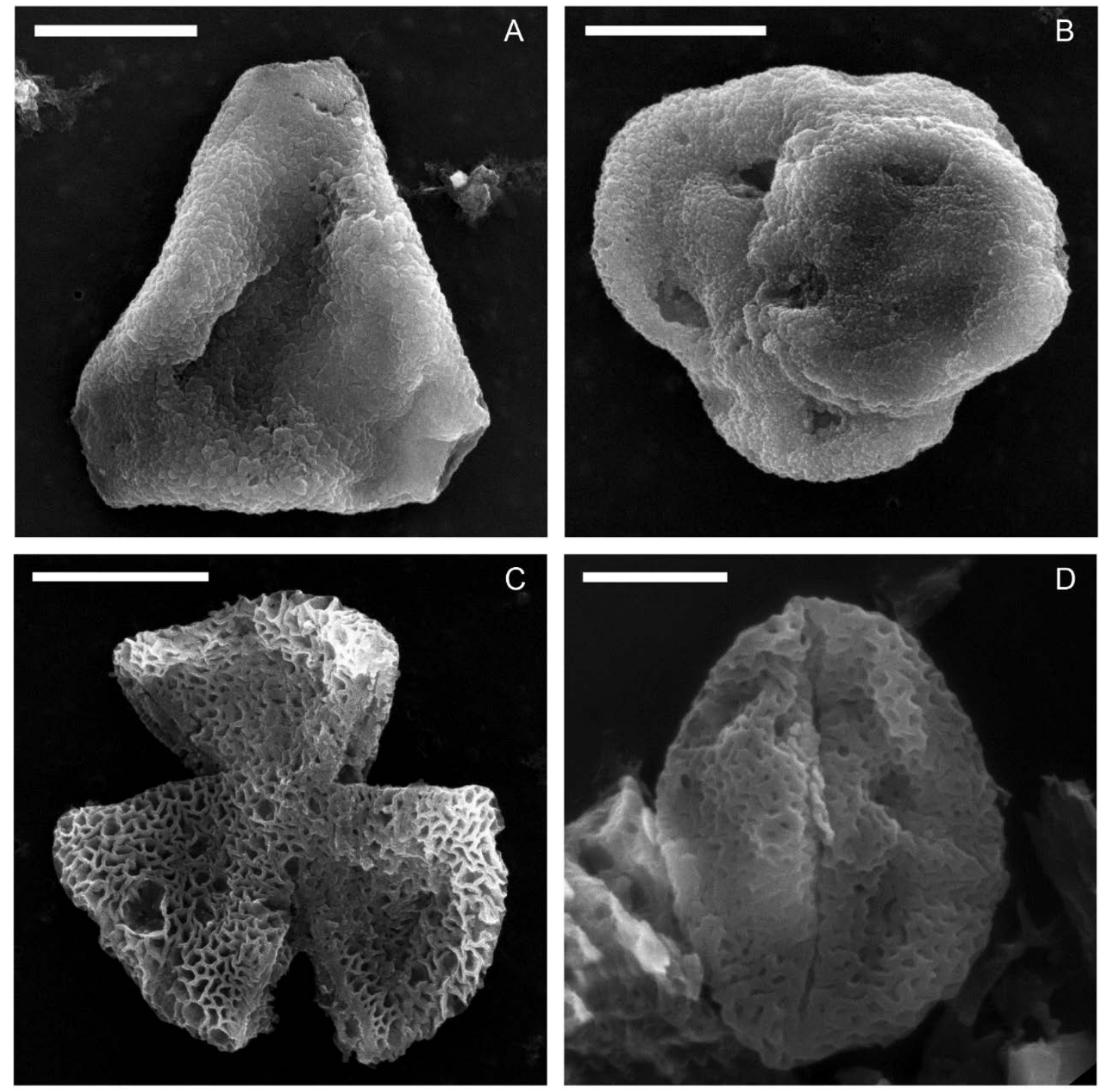

Imágenes al MEB de especies seleccionadas, muestra $20+10$. A. Proteacidites subscabratus. B. Periporopollenites demarcatus. C. Tricolpites bathyreticulatus. D. Liliacidites regularis. A-C: escala $=10 \mu \mathrm{m}$. D, escala $=5 \mu \mathrm{m}$. 